\title{
SHEAR AND FLEXURE BEHAVIOR OF HYBRID COMPOSITE BEAMS WITH HIGH PERFORMANCE CONCRETES
}

\author{
By: \\ Md. Saiful Hasib \\ B.Sc, Ahsanullah University of Science and Technology, Bangladesh, 2012
}

\author{
A Thesis \\ Presented to Ryerson University \\ In Partial Fulfillment of the \\ Requirements for the Degree of \\ Master of Applied Science \\ In the Program of \\ Civil Engineering
}

Toronto, Ontario, Canada, 2016

(C) Md. Saiful Hasib 2016 


\section{AUTHOR'S DECLARATION}

I hereby declare that I am the sole author of this thesis. This is a true copy of the thesis, including any required final revisions, as accepted by my examiners.

I authorize Ryerson University to lend this thesis to other institutions or individuals for the purpose of scholarly research.

I further authorize Ryerson University to reproduce this thesis by photocopying or by other means, in total or in part, at the request of other institutions or individuals for the purpose of scholarly research.

I understand that my thesis may be made electronically available to the public. 


\title{
SHEAR AND FLEXURE BEHAVIOR OF HYBRID COMPOSITE BEAMS WITH HIGH PERFORMANCE CONCRETES
}

\author{
Md. Saiful Hasib \\ Master of Applied Science, 2016 \\ Department of Civil Engineering \\ Ryerson University, Toronto, Canada
}

\begin{abstract}
Shear and flexure performances of composite beams with different engineered cementitious composites (ECC) to self-consolidating concrete (SCC) depth ratio were investigated. Shear reinforced composite ECC/SCC beams showed similar behavior compared to their non-shear reinforced counterparts until the formation of diagonal cracks but exhibited higher ultimate shear resistance and ductility. Compared to the full depth SCC and full depth ECC beams, non-shear reinforced composite ECC/SCC beams showed higher ductility and energy absorption capacity. Composite ECC/SCC beams showed higher number of cracks with lower crack width because of fiber bridging and micro-cracking characteristics of ECC. Code based equations and other design specifications were conservative in predicting shear strength of shear/non-shear reinforced composite ECC/SCC beams. Composite ECC/SCC flexure beams showed satisfactory flexural performance compared to their full depth ECC and SCC counterparts.
\end{abstract}




\section{ACKNOWLEDGEMENTS}

I would like to express my deepest gratitude to my supervisor, Dr. Khandaker M. Anwar Hossain, for his excellent guidance, support and patience during the development of this research. He provided me with countless opportunities to learn while gaining experience through his effective training. Without his time and countless efforts, this thesis would not have been completed. I consider myself very fortunate to have had the opportunity to work with him. Aside from engineering principles, he has taught me life lessons that I will carry through my life.

Financial support from Natural Science and Engineering Research Council (NSERC) of Canada is acknowledged.

I am also deeply grateful to Dr. Mohamed Sherir, Mr. Ali Ehsani Yeaginah and Mr. Kokilan Sathiyamoorthy for helping me in casting test specimens despite their busy schedules. Their help and suggestions were instrumental for successful completion of the experimental program. I would also like to thank Mr. Nidal Jaalouk and Mr. Min Yao, for their assistance during casting and testing in the concrete and structural laboratories.

Finally, heartiest appreciations to my wife and my in-laws who always supported and encouraged me throughout this journey. 


\section{DEDICATIONS}

To my wife and my in-laws

For their tireless support and encouragement towards success 


\section{TABLE OF CONTENTS}

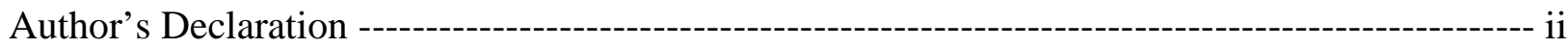

Abstract ------------------------------------------------------------------------------------------------------ iii

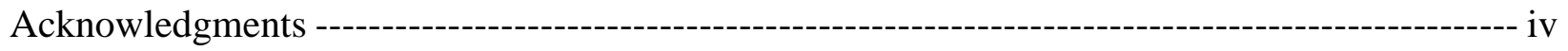

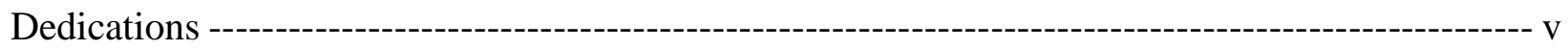

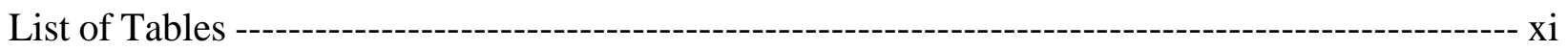

List of Figures ---------------------------------------------------------------------------------------------- xiii

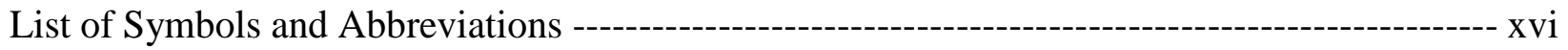

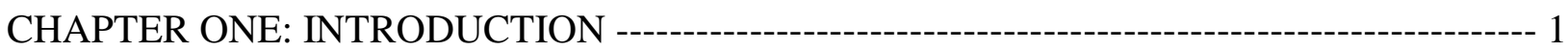

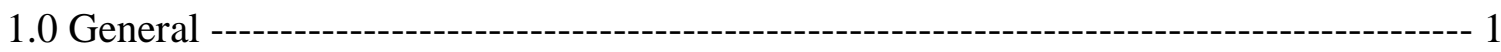

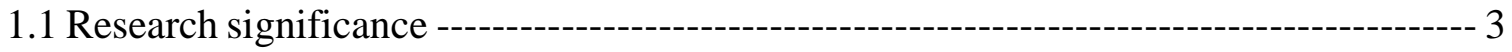

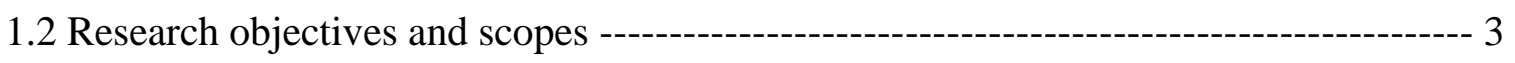

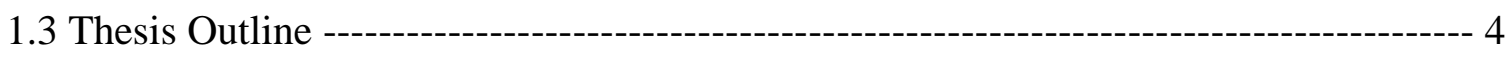

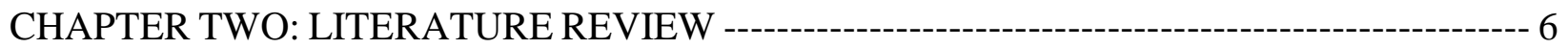

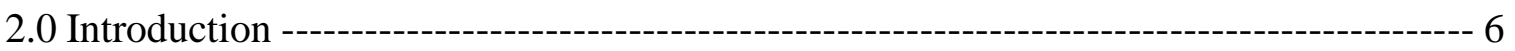

2.1 Self - Consolidating Concrete (SCC) -------------------------------------------------------- 6

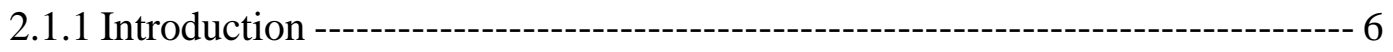

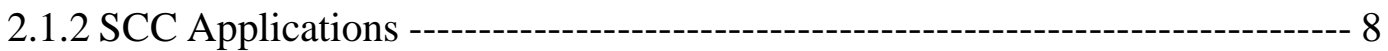

2.2 Engineered Cementitious Composites (ECC) ------------------------------------------- 9

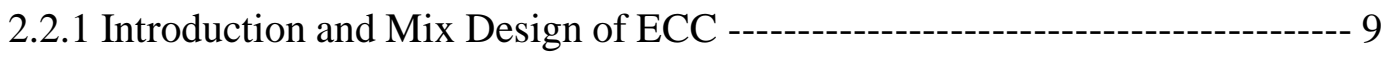

2.2.2 ECC Mixtures --------------------------------------------------------------------------- 12

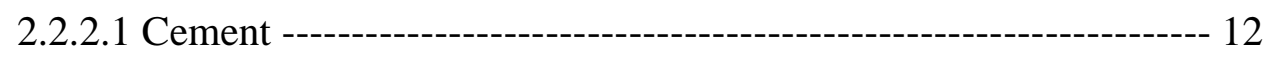

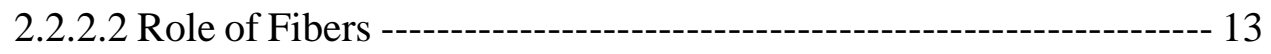

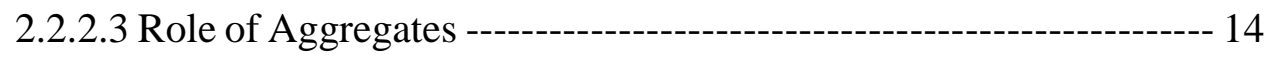

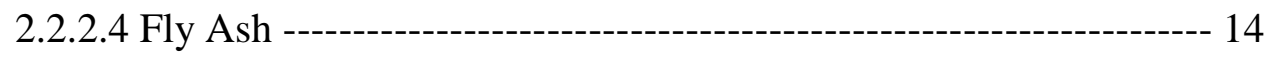

2.2.3 Mechanical Properties ------------------------------------------------------------- 15

2.2.3.1 Compressive Strength ------------------------------------------------ 15

2.2.3.2 Flexural Strength -------------------------------------------------------- 15

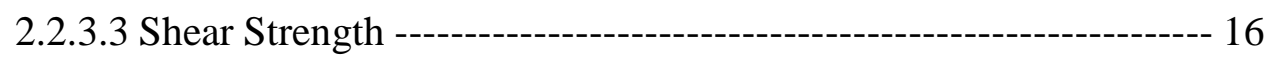




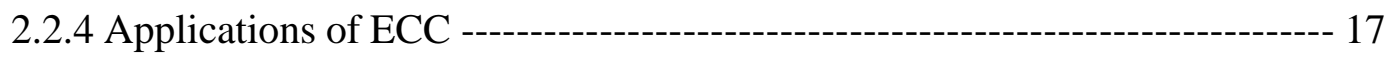

2.3 Research on structural performance of SCC, ECC and composite beams ------------- 20

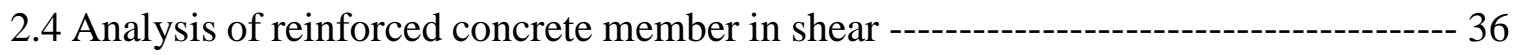

2.4.1 Basic shear transfer mechanism in beams without shear reinforcement ---- 36

2.4.2 Shear transfer mechanism of beams with shear reinforcement---------------- 38

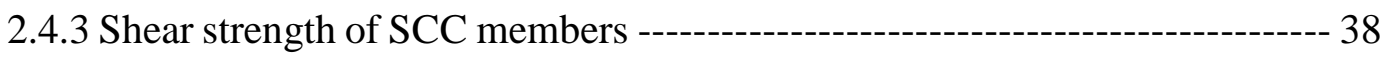

2.4.4 Shear Strength of ECC beams without stirrups ------------------------------- 39

2.4.5 Shear strength of ECC beams with stirrups ------------------------------------- 40

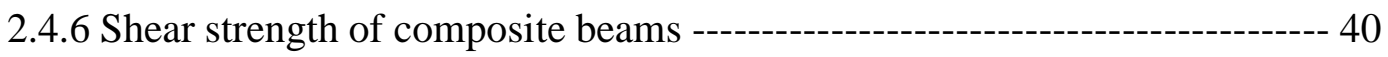

2.5 Flexural strength of SCC beam ------------------------------------------------------------- 42

2.5.1 Flexural Strength of ECC beam ------------------------------------------------- 43

2.5.2 Flexural Strength of UHPC beam ----------------------------------------------- 45

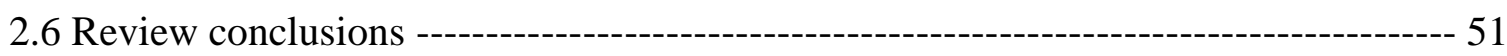

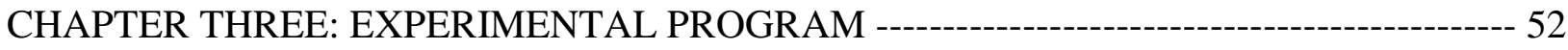

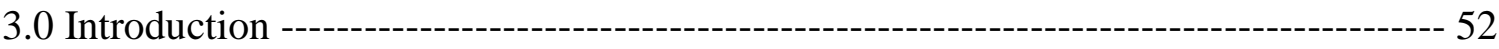

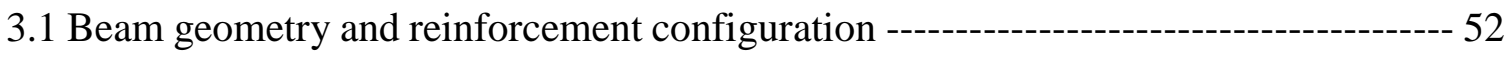

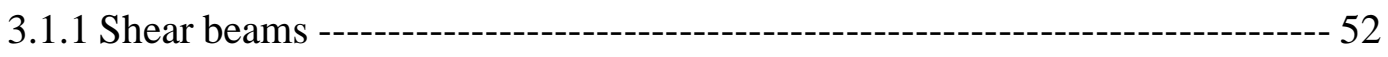

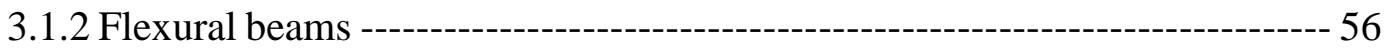

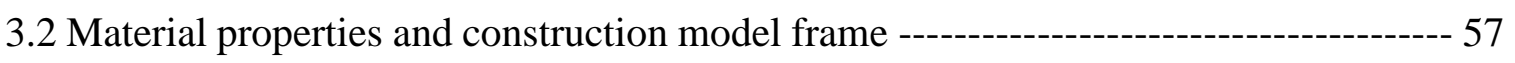

3.2.1 Mix design and mixing sequences for SCC, ECC ---------------------------- 57

3.2.2 Beam fabrication, casting and curing -------------------------------------------- 60

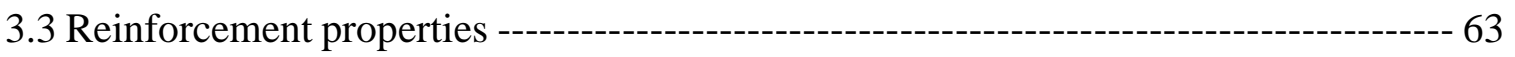

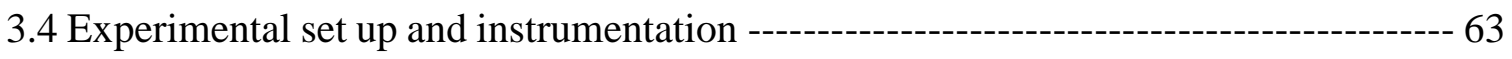

3.5 Summary -------------------------------------------------------------------------------------- 66

CHAPTER FOUR: EXPERIMENTAL RESULTS AND DISCUSSION ------------------------ 67

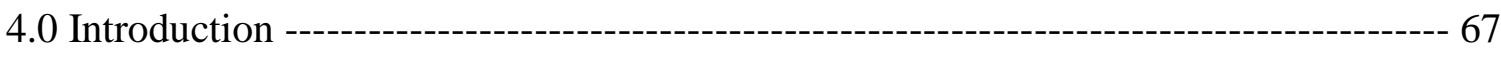

4.1 ECC, SCC and composite ECC/SCC shear beams without shear reinforcement ----- 67

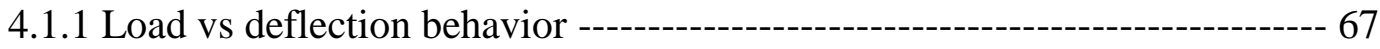

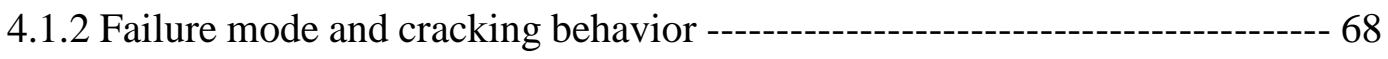

4.1.3 Post cracking shear resistance, ductility and energy absorption --------------- 71 
4.2 ECC, SCC and composite ECC/SCC shear beams with shear reinforcement 73

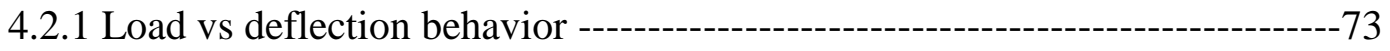

4.2.2 Failure mode and cracking behavior ----------------------------------75

4.2.3 Strain development in the flexural and shear reinforcement -----------------77

4.3 Flexural beams -----on 80

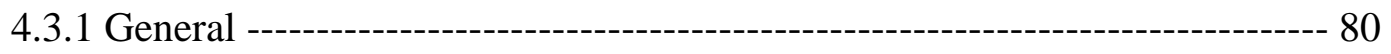

4.3.2 Load vs deflection behavior ------- 80

4.3.3 Failure mode, crack pattern and ultimate load capacity ------------------- 82

4.3.4 Strain development in flexural and shear reinforcements ------------------- 85

4.3.5 Ductility behavior and energy absorption of flexural beams ---------------- 87

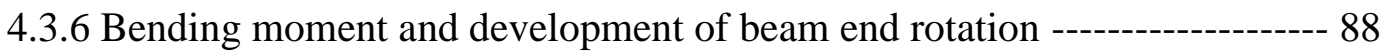

4.4 Summary ----- 89

CHAPTER FIVE: THEORETICAL ANALYSIS OF SHEAR AND FLEXURAL CAPACITIES

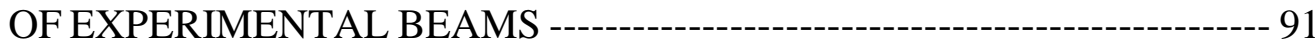

5.0 Introduction --- 91

5.1 Development of shear strength prediction equation of composite ECC/SCC beams 91

5.2 Development of flexural strength prediction equation of composite ECC/SCC flexural

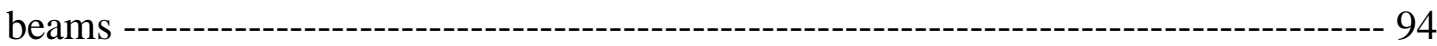

5.3 Shear strength prediction of ECC, SCC and composite ECC/SCC beams without shear reinforcement

5.3.1 Detail calculation of shear strength prediction of ECC, SCC and composite

ECC/SCC beams without shear reinforcement 97

5.3.1.1 Theoretical calculation of predicted shear strength of "Full SCC"

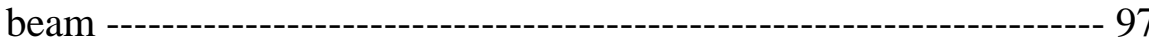

5.3.1.2 Theoretical calculation of predicted shear strength of "Full ECC" beam

5.3.1.3 Theoretical calculation of predicted shear strength of "E50-S50" beam 
5.3.1.4 Theoretical calculation of predicted shear strength of "E25-S75" beam

5.4 Shear strength prediction of ECC, SCC and composite ECC/SCC beams with shear reinforcement

5.4.1 Detail calculation of shear strength prediction of ECC, SCC and composite ECC/SCC beams with shear reinforcement 100

5.4.1.1 Theoretical calculation of predicted shear strength of "Full SCC-S" beam 100

5.4.1.2 Theoretical calculation of predicted shear strength of "Full ECC-S" beam 100

5.4.1.3 Theoretical calculation of predicted shear strength of "E50-S50-S" beam 101

5.4.1.4 Theoretical calculation of predicted shear strength of "E25-S75-S" beam 102

5.5 Analysis of shear resistance of ECC and FRC beams from previous research studies and performance of theoretical formulations 102

5.5.1 FRC beam without shear reinforcement -------------------------- 102

5.5.2 PVA-ECC beams without shear reinforcement ------------------------- 104

5.5.3 FRC/ECC beams with polypropylene (PP) and steel fiber with shear

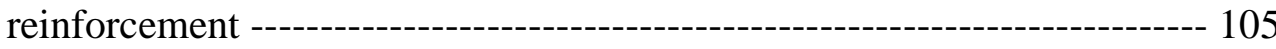

5.6 Moment capacity of ECC, SCC and ECC/SCC composite flexural beams -------- 106

5.6.1 Detail calculation of moment capacity prediction of ECC, SCC and composite ECC/SCC flexural beams 107

5.6.1.1 Theoretical calculation of predicted moment capacity of "Full SCCF" beam 107

5.6.1.2 Theoretical calculation of predicted moment capacity of "Full ECCF" beam 107

5.6.1.3 Theoretical calculation of predicted moment capacity of "E25-S75-

F" beam 108

5.7 Summary 109 
CHAPTER SIX: CONCLUSION --- 110

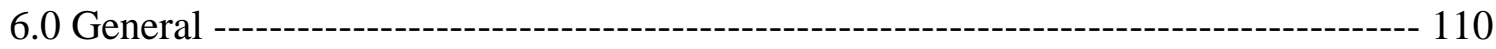

6.1 Conclusions --- 110

6.2 Recommendations for future research studies --_-_-_-_- 112

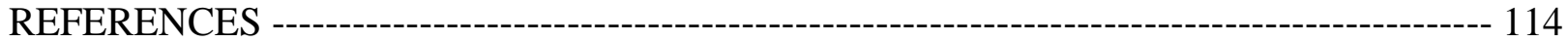




\section{LIST OF TABLES}

Table 2.1: Typical mix design of ECC material (Li, 2003) ---------------------------------------- 10

Table 2.2: Geometrical and Mechanical Properties of PVA fiber ------------------------------------ 13

Table 2.3: Specifications for Fly Ash ------------------------------------------------------------------- 15

Table 2.4: Details of FRC beams tested by Amin et al. (2016) --------------------------------- 21

Table 2.5: Mix proportion of ECC in used by Alyousif et al. (2015) ----------------------------- 22

Table 2.6: Details of ECC beams tested by Alyousif et al. (2015) -------------------------------- 22

Table 2.7: Mix proportion of ECC in used by Zhang et al. (2014) ------------------------------- 23

Table 2.8: Details of ECC beams tested by Zhang et al. (2014) ------------------------------------ 24

Table 2.9: Details of ECC beams tested by Dinh et al. (2010) ----------------------------------- 26

Table 3.1: Shear beams geometry and reinforcement configuration --------------------------------- 53

Table 3.2: Flexural beams geometry and reinforcement configuration ----------------------------- 56

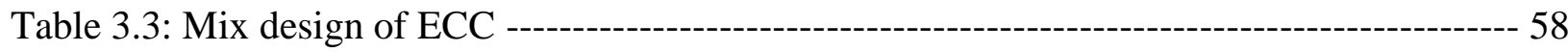

Table 3.4: Concrete compressive and flexural/tensile strength ----------------------------------- 62

Table 3.5: Rebar stress-strain response table ---------------------------------------------------- 63

Table 4.1: Experimental summary for shear beams without shear reinforcement ------------------ 69

Table 4.2: SRF, DF, Energy absorption capacity, and Contribution of aggregate and dowel actions for the shear beams without shear reinforcement ------------------------------ 71

Table 4.3: Summary of experimental results for tested shear beams with shear reinforcement

Table 4.4: Experimental strain values of tested shear beams with shear reinforcement --------- 79

Table 4.5: Summary of loads, moment and failure modes of experimented flexural beams ---- 83

Table 4.6: Yield load, ultimate load/moment and strain at different stages for flexural beams -

Table 4.7: Energy absorption and ductility index of flexural beams -------------------------------- 88

Table 5.1: Shear resistance of beams without shear reinforcement from experiment and theoretical predictions

Table 5.2: Shear resistance of beams with shear reinforcement from experiment and theoretical predictions 
Table 5.3: Shear resistance of ECC beams without shear reinforcement- experimental and

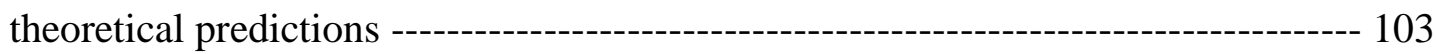

Table 5.4: Moment capacity of ECC beams without shear reinforcement- experimental and

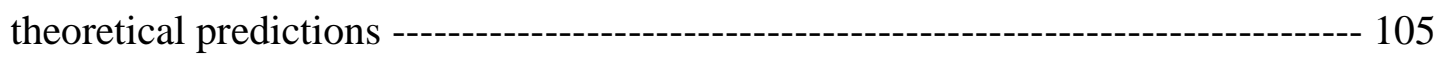

Table 5.5: Moment capacity of ECC beams with shear reinforcement- experimental and

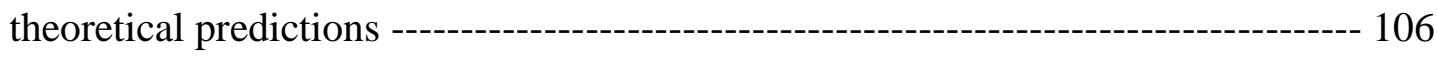

Table 5.6: Comparison of experimental and theoretical ultimate moment capacity of flexural

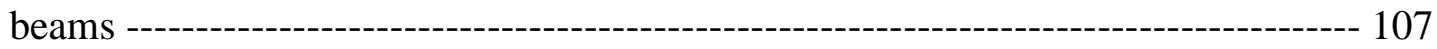




\section{LIST OF FIGURES}

Figure 2.1: Self consolidating concrete construction (www.tornadoseo.wordpress.com) --------- 7 Figure 2.2: Tensile Stress-Strain Curve and Crack Width Development

(Weimann \& Li. 2003) ---

Figure 2.3: Ductile response of ECC under flexural loading (Li 2011) ------------------------ 12

Figure 2.4: Difference in the Ultimate tensile strain of ECC between (a) Coated and (b)

Uncoated PVA fibers (Li 2003) ---

Figure 2.5: Typical Flexural Strength-Mid Span Deflection of Green ECC (Hossain \& Sherir 2014) ---

Figure 2.6: Spray repair of the Mitaka dam with ECC for water-proofing (Sakata, et al., 2004)-17

Figure 2.7:The Nabeaure Tower in Yokohoma, Japan uses precast ECC coupling beams in

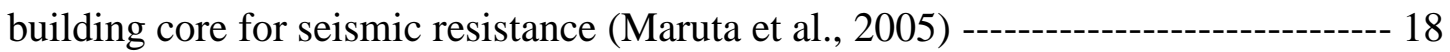

Figure 2.8: ECC patch repair on Michigan bridge deck (Li et al., 2005) ------------------ 19

Figure 2.9: ECC link-slab on Grove Street Bridge, Michigan (Qian et al., 2009) -------------- 20

Figure 2.10: ECC beams geometry and experimental set by tested by Amin et al. (2016)

(Dimensions in $\mathrm{mm}$ )

Figure 2.11: ECC beams geometry and experimental set by tested by Alyousif et al. (2015)

(Dimensions in mm) --- 23

Figure 2.12a: Reinforcement details for beams tested by Zhang et al. (2014) ---------------- 24

Figure 2.12b: Reinforcement details for beam RE-42 tested by Zhang et al. (2014) ------------ 24

Figure 2.12c: Reinforcement details for beam RE-30, 24 and 12 tested by Zhang et al. (2014)

(Dimensions in $\mathrm{mm}$ ) 25

Figure 2.13a: Reinforcement details for Beams B18-0a \& b, B18-1a \& b, B18-3a, b, c \& d; B185a \& b, and B18-7a \& b tested by Dinh et al. (2010) (Dimensions in mm) ------ 27

Figure 2.13b: Reinforcement details for Beams B18-2a, b, c \& d tested by Dinh et al. (2010) (Dimensions in $\mathrm{mm}$ ) 27

Figure 2.13c: Reinforcement details for Beams B27-1a \& b, B27-2a \& b, B27-3a \& b; B27-4a \& b; B27-5; B27-6; and B27-7 tested by Dinh et al. (2010) (Dimensions in mm) -- 27

Figure 2.14: Shear transfer mechanism of slender beams (Taylor 1970) --------------- 37

Figure 2.15: Force distribution mechanism of the composite shear beam (Hussein et al. 2015)- 40

Figure 2.16: Stress-strain and force distribution for rectangular SCC beam -------------------- 42 
Figure 2.17: Stress-strain distribution of reinforced ECC member (Lepech and Li 2009) ------- 44

Figure 2.18: Stress-force-strain distribution of reinforced UHPC beam ----------------------------- 46

Figure 2.19: Modified strain- stress-force distribution of reinforced UHPC beam ---------------- 47

Figure 2.20: Strain- stress-force distribution of reinforced UHPC beam with half depth fiber dispersion ------------------------------------------------------------------------------------------ 50

Figure 3.1: Shear beams without shear reinforcement showing four points loading

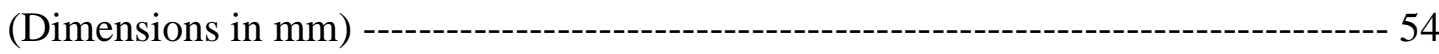

Figure 3.2: Shear beam cross-sections without shear reinforcement -------------------------------- 54

Figure 3.3: Shear beams with shear reinforcement showing four point loading ------------------- 55

Figure 3.4: Shear beams cross section with shear reinforcement ------------------------------------ 55

Figure 3.5: Flexural beams with reinforcement showing four point loading ------------------------ 56

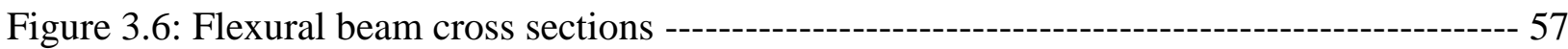

Figure 3.7: Mixing procedure for ECC concrete --------------------------------------------------------- 59

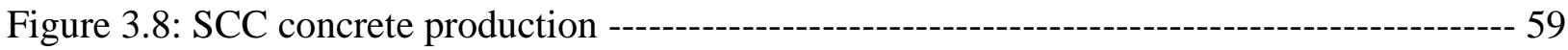

Figure 3.9: Typical formwork showing reinforcement for shear (top) and flexure (bottom)

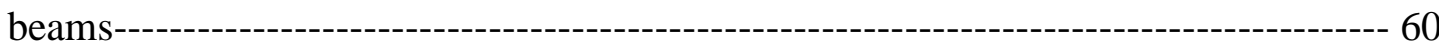

Figure 3.10: Beam casting showing concrete pouring and casted beams ----------------------------- 61

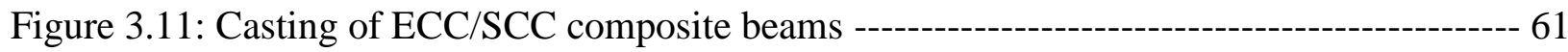

Figure 3.12: Curing of beams and control specimens ------------------------------------------------ 61

Figure 3.13: Flexural Stress vs Displacement renponse of SCC and ECC ------------------------ 62

Figure 3.14: Stress-strain response of reinforcement bars ------------------------------------------- 63

Figure 3.15: Experimental set-up and instrumentation of shear beam ------------------------------ 64

Figure 3.16: Strain gauge, LVDT and Inclinometer locations for shear beams --------------------- 64

Figure 3.17: Experimental set-up and instrumentation for flexural beams ------------------------- 65

Figure 3.18: Strain gauge, LVDT and Inclinometer locations in flexural beams ----------------- 65

Figure 4.1: Load vs deflection response for shear beams without shear reinforcement----------- 68

Figure 4.2: Failure modes and cracking patterns of tested shear beams without shear

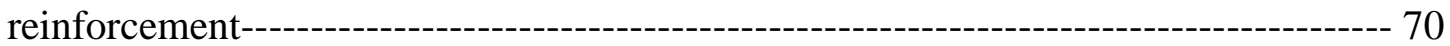

Figure 4.3: Comparison between SRF and DF of shear beams without shear reinforcement ---- 72

Figure 4.4: Energy absorption capacity of shear beams without shear reinforcement ------------- 73

Figure 4.5: Load vs mid span deflection responses for shear beams with shear reinforcement -- 74 
Figure 4.6a: Failure mode and cracking pattern of tested "Full SCC-S" shear beam -------------- 76 Figure 4.6b: Failure mode and cracking pattern of tested "Full ECC-S" shear beam ------------- 76 Figure 4.6c: Failure mode and cracking pattern of tested "E50-S50-S" composite shear beam - 77 Figure 4.6d: Failure mode and cracking pattern of tested "E25-S75-S" composite shear beam -77 Figure 4.7a: Load vs rebar strain curves for tested "Full SCC-S" shear beam ----------------------78 Figure 4.7b: Load vs rebar strain curves for tested "Full ECC-S" shear beam -------------------- 78

Figure 4.7c: Load vs rebar strain curves for tested E50-S50-S composite shear beam ------------78

Figure 4.7d: Load vs rebar strain curves for tested E25-S75-S composite shear beam -------------79

Figure 4.9a: Load vs deflection curve for tested "Full SCC-F" flexural beam --------------------- 80

Figure 4.9b: Load vs deflection curve for tested "Full ECC-F" flexural beam -------------------- 81

Figure 4.9c: Load vs deflection curve for tested E25-S75-F composite flexural beam ----------- 81

Figure 4.10a: Failure mode and cracking pattern for tested "Full SCC-F" flexural beam ------- 83

Figure 4.10b: Failure mode and cracking pattern for tested "Full ECC-F" flexural beam ------- 84

Figure 4.10c: Failure mode and cracking pattern for tested "E25-S75-F" composite flexural

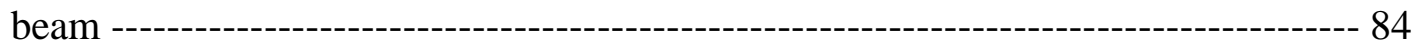

Figure 4.11a: Load vs strain responses for tested "Full SCC-F” flexural beam -------------------- 86

Figure 4.11b: Load vs strain responses for tested "Full ECC-F" flexural beam -------------------- 86

Figure 4.11c: Load vs strain responses for tested E25-S75-F composite flexural beam ---------- 87

Figure 4.12: Experimental end rotations for tested flexural beams ---------------------------------- 89

Figure 5.1: Force distribution mechanism of composite ECC/SCC shear beam ------------------ 91

Figure 5.2: Strain- stress-force distribution of reinforced composite ECC/SCC flexural beam

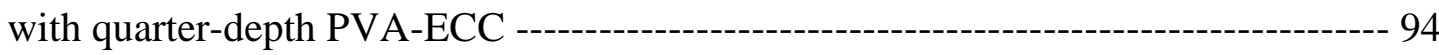




\section{LIST OF SYMBOLS AND ABBREVIATIONS}

\begin{tabular}{|c|c|}
\hline DF & Ductility factor \\
\hline DI & Ductility index \\
\hline ECC & Engineered cementitious composite \\
\hline FRC & Fiber reinforced concrete \\
\hline $\mathrm{HPC}$ & High performance concrete \\
\hline HPFRCC & High performance fiber reinforced cementitious composites \\
\hline HRWRA & High range water reducing admixtures \\
\hline LWSCC & Lightweight self -consolidating concrete \\
\hline LVDT & Linear variable differential transformers \\
\hline $\mathrm{NC}$ & Normal concrete \\
\hline $\mathrm{PE}$ & Polyethylene \\
\hline PVA & Poly-vinyl-alcohol \\
\hline $\mathrm{RC}$ & Reinforced concrete \\
\hline $\mathrm{SCC}$ & Self-consolidating concrete \\
\hline $\mathrm{SCM}$ & Supplementary cementing material \\
\hline SRF & Shear resistance factor \\
\hline Exp. & Experiment \\
\hline $\mathrm{a} / \mathrm{d}$ & Shear span to depth ratio \\
\hline $\mathrm{V}$ & Shear force in a concrete section \\
\hline $\mathrm{V}_{\mathrm{c}}$ & Shear resistance of compression zone \\
\hline $\mathrm{V}_{\mathrm{a}}$ & Interlocking action of aggregates \\
\hline $\mathrm{V}_{\mathrm{d}}$ & Dowel action \\
\hline $\mathrm{V}_{\mathrm{n}}$ & Shear resistance of the beam \\
\hline $\mathrm{b}$ & Width of the cross-section \\
\hline $\mathrm{d}$ & Effective depth \\
\hline $\mathrm{V}_{\mathrm{u}}$ & Ultimate shear force \\
\hline $\mathrm{M}_{\mathrm{u}}$ & Ultimate moment capacity \\
\hline $\mathrm{f}_{\mathrm{c}^{\prime}}$ & Cylinder compressive strength of concrete \\
\hline$A_{v}$ & Area of shear reinforcement \\
\hline
\end{tabular}




\begin{tabular}{ll}
$\mathrm{f}_{\mathrm{yt}}$ & Characteristic yield strength of reinforcement \\
$\mathrm{s}$ & Spacing of shear reinforcement \\
$\mathrm{h}$ & Total beam height \\
$\mathrm{f}_{\mathrm{t}}$ & Tensile stress of ECC \\
$\mathrm{D}_{\mathrm{y}}$ & Deflection \\
$\mathrm{D}_{\mathrm{c}}$ & Deflection at first diagonal crack \\
$\mathrm{D}_{\mathrm{u}}$ & Deflection at peak shear load \\
$\mathrm{a}$ & Depth of the equivalent compressive block \\
$a_{b}$ & Balance depth of the compression zone \\
$\mathrm{A}_{\mathrm{f}}$ & Cross-sectional area of steel fibers \\
$\mathrm{A}_{\mathrm{s}}$ & Area of tensile steel bars \\
$a_{s}$ & Shear span \\
$A_{s, \text { min }}$ & Minimum of tensile reinforcement \\
$A_{v}$ & Area of shear reinforcement \\
$A_{v, \text { min }}$ & Minimum area of shear reinforcement \\
$b_{t}$ & The width of tension zone \\
$\mathrm{C}$ & The distance of natural arises from the top fiber \\
$\mathrm{C}$ & Concrete compressive force \\
$C_{E C C}$ & ECC Concrete compressive force \\
$d_{a}$ & Maximum aggregate size \\
$d_{f:}$ & Diameter of fibers \\
$\mathrm{D}_{\mathrm{f}}$ & Lateral displacement at $80 \%$ of ultimate load at the descending part of the curve \\
$d_{v}$ & Effective depth of concrete block \\
$\mathrm{D}_{\mathrm{y}}$ & Lateral displacement at $80 \%$ of ultimate load at the ascending part of the curve \\
$\mathrm{E}_{\mathrm{f}}$ & Modulus of elasticity of steel fibers \\
$\mathrm{F}$ & Average pullout stress of fiber \\
$f_{c^{\prime}}$ & Compressive strength of normal strength concrete \\
$\mathrm{f}_{\mathrm{cf}}$ & Compressive strength of fibrous concrete \\
$\mathrm{f}_{\mathrm{y}}$ & Yield strength of tensile reinforcement bar \\
$f_{m c}$ & UHPC limiting compressive strength \\
$f_{m t}$ & UHPC tensile stress \\
\hline
\end{tabular}




$\begin{array}{ll}G_{m} & \text { Shear modulus of concrete matrix } \\ \mathrm{h} & \text { The overall height of the beam } \\ l_{f} & \text { Length of fibers } \\ M_{f} & \text { Moment resisting capacity of normal concrete } \\ \mathrm{M}_{\mathrm{n}} & \text { Nominal moment capacity of UHPC beam } \\ M_{r} & \text { Resisting moment capacity } \\ n & \text { Strain modular ratio } \\ \mathrm{r}_{\mathrm{f}} & \text { Radius of steel fibers } \\ s & \text { Spacing between shear reinforcement } \\ \mathrm{T}_{\mathrm{c}} & \text { UHPC tensile force based on fiber contribution } \\ T_{E C C-1} & \text { ECC concrete tensile force } \\ T_{E C C-2} & \text { ECC concrete tensile force } \\ \mathrm{T}_{\mathrm{ps}} & \text { UHPC steel reinforcement force } \\ T_{S t e e l} & \text { ECC tensile force of steel } \\ \mathrm{V}_{\mathrm{c}} & \text { Concrete shear capacity } \\ V_{f} & \text { Volume fraction of fibers } \\ V_{m} & \text { Volume fraction of the matrix } \\ \mathrm{V}_{\mathrm{p}} & \text { Shear resistance capacity of pre-stress reinforcement } \\ \mathrm{V}_{\mathrm{s}} & \text { Shear resistance of stirrups } \\ \mathrm{V}_{\text {shear }} & \text { Resisting shear capacity } \\ \alpha_{1} & \text { Concrete stress block parameter } \\ \beta_{1} & \text { Concrete stress block parameter } \\ \varepsilon_{c} & \text { Concrete Strain } \\ \varepsilon_{f} & \text { Fiber tensile strain } \\ \varepsilon_{m} & \text { UHP Concrete compressive strain at the top fiber } \\ \varepsilon_{m} & \text { UHP Concrete tensile strain } \\ \varepsilon_{\mathrm{s}} & \text { UHPC reinforcement strain } \\ \varepsilon_{y} & \text { Reinforcement strain } \\ \varepsilon_{(E C C)} & \text { Yield strain of ECC } \\ & \end{array}$




$\begin{array}{ll}\sigma_{c} & \text { Ultimate tensile strength of steel fiber reinforced composite prior to cracking } \\ \sigma_{f} & \text { Ultimate pull out strength of steel fiber } \\ \sigma_{m} & \text { Ultimate tensile strength of un-cracked concrete matrix } \\ \varphi_{c} & \text { Concrete Reduction factor } \\ \varphi_{s} & \text { Steel reduction factor } \\ \lambda & \text { Concrete stress block parameter } \\ \eta_{b} & \text { Fiber bond efficiency factor } \\ \eta_{l} & \text { Fiber length efficiency factor } \\ \eta_{o} & \text { Fiber orientation factor } \\ \theta & \text { Cracks angle } \\ \tau_{f} & \text { Bond strength between the fiber and matrix }\end{array}$




\section{CHAPTER ONE INTRODUCTION}

\subsection{General}

In conventional reinforced concrete structural design, compressive strength is the most common and most important material parameter. This is why, structural strength and more generally structural performance is often recognized to be controlled by the strength of materials; which means higher material compressive strength is expected to lead to the higher structural strength. This concept is correct only if the failure mode is truly governed by the material strength property. If fracture failure occurs, a high strength material does not necessarily mean the higher structural strength. Rather, a tougher and extreme ductile material can lead to a higher structural strength (Ramualdi and Batson, 1963). Therefore, polymeric fibers were employed as a reinforcing material in cementitious materials. The main use of fiber in cementitious materials is for the sake of enhancing the resistance and toughness in tension and shear. Modern fiber reinforced cementitious materials have been analyzed since 1960's (Gao and Zijl, 2005).

In the last few decades, notable research is being conducted worldwide with the aim of creating new composites, which will increase shear and flexural strength as well as the ductility of the structural concrete elements. One group of these super ductile composites is called as Engineered Cementitious Composites (ECCs) featuring high ductility and damage tolerance under mechanical loading including tensile and shear loadings (Li, 1997; Li et al., 2001; Li, 2003). Flexibility nature of ECC which came into view from laboratory testing to field applications leads to speedy construction, reduced maintenance and a longer life span for the structures (Li and Kanda, 1998; Wang and Li, 2006; Sahmaran et al., 2009). By employing micromechanics-based material optimization, tensile strain capacity in excess of $3 \%$ under uniaxial tensile loading can be attained with only 2\% fiber content by volume (Li, 1997; Lin and Li, 1997; Lin et al., 1999). Poly-vinyl alcohol (PVA) fiber is successfully used in the production of moderate strength ECC while PVA/polyethylene (PE) fibers can also be used for high strength. ECC strain hardens after first cracking, like a ductile metal, and demonstrates a strain capacity 300 to 500 times greater than conventional concrete. Even at large deformation, crack widths remain less than $60 \mathrm{~m}(\mathrm{Li}, 2003$; Li and Kanda, 1998; Li et al., 2002). 
On the other hand, for the improvement of productivity mainly in the transport and placement of fresh concrete; a new type of flow-able concrete named Self-Consolidating Concrete (SCC) was developed initially in Japan in the early 1980's (Hayakawa et al., 1993; Hossain and Lachemi, 2010). SCC is a highly flow-able concrete that can flow into place under its own weight. SCC achieves good consolidation without external or internal vibration and also without defects due to bleeding or segregation (Ozawa et al., 1989; Li, 1995; Yurugi, 1998; Petersson, 1998; Khayat et al., 2001; Lachemi et al., 2003; Poon and Ho, 2004b; Khatib, 2008). SCC typically has a higher content of fine particles and improved flow properties compared to the conventional concrete. SCC can be used to improve the productivity of casting congested sections and also to insure the proper filling of restricted areas with minimum or no consolidation (Khayat, 1999). It showed greater homogeneity of distribution of in-place compressive strength than conventionally vibrationcompacted concrete. It can also improve the working environment by eliminating the noise and pollution caused by vibrators and also reduces labor cost.

Over the last few years, researches have been conducted at Ryerson University to develop sustainable high performance concrete (including self-consolidating concrete 'SCC', fiber reinforced SCC, ECC and Ultra-High Performance Concrete 'UHPC') and innovative structural systems as well as construction technologies. Ryerson's research team has developed a UHPC through evaluation of mechanical/durability properties and structural performance in bridge deck joints (Sherir et al., 2015; Hossain et al., 2011, 2012 and 2014). New type of green cost-effective ECCs comprising locally available aggregates/industrial wastes (Sahmaran, 2009; Ozbay et al., 2011; Sherir, 2012) have been developed by Ryerson's research team and their potential applications in 'joint-free bridge deck with link slab', 'composite framed shear wall system' and 'coupling slab in shear wall structures' (Issani and Hossain, 2013; Rafiei et al., 2013; Hossain and Taormina, 2012) have been evaluated. In addition, team has been working on developing ECC using local sands instead of micro-silica sand which is relatively expensive and difficult to obtain. Extensive research studies have been conducted on material properties of the ECC by incorporating different supplementary cementitious material (SCM) such as fly ash, volcanic ash, blast furnace slag and metakaolin as replacement of cement as well as different type, size and volume of fibers (Hossain and Anwar, 2014; Sherir, 2012; Maulin, 2012; Sahmaran et al., 2010; Ozbay et al., 2011 and 2012). 
Research at Ryerson also leads to the development of a UHPC having a compressive strength of over $140 \mathrm{MPa}$. Fresh, mechanical and durability properties including bond strength of developed UHPC (known as Ryerson mix) as well as its structure performance as closure strip material in bridge deck have been investigated (Ametrano, 2010; Mak et al., 2011; Hossain et al., 2010, 2011, 2012 and 2014).

\subsection{Research significance}

The use of SCC and ECC in construction of building and bridge structures has been a new emerging technology. Although extensive researches have been conducted on the mix design and properties of SCC and ECC individually over the recent years and also there are many publications available on the structural performance of composite material using normal concrete and UHPC with steel fiber but very limited number of studies have been conducted on the structural performance of SCC and ECC as a combined composite material incorporating PVA fiber. In addition, design guidelines or performance-based design procedures incorporating structural performance and serviceability of composite ECC/SCC based structural elements are not available in Codes. The proposed research on the shear and flexural performance of composite ECC/SCC beams is a timely initiative to make significant contributions to the hybrid composite ECC/SCC technology. The findings of this research will surely benefit engineers, builders and local authorities when designing and constructing civil infrastructures.

\subsection{Research objectives and scopes}

The main objectives of this research program are to:

$\checkmark$ Perform the experimental investigations on the shear behavior of composite ECC/SCC beam using PVA fiber having variable ECC and SCC depth ratio with presence or absence of shear reinforcement.

$\checkmark$ Analyze and compare the shear behavior of composite ECC/SCC beams with and without shear reinforcement with their full depth ECC and full depth SCC beam counterparts based on concrete shear capacity, ultimate shear capacity, post-cracking shear transfer mechanism, post-cracking shear capacity, load-deflection response, ductility, energy absorbing capacity, strain development in concrete/and steel, failure modes, load/deflection at first flexure/inclined crack, number of crack and influence of ECC and SCC depth ratio. 
$\checkmark$ Carry out experimental tests on the flexural behavior of composite ECC/SCC flexural beam under four point loading and compare the results with their full depth ECC and full depth SCC flexural beam counterparts based on load-deflection response, ductility, strain development in concrete/and steel, failure modes, load/deflection at first flexure/inclined crack, rotation and number of cracks.

$\checkmark$ Compare the experimentally obtained moment and shear capacity of flexural and shear beams from this and previous research studies with those obtained from Code based equations, other existing design specifications and modified/developed equations based on existing Codes.

$\checkmark$ Derive conclusion and make recommendations for future research studies.

\subsection{Thesis Outline}

This thesis consists of 6 chapters presenting experimental and theoretical investigations on the structural performance of shear and flexural beams made with SCC and ECC materials.

Chapter 1 introduces ECC and SCC materials a summary of advancement in ECC as well as UHPC technology. It also describes the significance, objectives and scope of this research with a thesis outline.

Chapter 2 presents the comprehensive literature review on materials, mix design and properties of ECC and SCC including practical construction applications. It also presents research conducted on beams/composite beams made of ECC, SCC and UHPC materials as well as shear/flexural design procedures of ECC, SCC and ECC/SCC beams/composite beams based on Codes and other existing design specifications.

Chapter 3 describes the experimental program including material properties, geometric dimensioning of shear and flexural beams, fabrication/casting/curing of beam specimens, test setup, instrumentation and testing procedures. 
Chapter 4 presents the results of the experimental investigations on shear and flexural behavior of composite ECC/SCC beams in addition to full depth ECC and full depth SCC beams. The performance is described based on load-deflection response, strain development in rebar/concrete, moment end rotation behavior, energy absorption, ductility index, and crack formation/propagation and failure modes. Post -cracking shear transfer mechanism comparison between composite ECC/SCC beams and full depth ECC and full depth SCC beams is also described in this chapter.

Chapter 5 compares the experimental shear and flexure capacities of the tested beams (as well as from previous research studies) with those obtained from theoretical formulations and design specifications. Experimental shear resistance of tested ECC (with different fiber composition from previous research studies) beams with and without shear reinforcement was also analyzed and compared with those of theoretical formulations and design specifications.

Chapter 6 summarizes the findings of the research and provides recommendations for future research study. 


\section{CHAPTER TWO \\ LITERATURE REVIEW}

\subsection{Introduction}

The use of new generation of High Performance Concretes (HPCs) such as Self-Consolidating Concrete (SCC), Engineered Cementitious Composite (ECC) and Ultra High Strength/Performance Concrete (UHSC/UHPC) can significantly improve the process of casting through self-consolidation as well as improve strength, ductility and durability of structures. This chapter presents the following: (a) mix design and properties of SCC and ECC (b) practical construction applications of SCC/ECC/UHPC, (c) research studies conducted on SCC, ECC and composite beams with ECC/UHPC or ECC/SCC structural elements, (d) design aspects of SCC/ECC/UHPC beams and composite beams and (e) summary to illustrate the need for proposed research study in the context of current state of the technology.

\subsection{Self - Consolidating Concrete (SCC)}

\subsubsection{Introduction}

Placement of concrete generally requires consolidation by vibration in the forms. Selfconsolidating concrete (SCC) has been defined as a highly flow-able, yet stable concrete that can spread readily into place and fill the formwork without any consolidation as shown in Figure 2.1 (Khayat et al., 2000).

SCC, initially was developed in Japan in the late 1980s to be mainly used for highly congested steel bar reinforced structures in high activity seismic regions (Ozawa et al., 1989; Hossain and Lachemi, 2010). The use of SCC in the actual structure has steadily increased in the recent years and presents an excellent alternative to conventional concrete (JSCE 2008). The growing interest in SCC is leading concrete suppliers/manufactures, researchers and engineers into investigations to understand and develop new cost effective and high performance materials.

The primary advantage associated with SCC is the improvement of productivity mainly in the transport and placement of fresh concrete. The fluidity and high segregation resistance of SCC help to attain a high degree of mix homogeneity, minimal concrete voids and uniform strength as well as provides the potential for a superior level of finish and durability to the structures. 
The benefits of incorporating SCC in new construction projects are the most convincing aspect. Incorporating SCC in construction projects can reduce the cost and time of concrete construction as reported by Okamura (1996). Use of SCC in the construction of a liquefied natural gas tank decreased the number of lifts required and increased the height of the lift, for slip-form casting, resulting in faster productivity. SCC could reduce the number of workers required to place the concrete while adding other benefits and improving material properties. By using chemical/mineral admixtures, primarily super-plasticizers, and by decreasing the coarse-to-fine aggregate ratios the concrete is able to flow much better while preventing segregation. Also, since the water demand is reduced due to the use of super plasticizers, the strength and possibly the durability can be increased (EFNARC 2005; Yahia et al., 1999; Lachemi et al., 2003a-b; Hossain and Lachemi, 2009; Hossain et al., 2010; Hassan et al., 2012).

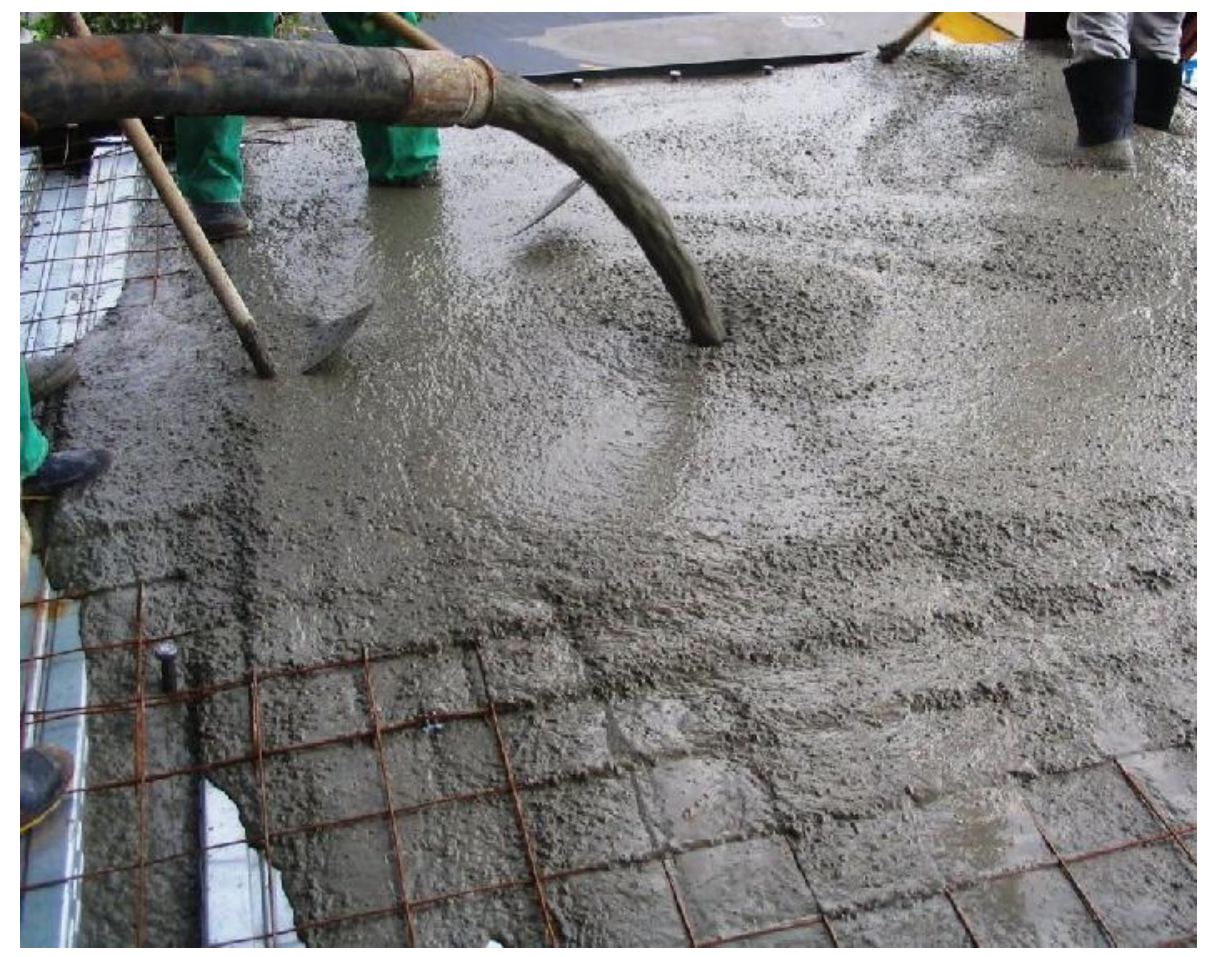

Figure 2.1: Self consolidating concrete construction (www.tornadoseo.wordpress.com) 


\subsubsection{Applications of SCC}

Lacombe et al. (1999) investigated the application of SCC as an overhead repair material. In this study three types of repair materials such as normal concrete, SCC and shotcrete were tested. Three concrete blocks were repaired at a depth of approximately $40 \mathrm{~mm}$ on one surface of each block. Viscosity Modifying Agent (VMA) was used to reduce bleeding and segregation in the SCC mixture. Following seven days from the repairs, observations were made for each repair method. Results indicated that the normal concrete did not possess suitable rheological properties and filling capacity to be used as an overhead repair material. It also developed considerable segregation and large air pockets which was quite expensive and required extensive skills. SCC performed well as a repair material creating a good bond and showed good rheological properties but unfortunately, SCC was expensive due to the use of chemical admixtures. Furthermore, labor was not a major factor in the placement of the SCC as it consolidated under its own weight. The mechanism of shotcrete bonding to old concrete was almost perfect, but skilled labor was required to perform the work and the cost was increased significantly. The research also suggested investigating more to develop cost-effective SCC in order to increase its use as a repair material. Other applications for SCC as a repair material were described by Campion and Jost (2000). SCC was used to repair a chloride-induced deteriorated cast-in-place bridge built in the 1960's in the Swiss Alps. The concrete structure lost a substantial amount of concrete and steel reinforcement on its underside. Formwork and placement of concrete followed the replacement of the steel reinforcement under the deck. The only poured concrete available to accommodate the task at hand was SCC which was pumped in to the formwork through the underside. Air holes were drilled at the top of the deck to allow the release of pressure generated when concrete is pumped in the formwork. SCC allowed the project to be finished on time while maintaining the required concrete quality throughout the entire project.

Khayat and Ai'tcin (1999) investigated projects in Canada where SCC was used. These included the rehabilitation of the Webster parking garage in Sherbrooke, the rehabilitation of the Beauhamois Dam near Montreal, the casting of experimental residential basement walls, and the construction of a reaction wall at the Universite de Sherbrooke. The use of SCC in these projects showed SCC to be an effective material for the repair of damaged structural sections. SCC also enhanced reliability and durability of newly constructed concrete walls. 
Other applications included self-consolidating high-performance concrete as discussed by Okamura (1996). The use of SCC in structures has gradually increased over the last few years. The Akashi Straits Bridge is one of the longest suspension bridges in the world and SCC was used in the construction of two anchorages of the bridge. The concrete was batched in an onsite plant and transported by pump through $200 \mathrm{~m}$ of pipes. The maximum size of coarse aggregate was $40 \mathrm{~mm}$ and despite the large size of aggregate, no segregation was observed. The use of SCC shortened the construction period of the two anchorages by $20 \%$, from 2.5 to 2 years.

Li (1995) discussed the use of SCC in Japan and the competitive edge gained by the firms when producing their own. Two projects in particular were highlighted as examples. One was the Kiba -Park Large Bridge, a 151-m cable-stayed pre-stressed concrete bridge, only required two workers to pour $650 \mathrm{~m}$ of SCC in nine months. The incentive to use SCC was the difficulty and high labor cost of placing normal concrete in heavily reinforced concrete structures. The second was a 70storey building, the tallest high-rise in Japan, which used $885 \mathrm{~m}$ of SCC pumped into steel tubular columns. The concrete was pumped in from the bottom at a maximum filling height of $40 \mathrm{~m}$.

\subsection{Engineered Cementitious Composites (ECC)}

\subsubsection{Introduction and Mix Design of ECC}

Engineered Cementitious Composite (ECC), as a new generation of High Performance Fiber Reinforced Cementitious Composite (HPFRCC) materials, is a ductile fiber reinforced cementitious composite designed micromechanically to achieve high damage tolerance under severe loading and high durability under normal service conditions (Li, 1998; Li et al., 2001; Li, 2003). The most important characteristic that differentiate ECC from conventional concrete and fiber reinforced concrete (FRC) is an ultimate tensile strain capacity in the range of 3\% to $5 \%$, depending on the specific ECC mixture. Formation of multiple closely spaced micro cracks allows this strain capacity over 300 times that of normal concrete. These cracks carry increasing load after formation and allow the material to exhibit strain hardening which is similar to many ductile metals. 
The distinctive strain hardening characteristic of ECC through micro-cracking is achieved through micromechanical tailoring of the components (i.e. cement, aggregate, and fibers) (Li, 1998; Lin et al., 1999; Li et al., 2001; Li, 2003) along with control of the interfacial properties between components though the components of ECC may be similar to FRC. A unique fracture property of ECC is attained through the careful customization and proportioning of the material such as selecting specific fiber properties (suitable strength, modulus of elasticity and aspect ratio) along with effective interfacial properties of fiber and the matrix (Li, 2003). Typical mix proportions of ECC using a polyvinyl-alcohol (PVA) fiber are given in Table 2.1.

Table 2.1: Typical mix design of ECC material (Li, 2003)

\begin{tabular}{|c|c|c|c|c|c|}
\hline Cement & Water & Sand & Fly Ash & (HRWRA)* $^{*}$ & Fiber (Vol. \%) \\
\hline 1 & 0.58 & 0.8 & 1.2 & 0.013 & 2.00 \\
\hline
\end{tabular}

*HRWRA: High range water reducing admixture; all ingredients proportion by weight except for fiber

Generally, most HPFRCCs depend on a high volume of fiber to achieve high performance but ECC uses low amounts, typically $2 \%$ by volume, of short discontinuous fiber. This low fiber volume, along with the common components allows flexibility in construction execution. Different types of fibers have been incorporated into ECC mixtures, but PVA fibers were found to be most effective and efficient for achieving the strain hardening characteristic after the first crack formation (Weimann and $\mathrm{Li}, 2003$ ). The typical uniaxial tensile stress-strain curve and cracking development of the ECC at 2\% PVA fiber is presented in Figure 2.2. 


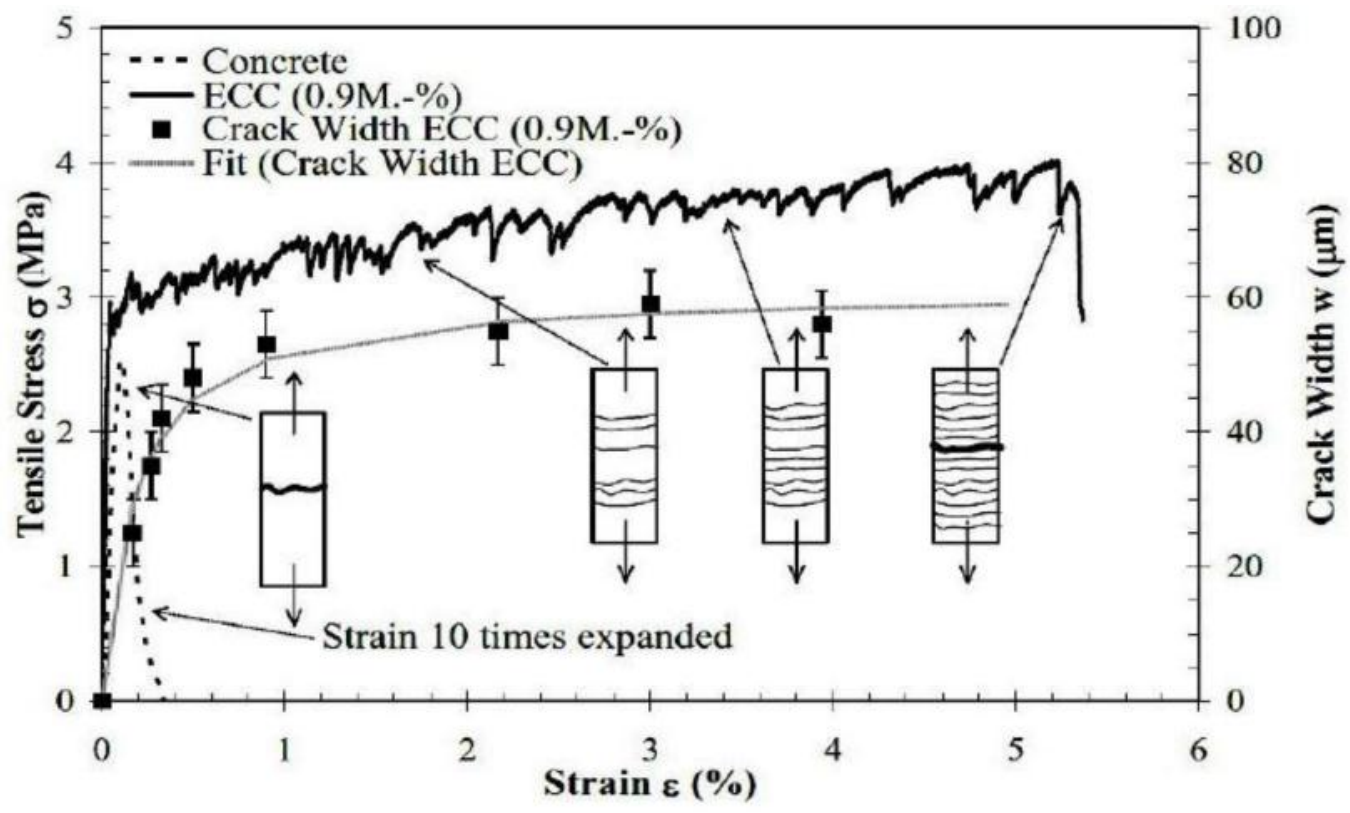

Figure 2.2: Tensile stress-strain curve and crack width development (Weimann and Li, 2003)

ECC's tensile stress is increased further due to its unique strain hardening characteristic after the formation of first crack. The crack widths at ultimate loading are remained below $80 \mathrm{~m}$. The steady-state cracking behavior is independent to the type of the loading and the amount of fiber reinforcement (Özbay et al., 2013; Ranade et al., 2014). The micro-cracking behavior and strain hardening characteristic are attained by the strength and fracture energy criteria proposed by Kanda and $\mathrm{Li}$ (1998). The satisfaction of the criterion will ensure the initiation of micro-cracking from initial flaw sites in the composites before the tensile loading reach the fiber bridging capacity (Kanda and Li, 1998; Yang and Li, 2007). The use of these micromechanical models for tailoring ECC material ensures the strain hardening characteristic and large bending capacity (Figure 2.3) similar to a ductile metal plate at its plastic deformation phase (Li, 2011; Nawy, 2008). 


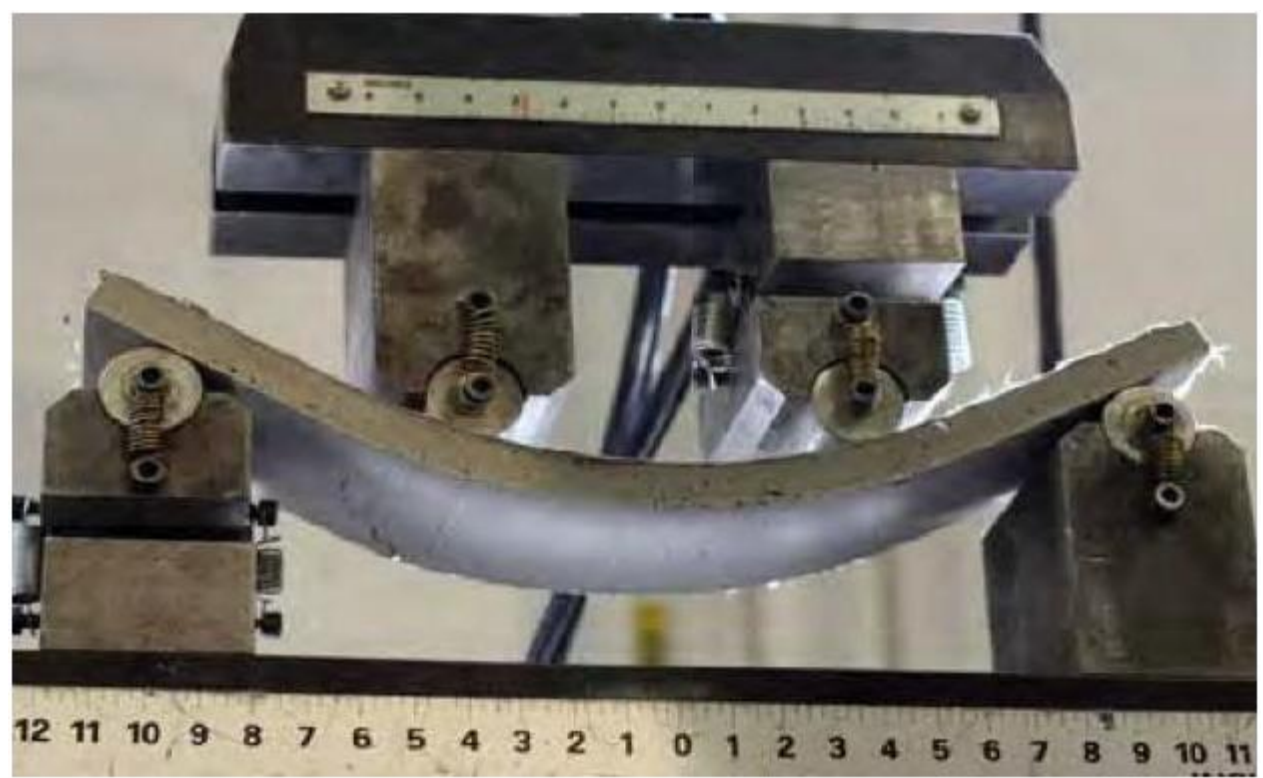

Figure 2.3: Ductile response of ECC under flexural loading (Li, 2011)

Using the same strength and fracture energy criteria, greener ECC mixes were developed by incorporating locally available crushed sand/mortar sand aggregates and fly ash/slag/metakaolin/volcanic ash as a replacement of cement (Sahmaran et al., 2009; Ozbay et al., 2012; Sherir 2015; Hossain et al., 2015; Hossain and Anwar, 2014; Sherir et al., 2014) Although each material influenced the mechanical and durability properties of the hardened ECC, but similar responses were attained as observed in experimental results.

\subsubsection{ECC Mixtures}

ECC utilizes similar ingredients as FRC. Generally, the materials used in standard ECC are cement, fine aggregate, water, fibers and some common chemical additives to attain desired workability. Discussion of each of these materials has been discussed below.

\subsubsection{Cement}

ECC can be produced using ordinary Portland cement. Compared with conventional concrete, ECC materials contain considerably higher cement content; typically two to three times higher than conventional structural concrete (Wang and Li, 2007b). Table 2.1 shows the mixture proportions of typical ECC. The high cement content in ECC is a consequence of rheology control for easy fiber dispersion and more essentially matrix toughness control for strain- hardening behavior. 


\subsubsection{Role of Fibers}

Unlike some high performance FRC, ECC does not utilize large amount of fiber. In general 2\% or less by volume of discontinuous fiber is adequate, even though the composite is designed for structural applications. The most common type of fiber used for production of ECC is Polyvinyl Alcohol (PVA) fibers. The short, discontinuous PVA fiber with high tensile strength and modulus of elasticity enhance the matrix's toughness while carries tensile stresses after the first crack formation through the fiber bridging characteristic. The fiber bridging transfers the stresses across the crack for maintaining the low crack widths (JCI-DFRCC Committee 2003). The surface of the PVA fiber is oil coated (by 1.2\% of mass) to tailor the interfacial properties among the fiber and matrix for strain hardening performance ( $\mathrm{Li}, 2003$; $\mathrm{Li}$ et al., 2002). The oil coating reduces the interfacial bonding, while increasing the tensile strain capacity of the ECC mix, therefore under tensile stresses; the fiber tends to be ruptured rather than pull out like other FRC (Li et al., 2002). Figure 2.4 shows the difference between coated and uncoated fibers and their effect on the stressstrain curves of ECC. Table 2.2 summarizes the essential properties of the PVA fiber for maintaining the strain hardening characteristic of the ECC mix.
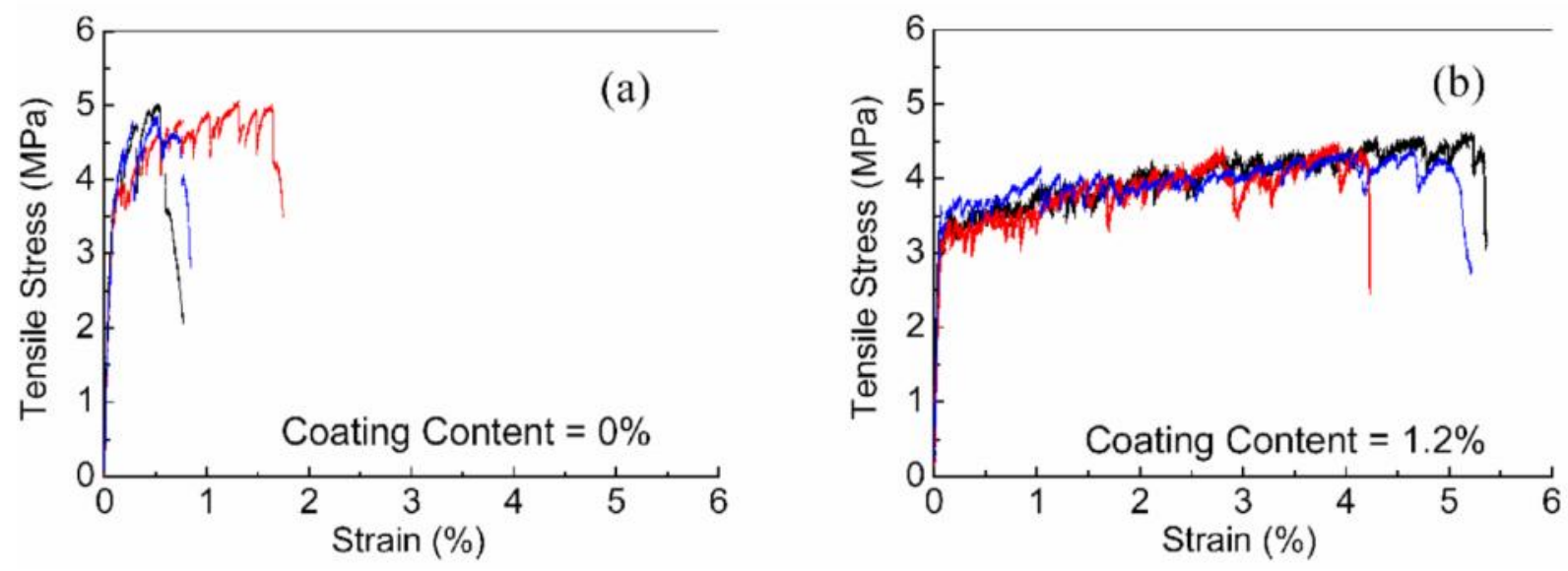

Figure 2.4: Difference in the ultimate tensile strain of ECC between (a) Coated and (b) Uncoated PVA fibers ( $\mathrm{Li}, 2003)$

Table 2.2: Geometrical and mechanical properties of PVA fiber

\begin{tabular}{|c|c|c|c|}
\hline Diameter $(\mathrm{m})$ & Length $(\mathrm{mm})$ & $\begin{array}{c}\text { Nominal strength } \\
(\mathrm{MPa})\end{array}$ & $\begin{array}{c}\text { Modulus of elasticity } \\
(\mathrm{GPa})\end{array}$ \\
\hline 39 & $6-12$ & 1620 & 42.8 \\
\hline
\end{tabular}




\subsubsection{Role of Aggregates}

The aggregate type and size are an important factor for fiber dispersion within the ECC mix to achieve a strain hardening and micro-cracking behavior. Increasing aggregate size creates problem with the fiber dispersion uniformity. The clumping and interaction of fibers would occur at higher volume; maximum aggregate size and simultaneously increase in interface toughness reduces the ductility of the ECC mix (Sahmaran et al., 2009). As a result, the standard ECC incorporates microsilica sand (maximum size of $110 \mathrm{~m}$ ) with an aggregate to binder ratio of 0.36 to maintain adequate stiffness and volume stability (Li et al., 1995). Researches revealed that using crushed sand with maximum aggregate size of $1.19 \mathrm{~mm}$ did not significantly influence the fiber dispersion and similar ductility responses and strain hardening characteristic of using micro-silica sand were attained (Sahmaran et al., 2009; Maulin, 2012; Sherir, 2012).

\subsubsection{Fly Ash}

Fly ash is the most widely used mineral admixture for concrete. It is a fine powder (typically 20 to $50 \mathrm{~m}$ in size) produced through the by-product of pulverized coal blown into a fire furnace at a power generating plant. The chemical compositions similar to the cementing material with much higher surface area typically between $250-600 \mathrm{~m}^{2} / \mathrm{kg}$ allows a better reaction with calcium hydroxide (Kosmatka and Panarese, 1988; Neville, 2002). The use of fly ash in the ECC mix leads to reduction of interfacial bonding among the PVA fiber and the matrix while increasing the frictional bonding among them (Wang and Li, 2007; Sahmaran et al., 2009; Peled and Shah, 2003). These characteristic are responsible for the tight crack width, improved ductility, durability and sustainability of the ECC mix (Yang et al., 2007; Bisaillon et al., 1994; Hussian and Rasheeduzzafar, 1994; Kuroda et al., 2000; Lepech and Li, 2005b; Karahan et al., 2012).

Fly ash consists primarily of silica, aluminum, iron, and calcium in a silicate glass form. Minor constituents can be found in the form of magnesium, sulfur, sodium, potassium, and carbon. According to American Society for Testing and Materials (ASTM), there are two classes of fly ash (Table 2.3) Class $\mathrm{C}$, which is normally produced from lignite or sub-bituminous coals and Class F, which is normally produced from bituminous coals (ASTM C618, 2012). Class C fly ashes differ from Class F fly ashes in that they are self-hardening even without the presence of cement. 
Table 2.3: Specifications for fly ash

\begin{tabular}{|l|l|}
\hline Class of fly ash & ASTM specification \\
\hline Class C & $\mathrm{SiO}_{2}+\mathrm{Al}_{2} \mathrm{O}_{3}+\mathrm{Fe}_{2} \mathrm{O}_{3}>50 \%$ \\
\hline Class F & $\mathrm{SiO}_{2}+\mathrm{Al}_{2} \mathrm{O}_{3}+\mathrm{Fe}_{2} \mathrm{O}_{3}>70 \%$ \\
\hline
\end{tabular}

\subsubsection{Mechanical Properties}

\subsubsection{Compressive Strength}

ECC exhibits a similar compressive strength as high performance concrete (HPC), typically ranging from 40 to $60 \mathrm{MPa}$ depending to the mix design parameters (Sherir, 2012; Hossain and Sherir, 2014). While a low young's modulus of $20.4 \mathrm{GPa}$ is employed, a linear behavior under compression prior to failure similar to HPC is attained (Wang and $\mathrm{Li}, 2003$ ).

The compressive strength of the ECC mix is reduced at higher fly ash content due to slow reactivity and development of hydration products at initial early ages (Hossain and Sherir, 2014; Mindess et al., 2003). The compressive strength of the ECC mix is improved by using larger sand aggregates such as crushed sand. The increase in maximum size results as a higher volume and dense interfacial transition zone among the sand particle and the matrix (Hossain and Sherir, 2014; Mehta and Monteiro, 2006).

\subsubsection{Flexural Strength}

The unique micro-structure of the ECC allows a high tensile strain capacity with multi microcracking and strain hardening characteristic $(\mathrm{Li}, 2011)$. Based on the mix design parameters, the flexural strength of the ECC varies from 5 to $16 \mathrm{MPa}$ (Wang and $\mathrm{Li}, 2003$ ).

Through extensive experimental investigations, it was confirmed that flexural strength of the ECC is reduced with increasing fly ash content due to reduced interface toughness among the PVA and the mortar, while the bending capacity is enhanced with improved frictional bonding. Using larger sand aggregates such as mortar or crushed sand, improved the flexural strength capacity, whereas the ductility was reduced due to increased interface toughness (Hossain and Sherir, 2014; Sahmaran et al., 2009; Li et al., 1995). Figure 2.5 illustrates the typical flexural strength response of a green ECC mix with high volume of fly ash at replacement levels of 55\% and $70 \%$. 

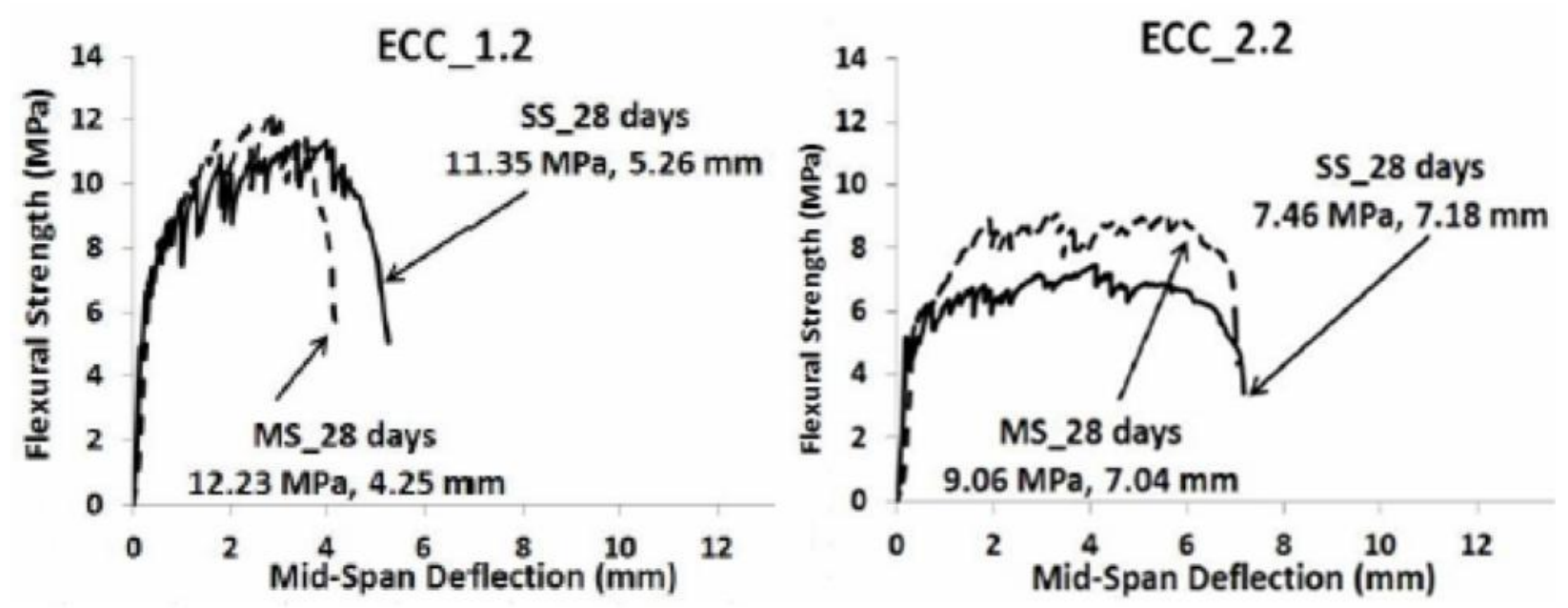

Figure 2.5: Typical flexural strength-mid span deflection of green ECC (Hossain and Sherir, 2014)

\subsubsection{Shear Strength}

Li et al. (1993) investigated the structural performance of ECC beams in response to intense shear loading. Four different types of beams with varying mix proportion, dry weight were tested to establish the link between shear behavior on a structural component level and the composite properties such as tensile strength, strain capacity and fracture energy determined on a material level. The ECC beams demonstrated shear strength about 300 times higher than normal plain concrete and 81 times higher than reinforced concrete. The cracking behavior in terms of crack width was better in the case of ECC beams and that significant reduction in crack width can translate directly into long term gains in durability because the structure remains less permeable of harmful external agents.

Furlan et al. (1997) performed extensive tests on the shear performance on fourteen beams variable with types and volume fraction of fiber. The experimental investigation revealed that, depending on the volume of fiber, the ultimate shear strength of ECC beams was 9 to 37 times higher than their normal concrete counterparts and fiber acted effectively as shear reinforcement, increasing the strength and ductility. The crack formation of fiber reinforced concrete was relatively slow and consequently, the deflections were reduced. However, cracking configuration at the end of testing in the fiber reinforced beams was more intense. 


\subsubsection{Applications of ECC}

To illustrate the versatility of ECC in real world applications, a number of recent/ongoing projects involving the use of ECC are briefly highlighted. Figure 2.6 shows the repair of the Mitaka Dam in Hiroshima-Prefecture, Japan in April, 2003 (Sakata et al., 2004). This dam is over 60 years old, with a severely damaged concrete surface. Cracks, spalling, and water leakage were concerns that prompted the use of ECC as a water-tight cover layer. This $20 \mathrm{~mm}$ layer was applied by spraying the ECC material directly onto approximately $600 \mathrm{~m}^{2}$ of the upstream dam surface.

A second large-scale application (Rokugo et al., 2005) in Japan used ECC for repair of a concrete gravity earth-retaining wall (18 $\mathrm{m}$ in width and $5 \mathrm{~m}$ in height) that has been damaged by (ASR) cracking. The decision to use ECC for the 50-70 mm thick repair was based on the need to prevent reflective cracking from the substrate concrete through the repair layer (Li and Lepech, 2004). Such reflective cracking was anticipated had normal concrete been used for the repair. Since this repair was completed, this project performance has been continuously monitored. Ten and twentyfour months following the repair, micro crack widths in the ECC repair layer remain below $50 \mathrm{~m}$ and 120 m respectively, while the maximum crack widths in the premixed concrete repair mortar section (used as a control) were $0.2 \mathrm{~mm}$ and $0.3 \mathrm{~mm}$, respectively (Kunieda and Rokugo, 2006).

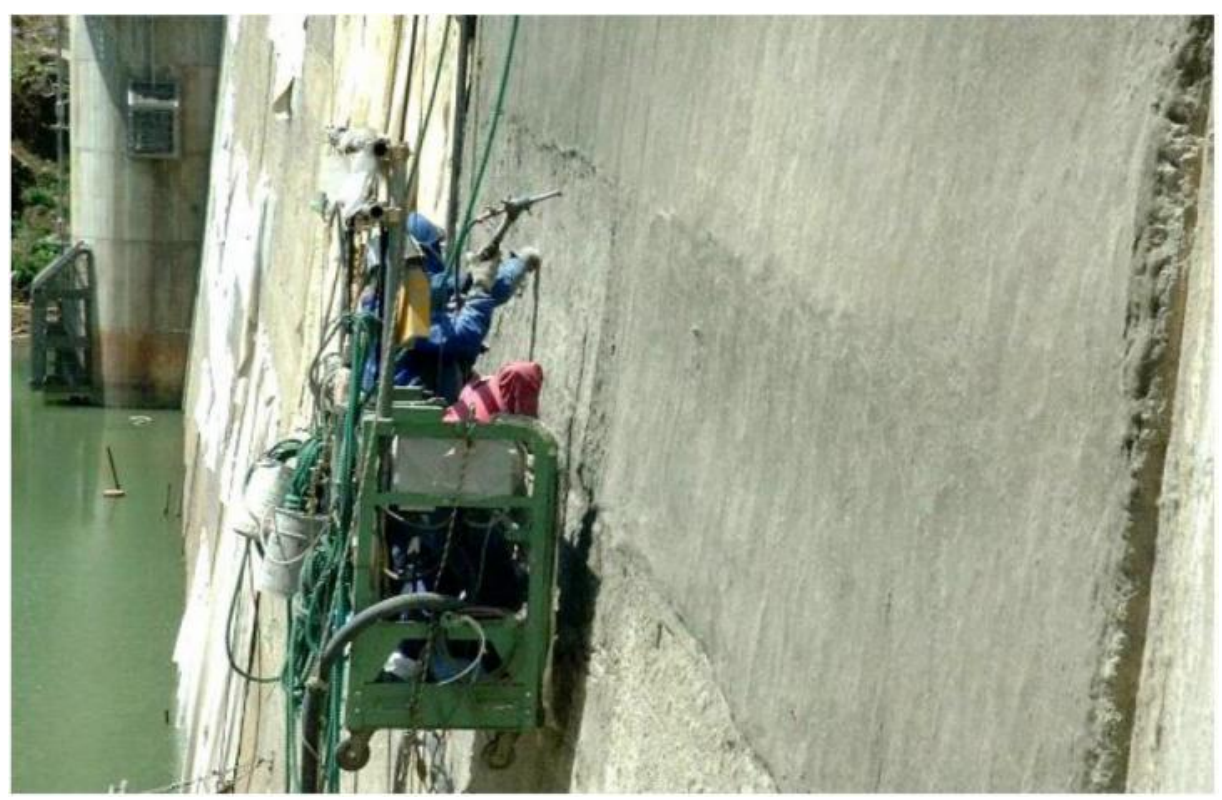

Figure 2.6: Spray repair of the Mitaka dam with ECC for water-proofing (Sakata et al., 2004) 
Also in Japan ECC has been used in structural applications as coupling beams (Maruta et al., 2005) within high rise concrete construction. Due to the high energy absorption capacity of steel reinforced ECC material, the application of this material in coupling beams which connect adjacent core walls is very advantageous for high rise buildings in seismic regions. The recent development of precast ECC coupling beam elements by Kajima Corporation in Japan can be easily integrated into current seismic construction practices. Currently two high-rise buildings in Tokyo, Japan has been built integrating ECC coupling beams (Figure 2.7).

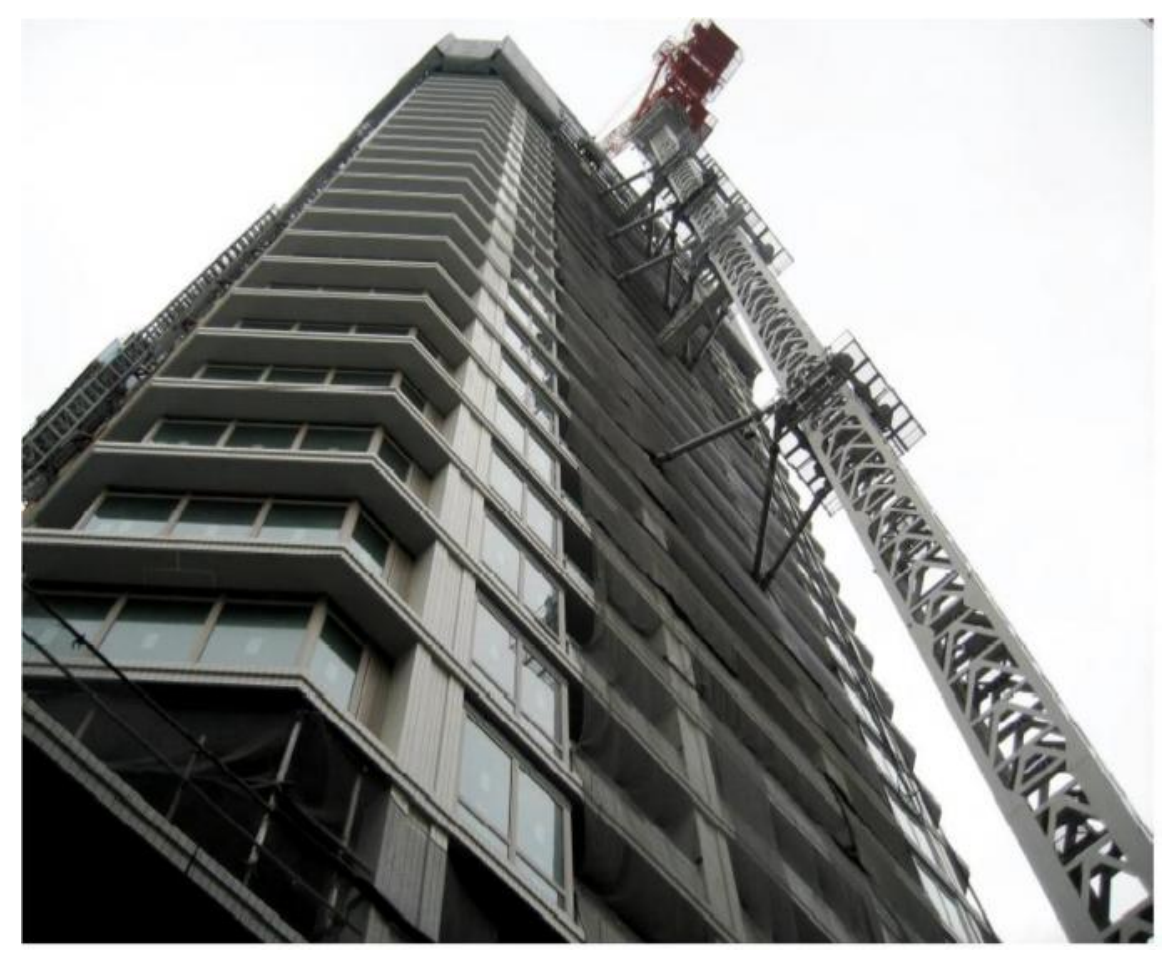

Figure 2.7: The Nabeaure tower in Yokohoma, Japan uses precast ECC coupling beams in building core for seismic resistance (Maruta et al., 2005)

As one of the first field applications of ECC in the US, a concrete bridge deck patch was completed in cooperation with the Michigan department of transportation (MDOT) in 2002. A complete summary of this work has been outlined by Li and Lepech (2004). During this work, one section of a deteriorated bridge deck was repaired with ECC while the remaining portion was repaired with a commercial concrete patching material commonly used by the MDOT (Figure 2.8). This repair scenario allowed for a unique ECC/concrete comparison subjected to identical environmental and traffic loads. The concrete repair material used was a pre-packaged, 
commercially available repair mortar. At this writing, the repaired bridge deck has experienced more than six complete Michigan winter cycles of freezing and thawing, in addition to live loads. While the ECC patch repair has survived in this combined loading environment with minor microcracking limited to less than $50 \mathrm{~m}$, the concrete repair portion has developed localized cracks in excess of $3.5 \mathrm{~mm}$ wide and required re-repair in 2005 .

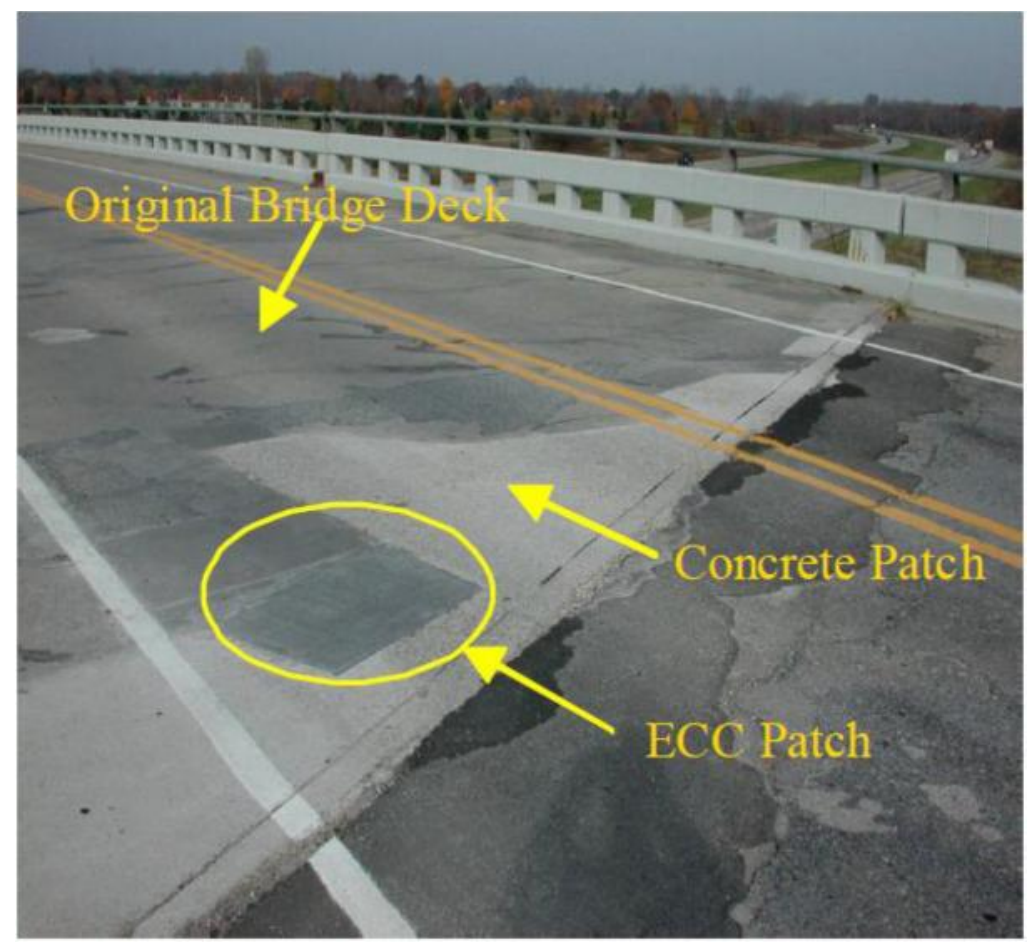

Figure 2.8: ECC patch repair on Michigan bridge deck (Li et al., 2005)

In addition to bridge deck patching repairs, the most recent field application of ECC in the US is with a bridge "link slab" completed in cooperation with MDOT in 2005 (Figure 2.9). Within this "link slab", the material ductility of ECC is leveraged to replace problematic expansion joints within simply support multi-span bridges with a ductile ECC slab which links the adjacent simple spans (Li et al., 2005). In this project, about $32 \mathrm{~m}^{3}$ of ECC were cast in place using standard readymix concrete trucks to build the first ECC link slab in US. With a strain capacity exceeding $2 \%$, these composites can be used to replace traditional steel expansion devices and can fully accommodate the thermal deformations of adjacent bridge spans. (a) during construction (b) after construction. 

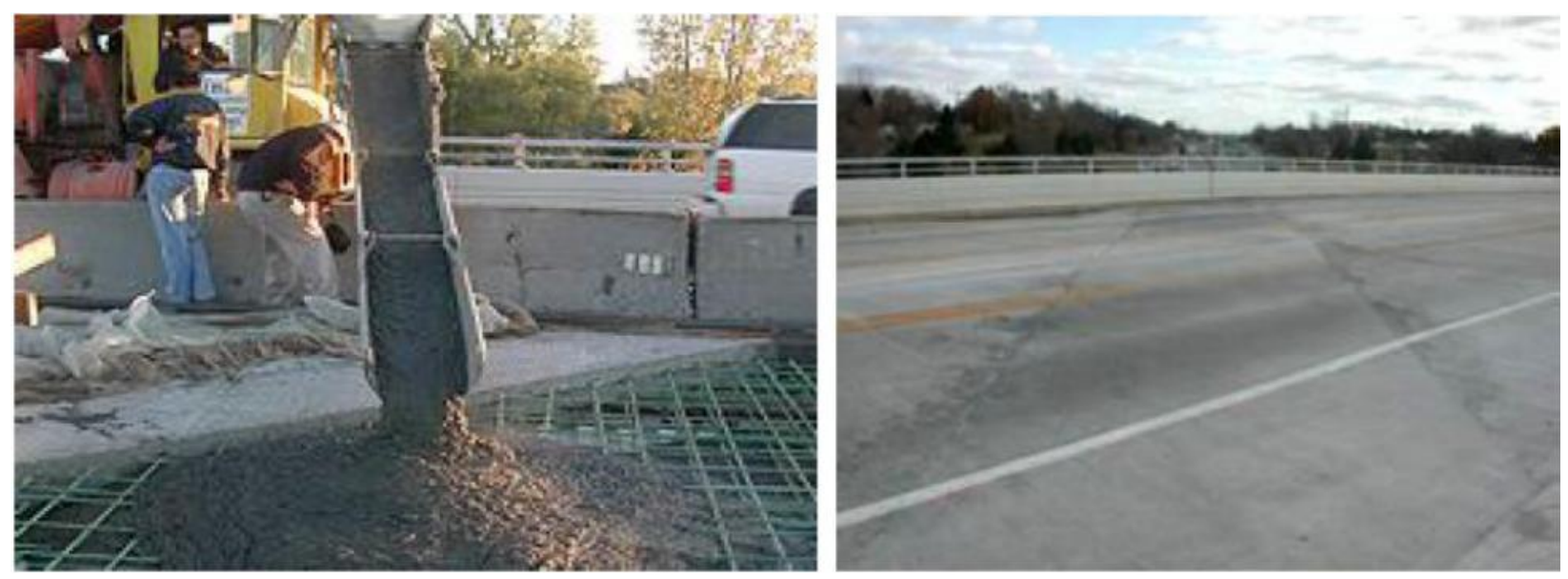

Figure 2.9: ECC link-slab on Grove Street Bridge, Michigan (Qian et al., 2009)

\subsection{Research on structural performance of SCC, ECC, FRC and composite beams}

Amin et al. (2016) studied shear strength on six FRC beams with stirrups using steel fiber. The variables of this research were fiber volumes and transverse reinforcement ratios of beams. Fourpoint loading was applied and tested to failure. The shear span to effective depth ratio (a/d) was kept constant 2.8 for all beam, the clear cover for each beam was $25 \mathrm{~mm}$. The beams contained two layers of three normal ductility $28 \mathrm{~mm}$ diameter tensile reinforcement (N28), which corresponds to a flexural reinforcement ratio of 0.0198 . Two $20 \mathrm{~mm}$ diameter longitudinal reinforcing bars (N20) were located at the top section of the beam. The steel fibers used in this study were the structural grade double end-hooked Dramix_5D-65/60-BG fiber. The fibers were $0.9 \mathrm{~mm}$ in diameter and $60 \mathrm{~mm}$ long. The specimens were designated using the notation BW-X$\mathrm{Y}-\mathrm{Z}$ where ' $\mathrm{W}$ ' is the dosage of steel fibers (in $\mathrm{kg} / \mathrm{m}^{3}$ ), ' $\mathrm{X}$ ' is the stirrup steel strength grade (in $\mathrm{MPa}$ ), ' $\mathrm{Y}$ ' is the diameter of stirrups (in $\mathrm{mm}$ )and ' $\mathrm{Z}$ ' is the stirrup spacing (in $\mathrm{mm}$ ) within the critical shear regions. For example, specimen B25-550-6-450 represents a beam reinforced with $25 \mathrm{~kg} / \mathrm{m}^{3}$ of steel fibers and $6 \mathrm{~mm}$ grade $550 \mathrm{MPa}$ stirrups spaced at $450 \mathrm{~mm} \mathrm{c} / \mathrm{c}$ within the critical shear regions. Details of the experimental ECC beams are presented in Table 2.4 and Figure 2.10. The test results showed that sufficient dosages of fiber could replace the minimum amount of transverse (ligature) shear reinforcement and also beams containing larger dosages of steel fibers, crack patterns tended to be more dispersed and cracks were visibly finer. As the load was increased towards ultimate, the cracks coalesced to from the failure crack. 
Table 2.4: Details of FRC beams tested by Amin et al. (2016)

\begin{tabular}{|c|c|c|c|c|c|c|c|}
\hline Beam code & $\begin{array}{c}\text { Fibre } \\
\text { dosage: } \\
\text { Mean } \\
\text { (St. Dev) } \\
\mathrm{kg} / \mathrm{m}^{3}\end{array}$ & $\begin{array}{c}\text { Compressive } \\
\text { strength, f' } \\
\text { (MPa) }\end{array}$ & $\begin{array}{c}\text { Shear } \\
\text { span to } \\
\text { depth } \\
\text { ratio, a/d } \\
\text { reinforcement } \\
\text { details }\end{array}$ & $\begin{array}{c}\text { Transverse } \\
\text { steel yield } \\
\text { strength } \\
\mathrm{f}_{\mathrm{y}} \text { (MPa) }\end{array}$ & $\begin{array}{c}\text { Transverse } \\
\rho_{\mathrm{s}} \%\end{array}$ & $\begin{array}{c}\text { Experimental } \\
\text { ultimate load, } \\
\mathrm{V}_{\mathrm{u}}\end{array}$ \\
\hline B25-550-6-450 & $25.0(0.5)$ & 34 & 2.8 & $\begin{array}{c}2 \text { leg R6 @ } \\
450 \mathrm{~mm}\end{array}$ & 553 & 1.98 & 363 \\
\hline B25-450-10-450 & $25.0(0.5)$ & 34 & 2.8 & $\begin{array}{c}2 \text { leg R10 @ } \\
450 \mathrm{~mm}\end{array}$ & 447 & 1.98 & 334 \\
\hline B25-400-6-300 & $23.0(4.6)$ & 46 & 2.8 & $\begin{array}{c}2 \text { leg R6 @ } \\
300 \mathrm{~mm}\end{array}$ & 402 & 1.98 & 322 \\
\hline B25-300-10-300 & $23.0(4.6)$ & 46 & 2.8 & $\begin{array}{c}2 \text { leg R10 @ } \\
300 \mathrm{~mm}\end{array}$ & 277 & 1.98 & 357 \\
\hline B50-550-6-450 & $53.6(10.2)$ & 36 & 2.8 & $\begin{array}{c}2 \text { leg R10 @ } \\
450 \mathrm{~mm}\end{array}$ & 553 & 1.98 & 462 \\
\hline B50-450-10-450 & $53.6(10.2)$ & 36 & 2.8 & $\begin{array}{c}2 \text { leg R10 @ } \\
450 \mathrm{~mm}\end{array}$ & 447 & 1.98 & 535 \\
\hline
\end{tabular}

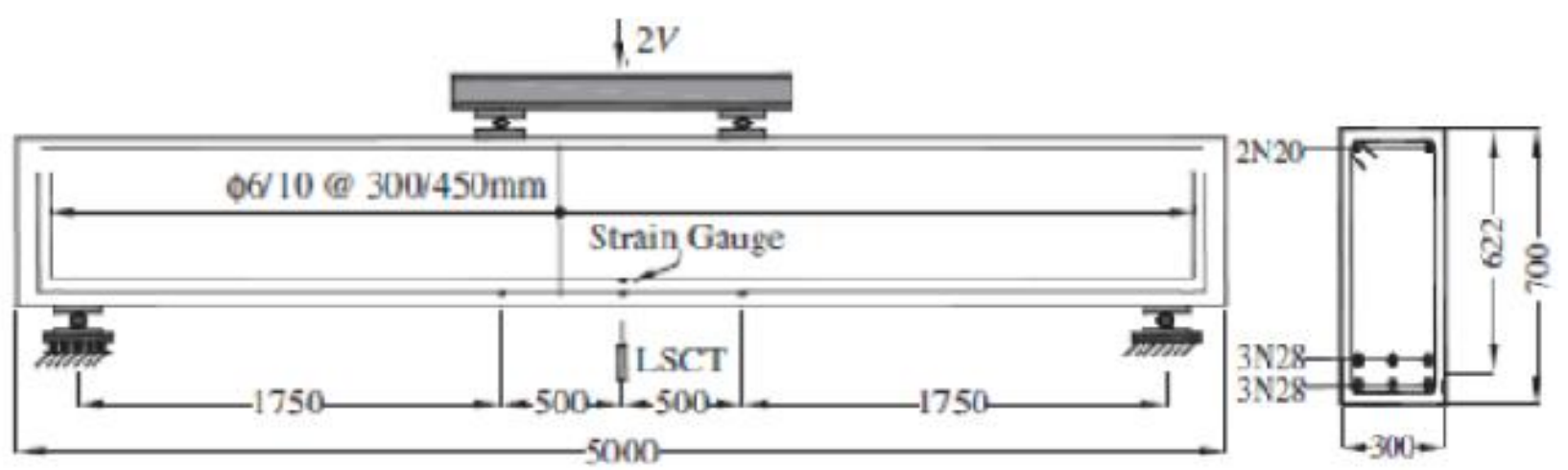

Figure 2.10: FRC beams geometry and experimental set by tested by Amin et al. (2016)

(Dimensions in $\mathrm{mm}$ ) 
Alyousif et al. (2015) tested six ECC beams without stirrup having three different shear spans to effective depth ratios and two main longitudinal reinforcement amounts to check the shear performance. For each a/d ratio, test specimens were reinforced with two different amounts of main longitudinal tensile reinforcements, whereas, for specimens with " $\mathrm{A}$ " in their notation, longitudinal tensile reinforcement of $2 \Phi 16$ was used. For " $B$ " specimens, longitudinal tensile reinforcement of $4 \Phi 16$ were used. To prevent local failure at the support points of reinforced beam specimens, a small number of shear reinforcements were used in these areas. No additional shear reinforcements were added along the beam length. Fibers used in ECC were polyvinyl alcohol (PVA) type with an average diameter of $39 \mathrm{~m}$, an average length of $8 \mathrm{~mm}$, and a tensile strength of $1610 \mathrm{MPa}$. Table 2.5 shows the mix portion of ECC. The four-point bending test setup was adopted to evaluate the behavior of reinforced beams under shear forces. Details of the experimental ECC beams are presented in Table 2.6 and Figure 2.11.

Table 2.5: Mix proportion of ECC in used by Alyousif et al. (2015)

\begin{tabular}{|c|c|c|c|c|c|}
\hline $\begin{array}{c}\text { PC } \\
\left(\mathrm{kg} / \mathrm{m}^{3}\right)\end{array}$ & $\begin{array}{c}\text { Fly ash } \\
\left(\mathrm{kg} / \mathrm{m}^{3}\right)\end{array}$ & $\begin{array}{c}\text { Water } \\
\left(\mathrm{kg} / \mathrm{m}^{3}\right)\end{array}$ & $\begin{array}{c}\text { Silica sand } \\
\left(\mathrm{kg} / \mathrm{m}^{3}\right)\end{array}$ & $\begin{array}{c}\text { PVA fiber } \\
\left(\mathrm{kg} / \mathrm{m}^{3}\right)\end{array}$ & $\begin{array}{c}\text { HRWRA } \\
\left(\mathrm{kg} / \mathrm{m}^{3}\right)\end{array}$ \\
\hline 375 & 823 & 318 & 446 & 26 & 2.3 \\
\hline \multicolumn{2}{|r|}{ PC: Portland cement; HRWRA: High range water reducing admixture } \\
\hline
\end{tabular}

Table 2.6: Details of ECC beams tested by Alyousif et al. (2015)

\begin{tabular}{|c|c|c|c|c|c|c|}
\hline Beam code & $\begin{array}{c}\text { Length, } \\
\mathrm{mm}\end{array}$ & $\begin{array}{c}\text { Compressive } \\
\text { strength, } \mathrm{f}_{\mathrm{c}} \\
(\mathrm{MPa})\end{array}$ & $\begin{array}{c}\text { Shear } \\
\text { span to } \\
\text { depth } \\
\text { ratio, a/d }\end{array}$ & $\begin{array}{c}\text { Longitudinal } \\
\text { reinforcement } \\
\text { ratio, } \rho_{\mathrm{s}} \%\end{array}$ & $\begin{array}{c}\text { Longitudinal } \\
\text { steel yield } \\
\text { strength, } \\
\mathrm{f}_{\mathrm{y}}(\mathrm{MPa})\end{array}$ & $\begin{array}{c}\text { Experimental } \\
\text { ultimate load, } \\
\mathrm{V}_{\mathrm{u}}(\mathrm{kN})\end{array}$ \\
\hline Beam 1A & 1130 & 46.1 & 1 & 1.29 & 520 & 501.47 \\
\hline Beam 1B & 1080 & 46.1 & 1 & 2.57 & 520 & 550.91 \\
\hline Beam 2A & 1560 & 46.1 & 2 & 1.29 & 520 & 220.66 \\
\hline Beam 2B & 1460 & 46.1 & 2 & 2.57 & 520 & 220.83 \\
\hline Beam 3A & 1990 & 46.1 & 3 & 1.29 & 520 & 143.27 \\
\hline Beam 3B & 1840 & 46.1 & 3 & 2.57 & 520 & 190.59 \\
\hline
\end{tabular}




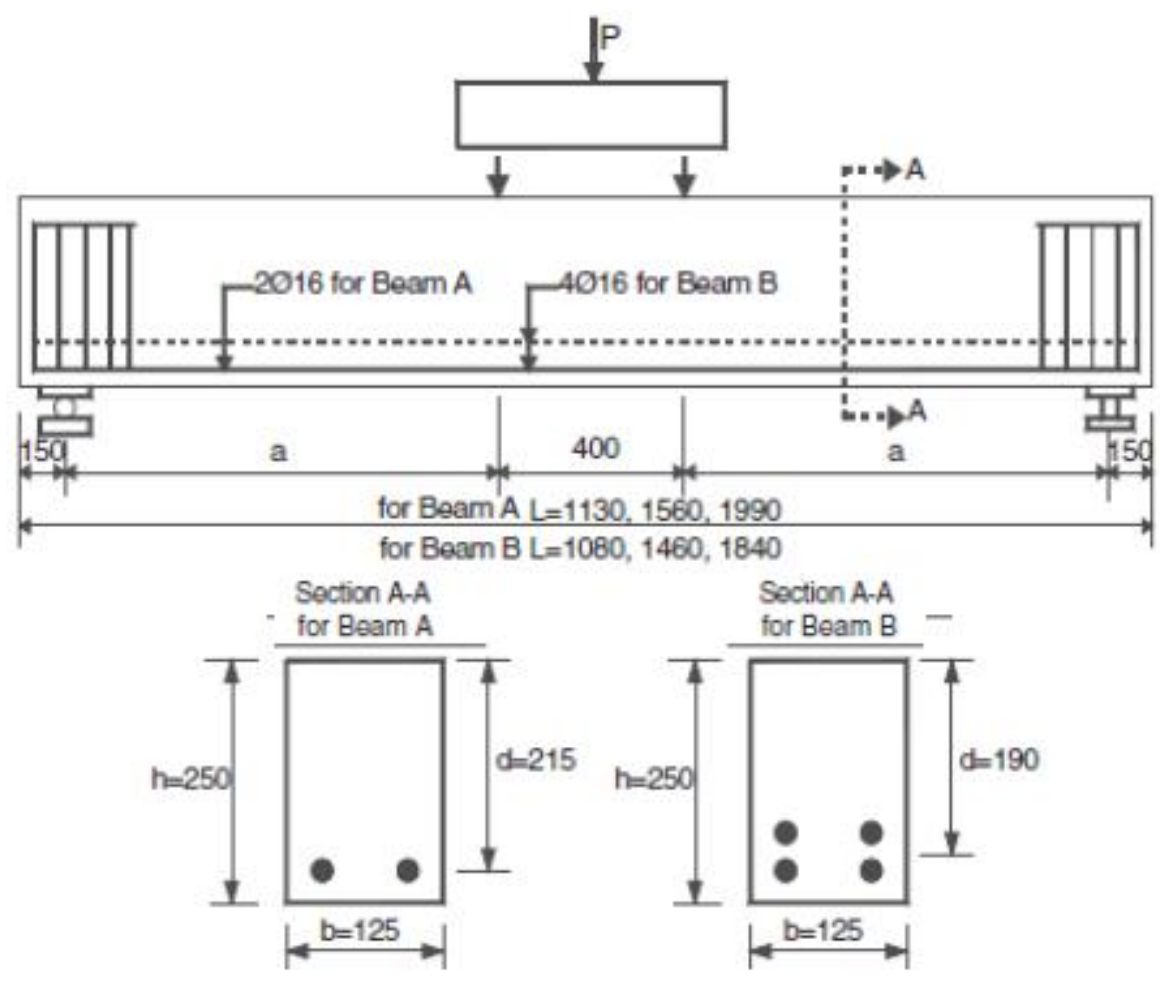

Figure 2.11: ECC beams geometry and experimental set by tested by Alyousif et al. (2015)

(Dimensions in $\mathrm{mm}$ )

Zhang et al. (2014) studied Shear capacity on four ECC beams with stirrups using Polypropylene (PP) fiber. The variables of this research were compressive strength, transverse reinforcement ratio and spacing of the shear reinforcement of each ECC beams. Length of the beam, a/d ratio and longitudinal reinforcement ratio were kept constant for all beams. The length and diameter of the fiber was $12 \mathrm{~mm}$ and 36 micrometer respectively. Details of ECC mix proportion are presented in Table 2.7. $25.4 \mathrm{~mm}$ dia rebar in tension zone and $6.35 \mathrm{~mm}$ dia rebar as shear reinforcement having yield strength $400 \mathrm{MPa}$ and $323 \mathrm{MPa}$ were used on the samples. Four point loading was applied on the beam until failure. Details of the experimental ECC beams are presented in Table 2.8 and Figure 2.12 (a, b and c).

Table 2.7: Mix proportion of ECC used by Zhang et al. (2014)

\begin{tabular}{|c|c|c|c|c|c|}
\hline Slump flow & W/C & \multicolumn{4}{|c|}{ Unit weight $\left(\mathrm{kg} / \mathrm{m}^{3}\right)$} \\
\hline$(\mathrm{mm})$ & $(\%)$ & Water & Cement & PP fiber & AE \\
\hline Approx. 500 & 27 & 371 & 1400 & 27 & 7 \\
\hline
\end{tabular}

W/C: Water cement ratio; AE: Acoustic emission; PP: Polypropylene 
Table 2.8: Details of ECC beams tested by Zhang et al. (2014)

\begin{tabular}{|c|c|c|c|c|c|c|c|c|}
\hline \multirow[t]{2}{*}{$\begin{array}{l}\text { Beam } \\
\text { code }\end{array}$} & \multirow[t]{2}{*}{$\begin{array}{l}\text { Length, } \\
\mathrm{mm}\end{array}$} & \multirow[t]{2}{*}{$\begin{array}{c}\mathrm{f}^{\prime}{ }_{c} \\
(\mathrm{MPa})\end{array}$} & \multirow{2}{*}{$\begin{array}{l}\text { Shear } \\
\text { span to } \\
\text { depth } \\
\text { ratio, } \\
\text { a/d }\end{array}$} & \multicolumn{2}{|c|}{$\begin{array}{c}\text { Shear } \\
\text { reinforcement } \\
\text { details }\end{array}$} & \multirow[t]{2}{*}{$\rho_{\mathrm{s}} \%$} & \multirow{2}{*}{$\begin{array}{c}\text { Transverse } \\
\text { steel yield } \\
\text { strength, } \\
\mathrm{f}_{\mathrm{y}}(\mathrm{MPa})\end{array}$} & \multirow{2}{*}{$\begin{array}{c}\text { Exp. } \\
\text { ultimate } \\
\text { load, } \mathrm{V}_{\mathrm{u}} \\
(\mathrm{kN})\end{array}$} \\
\hline & & & & $\mathrm{r}_{\mathrm{w}}(\%)$ & $\mathrm{s}(\mathrm{mm})$ & & & \\
\hline RE-42 & \multirow{4}{*}{2100} & 30.4 & \multirow{4}{*}{2.8} & 0.42 & 100 & \multirow{4}{*}{2.7} & \multirow{4}{*}{323} & 141.09 \\
\hline RE-30 & & 33.1 & & 0.30 & 140 & & & 130.56 \\
\hline RE-24 & & 31.5 & & 0.24 & 175 & & & 125.24 \\
\hline RE-12 & & 35.6 & & 0.12 & 350 & & & 126.05 \\
\hline
\end{tabular}

$r_{w}$ : Shear reinforcement ratio, $s$ : Spacing of shear reinforcements; $\rho_{\mathrm{s}} \%$ : Longitudinal reinforcement ratio; $\mathrm{f}^{\prime}$ ': Compressive strength

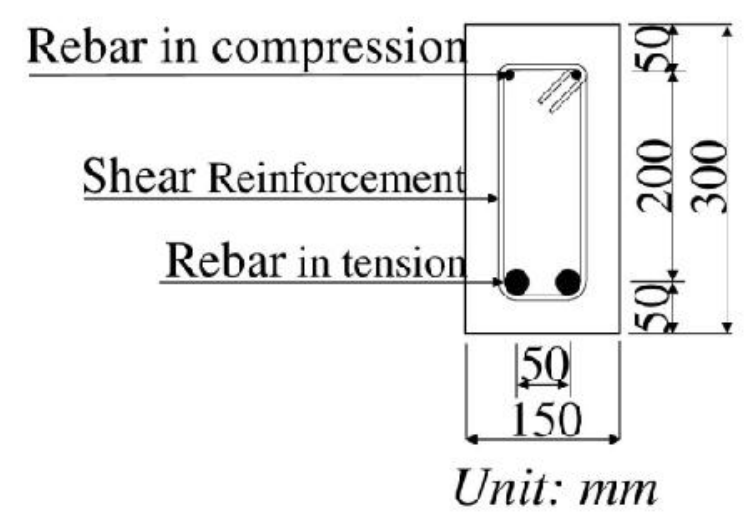

Figure 2.12a: Reinforcement details for beams tested by Zhang et al. (2014)

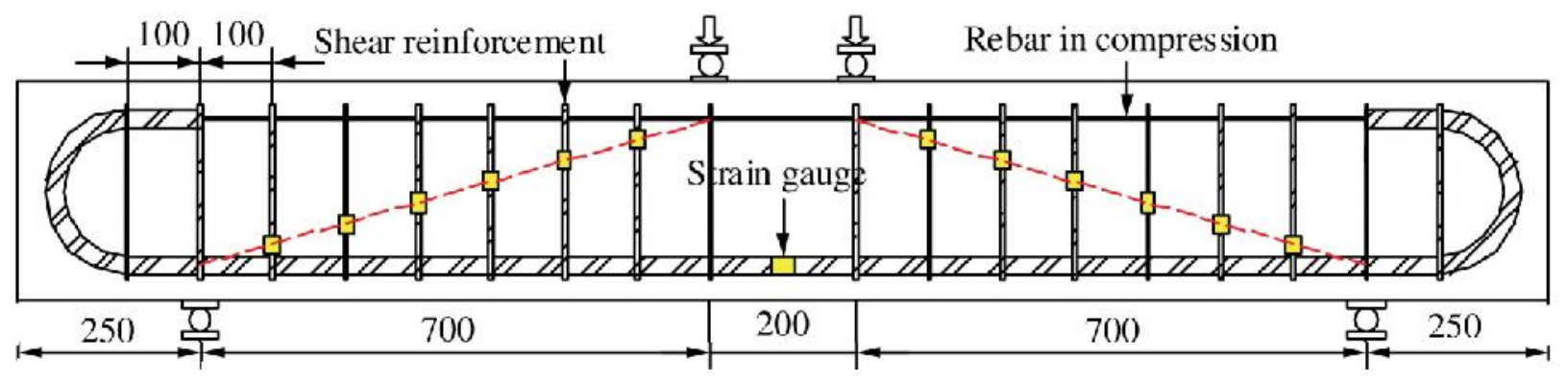

Figure 2.12b: Reinforcement details for beam RE-42 tested by Zhang et al. (2014)

(Dimensions in $\mathrm{mm}$ ) 


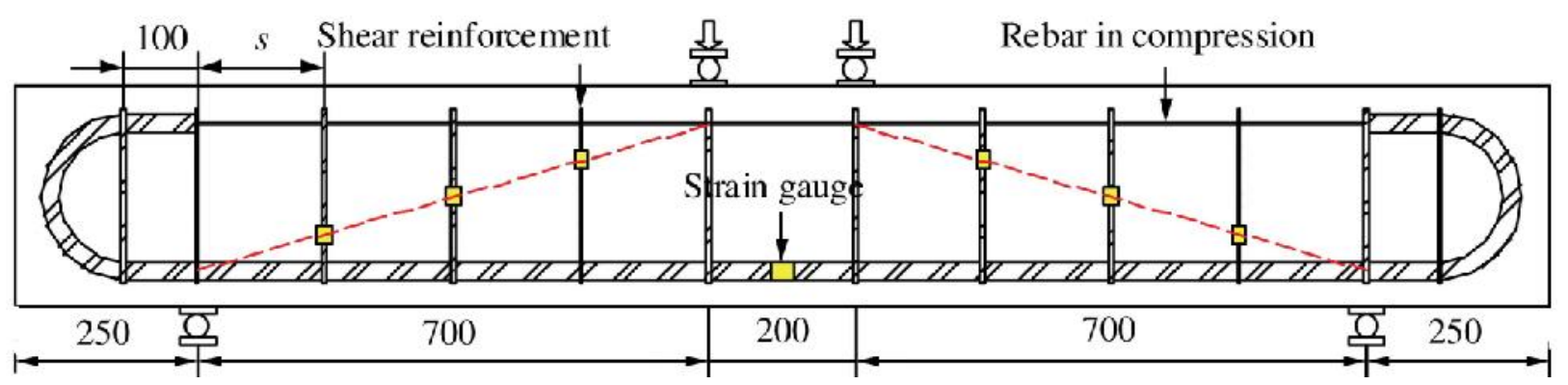

Figure 2.12c: Reinforcement details for beam RE-30, 24 and 12 tested by Zhang et al. (2014)

(Dimensions in $\mathrm{mm}$ )

Dinh et al. (2010) performed extensive tests on 24 FRC beams without shear reinforcement with varying a/d ratio, longitudinal reinforcement and volume fraction of steel fiber to study the shear behavior. The experimental program consisted of two series of beams: Series B18, with an overall beam depth of $455 \mathrm{~mm}$, and Series B27, with a beam depth of $685 \mathrm{~mm}$. Each beam was designed to fail in the longer shear span, with a span-to effective depth (a/d) ratio of approximately 3.5 that was selected to reduce any significant contribution from arch action to beam shear strength. Three types of steel fibers, all with hooked ends, were evaluated in volume fractions of either $0.75 \%$, or $1 \%$ or $1.5 \%$. Fiber Types 1 and 3 were $30 \mathrm{~mm}$ (1.2 in.) long with an aspect (length-to-diameter) ratio of 55 and 80, respectively. Type 2 fibers were $60 \mathrm{~mm}$ (2.4 in.) long with an aspect ratio of 80. Local ready mix concrete made of crushed limestone with $10 \mathrm{~mm}(3 / 8 \mathrm{in}$.) maximum size was used in all types of beams. Three types of longitudinal rebar $19 \mathrm{~mm} ; 22 \mathrm{~mm}$ and $25 \mathrm{~mm}$ dia having yield strength $496 \mathrm{MPa}, 448 \mathrm{MPa}$ and $455 \mathrm{MPa}$ respectively were used in this study. Three point loading was applied to all of the samples until failure. Details of the experimental ECC beams are presented in Table 2.9 and Figure 2.13 (a, b and c). 
Table 2.9: Details of ECC beams tested by Dinh et al. (2010)

\begin{tabular}{|c|c|c|c|c|c|c|}
\hline Beam code & $\begin{array}{l}\text { Shear span } \\
\text { to depth } \\
\text { ratio, a/d }\end{array}$ & $\begin{array}{l}\text { Longitudinal } \\
\text { reinforcement } \\
\text { ratio, } \rho_{\mathrm{s}} \%\end{array}$ & $\begin{array}{l}\text { Compressive } \\
\text { strength, } \mathrm{f}_{\mathrm{c}} \\
\text { (Mpa) }\end{array}$ & $\begin{array}{l}\text { Fiber } \\
\text { type }\end{array}$ & $\begin{array}{c}\text { Fiber } \\
\text { volume } \\
\text { fraction, } \\
V_{f}, \%\end{array}$ & $\begin{array}{c}\text { Ultimate } \\
\text { peak load, } \\
P_{u}, \mathrm{kN}\end{array}$ \\
\hline B18-1a & 3.43 & 2.0 & 44.8 & 1 & 0.75 & 441 \\
\hline B18-1b & 3.43 & 2.0 & 44.8 & 1 & 0.75 & 413 \\
\hline B18-2a & 3.5 & 2.0 & 38.1 & 1 & 1.0 & 437 \\
\hline B18-2b & 3.5 & 2.0 & 38.1 & 1 & 1.0 & 445 \\
\hline B18-2c & 3.5 & 2.7 & 38.1 & 1 & 1.0 & 503 \\
\hline B18-2d & 3.5 & 2.7 & 38.1 & 1 & 1.0 & 367 \\
\hline B18-3a & 3.43 & 2.7 & 31.0 & 1 & 1.5 & 384 \\
\hline B18-3b & 3.43 & 2.7 & 31.0 & 1 & 1.5 & 507 \\
\hline B18-3c & 3.43 & 2.7 & 44.9 & 1 & 1.5 & 494 \\
\hline B18-3d & 3.43 & 2.7 & 44.9 & 1 & 1.5 & 490 \\
\hline B18-5a & 3.43 & 2.7 & 49.2 & 2 & 1.0 & 445 \\
\hline B18-5b & 3.43 & 2.7 & 49.2 & 2 & 1.0 & 565 \\
\hline B18-7a & 3.43 & 2.0 & 43.3 & 3 & 0.75 & 498 \\
\hline B18-7b & 3.43 & 2.0 & 43.3 & 3 & 0.75 & 490 \\
\hline B27-1a & 3.5 & 2.0 & 50.8 & 1 & 0.75 & 908 \\
\hline B27-1b & 3.5 & 2.0 & 50.8 & 1 & 0.75 & 837 \\
\hline B27-2a & 3.5 & 2.0 & 28.7 & 2 & 0.75 & 872 \\
\hline B27-2b & 3.5 & 2.0 & 28.7 & 2 & 0.75 & 854 \\
\hline B27-3a & 3.5 & 1.6 & 42.3 & 1 & 0.75 & 846 \\
\hline B27-3b & 3.5 & 1.6 & 42.3 & 1 & 0.75 & 863 \\
\hline B27-4a & 3.5 & 1.6 & 29.6 & 2 & 0.75 & 663 \\
\hline B27-4b & 3.5 & 1.6 & 29.6 & 2 & 0.75 & 556 \\
\hline B27-5 & 3.5 & 2.1 & 44.4 & 1 & 1.5 & 1081 \\
\hline B27-6 & 3.5 & 2.1 & 42.8 & 2 & 1.5 & 1046 \\
\hline
\end{tabular}




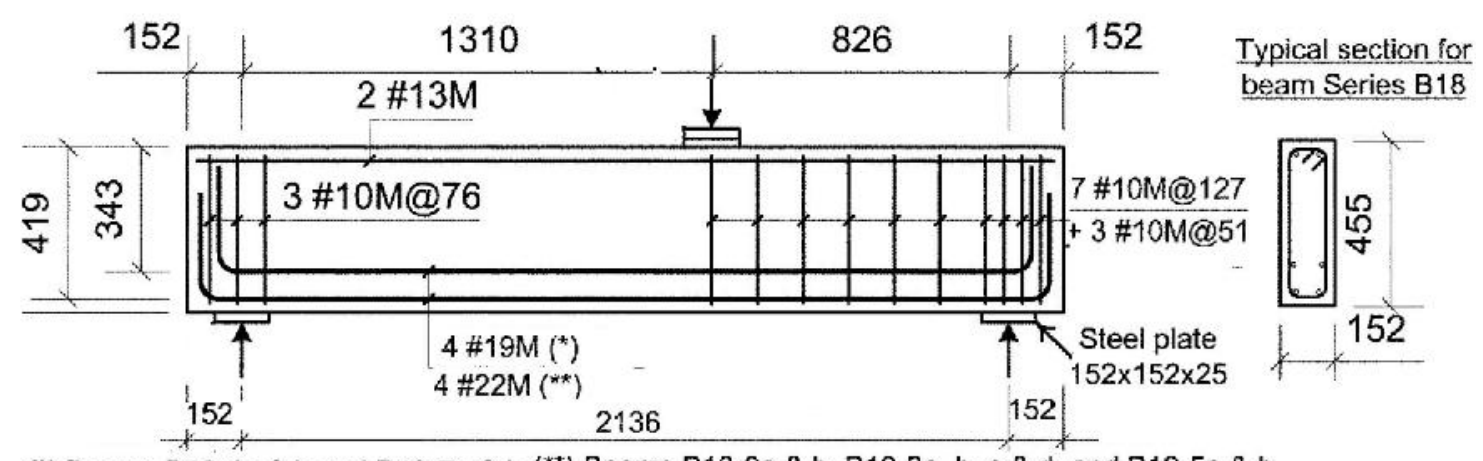

(*) Beams B18-1a \& b and B18-7a \& b (**) Beams B18-0a \& b, B18-3a, b, c \& d, and B18-5a \& b

Figure 2.13a: Reinforcement details for Beams B18-0a \& b, B18-1a \& b, B18-3a, b, c \& d; B18$5 \mathrm{a} \& \mathrm{~b}$, and B18-7a \& b tested by Dinh et al. (2010) (Dimensions in $\mathrm{mm}$ )

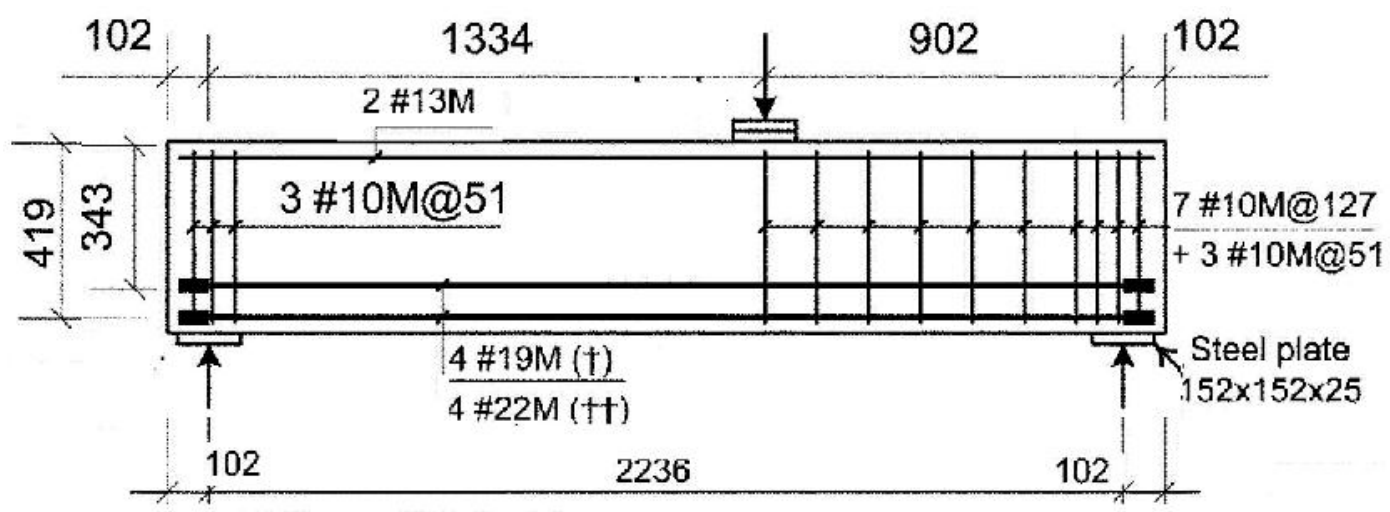

(†) Beams B18-2a \& b (††) Beams B18-2c \& d

Figure 2.13b: Reinforcement details for Beams B18-2a, b, c \& d tested by Dinh et al. (2010)

(Dimensions in $\mathrm{mm}$ )

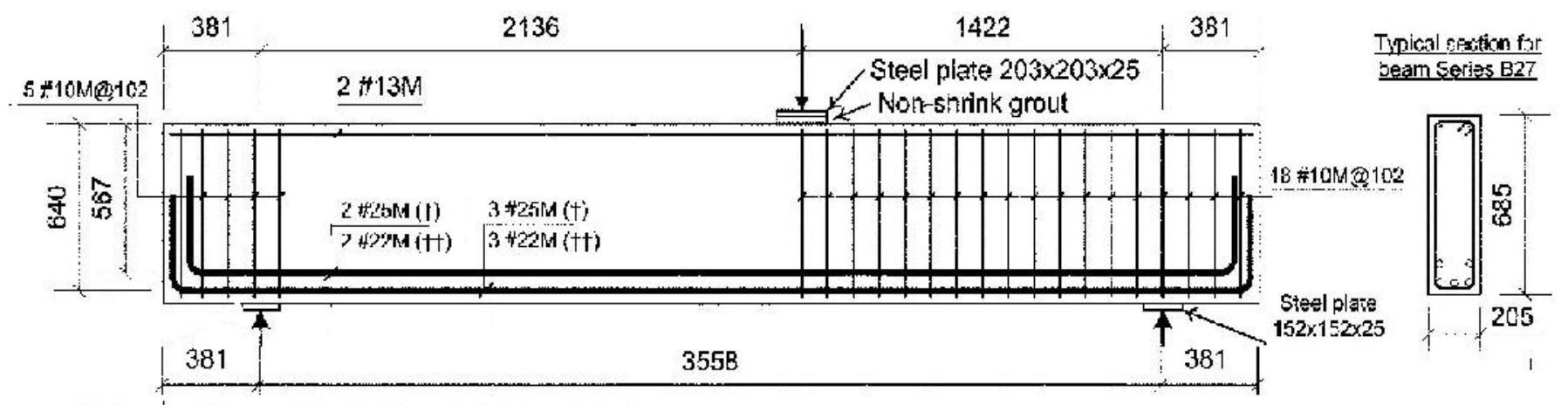

(†) Scams B27 1 a \& b; B27-2a \& b; B27 5; 827.6 (††i Beams B27-3a \& b; B27-4a \& b; B27-7

Figure 2.13c: Reinforcement details for Beams B27-1a \& b, B27-2a \& b, B27-3a \& b; B27-4a \& b; B27-5; B27-6; and B27-7 tested by Dinh et al. (2010) (Dimensions in mm) 
Lachemi et al. (2005) investigated the shear resistance of 18 flexurally reinforced selfconsolidating concrete beams without shear reinforcements and compared the results to that in normal concrete beams. They investigated the shear strength in SCC based on the assumption that SCC mixtures have comparatively smaller amount of coarse aggregates content which may reduce the shear resistance of concrete by reducing the aggregate interlock between the fracture surfaces. The tested beams were varied in depth $(150$ to $300 \mathrm{~mm})$ and have effective span of $800 \mathrm{~mm}$. The test parameters in their investigation included concrete type, maximum size of coarse aggregate, coarse aggregate content, and beam shear span-to-depth ratio. Shear strength, shear ductility, crack patterns, and failure modes of all experimental beams were compared to analyze the shear resistance mechanisms of SCC and NC beams in both pre- and post-cracking stages. The results of their investigation showed that SCC with the same maximum size of coarse aggregate but having a lower coarse aggregate content (as is the case for a typical SCC) showed similar concrete shear resistance characteristics in pre-cracking stage as compared with an NC. The results also revealed the development of lower post-cracking shear resistance in SCC due to lesser aggregate interlock and dowel action as a consequence of the presence of lower quantity of coarse aggregate compared with NC.

Hossain (2015) investigated the fresh, mechanical and durability properties of LWSCC mixtures produced from pumice aggregates and supplementary cementing materials derived from various combinations of volcanic ash, pumice powder and metakaolin. The fresh state properties are determined from slump flow, V-funnel flow time, bleeding, air content, and setting time and segregation tests. The mechanical properties and durability characteristics such as compressive strength, rapid chloride permeability, ultra-sonic pulse velocity, and freeze-thaw/frost resistance, resistance to salt scaling and drying shrinkage are evaluated. The use of volcanic ash, pumice and metakaolin as SCM has improved resistance to chloride penetration, freeze-thaw and salt scaling. Developed LWSCC mixtures have exhibited satisfactory durability and also satisfied the criteria for structural concrete. 
Hassan et al. (2008, 2010a-b) investigated strength, cracking and deflection performance of large scale self-consolidating concrete beams subjected to shear failure. Twenty concrete beams without shear reinforcement were tested to shear failure under simply supported three-point loading conditions. The variables were concrete type, coarse aggregate content, beam depth (150-750 $\mathrm{mm})$ and longitudinal reinforcing steel ratio of $1 \%$ and $2 \%$.The performance was evaluated based on crack pattern, crack width, load at first flexure/diagonal (shear) crack, ultimate shear resistance, post-cracking shear resistance/ductility, load deflection response and failure mode. The results showed that the ultimate shear strength of SCC beams was slightly lower than that of their normal concrete counterparts. The results also validated the performance of various Code-based equations in predicting the crack width and first flexural cracking moment/load.

Oliver et al. (2001) investigated a fracture mechanics model for the flexural-shear failure of reinforced concrete beams without stirrups. Assuming that the ultimate shear load is reached when the splitting crack starts to propagate, a predictive model is developed. The critical load is obtained considering the energy balance of the system during splitting crack propagation. The position of the critical diagonal crack is obtained using Kim and White's semi-empirical formula. By making a number of simplifying assumptions and using the empirical formula for the assessment of the fracture energy proposed by the CEB-FIP Model Code (1983), an analytical formula is obtained. The model is benchmarked against an empirical formula proposed by the CEB-FIP Model Code. The two formulas are shown to have the same form and the predictions are shown to be in agreement.

Li et al. (1994) reported the results of an experimental investigation of structural response of shear beams made of a special class of cementitious composites, referred to as ECC. It was designed with tailored material structure and was shown to exhibit pseudo strain-hardening tensile behavior. The improved performance in shear over conventional plain, fiber reinforced and wires mesh reinforced concrete was demonstrated. It was suggested that ECC could be utilized for structural applications where superior ductility and durability performance are desired. A preliminary experimental investigation of the shear behavior indicated that the shear response for PC, FRC and ECC mirrors that of the tensile properties of the corresponding cementitious materials. The shear strength and strain capacity of ECC materials were shown to be superior compared to ordinary concrete and FRC materials. It was also observed that the cracking behavior in terms of crack 
width was better in case of ECC material. In particular it was noted that after first crack, ECC allows continued straining with increase in load capacity, whereas FRC and the PC exhibit rapid load drop. The tensile and shear stress-strain curves, and the multiple cracking pattern revealed in ECC specimen indicated that the pseudo strain hardening tensile properties of ECC materials can be successfully translated into advantageous structural shear response. The good strength and ductility of ECC accompanied with distributed small cracks of widths in the range of $0.1 \mathrm{~mm}$, suggest that ECC can be exploited in applications where mechanical performance and structural durability are of major importance.

Maalej and Li (1994) studied the flexural behavior of a strain hardening ECC and compared with that observed in regular FRC. Unlike concrete or regular FRC, ECC materials were characterized by their ability to sustain higher levels of loading after first cracking while undergoing additional straining. This strain-hardening behavior gives ECC a significant advantage under flexural loading. In quasi-brittle material like FRC, the ratio of flexural strength to tensile strength is known to vary between 1 and 3, depending on the details of the reinforcement and the geometry of the specimen. In this paper, the strain hardening behavior observed in an ECC led to a high flexural strength to tensile strength ratio. In a third point bending test, the flexural strength of an ECC was found to be five times its tensile (first-cracking) strength. A simple theoretical model also predicted the same result. The proposed model can be used for the purpose of optimizing the flexural strength of ECC.

Speada and Bencardino (1997) investigated the behavior of composite concrete sections reinforced with conventional steel bars and steel fibers subjected to flexural cyclic loading beyond the yield point of steel bars. They analyzed composite sections by means of a mechanical model and concluded that the use of steel fibers to reinforce an ordinary concrete section coupled to traditional metal reinforcement influences the yield moment of the section and the ultimate moment. Specifically in the most advantageous situations in which steel fibers are present in 1-2\% by volume an increase of $20-25 \%$ in yield moment is obtained with an increase of $10-15 \%$ of the ultimate moment, whereas a $0.5 \%$ per volume fiber presence increases these values respectively by $8 \%$ and $5 \%$. Under cyclic loading the fiber-reinforced concrete section absorbs more energy than an ordinary reinforced concrete section. 
Zhang et al. (1998) carried out an experimental investigation on the behavior of the FRC under cyclic flexural loading. One type of polypropylene and two types of steel fibers in two different volume concentrations were studied. Load-deflection response was obtained for constant amplitude fatigue loading as well as for static loading. The damage level was recorded using acoustic emission techniques. The test results show that the addition of steel fibers increases the flexural fatigue strength considerably. Compare with plain concrete the fatigue strength for 2 million cycles was found to change from 60 percent to 90 percent of the ultimate flexural strength when steel fiber content is 1 percent volume. Furthermore, the results indicated that the accumulated damage level at failure in the static test of unreinforced concrete is of the same order of magnitude as in the fatigue testing of the same material. They concluded that absolute fatigue strength in flexure for low cycle fatigue can be improved considerably by using steel fiber reinforcement in fiber volume concentration from 1 to 2 percent volume. The use of polypropylene fiber reinforcement in addition to steel fiber only seems to improve fatigue strength marginally and little effect on fatigue performance. Using AE counts as damage measure much more damage is accumulated in static as well as fatigue testing of steel fiber concrete compared to plain concrete.

Bairagi et al. (2001) examined the different methods to determine the shear strength using steel fiber reinforced concrete (SFRC) specimens. The shear strength of concrete is the resistance of one layer with respect to other during slip at common surface of contact. They questioned that two planes failing simultaneously in double shear doesn't happen in reality and hence shear strength calculated in this manner could, be said to be erroneous and there exists no standard reliable and simplified method getting shear strength of concrete specimens. They checked the feasibility and reliability of a simple test method proposed by them with the test method suggested by JSCE method. Results obtained by their proposed method were $10 \%$ higher than that of JSCE method.

Fischer and $\mathrm{Li}$ (2002) investigated the effect of ductile deformation behavior of ECC on the response of steel reinforced flexural members to lateral load reversals. The combination of a ductile cementitious matrix and steel reinforcement was found to result in improved energy dissipation capacity, reduction of transverse steel reinforcement and damage tolerant inelastic deformation behavior. The comparisons of RC and R/ECC specimens indicated performance improvements resulting from the ductile deformation behavior of ECC. The intrinsic shear capacity of ECC provided sufficient shear resistance for the R/ECC members. ECC served as 
lateral confinement for the longitudinal reinforcing bars and prevented premature failure by reinforcement buckling. More importantly, the ductility of ECC increased the resistance against composite deterioration beyond crack localization. The synergistic interaction between steel reinforcement and the ECC matrix lead to improved performance of the flexural member as compared with conventional RC.

Li and Wang (2002) tested total 16 glass fiber reinforced polymer (GFRP) reinforced ECC beams with various shear span-depth ratios and longitudinal reinforcement ratios. The results revealed that under the same reinforcement configurations, ECC beams exhibit significant increases in flexural performance in terms of ductility, load carrying capacity, shear resistance and damage tolerance compared with the high-strength concrete (HSC) beam. The extent of improvement was found strongly dependent on the failure mode i.e. when the limit state was dominated by matrix behavior, more significant improvement was observed. Moreover, ECC beams without shear reinforcement demonstrated better performance than HSC beams with dense steel stirrups. Thus, the elimination of shear reinforcement is feasible when the concrete matrix is replaced by ECC.

Fischer and $\mathrm{Li}$ (2003) investigated the response of fiber reinforced polymer (FRP) reinforced ECC members with a focus on their flexural load-deformation behavior, residual deflection, damage evolution, and failure mode. Critical aspects of conventional FRP reinforced concrete members such as interfacial bond strength, flexural crack formation, composite deformation behavior, and brittle failure mode were briefly reviewed and compared to FRP reinforced ECC. The interaction of linear elastic FRP reinforcement and ECC matrix with ductile stress-strain behavior in tension results in nonlinear elastic flexural response characteristics with stable hysteretic behavior, small residual deflection, and ultimately gradual compression failure. Compatible deformations of reinforcement and matrix lead to low interfacial bond stress and prevented composite disintegration by bond splitting and cover spalling. Furthermore, flexural stiffness and strength as well as crack formation and widths in FRP-reinforced ECC members were found effectively independent of interfacial bond properties due to the tensile deformation characteristics of the cementitious matrix. A model for the load deflection envelope based on a nonlinear momentcurvature relationship was suggested. 
Sivaraja et al. (2007) carried out investigation on the response of reinforced concrete beams with fiber composites having 0.5 and $1 \%$ volume fractions of fibers under cyclic loading which simulates the seismic excitation. The critical parameters like first crack strength, yield and maximum strength are compared. They concluded that the ductility is the major parameter in seismic resistant design. In both, translation as well as rotation ductility, concrete with local fiber composites have much better performance than conventional concrete. Energy dissipation through load-deflection as well as moment rotation curves of fiber reinforced concrete beams indicated the improvement of about 200-300\% than conventional concrete.

Zhang et al. (2006) investigated layered ECC-concrete beams subjected to flexural load on both theoretical and experimental aspects. Four point bending tests were performed on six beam members with ECC layer at its tensile side. A semi-analytical approach for modeling the flexure behavior of layered ECC-concrete beams was also developed in this paper. The research confirmed that, by applying the ECC layer at the bottom of the beam, the maximum flexural strength improvement as compared to that of plain concrete can be up to $60 \%$ and with increase of the thickness of ECC layer, the flexural strength of the composite beam increased non-linearly. The ductility of beam has significantly increased as the critical crack mouth opening displacement and crack length was greatly increased comparing to plain concrete beams. The test results were compared to the model in terms of both flexural strength and ductility improvements, and good agreement was found.

Maalej et al. (2012) carried out a test which includes the use of hybrid fiber ECC for designing impact and blast resistant protective panels, strengthening of unreinforced masonry (URM) walls, strengthening of RC beams, and enhancing corrosion durability of RC beams. Beams with a hybrid fiber ECC layer depicted higher load-carrying capacity compared to their ordinary reinforced concrete counterparts as well as it showed significantly higher deflection capacity at peak load. The crack spacing hybrid fiber ECC beams was consequently much smaller than in the ordinary $\mathrm{RC}$ beam which played a major role in reducing crack-induced stress concentration resulting in more efficient stress distribution in the carbon fiber reinforced Polymer (CFRP) sheet and a better stress transfer between the CFRP and the concrete beam. The high strain capacity, fracture energy and damage tolerance of the hybrid fiber of ECC as well as the characteristic of its micro cracking response make the material highly desirable in applications. 
Fang et al. (2014) applied finite element method using ATENA software to simulate the flexural behaviors of the steel reinforced ECC and ECC/concrete composite beams. The effects of the ECC modulus, ECC tensile ductility, ECC thickness and ECC position on flexural behaviors in terms of ultimate moment, deflection and the maximum crack width of the steel reinforced ECC or ECC/concrete composite beam were also evaluated in this experiment. Results revealed that the ultimate load carrying capacity for composite beams one with ECC layer in tension zone and another with ECC layer in both compression and tension zone are about $17.8 \%$ and $16.1 \%$ higher than normal concrete beam. The ultimate moment was improved about $0.5 \%$ for the composite beam with ECC layer in compression zone.

Kim et al. (2006) did some research on the composite behavior of a RC flexural member repaired using the superior tensile capacity of ductile fiber reinforced cementitious composite (DFRCC) on the tensile face of a RC specimen is studied. Two types of DFRCC repaired RC specimens were tested, one was without shear stirrups and the other was with shear stirrups. By comparing these two types of DFRCC repaired specimens, the shear and flexure failure mechanism and interface de-bonding behavior as well as repairing capacity were also studied. The composite beams without stirrup and shorter thickness of DFRCC carried twice the strength as well as the center deflection was about four times higher compared to the normal concrete. On the other hand, the shear strength and center deflection of the composite beams with stirrup and higher thickness of DFRCC showed almost same results. The amount and the type of repaired material are not significant factors in improving shear capacity of RC members. The most important factor in repairing or improving shear capacity of RC members is delaying the interface failure between original member and repaired material.

Yuan et al. (2013) investigated the bending behavior on two ECC/concrete composite beams using basalt fiber-reinforced polymer (BFRP) with various longitudinal and transverse reinforcement ratios and ECC thicknesses. In this study, ECC layer was used in both tension and compression zone of the beam to compare the results. The load-carrying capacity, shear resistance, ductility, and damage tolerance were also analyzed. Theoretical analysis was also conducted to illustrate the effect of reinforcement ratio, compressive strength, and thickness of ECC on the ultimate moment, curvature and ductility of beams. Results revealed that the load carrying capacity and ultimate deformation capacity for the composite beam with ECC layer on compression zone (BREC-C) 
were 9.8 and $12 \%$ respectively higher than the normal concrete beam, on the other hand composite beam with ECC layer on tension zone (BREC-T) exhibited 16.3 and 28.6\% higher respectively which can be attributed to the fiber bridging effect of ECC in tension zone. Both composite beams showed higher ductility than normal concrete beam. However, BREC-T beam exhibited about 1.24 times better energy dissipation capacity than composite beams BREC-C beam. Moreover, the ECC layer in the tension zone can help prevent rupture failure of the FRP reinforcement at the ultimate stage. No sign of delamination between the concrete and ECC layer was observed during the loading process for the composite beams. Theoretical analysis was also effective in enhancing load-carrying and deformation capacities, shear resistance and ductility.

$\mathrm{Xu}$ et al. (2012) performed extensive research on 21 ultra-high toughness cementitious composite (UHTCC) beams to investigate the flexure behavior compared to the normal concrete beams. The UHTCC layer was placed on the tension zone of the composite beams with variable thickness. Ultimate flexural load, crack width, and the load-deflection relationship of composite beams in bending were also examined. According to the test results, UHTCC enhances the flexural behavior and the flexural bearing capacity of composite beams. The ultimate load was improved up to $135 \%$ compared to the normal concrete whereas the thickness of UHTCC layer did not play any significant role, however initial cracking load increased non-linearly with the increase of UHTCC layer. Moreover, application of UHTCC in the beam tension zone could effectively prevent from the development of macro cracks in upper concrete, and disperse them into multiple fine cracks which will be useful for enhancing the durability of retrofitted structures against the attack of harmful substances. Analytical analysis found that the simple elastic beam theory was applicable to determine the magnitudes of load-bearing capacity of composite beams.

Hussein et al. (2015) experimented on 16 composite beams made of ultra-high performance fiberreinforced concrete (UHPFRC) and normal strength or high strength concrete (NSC/HSC) without stirrup to investigate flexure and shear capacity of the composite beams compared to the NSC/HSC beams. The UHPFRC layer was placed on the tension zone of the composite section. The variable for the specimen was volume fraction of the steel fiber, however influence of shear connector was also examined in this study. Test results revealed that, the flexural capacity for UHPFRC-NSC composites with $1 \%, 1.5 \%$ and $2 \%$ fiber volume content was increased by $23 \%, 68 \%$ and $90 \%$, respectively and for UHPFRC-HSC composites the capacity increased by $45 \%, 54 \%$ and $77 \%$, 
respectively. The ductility of the composite beams significantly increased with increasing volume of fiber content ranges from 3.4 to 5.3 times than normal strength concrete beams. Because of the fiber bridging mechanism, toughness became 8 times higher for UHPFRC-NSC composites as well as 16 times higher for UHPFRC-HSC composites. On the other hand, the shear capacity for composite beams was increased by 1.7 to 2.0 times. Shear connector did not play any significant role in enhancing shear capacity or in load-deflection response; however the role of fiber volume content was very remarkable in increasing the ultimate shear capacity. The shear model for composite beams which was proposed in this study was also promising.

\subsection{Analysis of reinforced concrete member in shear}

Extensive researches have been carried out on the shear behavior of reinforced concrete elements. Despite this, there remain considerable areas of uncertainty and disagreement with respect to a rational theory to unify the approach towards shear design. Reinforced concrete shear is approached with classification into either members without transverse reinforcement or members with transverse reinforcement (Wight and Macgregor, 1997; Gastebled and May, 2001).

\subsubsection{Basic shear transfer mechanism in beams without shear reinforcement}

For slender beams, the shear force in a cracked section $(\mathrm{V})$ is mainly resisted by the shear resistance of compression zone $\left(\mathrm{V}_{\mathrm{c}}\right)$, interlocking action of aggregates $\left(\mathrm{V}_{\mathrm{a}}\right)$, and dowel action $\left(\mathrm{V}_{\mathrm{d}}\right)$, as shown in Figure 2.14. For rectangular beams, after an incline crack has formed, the proportion of the shear force transferred by the various mechanisms is as follows, 20 to 40 percent by the un-cracked concrete of compression zone; 33 to 50 percent by interlocking action of aggregates; and 15 to 25 percent by dowel action $\left(\mathrm{V}_{\mathrm{d}}\right)$. Meanwhile, in a relatively short beam, the load is transferred directly from the loading points to the supports owing to arch action (Taylor, 1970). 


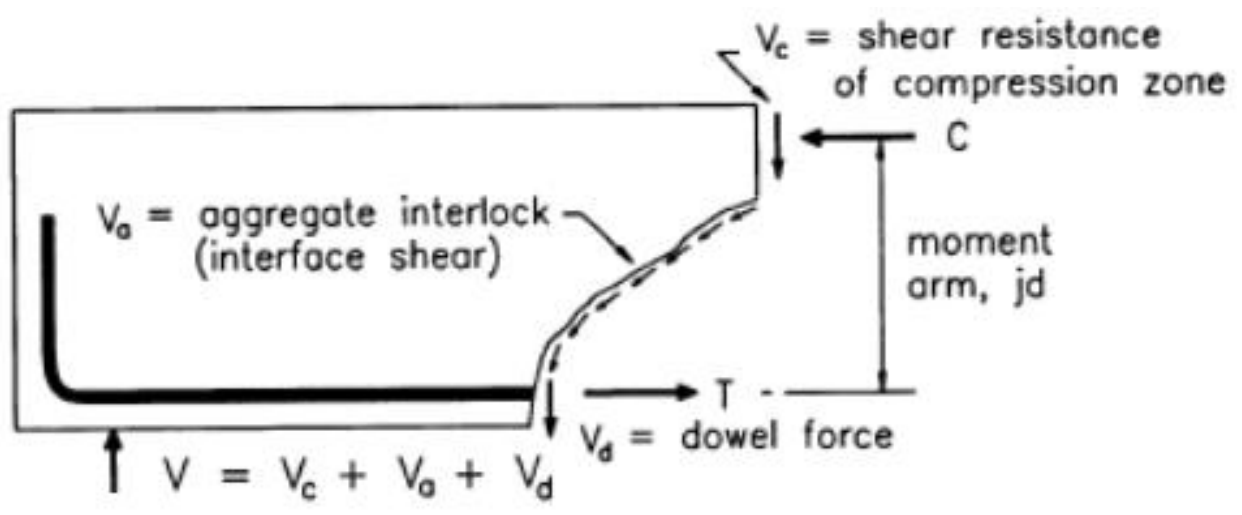

Figure 2.14: Shear transfer mechanism of slender beams (Taylor, 1970)

Interlocking action of aggregates: Previous experimental studies by Taylor (1970), has shown that a large portion of the total sheer force of the beam without web re-enforcement is carried across the cracks by aggregate interlocking. Among many variables, the width of the crack and the concrete strength are likely to be the most important factors. It is naturally expected that the interlocking force will be increased when the strength of concrete is high.

Dowel action: When shear displacement occurs along the cracks, a certain amount of shear force is transferred by means of the dowel action of the longitudinal bars. Although there is some contribution in dowel action by the number and arrangement of longitudinal bars, spacing of flexural cracks and the amount of concrete cover etc. The main factors influencing this action are the flexural rigidity of longitudinal bars and the strength of the surrounding concrete (Taylor, 1970).

Arch action: In relatively short beams, applied loads are transferred directly to the support by arch action. The main factors influencing this action are the span-to-height ratio of the analogous arch and the strength of the compression strut. The span-to-height ratio of the analogous arch is approximately equal to the shear span-to-depth ratio. The strength of the compression strut is closely related to the compressive strength of concrete and the area of tension reinforcement (Taylor, 1970). 


\subsubsection{Shear transfer mechanism beams with shear reinforcement}

Inclined crack causes the shear strength of beams to drop below the flexural capacity. The purpose of the shear reinforcement is to ensure the full flexural capacity can be developed. Prior to incline cracking, the strain in the stirrups is equal to the corresponding strain of the concrete beam, because concrete cracks at very small strain the stress in the stirrups prior to inclined cracking will not exceed 3 to $6 \mathrm{ksi}$. Thus, stirrups do not prevent inclined cracks from forming; they come into play only after the cracks have formed (Wight and Macgregor, 1997).

\subsubsection{Shear strength of SCC members}

For ordinary moment resisting frame beam/column, the shear capacity of concrete alone (or shear capacity of beam without stirrups) can be obtained by using clause CSA 11.3.4 and from Equation 2.1 as per CSA Standard A23.3-04 (2010).

$\mathrm{V}_{\mathrm{c}}=\varphi_{\mathrm{c}} \beta \sqrt{\mathrm{f}_{\mathrm{c}}^{\prime}} \mathrm{bd}$

where, the value of $\varphi_{c}$ is 0.65 as per clause 8.4.2 and $\beta$ is taken 0.21 as described in CSA clause

11.3.6.2 as the overall thickness of the member less than $250 \mathrm{~mm} ; \sqrt{\mathrm{f}_{\mathrm{c}}^{\prime}}$ should be less than $8 \mathrm{MPa}$; and $\mathrm{d}_{\mathrm{v}}=\max (0.9 \mathrm{~d}$ and $0.72 \mathrm{~h})$.

where, $\mathrm{d}$ : effective depth of the section and h: total height of the section.

Total shear resisting capacity of the member $\left(V_{r}\right)$ calculated from Equation 2.2 as per CSA (A 23.3):

$\mathrm{V}_{\mathrm{r}}=\mathrm{V}_{\mathrm{c}}+\mathrm{V}_{\mathrm{s}}+\mathrm{V}_{\mathrm{p}}$

Where $\mathrm{V}_{\mathrm{c}}$ : shear resistance of concrete, $\mathrm{V}_{\mathrm{s}}$ : shear resistance of stirrups and $\mathrm{V}_{\mathrm{p}}$ : shear resistance capacity of pre-stress reinforcement which should be taken zero in this study.

However the value of $V_{r}$ shall not exceed as described in Equation 2.3:

$\mathrm{V}_{\mathrm{r}, \max }=0.25 \varphi_{\mathrm{c}} \mathrm{f}_{\mathrm{c}}^{\prime} \mathrm{bd} \mathrm{d}_{\mathrm{v}}+\mathrm{V}_{\mathrm{p}}$

For the members with transverse/web/shear reinforcement perpendicular to the longitudinal axis, the value of $V_{S}$ can be obtained from Equation 2.4 as per CSA (A 23.3):

$\mathrm{V}_{\mathrm{s}}=\varphi_{\mathrm{s}} \frac{\mathrm{A}_{\mathrm{v}}}{\mathrm{s}} \mathrm{f}_{\mathrm{y}} \mathrm{d}_{\mathrm{v}} \cot \theta$ 
where, $\theta$ shall be taken $42^{\circ}$ as described in clause CSA 11.3.6.2; $A_{v}$ : area of shear reinforcement; s: spacing between shear reinforcement, $f_{y}$ : yield strength of tensile reinforcement bar (MPa). The value of $A_{v}$ shall be greater than minimum required shear reinforcement based on CSA 11.2.8.2 which can be obtain from Equation 2.5:

$\mathrm{A}_{\mathrm{v}, \text { min }}=0.06 \sqrt{\mathrm{f}_{\mathrm{c}}^{\prime} \mathrm{bs}} / \mathrm{f}_{\mathrm{y}}$

where, $b$ is the width of the beam.

\subsubsection{Shear strength of steel fiber reinforced UHPC beams without stirrups}

Imam et al. (1997) developed an equation (Equation 2.6) to predict the shear strength $\left(\mathrm{V}_{\text {shear }}\right.$ or $\left.\mathrm{V}_{c}\right)$ for UHPC beams consisting of steel and polypropylene fibers without web reinforcement.

$V_{\text {shear }}=0.6 \times \frac{1+\sqrt{\frac{5.08}{d_{a}}}}{\sqrt{1+\frac{d}{25 d_{a}}}} \times \sqrt[3]{\rho_{s}(1+4 F)} \times\left[\left(f_{c}^{\prime}\right)^{0.44}+275 \sqrt{\frac{\rho_{s}(1+4 F)}{\left(\frac{a_{s}}{d}\right)^{5}}}\right] * b * d$

In which, $d_{a}$ is the maximum aggregate size $(\mathrm{mm}), \rho_{\mathrm{s}}$ represents the longitudinal reinforcement ratio, $\mathrm{f}_{\mathrm{c}}^{\prime}$ is the compressive strength of the concrete (MPa), $\mathrm{d}$ is the effective depth of the beam, $\mathrm{b}$ is the width of the beam and $a_{s}$ is the shear span.

The value of fiber factor $(\mathrm{F})$ can be obtained from Equation 2.7:

$F=\left(\frac{L_{f}}{D_{f}}\right) V_{f} d_{f}$

where, $L_{f}$ is the fiber length $(\mathrm{mm}), D_{f}$ is the fiber diameter $(\mathrm{mm}), V_{f}$ is the volume fraction of fibers, and $\mathrm{d}_{\mathrm{f}}$ is the bond factor for steel fiber (for round fibers $=0.5$, for crimped fibers $=0.75$, and for indented fibers $=1.0$ ).

The same equation (Equation 2.6) has been used in this study with some modifications to predict the shear strength $\left(V_{\text {shear }}\right.$ or $V_{c}$ ) for ECC beams consisting of PVA fiber. The fiber factor that is being used in this equation (Equation 2.6) has been modified in terms of PVA fiber. The calculation of modified fiber factor $\mathrm{F}^{\prime}$ is discussed in Chapter 5. 


\subsubsection{Shear strength of FRC beams with stirrups}

The shear strength of steel fiber based FRC beams with stirrup can be calculated by using Equation 2.9 derived by combining shear capacity of concrete as per Equation 2.6 and capacity of shear reinforcement as per Equation 2.4 (CSA A 23.3):

$\mathrm{V}_{\text {shear }}=0.6 \times \frac{1+\sqrt{\frac{5.08}{\frac{.0}{d_{a}}}}}{\sqrt{1+\frac{d}{25 d_{a}}}} \times \sqrt[3]{\rho_{s}(1+4 \mathrm{~F})} \times\left[\left(f_{c}^{\prime}\right)^{0.44}+275 \sqrt{\frac{\rho_{s}(1+4 F)}{\left(\frac{a}{d}\right)^{5}}}\right] b d+\varphi_{s} \frac{A_{v}}{s} f_{y} d_{v} \cot \theta$

The same equation (Equation 2.9) has been used for the strength of PVA based ECC beams with stirrup with some modification to fiber factor calculation. The calculation of modified fiber factor for PVA, $\mathrm{F}^{\prime}$ is discussed in Chapter 5 for the calculation of shear strength of ECC beams with stirrups.

\subsubsection{Shear strength of composite beams}

Hussein and Amleh (2015) developed a design guideline for shear strength of composite members made of normal strength concrete (NSC) and ultra-high performance fiber-reinforced concrete (UHPFRC) without stirrup. Figure 2.15 shows the force distribution for the cross-section of singly reinforced composite beam.

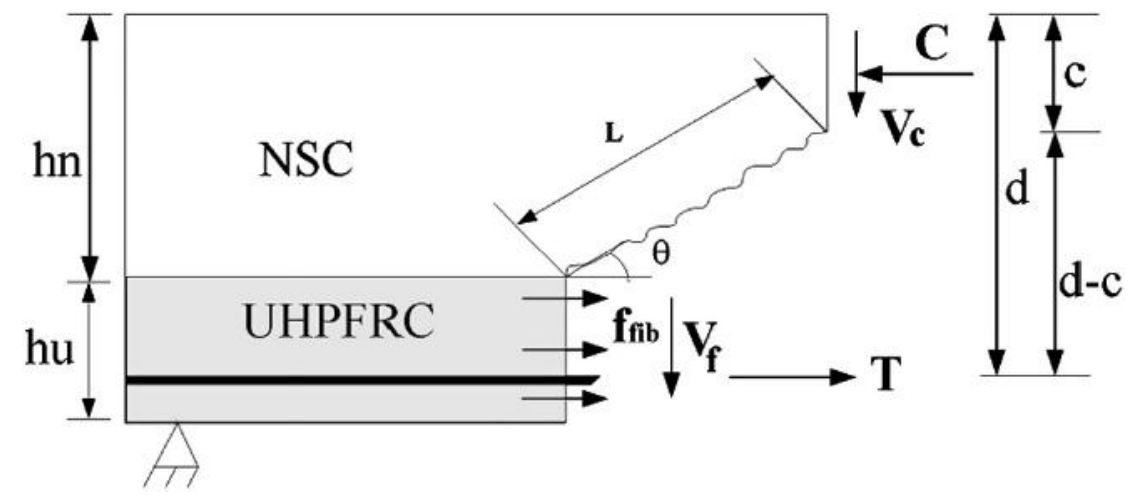

Figure 2.15: Force distribution mechanism of the composite shear beam (Hussein and Amleh, 2015).

The shear resistance of a UHPFRC-NSC beam is thus equivalent to the expected shear resistance of a NSC beam without shear reinforcement, $\mathrm{V}_{c}$, plus the additional shear resistance provided by the fibers, $V_{f}$, due to the improved post-cracking resistance of the UHPFRC layer as shown in Figure 2.15. 
The shear strength of UHPFRC-NSC/HSC composite beams can be calculated from Equation 2.10: $\mathrm{V}_{\mathrm{u}}=\mathrm{V}_{\mathrm{c}}+\mathrm{V}_{\mathrm{f}}$

The shear resistance provided by the fibers, $V_{f}$, can be obtained from Equation 2.11:

$\mathrm{V}_{\mathrm{f}}=\mathrm{F} * \tau * \mathrm{~b} *\left(\mathrm{~d}-\mathrm{h}_{\mathrm{n}}\right)$

In which, $h_{n}$ is the thickness of the NSC layer and $\tau$ is the average bond strength of fibers that can be obtained from tests on single fiber pull out test.

The shear contribution by compression zone above the neutral axis can be determined from the proposed Equation 2.12 by the CSA Standard A23.3-04 (2010).

$\mathrm{V}_{\mathrm{c}}=\varphi_{\mathrm{c}} \lambda \beta \sqrt{\mathrm{f}_{\mathrm{c}}^{\prime}} \mathrm{bd}$

Therefore, the shear capacity of the composite beam without shear reinforcement can be calculated by Equation 2.13:

$\mathrm{V}_{\mathrm{u}}=\varphi_{\mathrm{c}} \lambda \beta \sqrt{\mathrm{f}_{\mathrm{c}}^{\prime}} \mathrm{bd}+\mathrm{F} * \tau * \mathrm{~b} *\left(\mathrm{~d}-\mathrm{h}_{\mathrm{n}}\right)$

The shear strength of composite beams with stirrup can be calculated by using Equation 2.14 derived by combining shear capacity of concrete as per Equation 2.13 and the capacity of shear reinforcement as per Equation 2.4:

$\mathrm{V}_{\mathrm{u}}=\varphi_{\mathrm{c}} \lambda \beta \sqrt{\mathrm{f}_{\mathrm{c}}^{\prime}} \mathrm{bd} \mathrm{v}_{\mathrm{v}}+\mathrm{F} * \tau * \mathrm{~b} *\left(\mathrm{~d}-\mathrm{h}_{\mathrm{n}}\right)+\varphi_{\mathrm{s}} \frac{\mathrm{A}_{\mathrm{v}}}{\mathrm{s}} \mathrm{f}_{\mathrm{y}} \mathrm{d}_{\mathrm{v}} \cot \theta$

Based on the similar principle of force equilibrium of NSC/UHPFRC composite beam (Figure $2.15)$, the shear strength $\left(\mathrm{V}_{\text {shear }}\right)$ of composite ECC/SCC beams consisting of polyvinyl alcohol fiber (PVA) with/without shear reinforcement with modified fiber factor $\mathrm{F}^{\prime}$ has been developed in this study and discussed in Chapter 5. 


\subsection{Flexural strength of SCC beam}

The beam top and bottom flexural steel is designed at the location of maximum moments along the beam span. In the flexural reinforcement design, the design procedure is based on the simplified rectangular stress block shown in Figure 2.16 as per CSA Standard A23.3-04 (2010). In designing the beam flexural reinforcement, the limit of $\mathrm{f}^{\prime}{ }_{\mathrm{c}}$ is taken to be smaller than $80 \mathrm{MPa}$ for ordinary moment resisting frame based on clause 8.6.1.1 of CSA Standard A23.3.

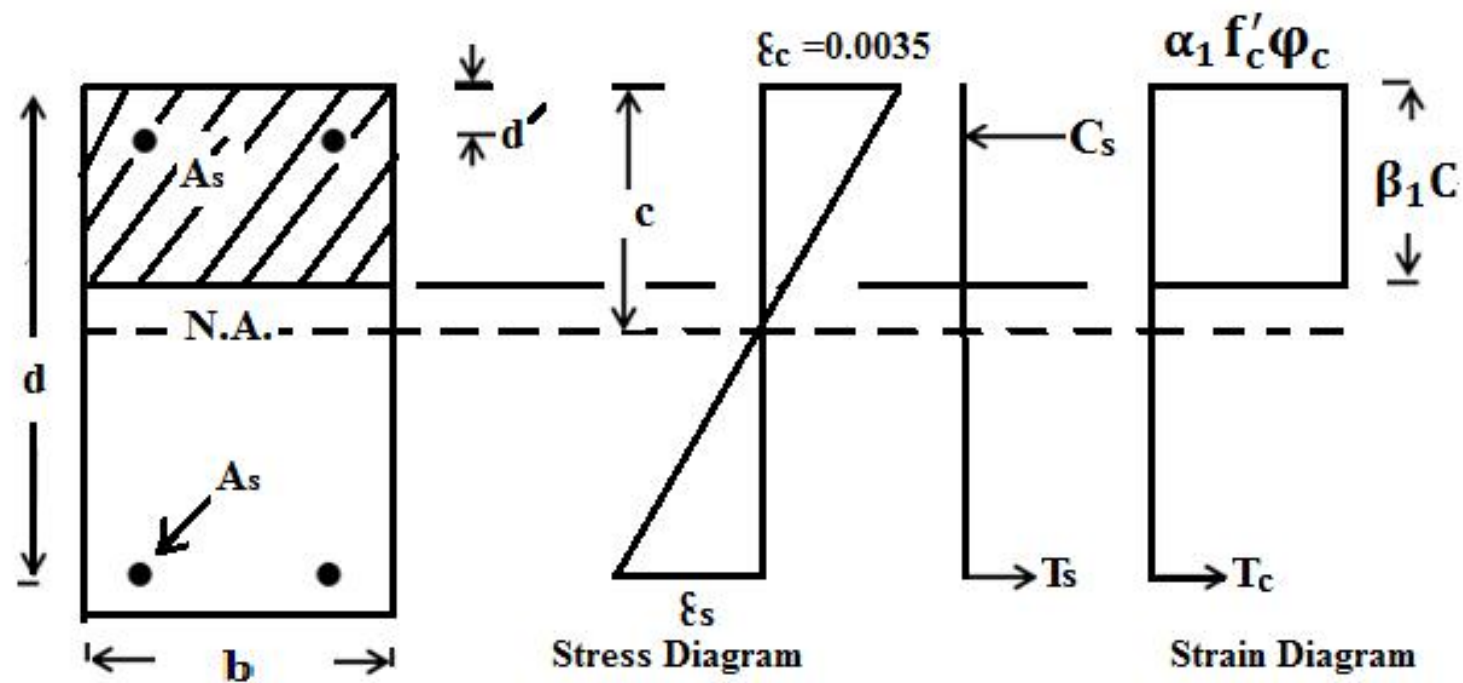

Figure 2.16: Stress-strain and force distribution for rectangular SCC beam

The depth of the compression block 'a' can be obtained from Equation 2.15:

$a=d-\sqrt{d^{2}-\frac{2\left|M_{f}\right|}{\alpha_{1} f_{c}^{\prime} \varphi_{c} b}}$

where, the value of $\varphi_{\mathrm{c}}$ is 0.65 as per clause 8.4.2. The values of $\alpha_{1}$ and $\beta_{1}$ and $\mathrm{C}_{\mathrm{b}}$ can be calculated based on the Equations 2.16 to 2.18 using clause CSA10.1.7 and CSA 10.5.2:

$\alpha_{1}=0.85-0.0015 f_{c}^{\prime} \geq 0.67$

$\beta_{1}=0.97-0.0025 f_{c}^{\prime} \geq 0.67$

$\mathrm{C}_{\mathrm{b}}=\frac{700}{700+\mathrm{f}_{\mathrm{y}}} \mathrm{d}$

$\mathrm{a}_{\mathrm{b}}$ is the balance depth of the compression zone is given by Equation 2.19

$\mathrm{a}_{\mathrm{b}}=\beta_{1} \mathrm{C}_{\mathrm{b}}$ 
Based on the clause CSA 10.5.2 if the value of $a \leq a_{b}$ therefore the area of tensile reinforcement should be calculated based on the following Equation 2.20:

$A_{s}=\frac{M_{f}}{\varphi_{s} f_{y}\left(d-\frac{a}{2}\right)}$

This steel is to be placed at the bottom of the beam for negative moment and top of the beam for positive moment. For our design the amount of reinforcement located at the top of the section $A_{S}^{\prime}$ has been neglected.

The minimum amount of tensile reinforcement from clause CSA 10.5.1.2 for flexural members can be calculated from Equation 2.21:

$A_{\mathrm{s}, \min }=\frac{0.2 \sqrt{\mathrm{f}_{\mathrm{c}}^{\prime}}}{\mathrm{f}_{\mathrm{y}}} \mathrm{b}_{\mathrm{t}} \mathrm{h}$

where, $b_{t}$ is the width of tension zone of the section.

For checking the flexural capacity of beam and column in the tested frame in this study, the value of compression block ' $\mathrm{a}$ ' can be obtain from Equation 2.22 with related experimental values for $\mathrm{f}_{\mathrm{c}}^{\prime}$ and $\mathrm{f}_{\mathrm{y}}$ :

$\mathrm{a}=\frac{\varphi_{\mathrm{s}} A_{\mathrm{s}} \mathrm{f}_{\mathrm{y}}}{\alpha_{1} \varphi_{\mathrm{c}} \mathrm{f}_{\mathrm{c}}^{\prime} \mathrm{b}}$

Therefore the flexural or moment capacity of beam/column in the tested frame used in this study can be obtained from Equation 2.23:

$\mathrm{M}_{\mathrm{f}}=\varphi_{\mathrm{s}} \mathrm{A}_{\mathrm{s}} \mathrm{f}_{\mathrm{y}}\left(\mathrm{d}-\frac{\mathrm{a}}{2}\right)$

\subsubsection{Flexural Strength of ECC beam}

Lepech and $\mathrm{Li}$ (2009) developed a design guideline for flexural strength of ECC flexural members.

Figure 2.17 shows strain-stress and force distribution for the cross-section of singly reinforced ECC beam. 


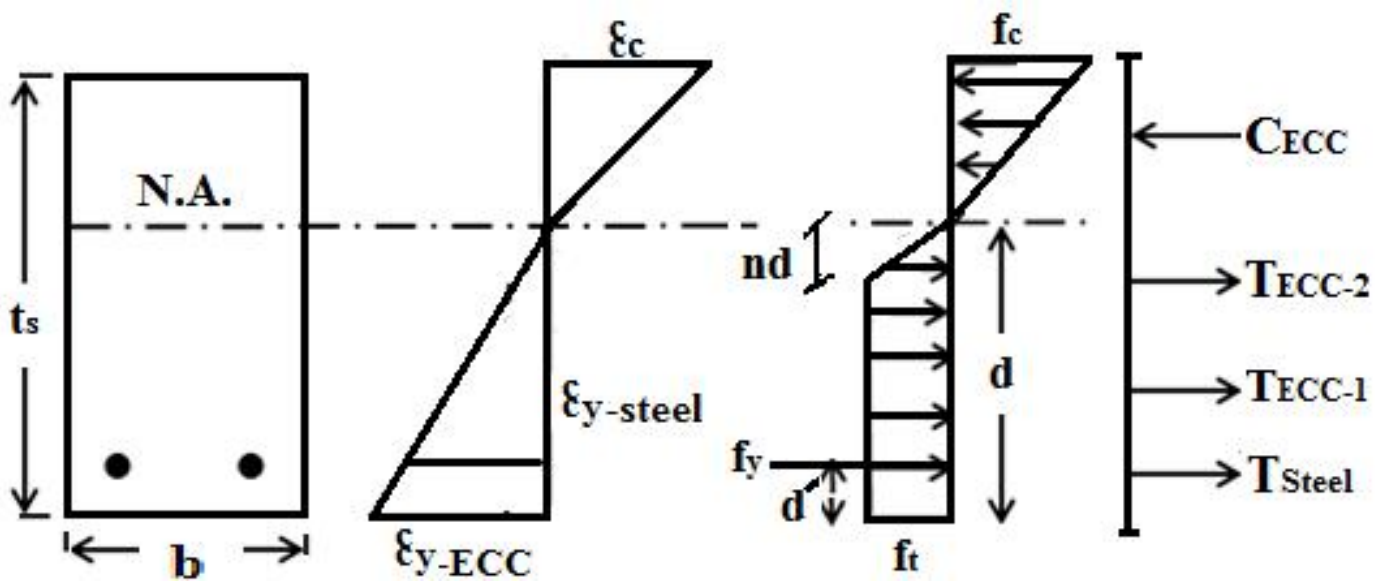

Figure 2.17: Stress-strain distribution of reinforced ECC member (Lepech and Li, 2009)

In Figure 2.17, $\mathrm{b}$ and $\mathrm{t}_{\mathrm{s}}$ represent the width and depth of the section, respectively, $\mathrm{d}$ is the distance from neutral axis to the center of the reinforcing bars and $\mathrm{d}^{\prime}$ is the distance from the tension face to the center of reinforcing bars. In addition, $\varepsilon_{\mathrm{c}}$ : compressive strain of ECC, $\varepsilon_{\mathrm{y}(\text { steel })}$ : compressive strain of steel, $\varepsilon_{\mathrm{y}(\mathrm{ECC})}$ : yield strain of ECC. The $\mathrm{C}_{\mathrm{ECC}}, \mathrm{T}_{\mathrm{ECC}-1}, \mathrm{~T}_{\mathrm{ECC}-2}, \mathrm{~T}_{\text {Steel }}$ respectively are representing the compressive force, tensile forces of ECC and tensile force of steel.

Caner and Zia (1998) proposed stress criterion to determine the corresponding tension kink and neutral axis for calculation the resisting moment capacity. The modular ratio is presented by Equation 2.24:

$\mathrm{n}_{\varepsilon}=\frac{\varepsilon_{\mathrm{y}(\mathrm{ECC})}}{0.4 \varepsilon_{\mathrm{y}(\text { steel })}}$

The $\mathrm{n}_{\varepsilon}$ represent the strain modular ratio, $\varepsilon_{\mathrm{y}(\text { steel) }}$ and $\varepsilon_{\mathrm{y}(\mathrm{ECC})}$ denote the yield strain of elasticplastic behavior of steel reinforcement and ECC, respectively.

The depth of the neutral axis was determined based on the modular ratio and the equilibrium of resisting forces across the depth of ECC member. Lepech and $\mathrm{Li}$ (2009) proposed equations for calculating the ECC tensile forces. The resisting forces across the depth of the ECC section and their equilibrium are presented through Equations 2.25 to 2.29 respectively. 
$\mathrm{T}_{\text {Steel }}=0.4 \mathrm{f}_{\mathrm{y}} \mathrm{A}_{\mathrm{s}}$

$\mathrm{T}_{\mathrm{ECC}-1}=\mathrm{f}_{\mathrm{t}}\left[\left(1-\mathrm{n}_{\varepsilon}\right) \mathrm{d}+\mathrm{c}\right] \mathrm{b}$

$\mathrm{T}_{\mathrm{ECC}-2}=0.5 \mathrm{f}_{\mathrm{t}} \mathrm{n}_{\varepsilon} \mathrm{db}$

$\mathrm{C}_{\mathrm{ECC}}=0.5 \mathrm{f}_{\mathrm{t}}\left(\frac{1}{\mathrm{n}_{\varepsilon} \mathrm{d}}\right)\left(\mathrm{t}_{\mathrm{s}}-\mathrm{d}-\mathrm{c}\right)^{2} \mathrm{~b}$

$\mathrm{T}_{\text {steel }}+\mathrm{T}_{\mathrm{ECC}-1}+\mathrm{T}_{\mathrm{ECC}-2}=\mathrm{C}_{\mathrm{ECC}}$

where, $\mathrm{f}_{\mathrm{t}}$ is the tensile stress of the ECC.

Lepech and Li (2009) projected the yield (tensile) strain of ECC material from a pool of 40 separate tensile test results is $0.02 \%$, this value is chosen as a statistically representative value for the first cracking strain of ECC material. The yield (tensile) stress of the ECC material is set at $3.45 \mathrm{MPa}$ from Lepech and $\mathrm{Li}$ (2009) which was again chosen as a statistically representative value from the pool of tensile test results while the actual ultimate strength is typically above this value.

The resisting moment capacity $\mathrm{M}_{\mathrm{r}}$ is calculated by summing the contribution of all forces about the neutral axis and is presented in Equation 2.30:

$\mathrm{M}_{\mathrm{r}}=\left\{\mathrm{T}_{\text {Steel }} \mathrm{d}+\mathrm{T}_{\mathrm{ECC}-1}\left(\frac{\left(1-\mathrm{n}_{\varepsilon}\right) \mathrm{d}+\mathrm{c}}{2}+\mathrm{n}_{\varepsilon} \mathrm{d}\right)+\mathrm{T}_{\mathrm{ECC}-2}\left(\frac{2}{3}\right) * \mathrm{v}^{*} \mathrm{~d}+\mathrm{C}_{\mathrm{ECC}}\left(\frac{2}{3}\right)\left(\mathrm{t}_{\mathrm{s}}-\mathrm{d}-\mathrm{c}\right)\right\}\left(\frac{1}{1000}\right)$

\subsubsection{Flexural Strength of UHPC beam}

The general stress-strain and force distribution for reinforced UHPC beam for flexural resistance

is shown in Figure 2.18 (Hossain, 2014). In linear strain distribution, $\varepsilon_{\mathrm{mc}}, \varepsilon_{\mathrm{ps}}$ and $\varepsilon_{\mathrm{mt}}$ represent concrete compressive strain at the top fiber, strain in reinforcement, and concrete tensile strain at the bottom fiber. Typically it assumes a triangular concrete stress distribution and non-uniform tensile stress distribution $\left(\mathrm{f}_{\mathrm{t}}\right.$ ) below the neutral axis (NA) due to fiber contribution. 


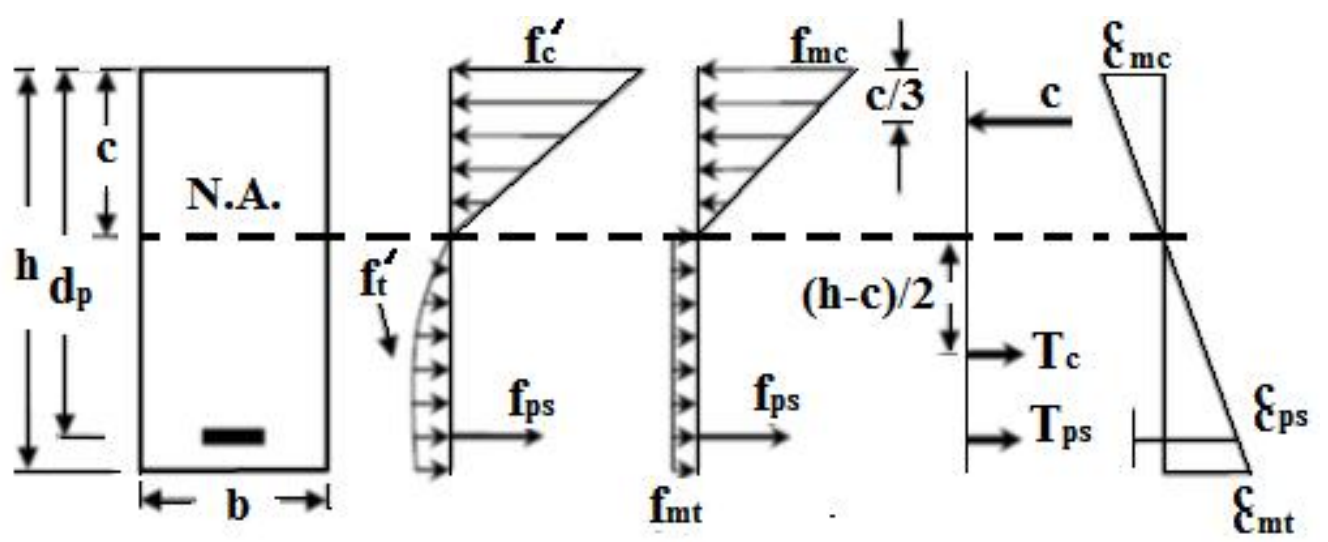

Figure 2.18: Stress-force-strain distribution of reinforced UHPC beam

In Figure 2.18, $b$ and $d_{p}$ represent the width and depth of the section, respectively, $c$ is the distance from neutral axis to the top of the section. In addition, $\mathrm{f}_{\mathrm{mc}}$ : limiting compressive strength of UHPC, $\mathrm{f}_{\mathrm{mt}}$ : tensile stress of UHPC, $\mathrm{T}_{\mathrm{c}}$ : UHPC tensile force based on fiber contribution, $\mathrm{T}_{\mathrm{ps}}$ : UHPC steel reinforcement force, mc: UHPC compressive strain at fop fiber, mt: UHPC tensile strain, ps: UHPC reinforcement strain.

The limiting compressive strength $\left(\mathrm{f}_{\mathrm{mc}}\right)$ for UHPC beam can be calculated as a function of compressive strength (f'c) based on Equation 2.31:

$\mathrm{f}_{\mathrm{mc}}=0.85 \mathrm{f}_{\mathrm{c}}^{\prime}$

A uniform tensile stress distribution of $\mathrm{f}_{\mathrm{mt}}$ acting from the neutral axis to the extreme tension fiber can be used to approximate the UHPC tensile force based on fiber contribution $\left(\mathrm{T}_{\mathrm{c}}\right)$ as shown in Equation 2.32, where $\mathrm{h}$ is the overall height of the beam and $\mathrm{c}$ is the distance of N.A. from the top fiber.

$T_{c}=f_{m t}(h-c) b$

Compressive concrete force (C) can be calculated from Equation 2.33:

$\mathrm{C}=\frac{1}{2} \mathrm{f}_{\mathrm{mc}} \mathrm{cb}$

where, force in the steel reinforcement $\left(\mathrm{T}_{\mathrm{ps}}\right)$ can be calculated based on steel stress and flexural resistance of UHPC beam can be calculated by using equilibrium of forces as used in normal RC beam. 
Moment/flexural resistance of reinforced UHPC beam can be derived by using usual procedures and by assuming some modifications in the stress-strain and force distribution of reinforced UHPC beam (Henager and Doherty, 1976; Khalil and Tayfur, 2013; Hossain, 2014) as shown in Figure 2.19 with the following assumptions:

$\checkmark$ All fibers are aligned in the direction of the stress.

$\checkmark$ Fibers are fully bonded to the matrix, equal strains in fiber and matrix occurs before cracking.

$\checkmark$ The Poisson's ratio in fiber and matrix is equal to zero.

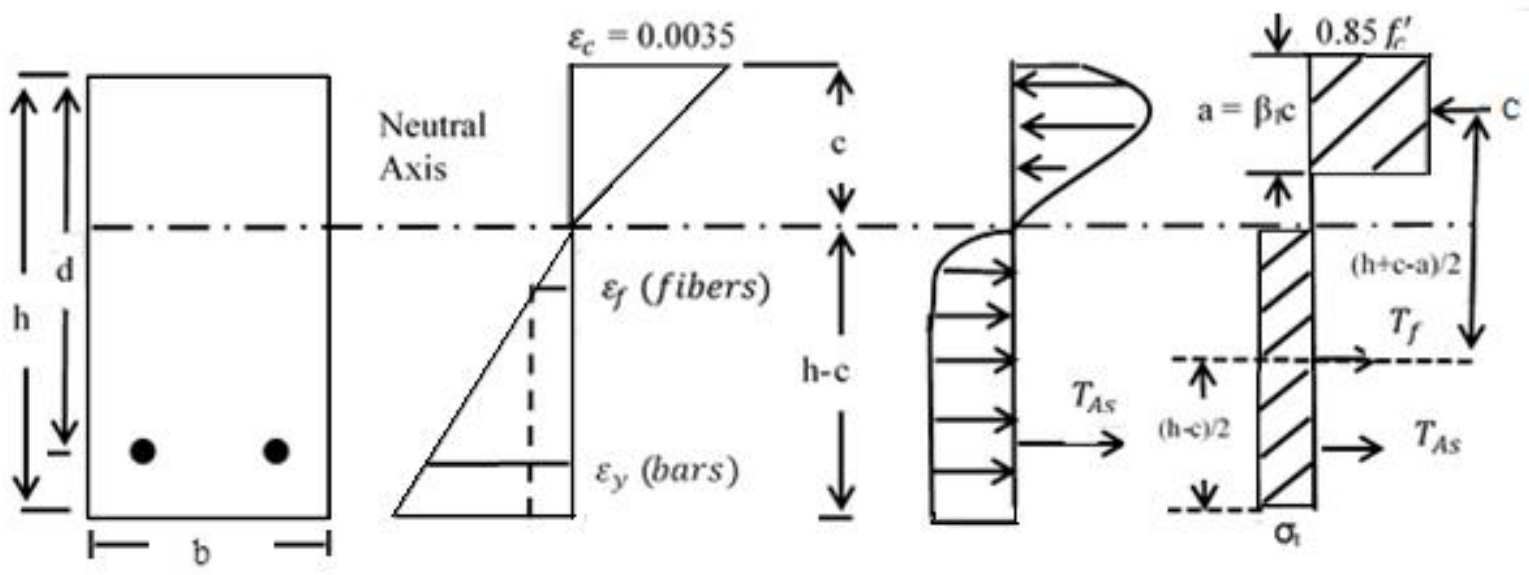

Figure 2.19: Modified strain- stress-force distribution of reinforced UHPC beam with full depth fiber dispersion

The ultimate tensile strength of steel fiber reinforced composite prior to cracking $\left(\sigma_{\mathrm{c}}\right)$ in MPa can be derived from Equation 2.34:

$\sigma_{\mathrm{c}}=\sigma_{\mathrm{f}} \mathrm{V}_{\mathrm{f}}+\sigma_{\mathrm{m}} \mathrm{V}_{\mathrm{m}}$

where, $\sigma_{\mathrm{f}}$ : ultimate pull out strength of steel fiber $(\mathrm{MPa}) ; \sigma_{\mathrm{m}}$ : ultimate tensile strength of uncracked concrete matrix $(\mathrm{MPa}) ; \mathrm{V}_{\mathrm{f}}$ : volume fraction of fiber and $\mathrm{V}_{\mathrm{m}}$ : volume fraction of the matrix. The orientation, length and bonding characteristics of fibers will influence the strength of fiber reinforced concrete; Equation 2.35 derived from Equation 2.34 has incorporated all of these parameters:

$\sigma_{\mathrm{c}}=\sigma_{\mathrm{m}} \mathrm{V}_{\mathrm{m}}+2 \eta_{\mathrm{o}} \eta_{\mathrm{b}} \eta_{\mathrm{l}} \mathrm{V}_{\mathrm{f}} \tau_{\mathrm{f}}\left(\mathrm{l}_{\mathrm{f}} / \mathrm{d}_{\mathrm{f}}\right)$ 
Neglecting the contribution of the matrix in carrying any stress based on the law of mixture and applying the corrections of orientation, bond efficiency and length efficiency factor, the most common expression of ultimate tensile strength of fiber reinforced concrete ( $\sigma_{t}$ in MPa) as shown in Figure 2.19 is given by Equation 2.36 (Ahmed and Pama, 1992; Hossain, 2014):

$\sigma_{\mathrm{t}}=2 \eta_{\mathrm{o}} \eta_{\mathrm{b}} \eta_{\mathrm{l}} \mathrm{V}_{\mathrm{f}} \tau_{\mathrm{f}}\left(\mathrm{l}_{\mathrm{f}} / \mathrm{d}_{\mathrm{f}}\right)$

where, $\eta_{\mathrm{o}}$ : orientation factor $=0.41 ; \eta_{\mathrm{b}}$ : bond efficiency factor $=0.5$ for round steel fibers.

In this study, bond efficiency factor $\left(\eta_{\mathrm{b}}\right)$ for PVA fiber can be calculated using Equation 2.8. $\eta_{1}$ is the length efficiency factor can be calculated from Equation 2.37:

$\eta_{\mathrm{t}}==1-\left[\left(\tanh \left(\frac{\beta l_{\mathrm{f}}}{2}\right)\right) /\left(\beta \mathrm{l}_{\mathrm{f}} / 2\right)\right]$

Where the value for $\beta$ coefficient can be obtained from Equation 2.38:

$\beta=\sqrt{\frac{2 \pi G_{m}}{E_{f} A_{f} L_{n}\left(\frac{S}{r_{f}}\right)}}$

The value for $\mathrm{S}$, steel fiber characteristic is defined in Equation 2.39:

$\mathrm{S}=25\left(\frac{\mathrm{l}_{\mathrm{f}}}{\mathrm{V}_{\mathrm{f}} \mathrm{d}_{\mathrm{f}}}\right)^{1 / 2}$

where, $\mathrm{V}_{\mathrm{f}}$ : volume fraction of steel fiber; $\boldsymbol{\tau}_{\mathrm{f}}$ : bond strength between the fiber and matrix $(\mathrm{MPa}) ; 1_{\mathrm{f}}$ : length of fibers $(\mathrm{mm})$; $\mathrm{d}_{\mathrm{f}}$ : diameter of fibers $(\mathrm{mm}) ; \mathrm{G}_{\mathrm{m}}$ : shear modulus of concrete matrix (MPa); $E_{\mathrm{f}}$ : modulus of elasticity of steel fibers (MPa); $\mathrm{A}_{\mathrm{f}}$ : cross-sectional area of steel fibers $\left(\mathrm{mm}^{2}\right)$ and $\mathrm{r}_{\mathrm{f}}$ : radius of steel fibers $(\mathrm{mm})$.

Provided that the average sliding friction bond strength $\left(\tau_{\mathrm{f}}\right)$ is known and assuming that it does not vary with the angle of the fiber to the crack and also assuming that the mean fiber pullout length is $(1 / 4)$ then the average pullout stress per fiber $(\mathrm{F})$ is given by Equation 2.40:

$\mathrm{F}=\tau_{\mathrm{f}}\left(\frac{\mathrm{l}_{\mathrm{f}}}{\mathrm{d}_{\mathrm{f}}}\right)$ 
Bond stress depends on a variety of factors: water cement ratio, curing conditions, fiber surface characteristics, fiber geometry, and age. According to Hannat (1978) and Hossain (2014), the measured value for $\tau_{\mathrm{f}}$ varies between 3 and $8.3 \mathrm{~N} / \mathrm{mm}^{2}$. According to Chan et al. (2004), bond characteristics of straight steel fiber in silica fume based ultra-high strength concrete (UHSC) matrix vary between 4.8 and $5.5 \mathrm{MPa}$ with $0 \%$ to $40 \%$ of silica fume, respectively. The frictional bond strength of fiber matrix $\left(\tau_{\mathrm{f}}\right)$ is given by Equation 2.41 as per Henager and Doherty (1976) and Hossain (2014):

$\tau_{\mathrm{f}}=0.66 \sqrt{ } \mathrm{f}_{\mathrm{c}}{ }^{\prime}$

where, $\mathrm{f}_{\mathrm{c}}$ is the compressive strength of normal strength concrete (MPa)

Based on Hossain (2014), the maximum usable strain at the extreme concrete compression fiber $\left(\varepsilon_{\mathrm{c}}\right)$ as shown in Figure 2.19 can be taken as 0.0035 . There are some data that indicate 0.003 may be conservative. Work by Williamson (1974) indicates that 0.0033 may be more realistic for steel fiber concrete. Swamy and Al-Ta'an (1981) recommended 0.0035. Based on a study of plastic hinges, Hassoun and Sahebjam (1985) recommended a failure strain of 0.0035 for concrete with 1.0 percent steel fibers as per ACI Committee 544.4 R-88 (1994). Taking into account the large ductility and compressive strength of UHPC the equivalent compressive stress block values can be specified as shown in Figure 2.19. For strengths above $30 \mathrm{MPa}, \beta_{1}$ shall be reduced continuously at a rate of 0.05 for each $7 \mathrm{MPa}$ of strength in excess of $30 \mathrm{MPa}$, but $\beta 1$ shall not be taken less than 0.65 as per ACI 318 (2011).

With the completion of compressive and tensile strength blocks, the process of flexural analysis of the beams can be carried out using the principles of force equilibrium and strain compatibility. The nominal moment capacity $\left(\mathrm{M}_{\mathrm{n}}\right)$ for singly reinforced UHPC beams can be calculated by Equation 2.42:

$M_{n}=A_{S} f_{y}(d-a / 2)+\sigma_{t} b(h-c)(h+c-a) / 2$

The value of ' $a$ ' can be calculated from Equation 2.43:

$a=\left(A_{s} f_{y}+\sigma_{t} b h\right) /\left(\lambda f_{c f}^{\prime} b+\sigma_{t} b\right)$ 
where, $\mathrm{f}_{\mathrm{cf}}$ : compressive strength of fibrous concrete (MPa), $\mathrm{A}_{\mathrm{s}}$ : area of tensile steel bars $\left(\mathrm{mm}^{2}\right)$, $\mathrm{f}_{\mathrm{y}}$ : yield strength of tensile reinforcement bar (MPa), c: neutral axis depth (mm), b: width of the beam cross section $(\mathrm{mm}), \mathrm{h}$ : height of the beam cross section $(\mathrm{mm}), \lambda$ : concrete stress block parameter (equal to 0.86 for $\left.\mathrm{f}_{\mathrm{c}}^{\prime} \geq 55 \mathrm{MPa}\right), \mathrm{f}_{\mathrm{c}}$ : compressive strength of plain concrete (MPa), $\beta 1$ : concrete stress block parameter (equal to 0.65 for $\mathrm{f}_{\mathrm{c}} \geq 55(\mathrm{MPa})$, a: depth of the equivalent compressive block (mm).

Based on the principle of force equilibrium and strain- stress distribution of reinforced UHPC beam (full depth fiber dispersion, Figure 2.19), flexural analysis of singly reinforced UHPC with half depth fiber dispersion Figure 2.20 can be derived as follows.

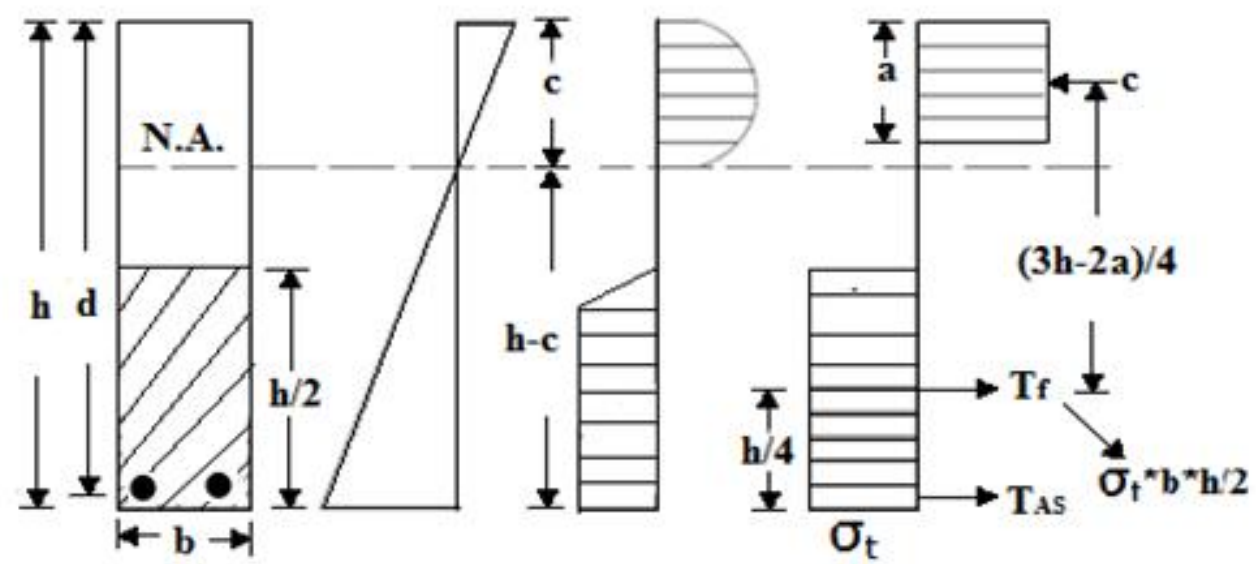

Figure 2.20: Strain- stress-force distribution of reinforced UHPC beam with half depth finer dispersion

The nominal moment capacity $\left(\mathrm{M}_{\mathrm{n}}\right)$ for singly reinforced UHPC beams for half depth fiber dispersion can be calculated by Equation 2.44:

$M_{n}=A_{s} f_{y}(d-a / 2)+\sigma_{t} b h(3 h-2 a) / 8$

The value of ' $a$ ' can be calculated from Equation 2.45:

$a=\left(A_{s} f_{y}+\sigma_{t} b h / 2\right) / \lambda f_{c f}^{\prime} b$

Based on the principle of force equilibrium and strain- stress distribution of reinforced UHPC beam with half depth fiber dispersion (Figure 2.20), flexural analysis of singly reinforced composite ECC/SCC beam with quarter depth PVA fiber dispersion has been developed in this study and discussed in Chapter 5. 


\subsection{Review conclusions}

Research has been conducted on the material properties of SCC, ECC and FRC for tailoring enhanced mechanical and durability properties. SCC and ECC have been used in many structural applications over the last decades. Literature review confirmed the use of composite ECC/SCC in very few structural applications and to date, very few research studies have been conducted to study their shear and flexure performance in building and bridge structures. This warrants investigations on the evaluation of structural performance of composite ECC/SCC based structural elements and to develop design guidelines for practical construction. The current study on the evaluation of shear and flexural resistance of composite ECC/SCC beams compared to their full depth SCC and ECC counterparts is a timely initiative and will contribute to the existing knowledge of such technology. 


\section{CHAPTER THREE \\ EXPERIMENTAL PROGRAM}

\subsection{Introduction}

An experimental research had been conducted to study the shear and flexural behavior of composite ECC/SCC beams. Four composite shear beams (two without shear reinforcement and tow with shear reinforcement) and one singly reinforced composite flexural beams were tested under four point static loading to failure. In addition, two full depth SCC shear beams (one without shear reinforcement and one with shear reinforcement), two full depth ECC shear beams (one without shear reinforcement and one with shear reinforcement), one SCC flexural beam and one ECC flexural beams were tested as control specimen to compare the structural performance compared with their composite ECC/SCC beam counterparts. Two types of concrete, Self-Consolidating Concrete (SCC) and Engineered Cementitious Composite (ECC) were used to cast all the composite beams.

This chapter will describe the geometric dimensions of beam specimens, properties of the materials, and experimental program.

\subsection{Beam geometry and reinforcement configuration}

\subsubsection{Shear beams}

The experimental program was designed to evaluate shear behavior of ECC, SCC and composite ECC/SCC beams and estimate concrete contribution to overall shear resistance $\left(\mathrm{V}_{\mathrm{c}}\right)$. Total of eight shear beams with and without shear reinforcement were cast and tested. From Table 3.1, first four beams were designed only for adequate flexural reinforcements without shear reinforcement as shown in Figures 3.1 and 3.2. "Full SCC" denotes $200 \mathrm{~mm}$ height of SCC, "Full ECC" denotes 200 mm height of ECC, "E50-S50" denotes $100 \mathrm{~mm}$ height (half depth) of ECC at bottom with 100 $\mathrm{mm}$ height of SCC at top and "E25-S75" denotes $50 \mathrm{~mm}$ height (quarter depth) of ECC at bottom with $150 \mathrm{~mm}$ height of SCC at top. Last four beams were designed with the same amount of flexural reinforcement as in the first set of beams in addition to the stirrups provided at $133.5 \mathrm{~mm}$ spacing (c/c) as indicated in Figure 3.3 and Figure 3.4. "Full SCC" and "Full ECC" served as control specimens for beams without shear reinforcement as well as "Full SCC-S" and "Full ECC-S" served as control specimens for beams with shear reinforcement. 
All beams were $100 \mathrm{~mm}$ wide (b) with total depth (h) $200 \mathrm{~mm}$. The shear span-to-depth ratio (a/d) was kept constant at a value of 1.53 to ensure shear rather bending failure of all beams. The total length of all the beams was at $1100 \mathrm{~mm}$ with an effective span of $800 \mathrm{~mm}$. Beams with the shear reinforcements were provided with 2, \#6 $\mathrm{mm}$ diameter hanger bars at the top to support $6 \mathrm{~mm}$ dia stirrups (plain steel bar) provided at $133.5 \mathrm{~mm} \mathrm{c} / \mathrm{c}$ as shown Figure 3.4. Flexural reinforcements were provided with $10 \mathrm{~mm}$ dia deformed steel bars. Flexural reinforcement ratio was kept constant for all beams as $1.14 \%$. Geometric dimensions and reinforcement details of the experimental beams are summarized in Table 3.1.

The beam designation included a combination of letters and numbers to indicate concrete type ( $\mathrm{S}$ or E) and ratio of ECC to SCC depth in the cross-section (25 or 50 or 75). In addition, a letter of "S" at the end indicates the presence of shear reinforcement. For example, full depth SCC beams having shear reinforcement are coded as "Full SCC-S".

Table 3.1: Shear beams geometry and reinforcement configuration

\begin{tabular}{|c|c|c|c|c|c|}
\hline Beam code & $\begin{array}{l}\text { Effective } \\
\text { depth } \\
\text { (d), mm }\end{array}$ & $\begin{array}{c}\text { Total } \\
\text { height } \\
(\mathrm{h}), \mathrm{mm}\end{array}$ & $\begin{array}{c}\text { Shear span } \\
\text { to } \\
\text { depth } \\
\text { ratio, } \\
(\mathrm{a} / \mathrm{d})\end{array}$ & $\begin{array}{c}\text { Flexural } \\
\text { reinforcement } \\
\text { ratio, } \rho \\
\left(=100 \mathrm{~A}_{\mathrm{s}} / \mathrm{b}^{*} \mathrm{~d}\right) \\
\%\end{array}$ & $\begin{array}{l}\text { Shear } \\
\text { reinforcement } \\
\text { spacing, } \\
\mathrm{mm}\end{array}$ \\
\hline \multicolumn{6}{|c|}{ Width $(b)=100 \mathrm{~mm}$, Effective span $(\mathrm{S})=800 \mathrm{~mm}$ and Length $=1100 \mathrm{~mm}$} \\
\hline \multicolumn{6}{|c|}{ Beams without shear reinforcement } \\
\hline Full SCC & 175 & 200 & 1.53 & 1.14 & N/A \\
\hline Full ECC & 175 & 200 & 1.53 & 1.14 & N/A \\
\hline E50-S50 (half depth ECC) & 175 & 200 & 1.53 & 1.14 & N/A \\
\hline E25-S75 (quarter depth ECC) & 175 & 200 & 1.53 & 1.14 & N/A \\
\hline \multicolumn{6}{|c|}{ Beams with shear reinforcement } \\
\hline Full SCC-S & 175 & 200 & 1.53 & 1.14 & 133.5 \\
\hline Full ECC-S & 175 & 200 & 1.53 & 1.14 & 133.5 \\
\hline E50-S50-S (half depth ECC) & 175 & 200 & 1.53 & 1.14 & 133.5 \\
\hline E25-S75-S (quarter depth ECC) & 175 & 200 & 1.53 & 1.14 & 133.5 \\
\hline
\end{tabular}






Figure 3.1: Shear beams without shear reinforcement showing four points loading (Dimensions in $\mathrm{mm}$ )

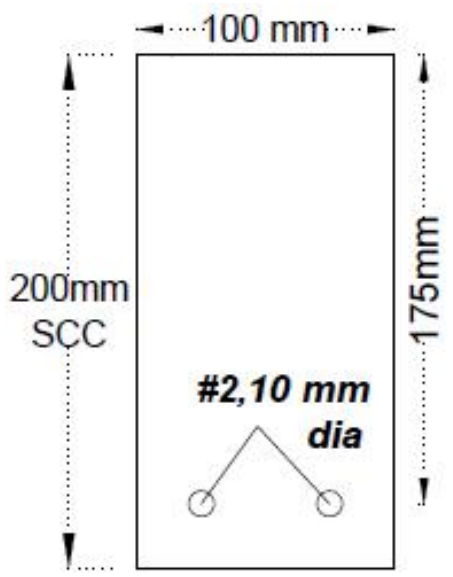

Full SCC

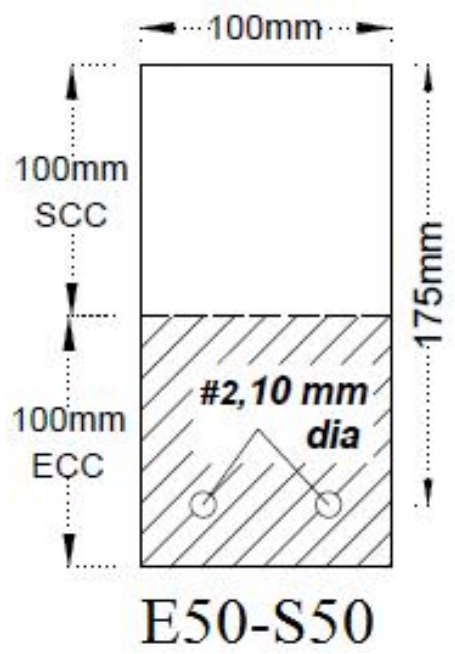

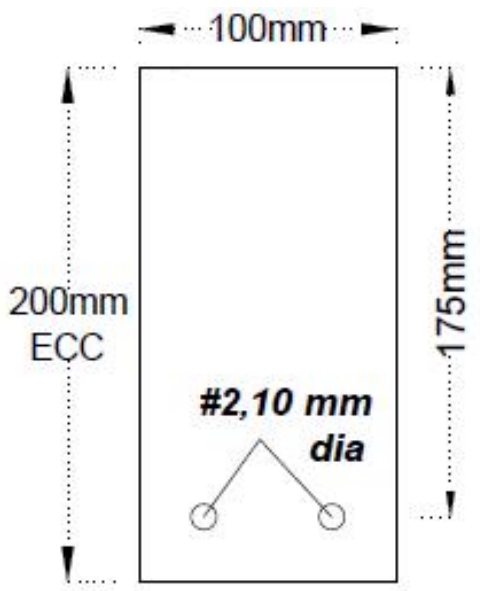

Full ECC

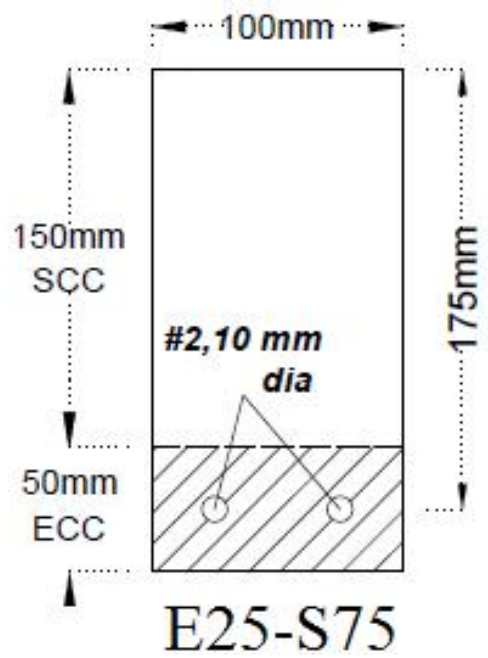

Figure 3.2: Shear beam cross-sections without shear reinforcement 


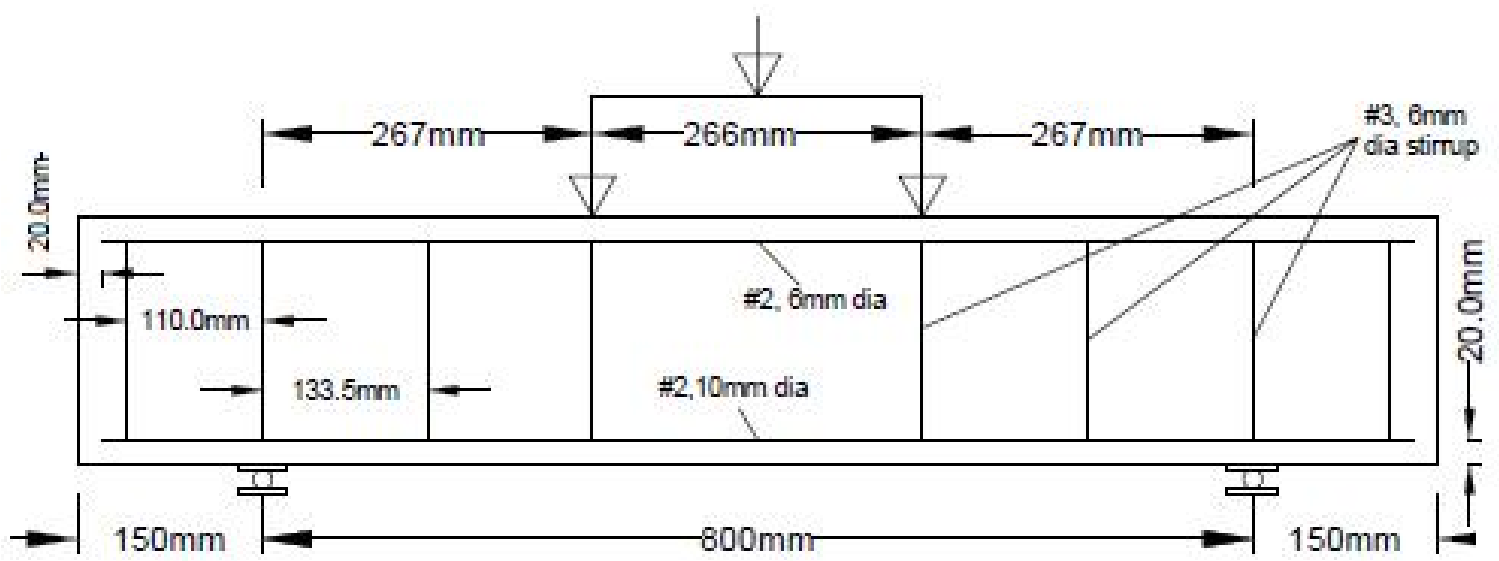

Figure 3.3: Shear beams with shear reinforcement showing four point loading
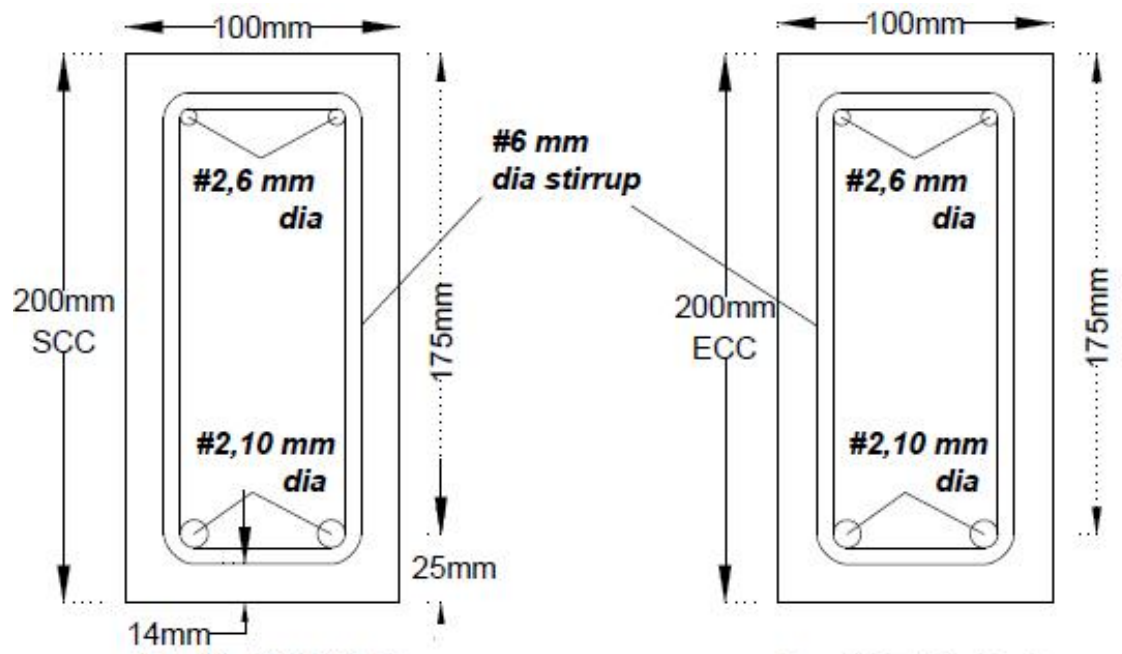

Full SCC-S

Full ECC-S
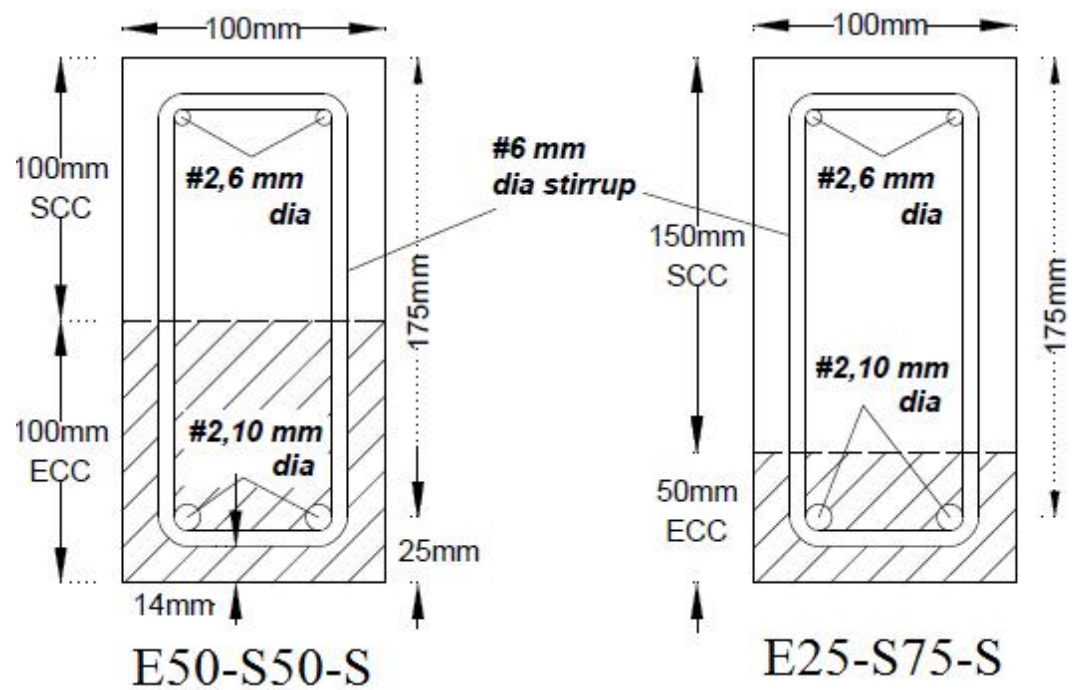

Figure 3.4: Shear beams cross section with shear reinforcement 


\subsubsection{Flexural beams}

The experimental program was designed to evaluate flexural behavior of full depth ECC, SCC and composite ECC/SCC beams and estimate ultimate flexural capacity. A total of 3 flexural beams with adequate shear reinforcement were casted and tested. All beams were designed as underreinforced and were singly reinforced and they were denoted as "Full SCC-F", "Full ECC-F" and "E25-S75-F" where the letter "F" denotes flexural. The width and effective depth of the beams were maintained at $150 \mathrm{~mm}$ and $201 \mathrm{~mm}$ for all beams while shear span to effective depth ratio was kept at 5.72 to make the beams fail in flexure. Flexural reinforcement ratio $0.66 \%$ was kept constant for all beams. All beams had a clear cover of $20 \mathrm{~mm}$. Twenty $6 \mathrm{~mm}$ plain steel bars @ $60 \mathrm{~mm} \mathrm{c/c}$ were placed as shear reinforcement on both side. Flexural beam cross-sections and reinforcement configurations are shown in Table 3.2 and Figures 3.5 and 3.6.

Table 3.2: Flexural beams geometry and reinforcement configuration

\begin{tabular}{|c|c|c|c|c|c|c|}
\hline Beam code & $\begin{array}{c}\text { Beam } \\
\text { type }\end{array}$ & $\begin{array}{l}\text { Beam } \\
\text { height } \\
\text { (h), mm }\end{array}$ & $\begin{array}{l}\text { Effective } \\
\text { depth } \\
\text { (d), mm }\end{array}$ & $\begin{array}{l}\text { Bottom } \\
\text { flexural } \\
\text { reinforcement }\end{array}$ & $\begin{array}{l}\text { Compression } \\
\text { flexural } \\
\text { reinforcement }\end{array}$ & $\begin{array}{l}\text { Flexural } \\
\text { reinforcement } \\
\text { ratio, } \rho_{\mathrm{s}} \%\end{array}$ \\
\hline \multicolumn{7}{|c|}{ Width:150 mm, Length: 3300 mm, Span, S: $3000 \mathrm{~mm}$} \\
\hline Full SCC-F & Singly & 232 & 201 & 2, \# 10mm & $2, \# 6 \mathrm{~mm}$ & 0.66 \\
\hline Full ECC-F & Singly & 232 & 201 & 2, \# 10mm & $2, \# 6 \mathrm{~mm}$ & 0.66 \\
\hline $\begin{array}{l}\text { E25-S75-F } \\
\text { (quarter depth } \\
\text { ECC) }\end{array}$ & Singly & 232 & 201 & 2, \# 10mm & 2, \#6 mm & 0.66 \\
\hline \multicolumn{7}{|c|}{$\begin{array}{l}10 \mathrm{~mm} \text { dia deformed and } 6 \mathrm{~mm} \text { dia plain steel bars were used as flexural } \\
\text { and shear reinforcements respectively } \\
\text { All beams had a clear cover of } 20 \mathrm{~mm} \\
6 \mathrm{~mm} \text { plain steel bar @ } 60 \mathrm{~mm} \mathrm{c} / \mathrm{c} \text { was used as shear reinforcement }\end{array}$} \\
\hline
\end{tabular}



Figure 3.5: Flexural beams with reinforcement showing four point loading 


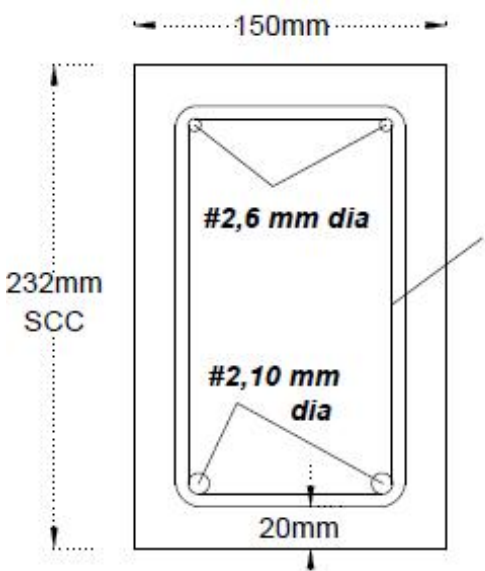

Full SCC-F

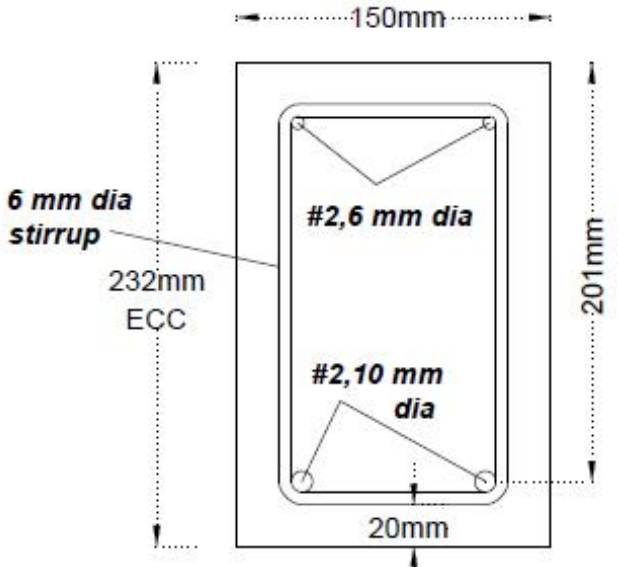

Full ECC-F

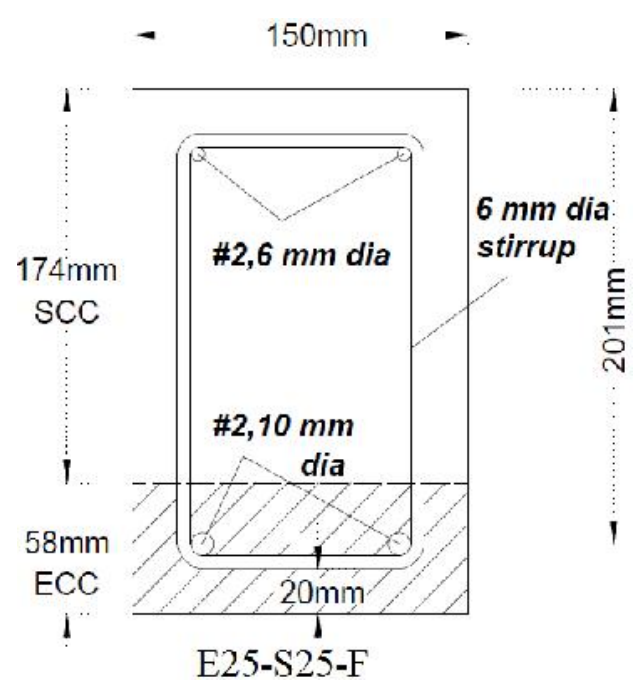

Figure 3.6: Flexural beam cross sections

\subsection{Material properties and construction model frame}

This section presents the detail construction methodologies used for experimental investigation including mix design and mixing sequences for SCC, ECC and composite ECC/SCC beams as well as casting and fabrication sequences of the specimens.

\subsubsection{Mix design and mixing sequences for SCC, ECC}

A 175-liter shear drum mixer was used for mixing all concrete mixes. The ECC (one of the mix developed at Ryerson) has a water/cementitious material ratio of 0.30, PVA fiber content of $1 \%$ fibers/kg of dry material. It consists of general purpose cement and fly ash (FA) as the cementing material, water, natural grain silica sand with 110 micrometer nominal size, Polyvinyl Alcohol 
(PVA) fibers and a polycarboxylate-based high range water reducing admixture (HRWRA) as shown in Table 3.3. The PVA fibers are 38 microns in diameter, $8 \mathrm{~mm}$ in length, a tensile strength of $1600 \mathrm{MPa}$, modulus of elasticity of $40 \mathrm{GPa}$, and has a melting point of $225^{\circ} \mathrm{C}$, as shown in Fig. 3.7. For casting ECC weighted solid contents except for the PVA fibers were introduced into the shear mixture and mixed for 1 minutes. After that $75 \%$ of the water was added to $50 \%$ HRWR and mixed together then the mix of water and HRWR was added gradually to the mixer and mixed for additional 2 to 3 minutes. Then the remaining water and HRWRA was introduced again with same procedure to the mix, and mixed for another 2 minutes for the development of a uniform and consistent mortar mixture. Lastly, the PVA fibers were added to the mortar for another 3 minutes of stirring until all fibers were dispersed with mortar mixture. The mixing sequence and the resulting flow-able ECC mix is presented in Figure 3.7.

Table 3.3: Mix design of ECC

\begin{tabular}{|c|c|c|c|c|c|c|}
\hline \multirow{2}{*}{ Mixture } & \multicolumn{3}{|c|}{ Ingredients per 1 part of cement } & $\begin{array}{c}\text { PVA } \\
\left(\mathrm{kg} / \mathrm{m}^{3}\right)\end{array}$ & $\begin{array}{c}\text { HRWRA } \\
\left(\mathrm{kg} / \mathrm{m}^{3}\right)\end{array}$ & w/b \\
\cline { 2 - 6 } & Cement & Fly ash (FA) & $\begin{array}{c}\text { Silica } \\
\text { sand }\end{array}$ & 26 & 5.4 & 0.27 \\
\hline ECC & 1 & 1.2 & 0.80 & 26 \\
\hline \multicolumn{3}{|r}{ w: water; b: binder; HRWRA: High range water reducing admixture } \\
\hline
\end{tabular}

The SCC was made with commercially available dry content (30 kg) pre-packaged bags. The dry content included the nominal aggregate size of $10 \mathrm{~mm}$, Portland cement, silica fume and airentraining admixtures. For each pre-package bag, 2.4 liter of water was added for development of the SCC mixture. The dry ready mix packages were introduced into the mixer for a 30 seconds of mixing. After that $50 \%$ of the potable water was added to the dry content in period of 2 minutes of mixing. The remaining $50 \%$ of the water was slowly added to the mix for additional 2 to 3 minutes until the required flow ability and workability was achieved. The flow-able SCC is shown in Figure 3.8 . 

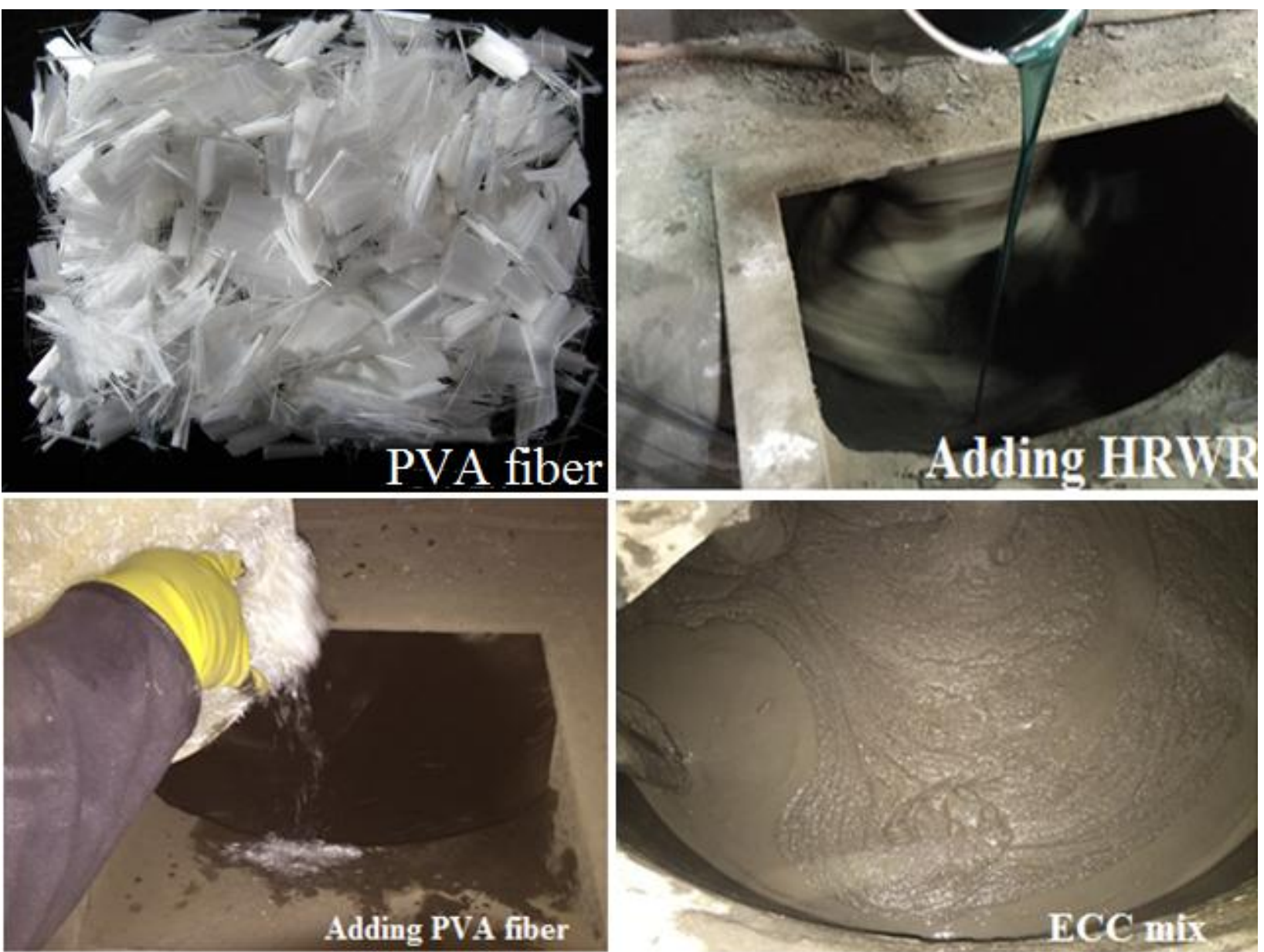

Figure 3.7: Mixing procedure for ECC concrete
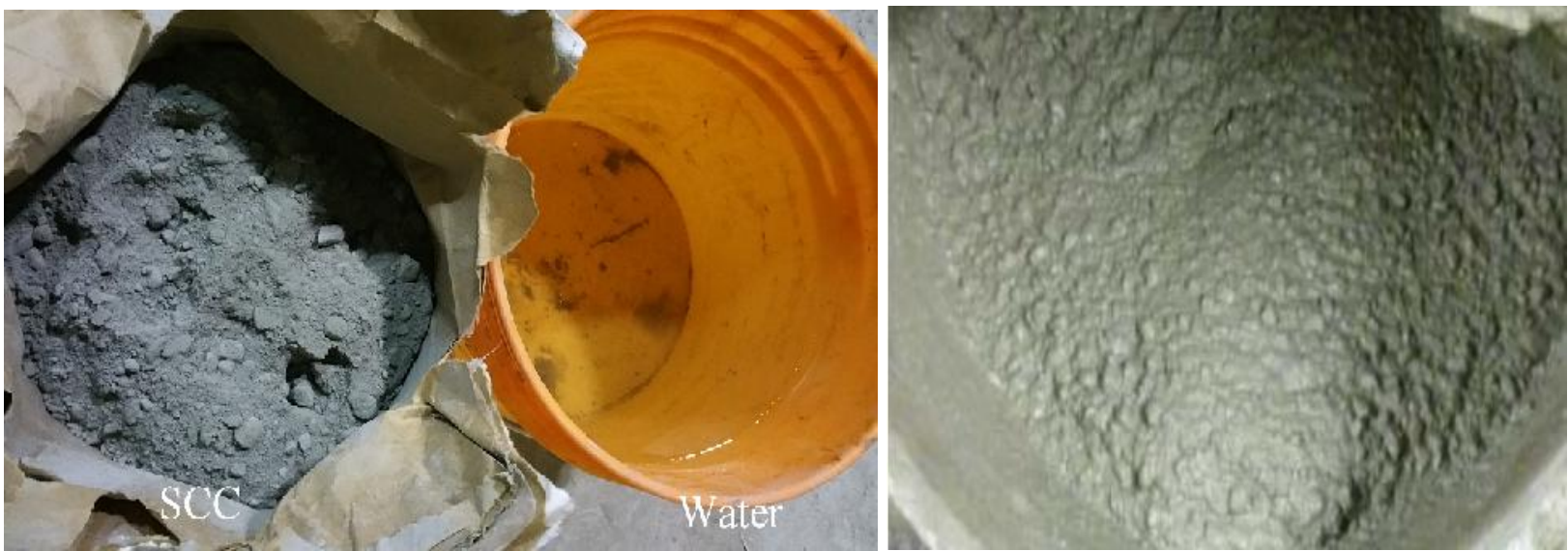

Figure 3.8: SCC concrete production 


\subsubsection{Beam fabrication, casting and curing}

Wooden formworks were prepared for casting SCC, ECC and composite ECC/SCC shear and flexure beams. Figure 3.9 shows the typical formwork for shear and flexure beams exhibiting both main and shear reinforcement position. For specimens with shear reinforcement, rebar were ground smooth to facilitate the fixing of strain gauges at left and right side of the stirrups near the support as well as at the mid-span of the flexural reinforcing bar (tension rebar).

Immediately after the SCC and ECC mixing, flow-able concretes were poured into formwork from one side until it flow and reached the other side to avoid any vibration or compaction. Visual observation showed that the SCC properly filled the forms with ease of movement around reinforcing bars in each reinforcement configuration and same was the case for ECC. Figure 3.10 shows the pouring of concrete and the casted beams in the mold.

To cast composite ECC/SCC beams, ECC concrete was mixed first then poured into the formwork up to desired height and followed the same procedure to achieve flow ability. As there was no external joint or adhesive used in between two layers, so the waiting period was approximately half an hour to let the ECC concrete settle down. Some small scratches was made on the surface of the ECC concrete to make good interaction between ECC and SCC. After that, SCC concrete was mixed and poured on the top of the ECC concrete and filled the formwork. Figure 3.11 shows the procedure of casting composite beams. Beam molds were removed after 48 hours of casting and the beams were cured by covering plastic bags until 28 days of testing as shown in Figure 3.12.
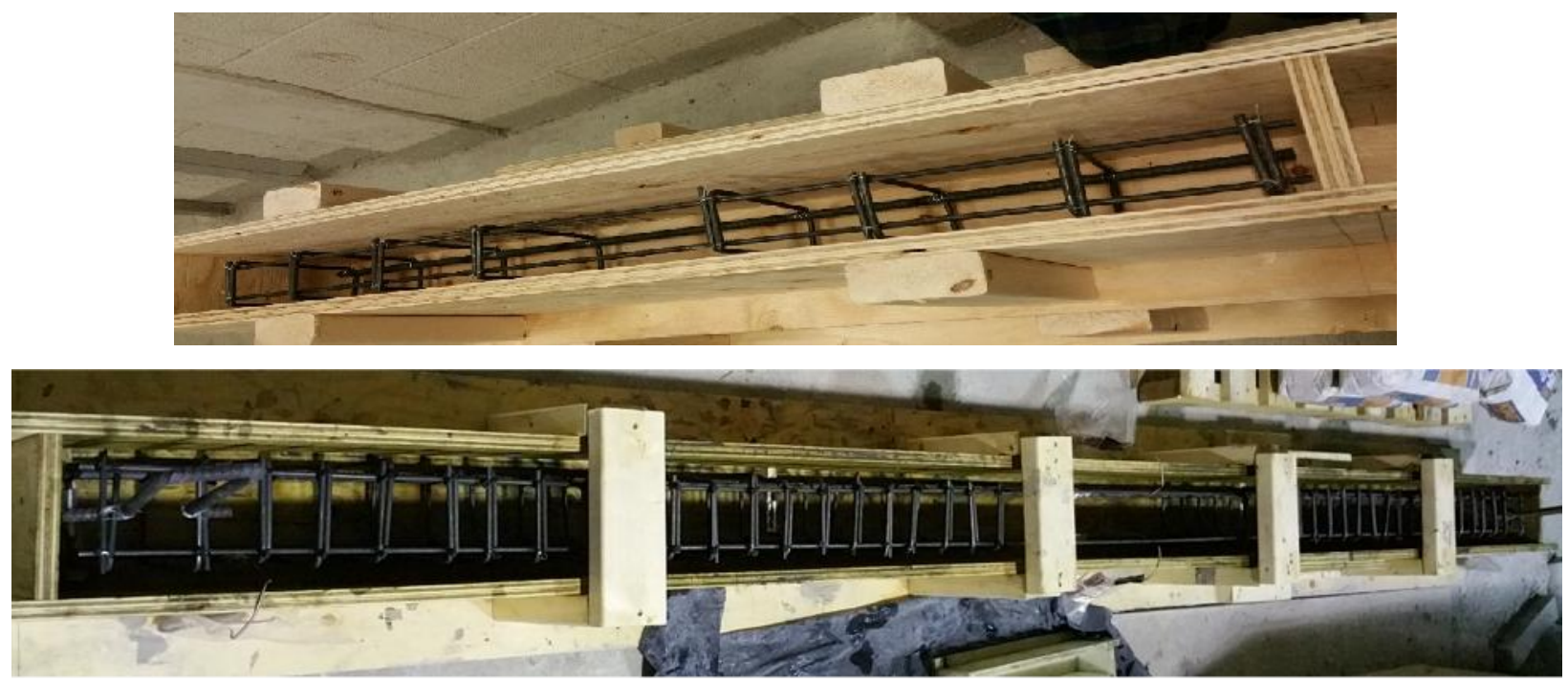

Figure 3.9: Typical formwork showing reinforcement for shear (top) and flexure (bottom) beams 

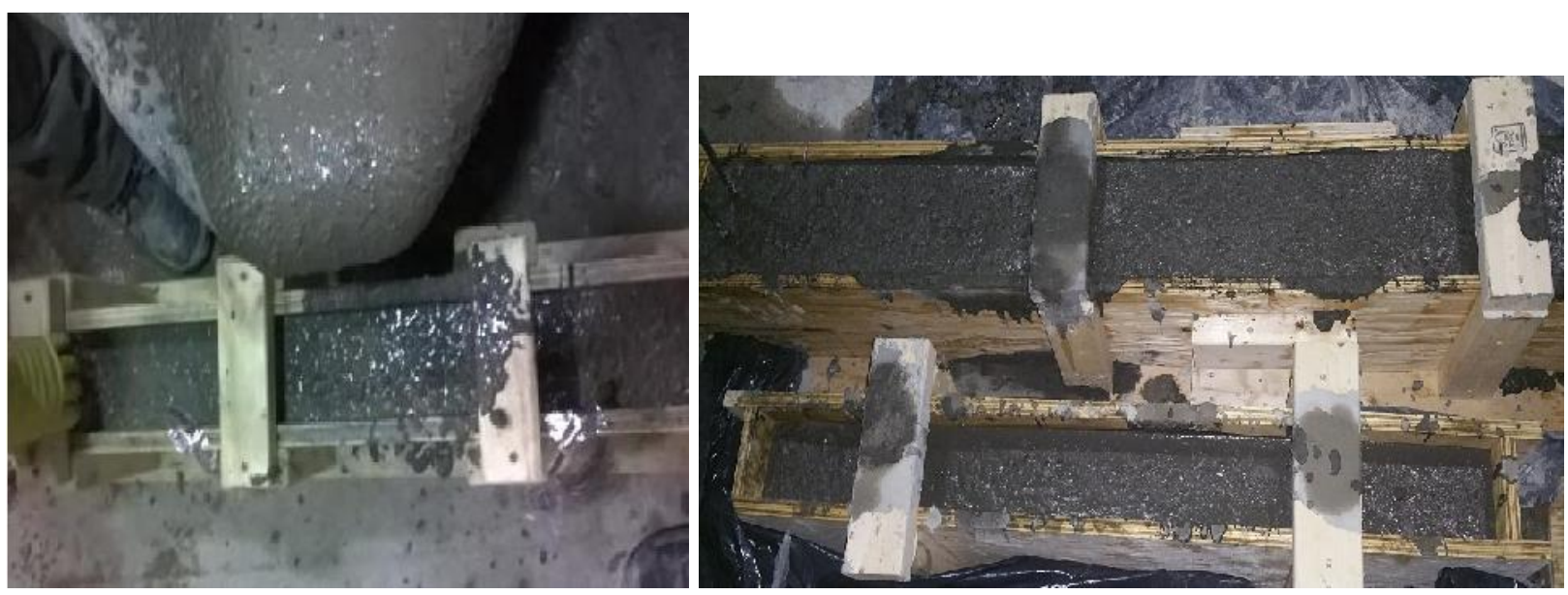

Figure 3.10: Beam casting showing concrete pouring and casted beams
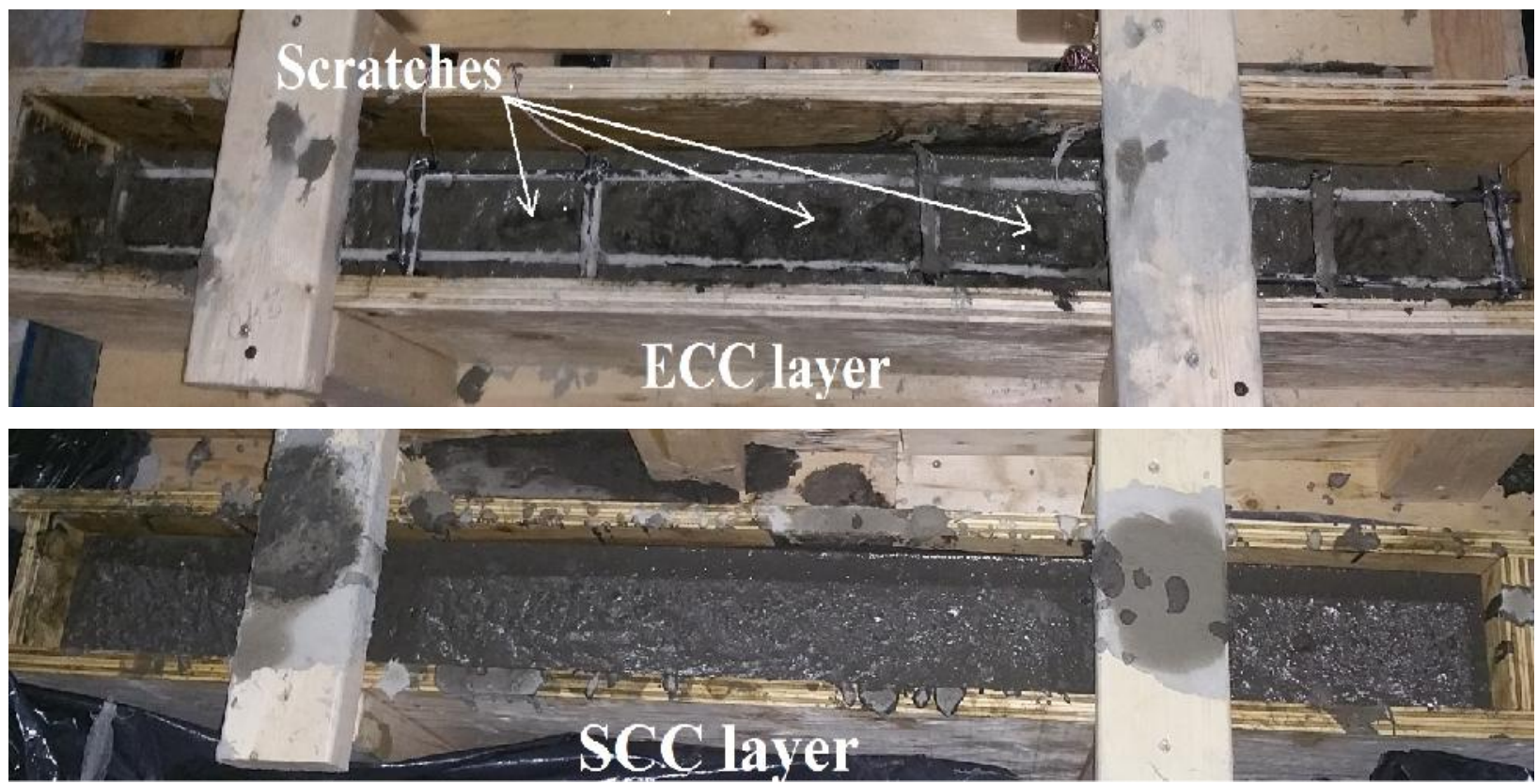

Figure 3.11: Casting of ECC/SCC composite beams

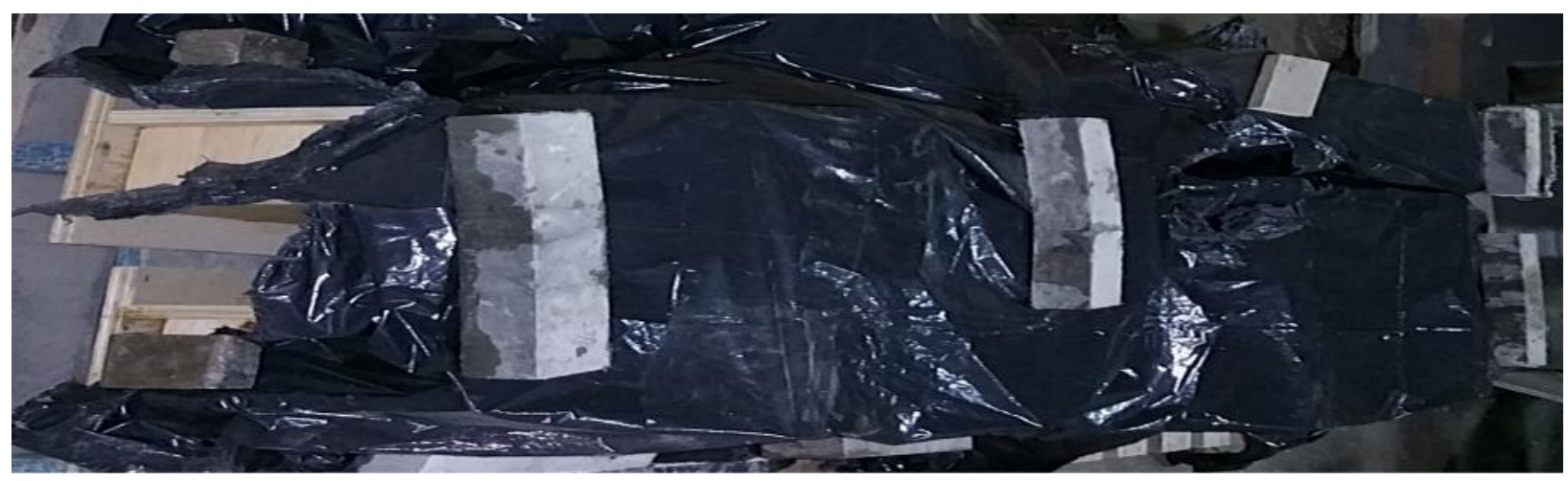

Figure 3.12: Curing of beams and control specimens 
Control specimens in the form of cylinders and beams were also cast to determine strength of concrete and cured under similar conditions as beam specimens until testing. The compressive strength of SCC and ECC was determined from $100 \times 200 \mathrm{~mm}$ control cylinders for each batch according to ASTM C39 (2003). Flexural strength of the SCC and ECC at 28 days was determined from beam four point bending test as per ASTM C78 (2010). The four-point bending test was performed using a closed-loop controlled servo-hydraulic system under displacement condition at a loading rate of $0.005 \mathrm{~mm} / \mathrm{s}$. Total length, height and width of the flexural beam specimens were $304.8 \mathrm{~mm}, 76.0 \mathrm{~mm}$ and $50.0 \mathrm{~mm}$ respectively. Typical load/flexural stress vs mid span deflection responses of SCC and ECC are presented in Figure 3.13. ECC showed significant post-pick stain hardening behavior due to its micro cracking characteristics compared to SCC. Table 3.4 shows the compressive strength and flexural strength of concrete at the age of testing (28 days) - mean value of at least three specimens are reported.
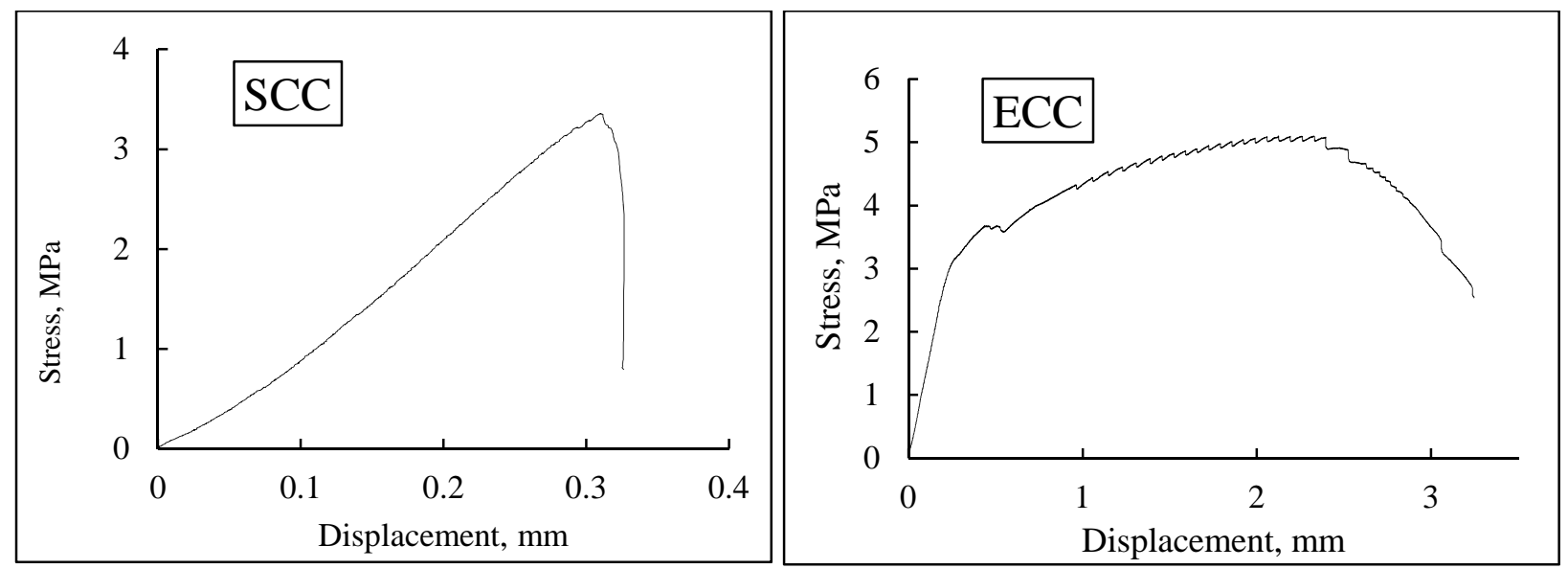

Figure 3.13: Flexural stress vs displacement renponse of SCC and ECC

Table 3.4: Concrete compressive and flexural/tensile strength

\begin{tabular}{|c|c|c|}
\hline \begin{tabular}{c} 
SCC \\
\hline $\begin{array}{c}\text { Concrete compressive strength (MPa) at the age } \\
\text { of testing (28 day) }\end{array}$
\end{tabular} & 59 & 73 \\
\hline $\begin{array}{c}\text { Flexural strength (MPa) at the age of testing } \\
\text { (28 day) }\end{array}$ & 3.2 & 5.1 \\
\hline
\end{tabular}




\subsection{Reinforcement properties}

Coupon tension tests were also performed to determine yield and ultimate strength deformed reinforcing mild steel bars used to construct frame specimens. Stress-strain response of $10 \mathrm{~mm}$ and $6 \mathrm{~mm}$ bars are presented in Figure 3.14. Table 3.5 lists the mean value of steel yield strength $\left(\mathrm{f}_{\mathrm{y}}\right)$ and yield strain for each diameter steel bar shape as derived from at least three coupon specimens.

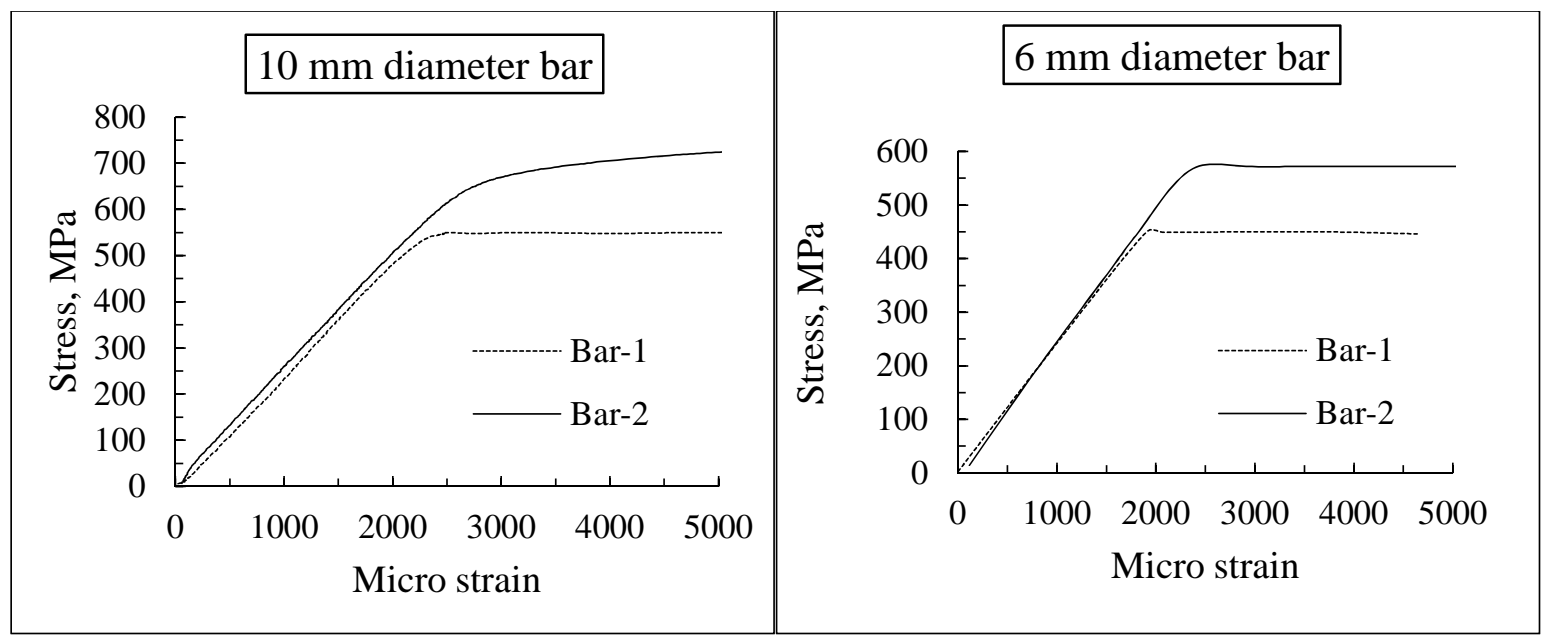

Figure 3.14: Stress-strain response of reinforcement bars (Sathiyamoorthy, 2016)

Table 3.5: Rebar stress-strain response table (Sathiyamoorthy, 2016).

\begin{tabular}{|c|c|c|c|c|c|c|}
\hline \multirow{2}{*}{$\begin{array}{c}\text { Rebar } \\
\text { diameter }\end{array}$} & \multicolumn{3}{|c|}{ Yield stress (MPa) } & \multicolumn{3}{c|}{ Yield micro-strain } \\
\cline { 2 - 7 } & Bar-1 & Bar-2 & Average & Bar-1 & Bar-2 & Average \\
\hline $6 \mathrm{~mm}$ & 450 & 448 & 449 & 1895 & 1892 & 1893 \\
\hline $10 \mathrm{~mm}$ & 532 & 628 & 567 & 2330 & 2380 & 2355 \\
\hline
\end{tabular}

\subsection{Experimental set up and instrumentation}

All specimens were tested as simply supported beam under four-point loading condition. Experimental set-up for shear beam beams without and with shear reinforcement is shown in Figure 3.15. LVDT (Linear variable displacement transducer) was fixed at mid span to measure the central deflection and one inclinometer was also fixed near to the support to measure the angle of rotation. Figure 3.16 shows the location of steel strain gauges that were attached to measure strain in the flexural and shear reinforcement. 


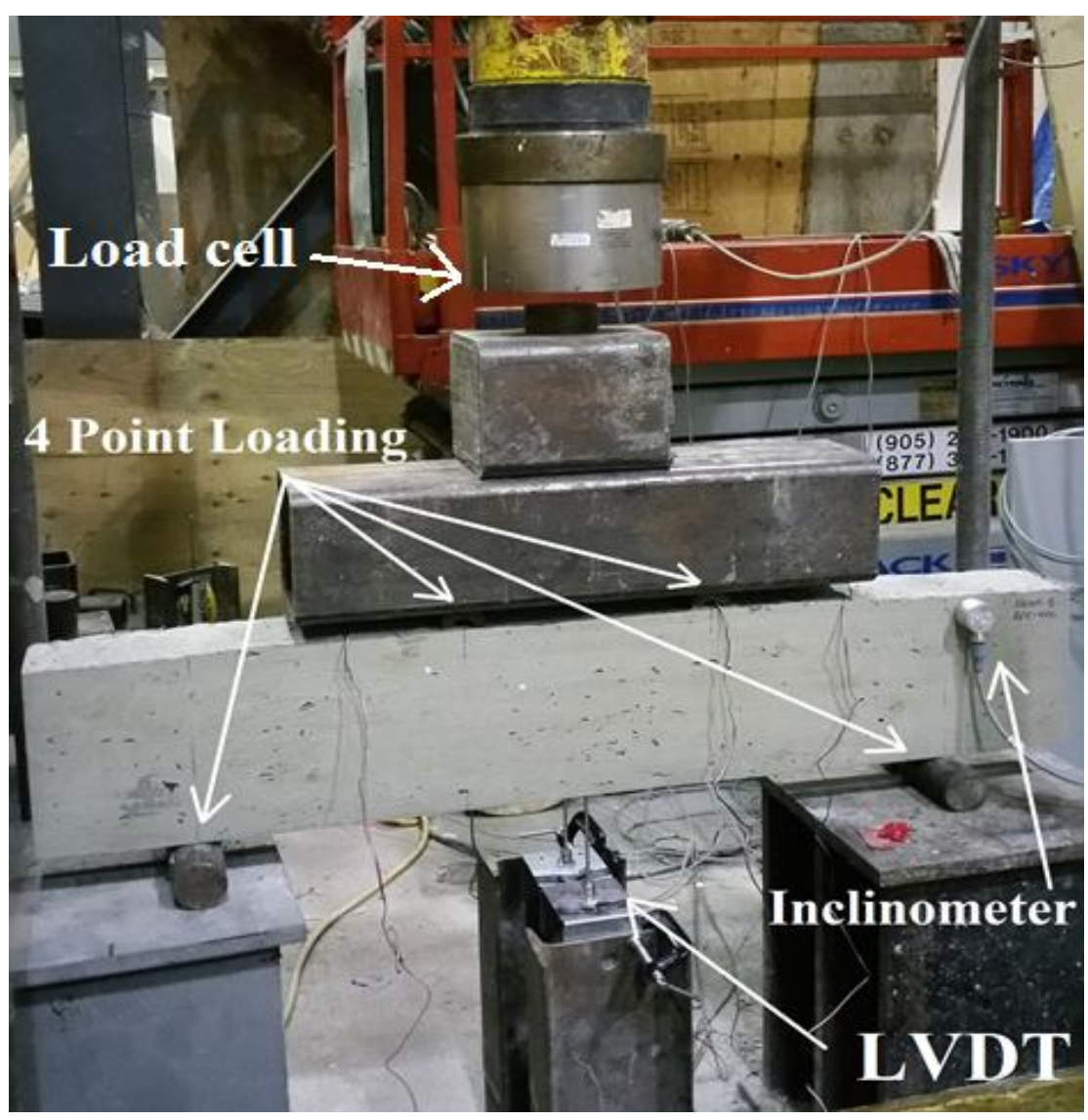

Figure 3.15: Experimental set-up and instrumentation of shear beam

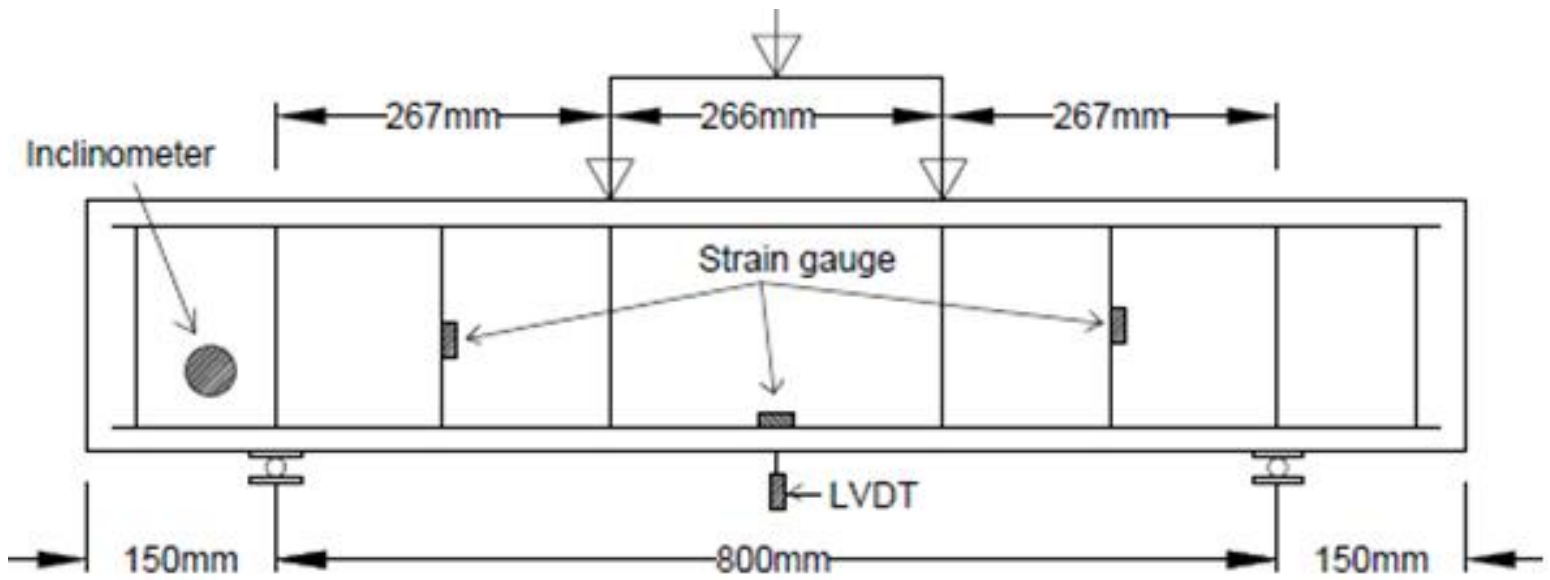

Figure 3.16: Strain gauge, LVDT and Inclinometer locations for shear beams 
Experimental set-up for flexural beams tested under four point loading as well is shown in Figure 3.17. Three LVDTs (Linear variable displacement transducer) were fixed at mid span and $750 \mathrm{~mm}$ from the left and right support to measure the deflection. An inclinometer was also fixed near the support to measure the rotation angle. Strain gauges were installed on the shear and flexural reinforcement at strategic location as shown in Figure 3.18 to monitor strain development.

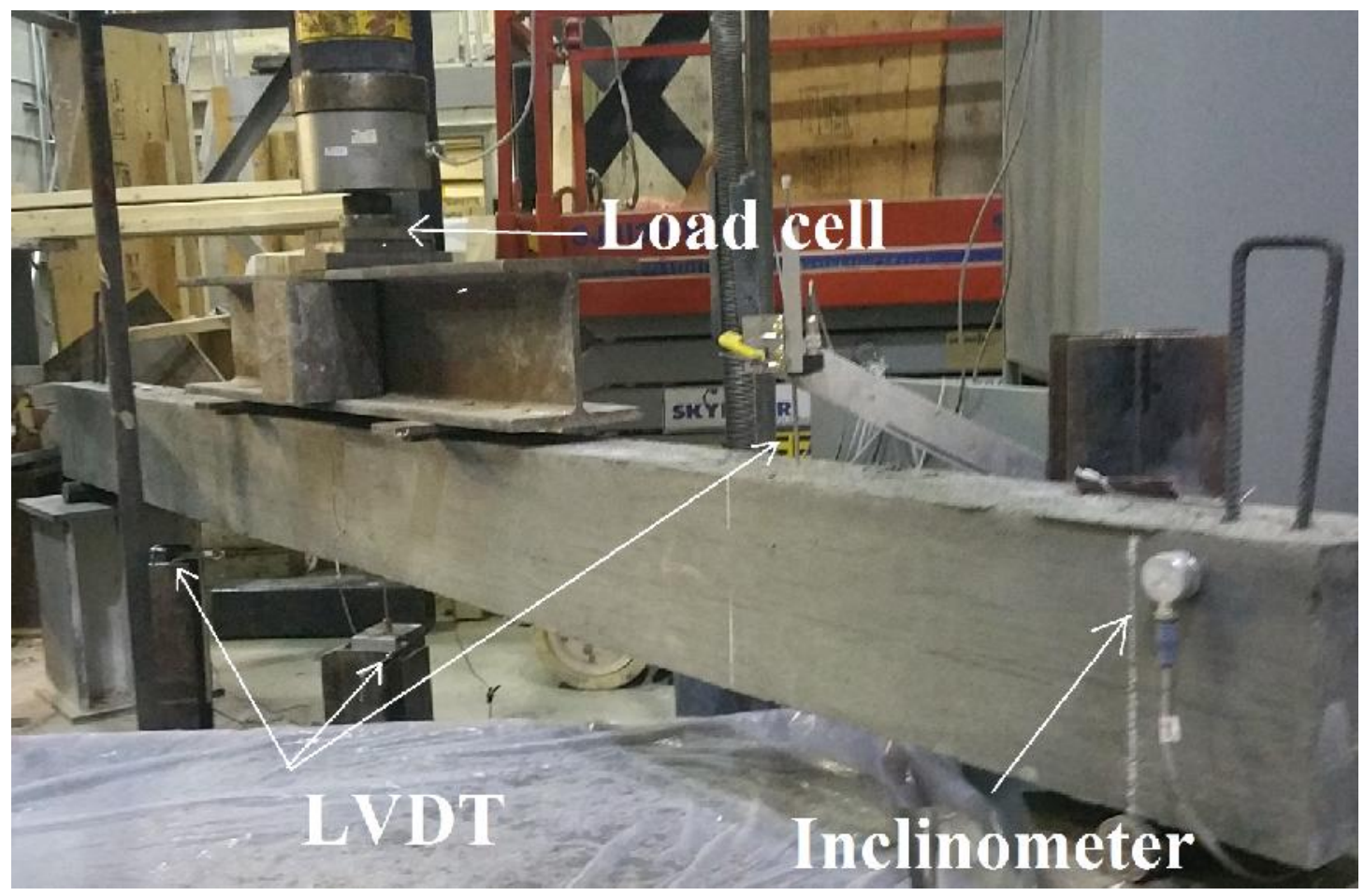

Figure 3.17: Experimental set-up and instrumentation for flexural beams

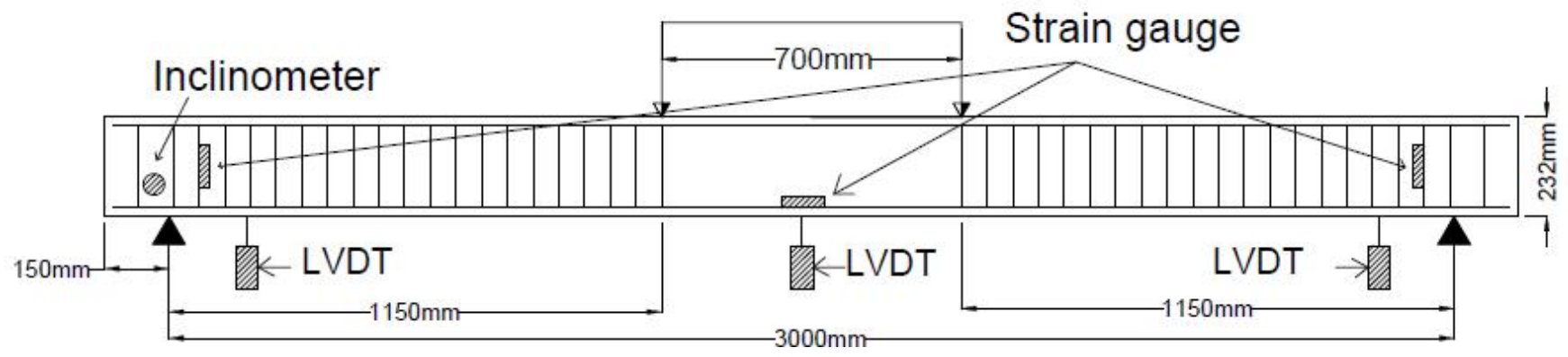

Figure 3.18: Strain gauge, LVDT and Inclinometer locations in flexural beams 
A hydraulic jack was used to apply the load incrementally with $5 \mathrm{kN}$ for each increment and the load was kept constant for some minutes after each increment to observe the crack pattern. All strain gauges, load, LVDT and Inclinometer were connected to a computer control data acquisition systems. The initiation and development of shear and flexural cracks and cracking loads at various stages were recorded during the test. During testing to failure, load-deformation response, rotation angle and strain development in steel/concrete were recorded. Test also provided information on the overall behavior of the beam including development of crack, crack patterns, load transfer mechanism and failure modes.

\subsection{Summary}

Experimental research program is descried by illustrating beam specimen preparation (fabrication and casting), material properties, specimen instrumentation and test procedure. A total of 8 shear beams and 3 flexural beams were tested to failure. The test results will be presented and described in Chapter Four. 


\section{CHAPTER FOUR \\ EXPERIMENTAL RESULTS AND DISCUSSION}

\subsection{Introduction}

This Chapter presents the results of the experimental investigation on shear and flexural behavior of composite ECC/SCC beams (half depth or quarter depth ECC) in addition to control ECC/SCC beams. The performance is described based on load-deflection response, first diagonal crack load, strain development, moment-end rotation response, energy absorption, ductility index, crack formation and propagation and failure modes. Comparison between composite ECC/SCC beams and full depth ECC/SCC beams with especial reference to post--cracking shear transfer mechanism is also presented.

\subsection{ECC, SCC and composite ECC/SCC shear beams without shear reinforcement}

Experimental tests had been carried out to study the shear behavior of the composite ECC/SCC beams including full depth ECC/SCC beams. Total four (one full depth ECC, one full depth SCC and two ECC/SCC composite beams with different ECC to SCC height ratio) shear beams without shear reinforcement were tested under four point loading to failure. ECC and SCC were used to cast all beams. Shear span to effective depth ratio (a/d) was kept constant as 1.53 as well as adequate flexural reinforcement was provided with the reinforcement ratio of $1.14 \%$ for all beams. However, no shear reinforcement was provided in these beams.

\subsubsection{Load vs deflection behavior}

Experimental load vs deflection curves for the tested ECC, SCC and composite ECC/SCC shear beams without shear reinforcement are shown in Figure 4.1. Changing of the slope of the curve indicates the reduction of the beam stiffness. The initial straight line segment of the curve shows that, stiffness of the beam remained constant prior to the flexural cracking. Development of the cracks throughout the loading period is indicated by abrupt changes (formation of kinks) in the loaddeflection curves. Decrease of the beam stiffness was noticed in all types of beams right after the formation of inclined/diagonal crack. When the load reached the ultimate shear capacity, a sudden brittle shear failure was occurred. A significant reduction in the load carrying capacity was observed immediately after the shear failure. 
The ultimate load/shear capacity of both composite beams "E50-S50" and "E25-S75" was about $71 \%$ and 24\% higher than "Full SCC" and "Full ECC" beams, respectively as per Figure 4.1. Moreover, the mid span deflection for composite beams at ultimate load stage ranged from 5 to 6 mm whereas "Full SCC" and "Full ECC" beams exhibited $3.17 \mathrm{~mm}$ and $3.05 \mathrm{~mm}$, respectively.

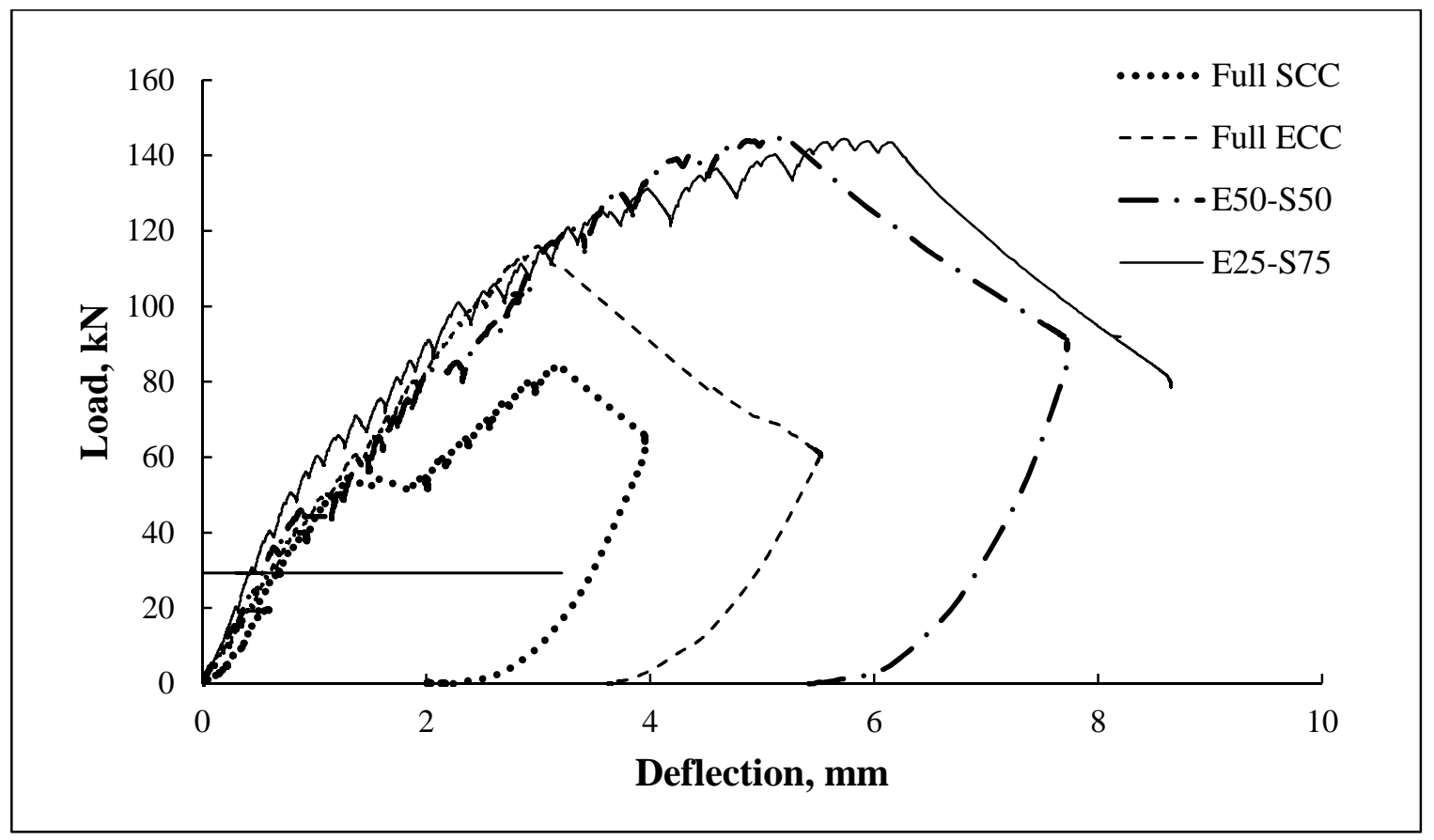

Figure 4.1: Load vs deflection response for shear beams without shear reinforcement

\subsubsection{Failure mode and cracking behavior}

Fine vertical flexural cracks were formed during loading within the mid span (zero shear regions) of all beams. With further increase of load, new flexural cracks were observed within the zero shear regions as well as in the shear span until to the formation of first shear cracks. The inclined shear crack initially formed near the support, as expected. With further increase of load, propagation of the diagonal shear cracks occurred towards the loading point of the beam with the formation of additional shear and flexural cracks. Finally, sudden shear failure was occurred immediately after dominant shear cracks formed within one or two side of the shear span a shown in Figure 4.2. The volume of sound at shear failure was identifiably louder in the case of all beams. Table 4.1 indicates the experimental summary for shear beams without shear reinforcement showing concrete compressive strength, failure modes, shear loads at first flexure/diagonal crack, deflection at first diagonal crack, peak shear load, peak load deflection and angle of diagonal crack. 
Table 4.1: Experimental summary for shear beams without shear reinforcement

\begin{tabular}{|c|c|c|c|c|c|c|c|c|c|c|c|}
\hline \multirow[t]{2}{*}{ Beam code } & \multirow[t]{2}{*}{$\mathrm{a} / \mathrm{d}$} & \multicolumn{2}{|c|}{$\begin{array}{l}\text { Concrete } \\
\text { strength } \\
(\mathrm{MPa})\end{array}$} & \multirow[t]{2}{*}{$\begin{array}{l}\text { Failure } \\
\text { pattern }\end{array}$} & \multirow[t]{2}{*}{$\begin{array}{l}\mathrm{V}_{\mathrm{fl}} \\
(\mathrm{kN})\end{array}$} & \multirow[t]{2}{*}{$\begin{array}{c}\mathrm{D}_{\mathrm{c}} \\
(\mathrm{mm})\end{array}$} & \multirow[t]{2}{*}{$\begin{array}{l}\mathrm{V}_{\mathrm{c}} \\
(\mathrm{kN})\end{array}$} & \multirow[t]{2}{*}{$\begin{array}{l}\mathrm{V}_{\mathrm{u}} \\
(\mathrm{kN})\end{array}$} & \multirow[t]{2}{*}{$\begin{array}{c}\mathrm{D}_{\mathrm{u}} \\
(\mathrm{mm})\end{array}$} & \multirow{2}{*}{$\begin{array}{l}\text { Diagonal } \\
\text { crack } \\
\text { angle } \\
\text { (Degree) }\end{array}$} & \multirow[t]{2}{*}{$\begin{array}{l}\text { Crack } \\
\text { width, } \\
(\mathrm{mm})\end{array}$} \\
\hline & & SCC & ECC & & & & & & & & \\
\hline Full SCC & 1.53 & \multirow{4}{*}{59} & \multirow{4}{*}{73} & Shear & 5 & 0.91 & 40 & 84.55 & 3.17 & 40 & $0.05-0.90$ \\
\hline Full ECC & 1.53 & & & Shear & 5 & 1.34 & 60 & 116.07 & 3.05 & 40 & $0.10-0.45$ \\
\hline $\begin{array}{l}\text { E50-S50 (half } \\
\text { depth ECC) }\end{array}$ & 1.53 & & & Shear & 5 & 1.82 & 65 & 144.69 & 5.07 & 40 & $0.05-0.35$ \\
\hline $\begin{array}{c}\text { E25-S75 } \\
\text { (quarter depth } \\
\text { ECC) }\end{array}$ & 1.53 & & & Shear & 5 & 1.18 & 60 & 144.4 & 5.73 & 45 & $0.05-0.55$ \\
\hline $\mathrm{D}_{\mathrm{c}}:$ Defl & $\begin{array}{l}\text { tion a } \\
V_{\mathrm{fl}}: \mathrm{S}\end{array}$ & & nal & $\mathrm{V}_{c}:$ & $a r$ & $\mathrm{tdi}$ & 1 & $\mathrm{D}_{\mathrm{u}}: \mathrm{I}$ & ctio & $\begin{array}{l}\text { eck she } \\
\text { ratio }\end{array}$ & \\
\hline
\end{tabular}

Formation of the first flexural crack was observed at lower load around $5 \mathrm{kN}$ (Table 4.1) in all types of beams which is an indication of lower bending/flexural strength of shear beams. As the shear span to depth $(\mathrm{a} / \mathrm{d})$ ratio was same for all beams, the angle of dominant diagonal crack was nearly close to each other within the range of 40-45 degree. Diagonal shear crack loads varied from $47.3 \%$ to $51.7 \%$ of ultimate loads for "Full SCC" and "Full ECC" beams and 41.5 to $45 \%$ of ultimate loads for composite ECC/SCC beams. "Full SCC" and "Full ECC" beams had about 15 to 21 cracks at failure whereas "E50-S50" and "E25-S75" beams had around 34 to 46 cracks. So both composite ECC/SCC beams developed more cracks than full depth SCC and ECC beams at failure. The crack widths for "Full SCC" and "Full ECC" beams ranged from 0.05 to $0.9 \mathrm{~mm}$ whereas E50-S50 and E25-S75 composite beams showed significantly less crack width ranged from 0.05 to $0.55 \mathrm{~mm}$. In all beams, cracks were formed along the longitudinal tension steel at the bottom of the compression strut and the resulting failure mechanism is called shear-tension failure since all of these beams had the same effective span to depth ratio 1.53. Bearing failure was also noticed at the loading point on both composite ECC/SCC beams but occurred after dominant shear crack which did not effect on the shear performance of the composite beams. Overall, the failure modes of "Full SCC", "Full ECC" and E50-S50, E25-S75 composite beams were found similar. 

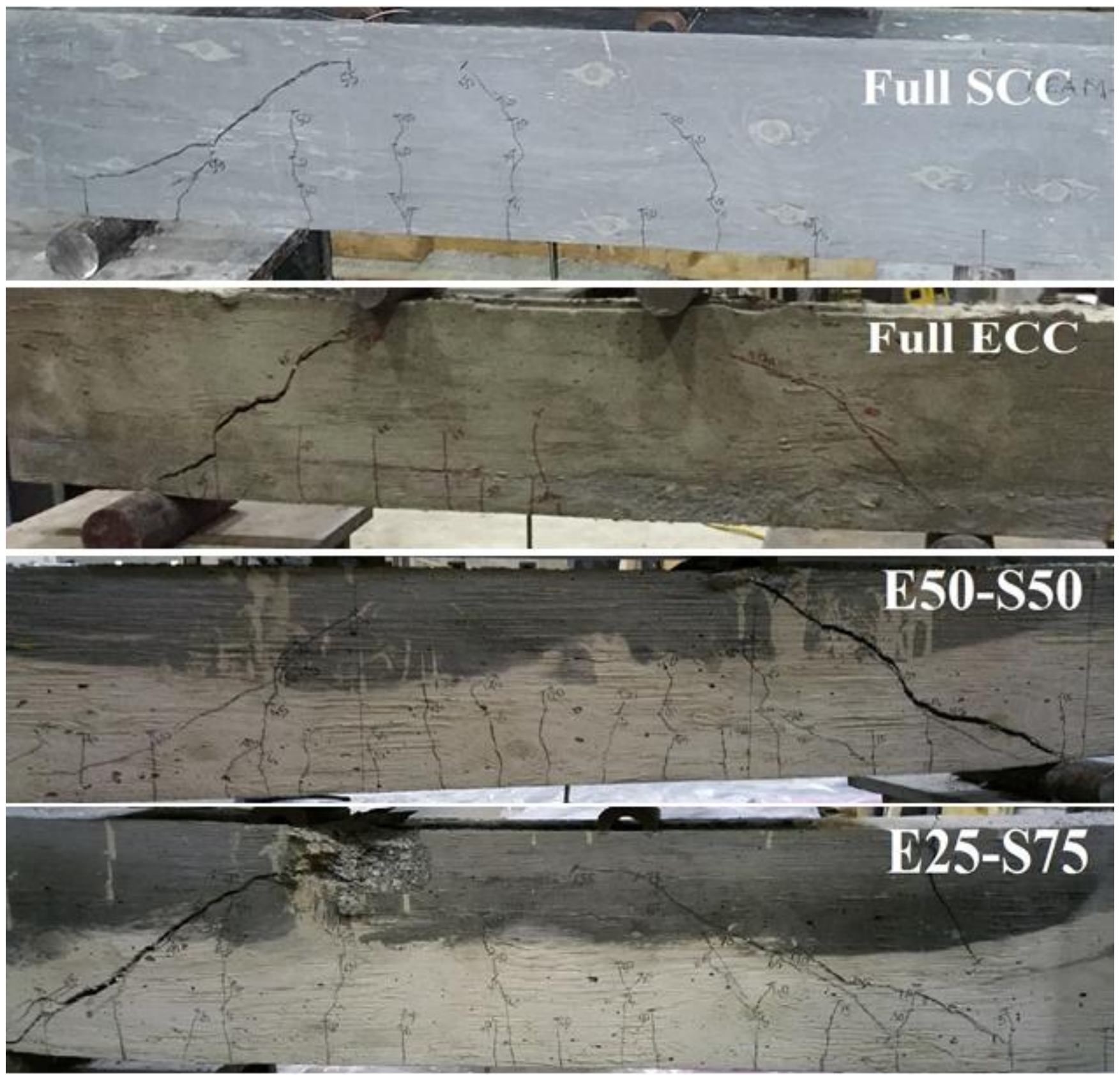

Figure 4.2: Failure modes and cracking patterns of tested shear beams without shear reinforcement 


\subsubsection{Post cracking shear resistance, ductility and energy absorption capacity}

Aggregate interlock mechanism and dowel action play significant roles in the increase of shear resistance from $V_{c}$ (shear resistance at the formation of inclined crack) to $V_{u}$ (ultimate shear resistance or peak load). In this study, the shear at the first diagonal crack is denoted as concrete shear resistance $\left(\mathrm{V}_{\mathrm{c}}\right)$ and it was identified from the visual observation during the testing of "Full SCC", "Full ECC", and E50-S50, E25-S75 composite beams. The ultimate shear resistance ( $\left.\mathrm{V}_{\mathrm{u}}\right)$ was identified from the maximum load (peak load) that a beam can carry before failure. It is important to analyze the post cracking shear resistance of concrete beams due to aggregate interlock and dowel action to characterize the performance of "Full SCC", "Full ECC", and E50-S50, E25-S75 composite beams. Similar analysis was carried out by previous researchers, Lachemi et al. (2005) and Hassan et al. (2010), by introducing a shear resistance factor (SRF). SRF is defined as the ratio of the failure load to the load at the first diagonal crack as per Equation 4.1:

$\mathrm{SRF}=\mathrm{V}_{\mathrm{u}} / \mathrm{V}_{\mathrm{c}}$.

The post cracking shear ductility was defined as the ratio of the deflection at failure load to the deflection at first diagonal crack load by previous researcher Hassan et al. (2010). In this study, ductility of the shear beam is also defined by the ductility factor (DF) as per Equation 4.2:

$\mathrm{DF}=\mathrm{D}_{\mathrm{u}} / \mathrm{D}_{\mathrm{c}}$

where, $D_{c}$ and $D_{u}$ are the deflection at first diagonal crack and peak/failure load, respectively as presented in Table 4.1 .

Table 4.2: SRF, DF, energy absorption capacity, and contribution of aggregate_dowel actions for the shear beams without shear reinforcement

\begin{tabular}{|c|c|c|c|c|c|}
\hline Beam code & $\begin{array}{c}\text { Shear span } \\
\text { to depth } \\
\text { ratio (a/d) }\end{array}$ & $\begin{array}{c}\text { Shear } \\
\text { resistance } \\
\text { factor (SRF) }\end{array}$ & $\begin{array}{c}\text { Ductility } \\
\text { factor } \\
\text { (DF) }\end{array}$ & $\begin{array}{c}\text { Energy } \\
\text { absorption } \\
\text { capacity at } \\
85 \% \text { ultimate } \\
\text { load (J) }\end{array}$ & $\begin{array}{c}\text { Contribution of } \\
\text { aggregate_dowel } \\
\text { actions (\%) }\end{array}$ \\
\hline Full SCC & 1.53 & 2.11 & 3.48 & 162.1 & 52 \\
\hline Full ECC & 1.53 & 1.93 & 2.27 & 333.6 & 48 \\
\hline E50-S50 (half depth ECC) & 1.53 & 1.93 & 2.78 & 654.8 & 48 \\
\hline E25-S75 (quarter depth ECC) & 1.53 & 2.22 & 4.84 & 714.4 & 55 \\
\hline
\end{tabular}


Shear resistance factor and ductility factor for the shear beams without shear reinforcement are shown in Table 4.2. Main portion of the shear is transferred through aggregate interlock mechanism and dowel action in the post-cracking stage. When considering the aggregate interlock mechanism, coarse aggregate content and its quality affect the post-cracking -stage shear transfer capacity. Table 4.2 shows that "Full SCC" and E25-S75 composite beams exhibit higher SRF because of the presence of higher percentage of aggregate (especially coarse aggregate in SCC) than their "Full ECC" and E50-S50 counterparts. On the other hand, shear ductility (defined by DF) of "Full SCC" and E25-S75 composite beams was also found about $9 \%$ to $15 \%$ higher than corresponding "Full ECC" and E50S50 beams.

Energy absorption capacity of all beams was calculated by area under the shear load vs deflection curve (Figure 4.1) up to the post peak shear of $85 \%$ of the ultimate shear load $\left(\mathrm{V}_{\mathrm{u}}\right)$ and presented in Table 4.2. E50-S50 and E25-S75 beams absorbed respectively 4 and 4.4 times higher energy than "Full SCC" beam and 1.96 and 2.14 times higher energy than "Full ECC" beam, respectively.

Figure 4.3 and Figure 4.4 show the graphical comparison of shear resistance factor (SRF), ductility factor (DF) and energy absorption capacity of shear beams without shear reinforcement, respectively.

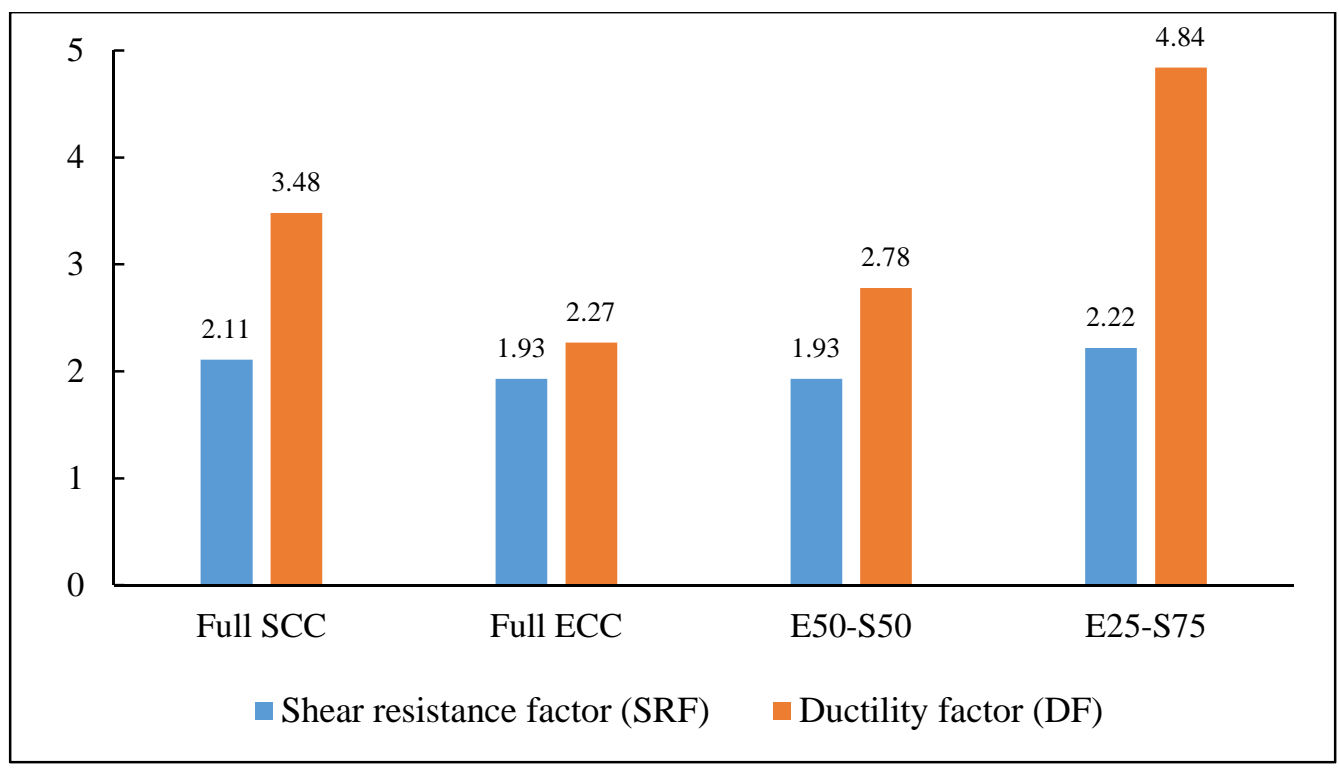

Figure 4.3: Comparison between SRF and DF of shear beams without shear reinforcement 


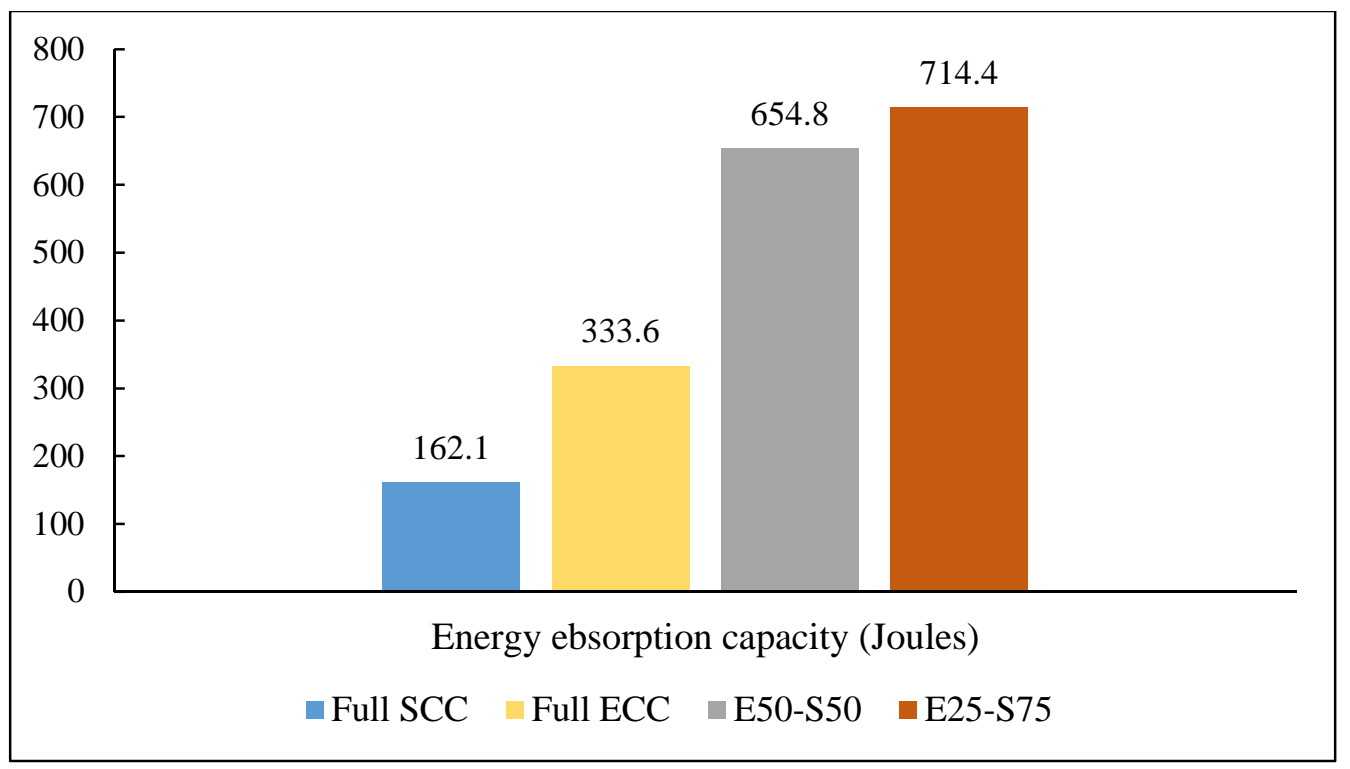

Figure 4.4: Energy absorption capacity of shear beams without shear reinforcement

\subsection{ECC, SCC and composite ECC/SCC shear beams with shear reinforcement}

Experimental tests had been carried out to study the shear behavior of the composite ECC/SCC beams compared to full depth ECC and SCC beams. Total four (one full depth ECC, one full depth SCC and two composite ECC/SCC beams with different height ratio) shear beams with shear reinforcement were tested under four point loading to failure. ECC and SCC were used to cast all beams. Shear span to effective depth ratio (a/d) was kept constant as 1.53 as well as adequate flexural reinforcement was provided with the reinforcement ratio of $1.14 \%$ for all beams. Shear reinforcement was provided within the shear span of the beam at $133 \mathrm{~mm}$ of center to center spacing but no shear reinforcement was provided within the zero shear regions.

\subsubsection{Load vs deflection behavior}

Load vs mid span deflection responses for the beams with shear reinforcements are shown in Figure 4.5. The initial straight line segment of the curve shows that stiffness of the beam was constant similar to beams without shear reinforcement prior to flexural cracking. After formation of the inclined crack, a small reduction in the slope was observed but reduction in the slope for beams without shear reinforcement were high. This indicates that the beam with shear reinforcement were stiffer than those without shear reinforcement after the formation of inclined cracks. 
Even after the formation of inclined crack, deflection curve was almost straight line prior to failure or until yielding of reinforcement. All shear beams with shear reinforcement failed at a much higher load than those beams without shear reinforcement (Figure 4.1 and Figure 4.5), as expected. The ultimate load capacity for "Full SCC-S" and "Full ECC-S" beams was about 15 to $37 \%$ higher than the beams without shear reinforcement, whereas E50-S50-S and E25-S75-S composite beams showed 3.5 to $4.5 \%$ higher capacity compared to the shear beams without shear reinforcement because of the fiber bridging and micro cracking characteristics (with very low crack width) of ECC. The mid span deflection at failure load ranged from 3.25-5.23 $\mathrm{mm}$ for shear beams with shear reinforcement whereas 3.17-5.73 $\mathrm{mm}$ for shear beams without shear reinforcement (Figure 4.5 and Figure 4.1).

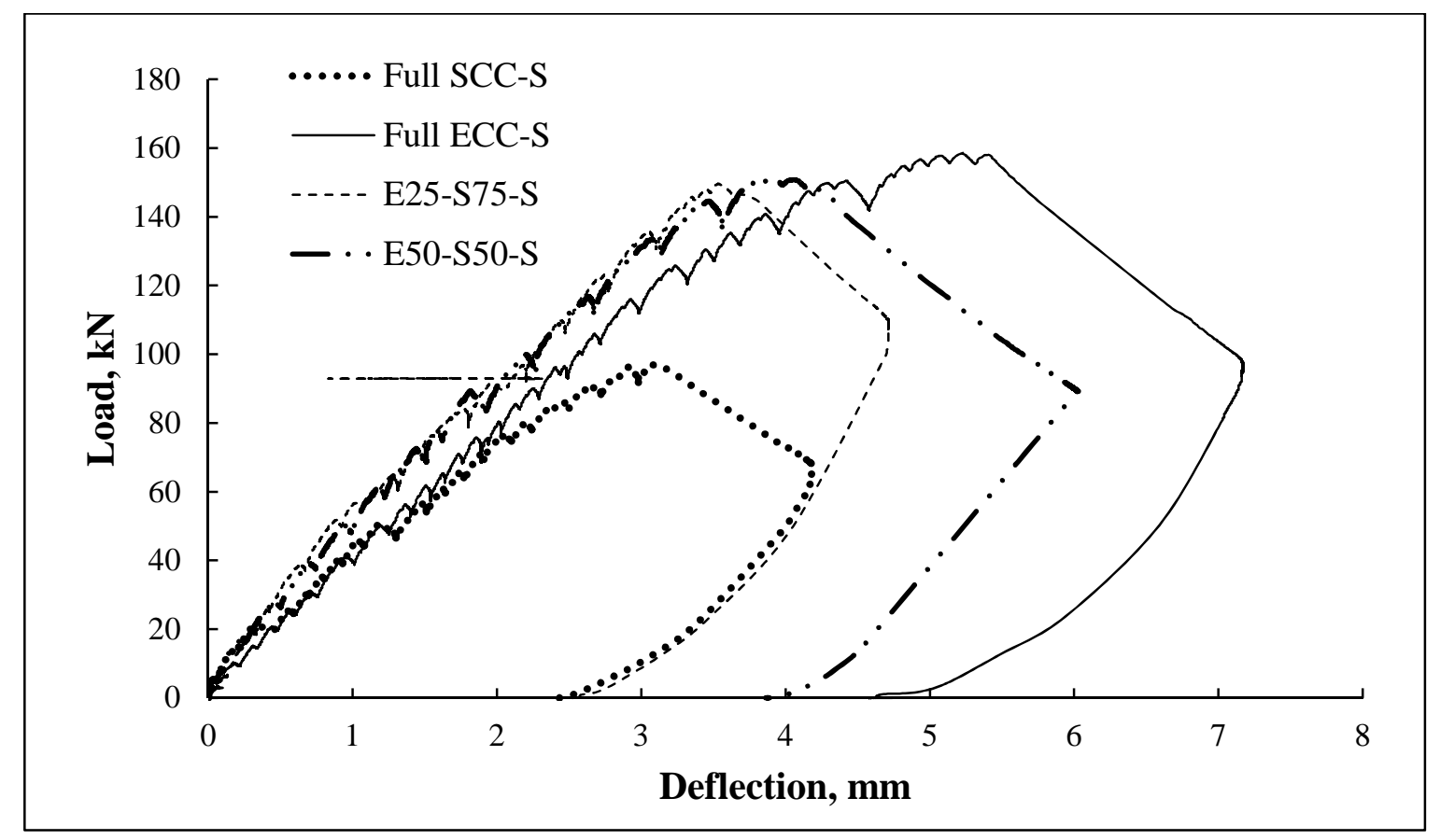

Figure 4.5: Load vs mid span deflection responses for shear beams with shear reinforcement 


\subsubsection{Failure mode and cracking behavior}

Figure 4.6(a-d) shows the failure mode and cracking pattern in the ECC, SCC and composite ECC/SCC shear beams with shear reinforcement. The crack pattern of all of the beams with shear reinforcement is almost similar to those without shear reinforcement until the formation of diagonal cracks but beams with shear reinforcement showed higher load carrying capacity after the formation of diagonal crack until failure. The angle of dominant diagonal crack was approximately within the range of 25-45 degree which was significantly less than the beams without shear reinforcement. Inclined cracks intersected through many shear reinforcement. Table 4.3 summarizes experimental results indicating concrete compressive strength, failure modes, shear loads at first flexure/diagonal crack, deflection at first diagonal crack, peak shear load, peak load/ deflection and angle of diagonal crack of the shear beams with shear reinforcement.

Table 4.3: Summary of experimental results for tested shear beams with shear reinforcement

\begin{tabular}{|c|c|c|c|c|c|c|c|c|c|c|c|}
\hline \multirow[t]{2}{*}{ Beam code } & \multirow[t]{2}{*}{$(\mathrm{a} / \mathrm{d})$} & \multicolumn{2}{|c|}{$\begin{array}{c}\text { Concrete } \\
\text { strength } \\
(\mathrm{MPa})\end{array}$} & \multirow[t]{2}{*}{$\begin{array}{l}\text { Failure } \\
\text { pattern }\end{array}$} & \multirow[t]{2}{*}{$\begin{array}{c}\mathrm{V}_{\mathrm{fl}} \\
(\mathrm{kN})\end{array}$} & \multirow[t]{2}{*}{$\begin{array}{c}\mathrm{D}_{\mathrm{c}} \\
(\mathrm{mm})\end{array}$} & \multirow[t]{2}{*}{$\begin{array}{c}\mathrm{V}_{\mathrm{c}} \\
(\mathrm{kN})\end{array}$} & \multirow[t]{2}{*}{$\begin{array}{c}\mathrm{V}_{\mathrm{u}} \\
(\mathrm{kN})\end{array}$} & \multirow[t]{2}{*}{$\begin{array}{c}\mathrm{D}_{\mathrm{u}} \\
(\mathrm{mm})\end{array}$} & \multirow{2}{*}{$\begin{array}{c}\text { Diagonal } \\
\text { crack } \\
\text { angle } \\
\text { (Degree) }\end{array}$} & \multirow[t]{2}{*}{$\begin{array}{l}\text { Crack } \\
\text { width, } \\
(\mathrm{mm})\end{array}$} \\
\hline & & SCC & $\mathrm{ECC}$ & & & & & & & & \\
\hline Full SCC-S & 1.53 & \multirow{4}{*}{59} & \multirow{4}{*}{73} & Shear & 5 & 1.35 & 50 & 97.2 & 3.25 & 30 & $0.10-0.75$ \\
\hline Full ECC-S & 1.53 & & & Shear & 4 & 1.76 & 75 & 158.6 & 5.23 & 45 & $0.05-0.45$ \\
\hline $\begin{array}{c}\text { E50-S50-S (half } \\
\text { depth ECC) }\end{array}$ & 1.53 & & & Shear & 5 & 1.58 & 70 & 151.5 & 4.09 & 35 & $0.05-0.25$ \\
\hline $\begin{array}{c}\text { E25-S75-S (quarter } \\
\text { depth ECC) }\end{array}$ & 1.53 & & & Shear & 5 & 1.34 & 65 & 149.7 & 3.93 & 25 & $0.10-0.50$ \\
\hline \multicolumn{12}{|c|}{$\mathrm{D}_{\mathrm{c}}$ : Deflection at first diagonal crack; $\mathrm{V}_{\mathrm{c}}$ : Shear at first diagonal crack; $\mathrm{D}_{\mathrm{u}}$ : Deflection at peck shear load; } \\
\hline
\end{tabular}

Shear reinforcement helped to increase the load immediately after the formation of inclined cracks. Properly spaced shear reinforcement kept the inclined crack together without further opening of shear crack. The crack widths for "Full SCC-S" and "Full ECC-S" beams ranged from 0.1 to 0.75 mm whereas E50-S50-S and E-25-S75-S composite beams showed significantly less crack width ranged from 0.05 to $0.50 \mathrm{~mm}$. Shear beams with shear reinforcement showed less crack width than 
shear beams without shear reinforcement. Concrete crushing was noticed only on E50-S50-S (Figure 4.6c) composite beam occurred near the loading point at ultimate stage and final failure mechanism was shear compression failure. Overall, the failure modes of "Full SCC-S", "Full ECCS" and E50-S50-S, E25-S75-S composite beams were found similar (Figure 4.6a-d).

The diagonal crack was identified by two methods during testing, one was by visual inspection on cracking and the other was by strain data in the shear reinforcement. Diagonal shear cracking loads varied from 43 to $51 \%$ of ultimate loads for shear beams with shear reinforcement and 45 to $52 \%$ of ultimate loads for shear beams without shear reinforcement. "Full SCC-S" beam had developed around 18 cracks at failure whereas "Full ECC-S", E50-S50-S and E25-S75-S beams had developed around $34-44$ cracks because of the presence of fiber in ECC, as expected (Figure 4.6a-d).

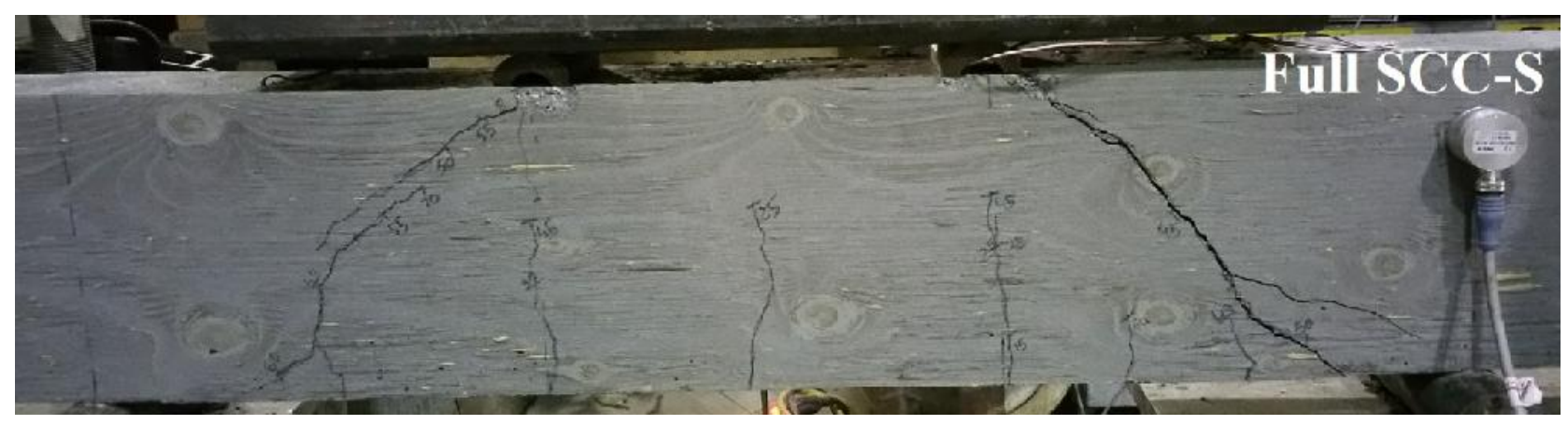

Figure 4.6a: Failure mode and cracking pattern of tested "Full SCC-S" shear beam

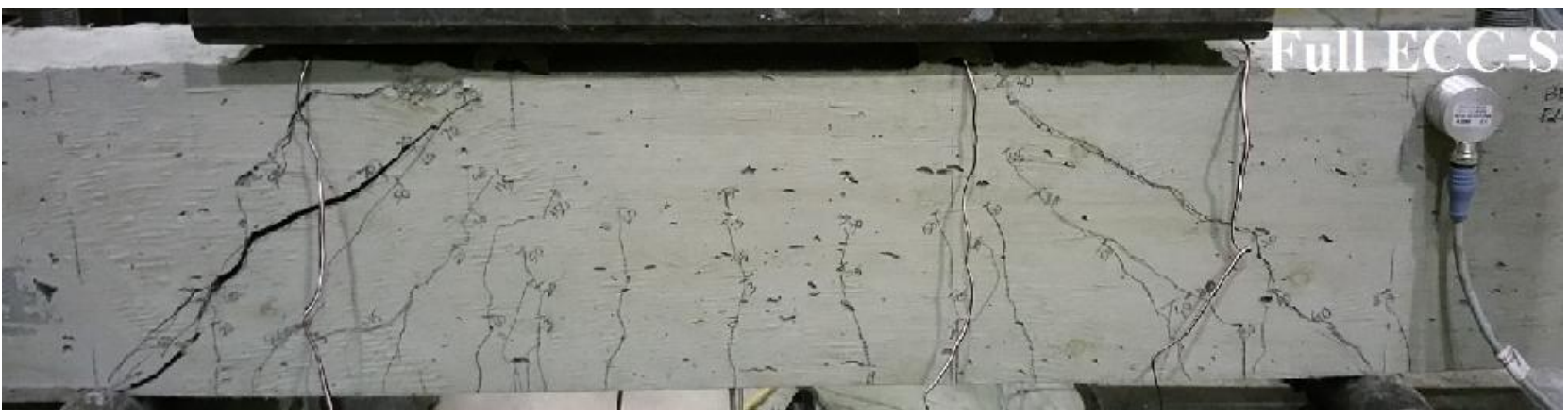

Figure 4.6b: Failure mode and cracking pattern of tested "Full ECC-S" shear beam 


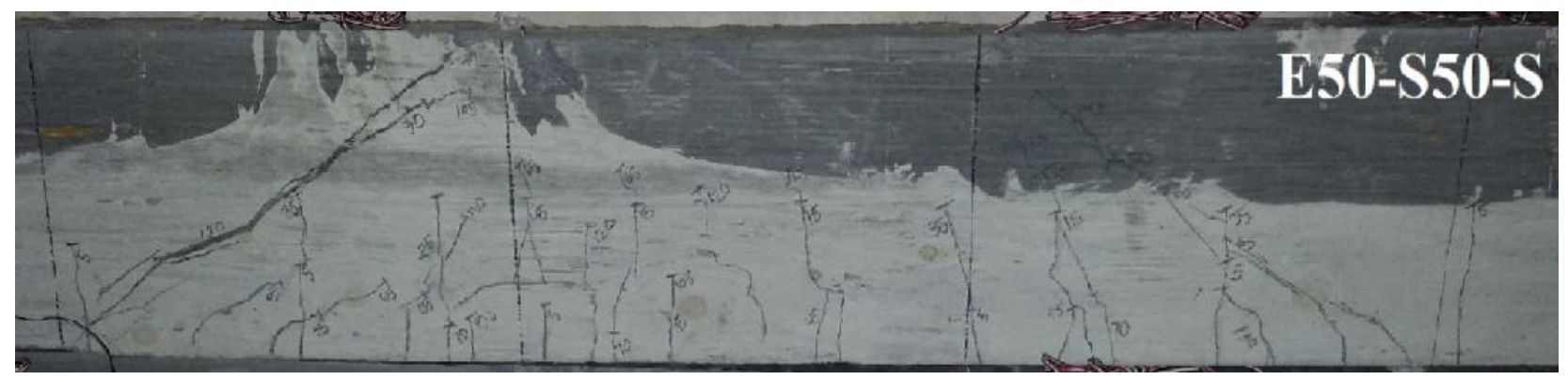

Figure 4.6c: Failure mode and cracking pattern of tested "E50-S50-S" composite shear beam

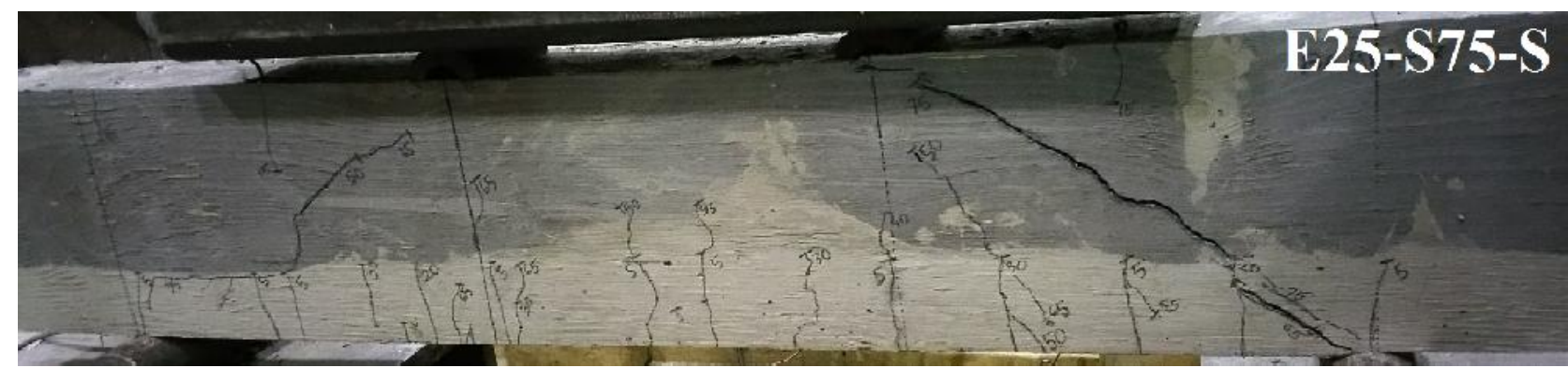

Figure 4.6d: Failure mode and cracking pattern of tested "E25-S75-S" composite shear beam

\subsubsection{Strain development in the flexural and shear reinforcement}

Load vs rebar strain curves for shear beams with shear reinforcement are shown in Figure 4.7(a-d). For "Full SCC-S", "Full ECC-S" and E25-S75-S beams, the yielding of bottom flexural reinforcement occurred between diagonal cracking and failure (Figure 4.7a, b and d). As a result yielding of flexural reinforcement did not affect the load at first inclined crack. Even though flexural reinforcement yielded first in these three beams (Figure 4.7a, b and d), ultimate failure mode was shear due to the larger shear reinforcement spacing and this spacing was not adequate to keep the inclined crack together without further widening. On the other hand, E50-S50-S beam failed before yielding of the bottom reinforcement (Figure 4.7c). Shear reinforcement did not yield for any of the shear beams with shear reinforcement (Figure 4.7a-d). Therefore, failure of all of the shear beams with shear reinforcement occurred before yielding of shear reinforcement by widening of the inclined crack following concrete crushing at the loading point (Figure 4.6). Table 4.4 summarizes the values of strain at first inclined cracking in shear and flexural rebar as well as loads at which shear and flexural rebar yielded. 


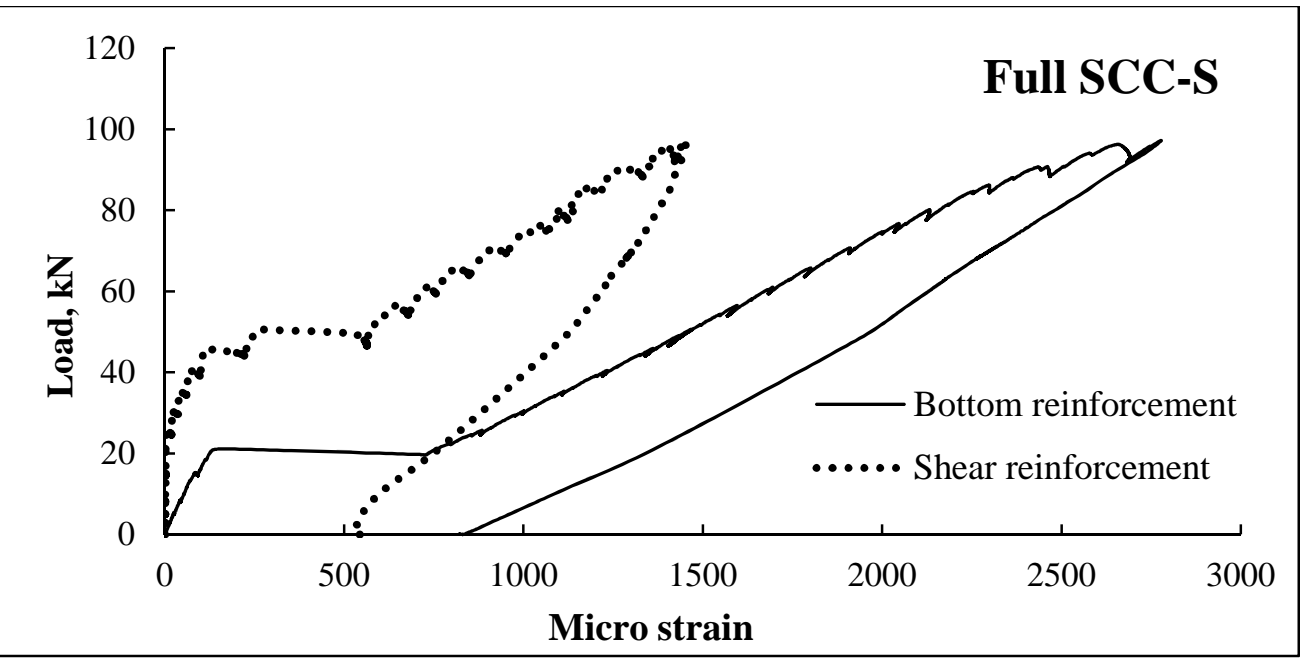

Figure 4.7a: Load vs rebar strain curves for tested "Full SCC-S" shear beam

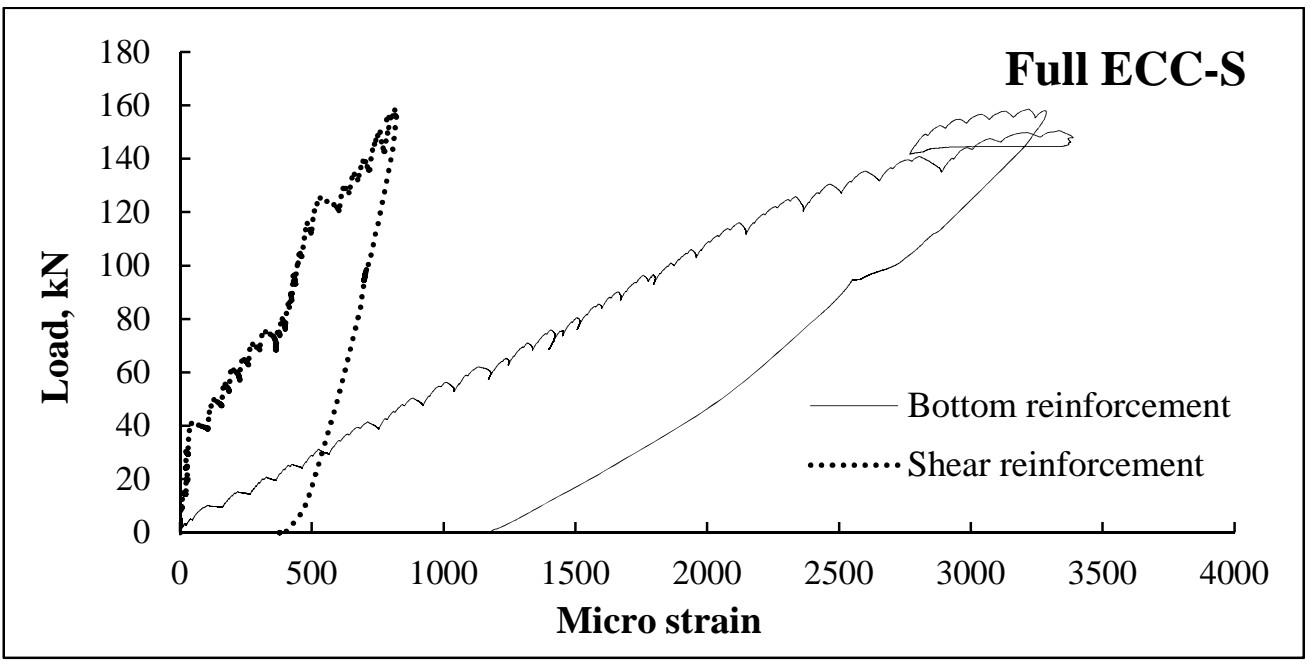

Figure 4.7b: Load vs rebar strain curves for tested "Full ECC-S" shear beam

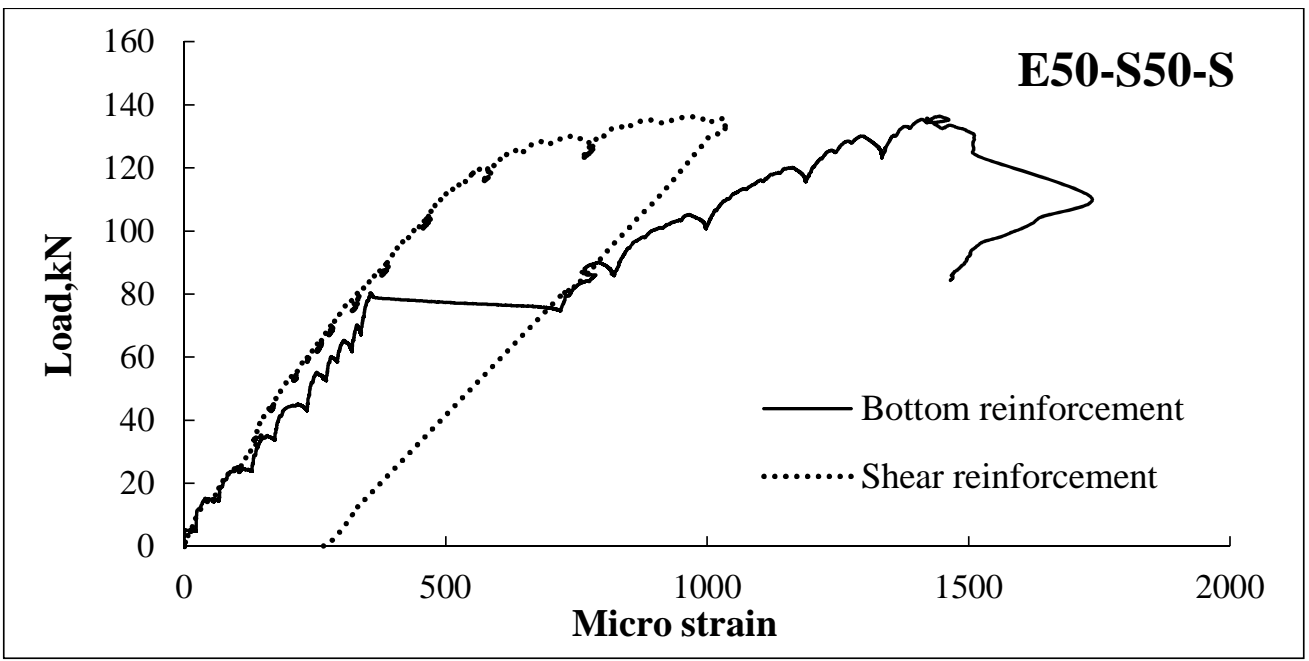

Figure 4.7c: Load vs rebar strain curves for tested E50-S50-S composite shear beam 


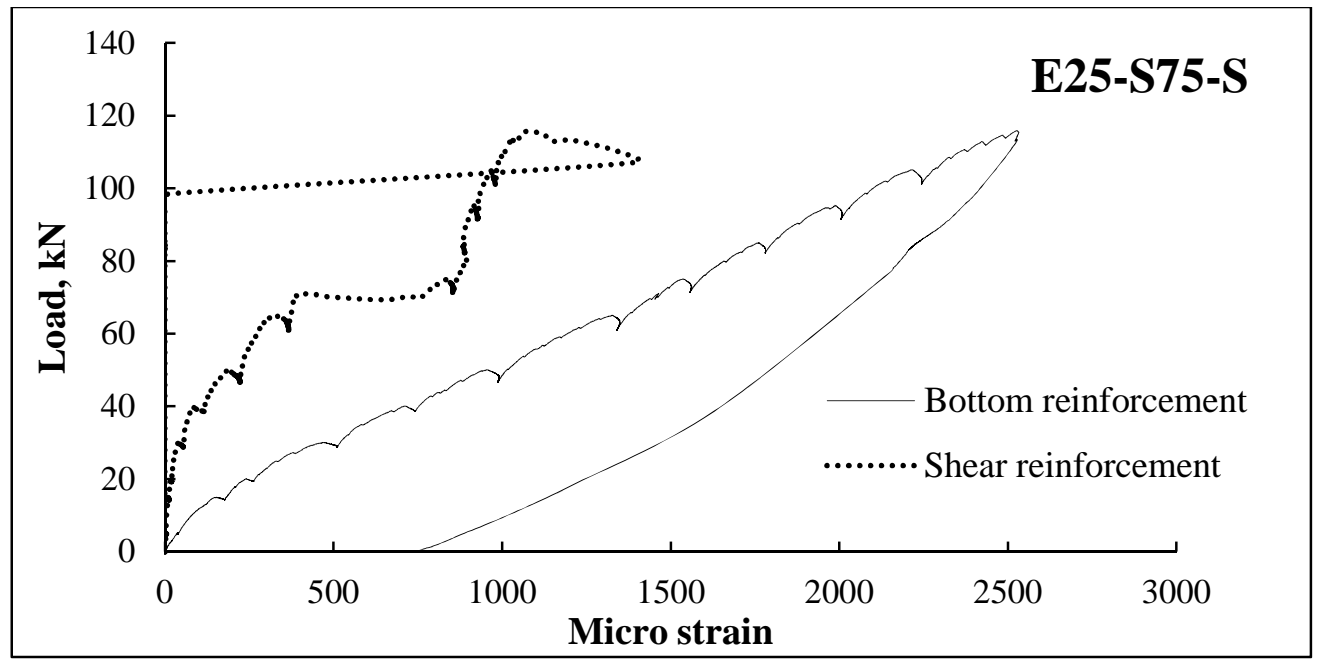

Figure 4.7d: Load vs rebar strain curves for tested E25-S75-S composite shear beam

Table 4.4: Experimental strain values of tested shear beams with shear reinforcement

\begin{tabular}{|c|c|c|c|c|c|c|c|}
\hline \multirow[b]{3}{*}{ Beam code } & \multirow[b]{3}{*}{$\begin{array}{l}\text { Failure } \\
\text { mode }\end{array}$} & \multicolumn{4}{|c|}{ Steel strain } & \multirow{2}{*}{\multicolumn{2}{|c|}{ Shear load $(\mathrm{kN})$}} \\
\hline & & \multicolumn{2}{|c|}{ Stirrup (micro strain) } & \multicolumn{2}{|c|}{$\begin{array}{l}\text { Bottom flexural } \\
\text { rebar (micro strain) }\end{array}$} & & \\
\hline & & $\begin{array}{c}\text { At first } \\
\text { diagonal } \\
\text { cracking } \\
\text { stage }\end{array}$ & $\begin{array}{c}\text { At } \\
\text { ultimate } \\
\text { stage }\end{array}$ & $\begin{array}{l}\text { At first } \\
\text { diagonal } \\
\text { cracking } \\
\text { stage }\end{array}$ & $\begin{array}{c}\text { At } \\
\text { ultimate } \\
\text { stage }\end{array}$ & $\begin{array}{c}\text { At } \\
\text { stirrup } \\
\text { yielding }\end{array}$ & $\begin{array}{l}\text { At bottom } \\
\text { flexural } \\
\text { rebar } \\
\text { yielding }\end{array}$ \\
\hline Full SCC-S & Shear & 257 & 1456 & 1455 & 2777 & NA & 87.5 \\
\hline Full ECC-S & Shear & 82 & 814 & 514 & 3220 & NA & 123.68 \\
\hline E50-S50-S (half depth ECC) & Shear & 281 & 976 & 330 & 1444 & NA & NA \\
\hline $\begin{array}{c}\text { E25-S75-S (quarter depth } \\
\text { ECC) }\end{array}$ & Shear & 188 & 1078 & 952 & 2527 & NA & 109.93 \\
\hline
\end{tabular}

\subsection{FLEXURAL BEAMS}

\subsubsection{General}

Three singly reinforced beams (one full depth SCC, one full depth ECC and one composite ECC/SCC) were tested under four point loading. Shear span to effective depth ratio $(\mathrm{a} / \mathrm{d})$ and the flexural reinforcement ratio were kept constant at 5.72 and $0.66 \%$ respectively for each of the beams. Adequate shear reinforcement was provided within the beam except at the zero shear regions of $700 \mathrm{~mm}$ (pure bending region). Details of these beams were discussed in Chapter three. 


\subsubsection{Load vs deflection behavior}

Figure 4.9(a-c) shows the experimental load vs deflection curves for singly reinforced full depth SCC, full depth ECC and composite ECC/SCC flexural beams. Total span of the beam was 3000 $\mathrm{mm}$ and deflection was recorded at 3 different locations; at $750 \mathrm{~mm}$ from the left support $(\mathrm{X}=750$ $\mathrm{mm})$, at mid span $(X=1500 \mathrm{~mm})$, and at $2250 \mathrm{~mm}$ from the left support $(X=2250 \mathrm{~mm})$. The deflection responses were closely linear (constant slope) up to first flexural crack in all three beams. After formation of the flexural cracks, changes in slope of the load-deflection curves were identified and the slope of the post cracking response remained reasonably linear until yielding of the reinforcement occurred.

Beam stiffness changed dramatically, when yielding of reinforcement occurred. The LVDTs close to the left and right supports $(X=750 \mathrm{~mm}$ and $2250 \mathrm{~mm}$ ) recorded nearly same deflection until the yielding of reinforcement occurred, as expected. However, mid span deflection was about two times higher than those recorded near the supports (Figure 4.9a-c) until the yielding of reinforcement.

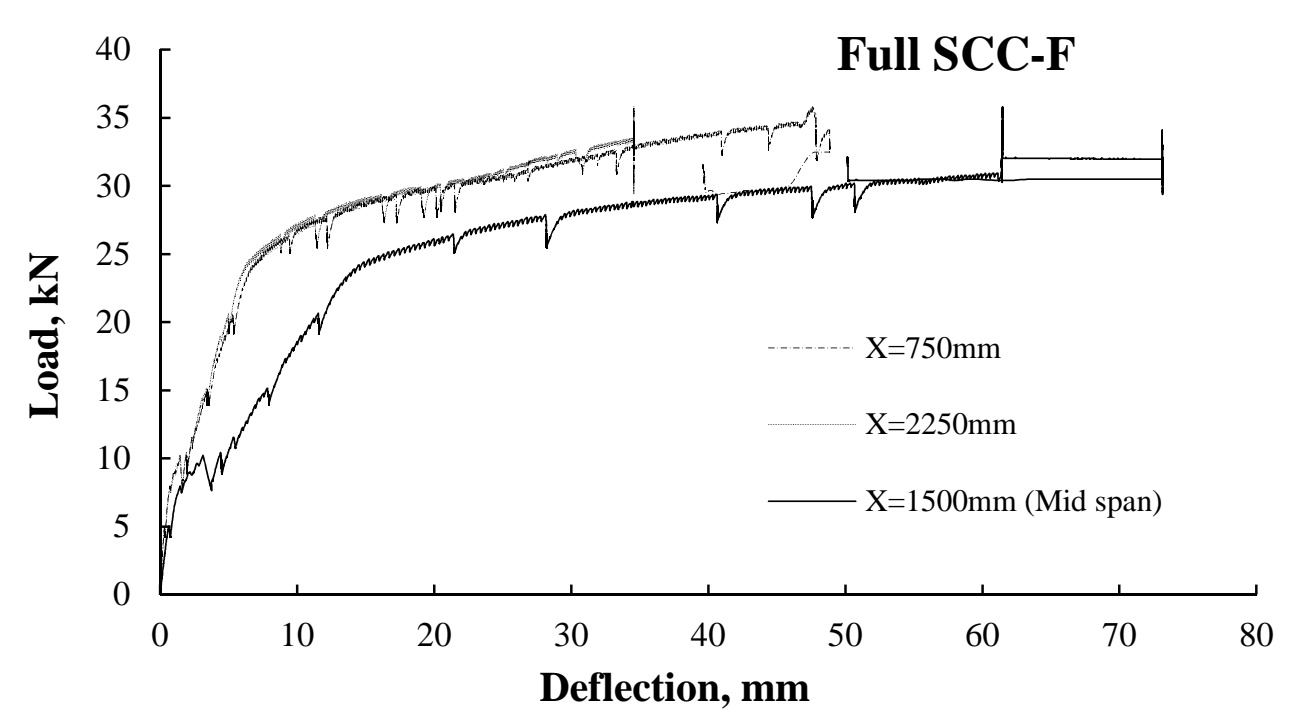

Figure 4.9a: Load vs deflection curve for tested "Full SCC-F" flexural beam 


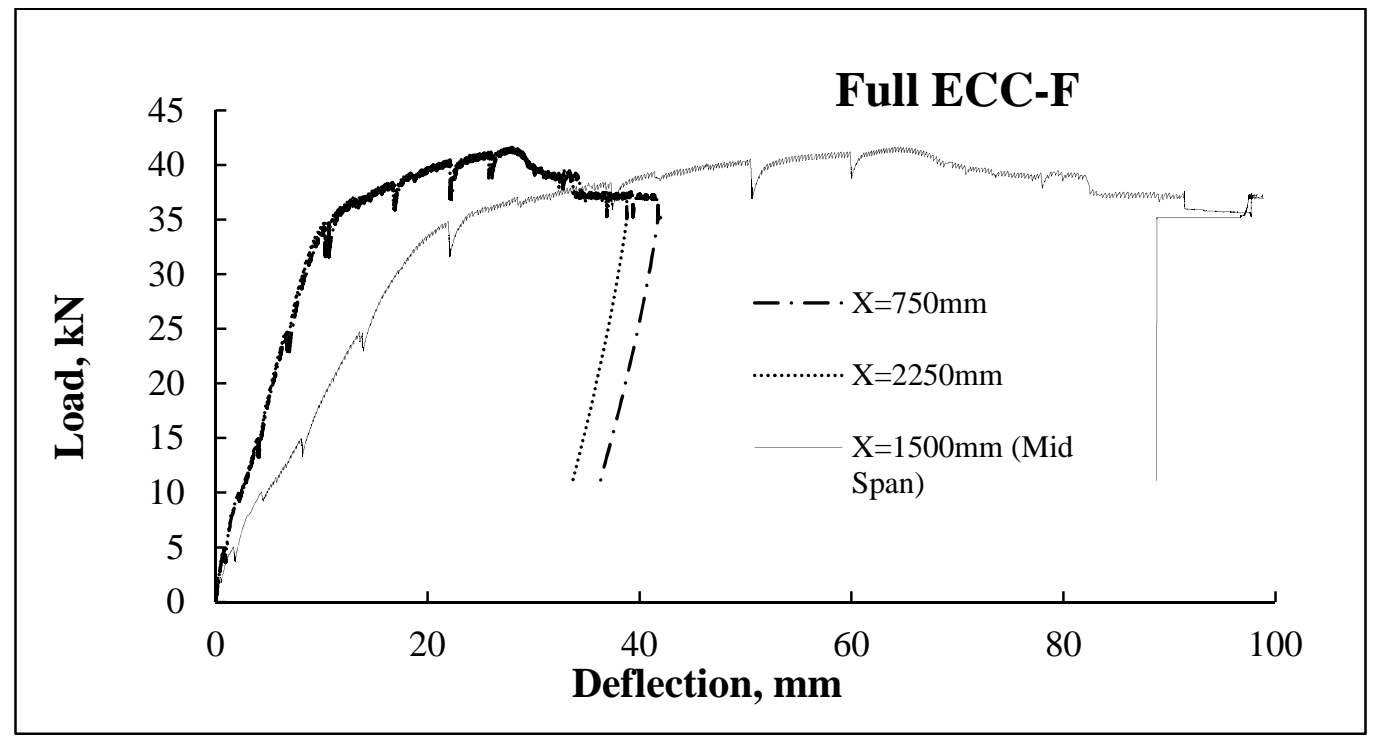

Figure 4.9b: Load vs deflection curve for tested "Full ECC-F" flexural beam

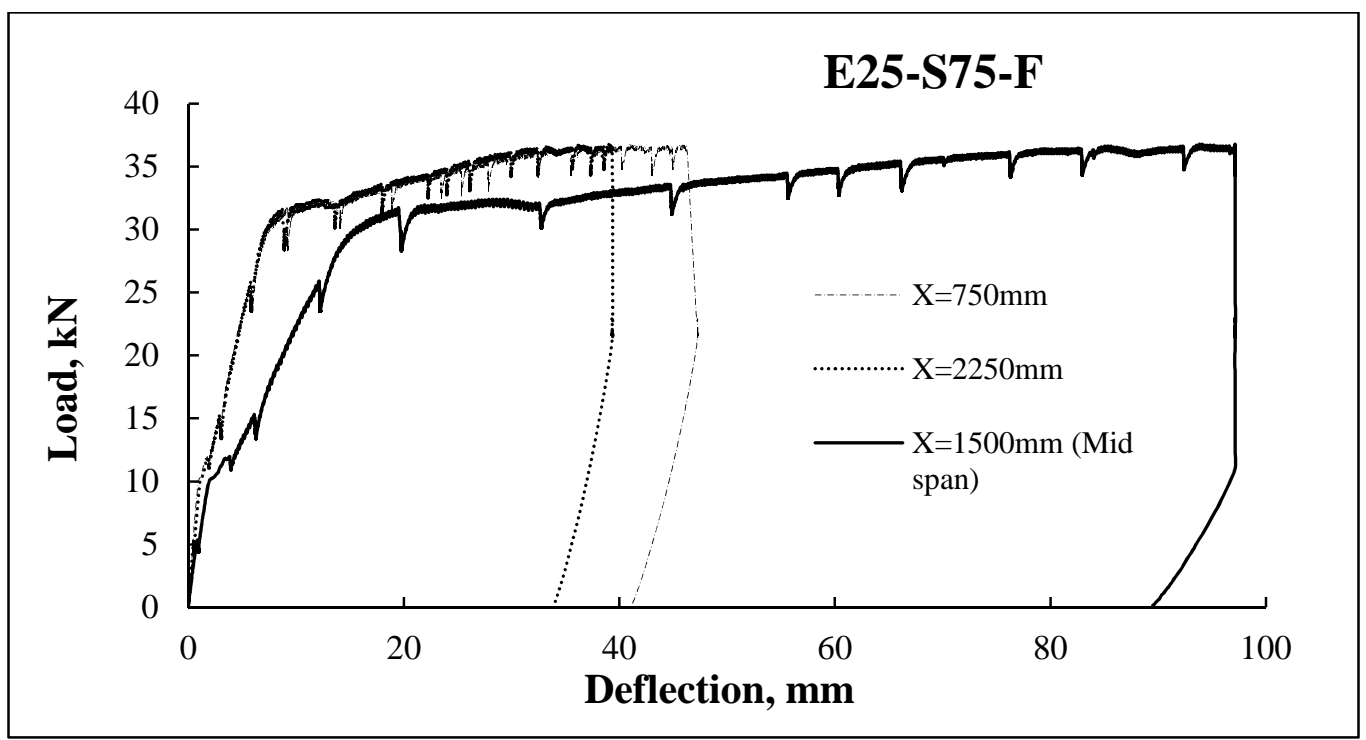

Figure 4.9c: Load vs deflection curve for tested E25-S75-F composite flexural beam 


\subsubsection{Failure mode, crack pattern and ultimate load capacity}

Formation of cracks was marked on the beam at every $10 \mathrm{kN}$ load interval during testing. Figure 4.10 (a-c) shows the crack pattern and failure modes of "Full SCC-F", "Full ECC-F" and "E25S75-F" flexural beams, respectively. All beams exhibited flexural mode of failure by the development of flexural cracks. First hairline vertical flexural cracks were formed within the mid span of all three beams (zero shear regions). Table 4.5 summarizes experimental results indicating concrete compressive/flexural strength of ECC and SCC, failure modes of the beam, and loads at first flexure/diagonal crack, ultimate load and number of cracks. The load at first vertical flexural crack occurred at mid span was about $5 \mathrm{kN}, 6 \mathrm{kN}$ and $5.5 \mathrm{kN}$ for "Full SCC-F", "Full ECC-F" and "E25-S75-F" beams, respectively which was at about 14\% to 15\% of their ultimate failure load.

New hairline cracks were found within the zero shear regions (maximum moment) as well as in the shear span upon further increase in load. At the same time, with the increase in load, the existing cracks were propagated from the bottom of the beam towards the top loading point. At the failure stage, cracks propagated to the top of the beam within the mid span region and failure also occurred within the same region showing flexural failure (Figure $4.10 \mathrm{a}-\mathrm{c}$ ).

No shear crack was identified in any of the flexural beams. Failure of the beams associated with crushing of the concrete was occurred long after the yielding of flexural reinforcing steels. The total

ultimate load (moment) at beam failure were $35.8 \mathrm{kN}(20.58 \mathrm{kNm}), 41.65 \mathrm{kN}(23.95 \mathrm{kNm})$ and $36.77 \mathrm{kN}(21.14 \mathrm{kNm})$ for "Full SCC-F", "Full ECC-F" and "E25-S75-F" beams respectively. Number of cracks was also higher for "Full ECC-F" and "E25-S75-F" beams as expected because of the fiber bridging characteristics of ECC. 
Table 4.5: Summary of loads, moment and failure modes of experimented flexural beams

\begin{tabular}{|c|c|c|c|c|c|c|c|c|c|}
\hline Beam code & $\begin{array}{c}\mathrm{f}_{\mathrm{c}}^{\prime} \\
\mathrm{SCC} \\
(\mathrm{MPa})\end{array}$ & $\begin{array}{c}\mathrm{f}_{c}^{\prime}, \\
\mathrm{ECC} \\
(\mathrm{MPa})\end{array}$ & $\begin{array}{c}\text { Concrete } \\
\text { flexural } \\
\text { strength, } \\
\text { SCC } \\
\text { (MPa) }\end{array}$ & $\begin{array}{c}\text { Concrete } \\
\text { flexural } \\
\text { strength, } \\
\text { ECC } \\
\text { (MPa) }\end{array}$ & $\begin{array}{l}\text { Failure } \\
\text { mode }\end{array}$ & $\begin{array}{c}\text { First } \\
\text { flexural } \\
\text { crack } \\
\text { load* } \\
(\mathrm{kN})\end{array}$ & $\begin{array}{l}\text { First } \\
\text { web } \\
\text { shear } \\
\text { crack } \\
\text { load* } \\
(\mathrm{kN})\end{array}$ & $\begin{array}{c}\text { Ultimate } \\
\text { load* } \\
\text { (Moment) } \\
\text { kN(kNm) }\end{array}$ & $\begin{array}{c}\text { \# } \\
\text { cracks } \\
\text { at } \\
\text { failure }\end{array}$ \\
\hline Full SCC-F & \multirow{3}{*}{59} & \multirow{3}{*}{73} & \multirow{3}{*}{3.2} & \multirow{3}{*}{5.1} & Flexural & 5 & NA & $35.8(20.58)$ & 53 \\
\hline Full ECC-F & & & & & Flexural & 6 & NA & $41.65(23.95)$ & 72 \\
\hline $\begin{array}{c}\text { E25-S75-F } \\
\text { (quarter depth } \\
\text { ECC) }\end{array}$ & & & & & Flexural & 5.5 & NA & $36.77(21.14)$ & 63 \\
\hline $\begin{array}{r}\mathrm{f}_{\mathrm{c}}^{\prime} \text { : Compres } \\
\text { beams; }\end{array}$ & ren & 1: $\mathrm{C}$ & $t$ at 5. & d: Cor & at 0.7 & exura & $\mathrm{brc}$ & ratio: 0.66 & for all \\
\hline
\end{tabular}
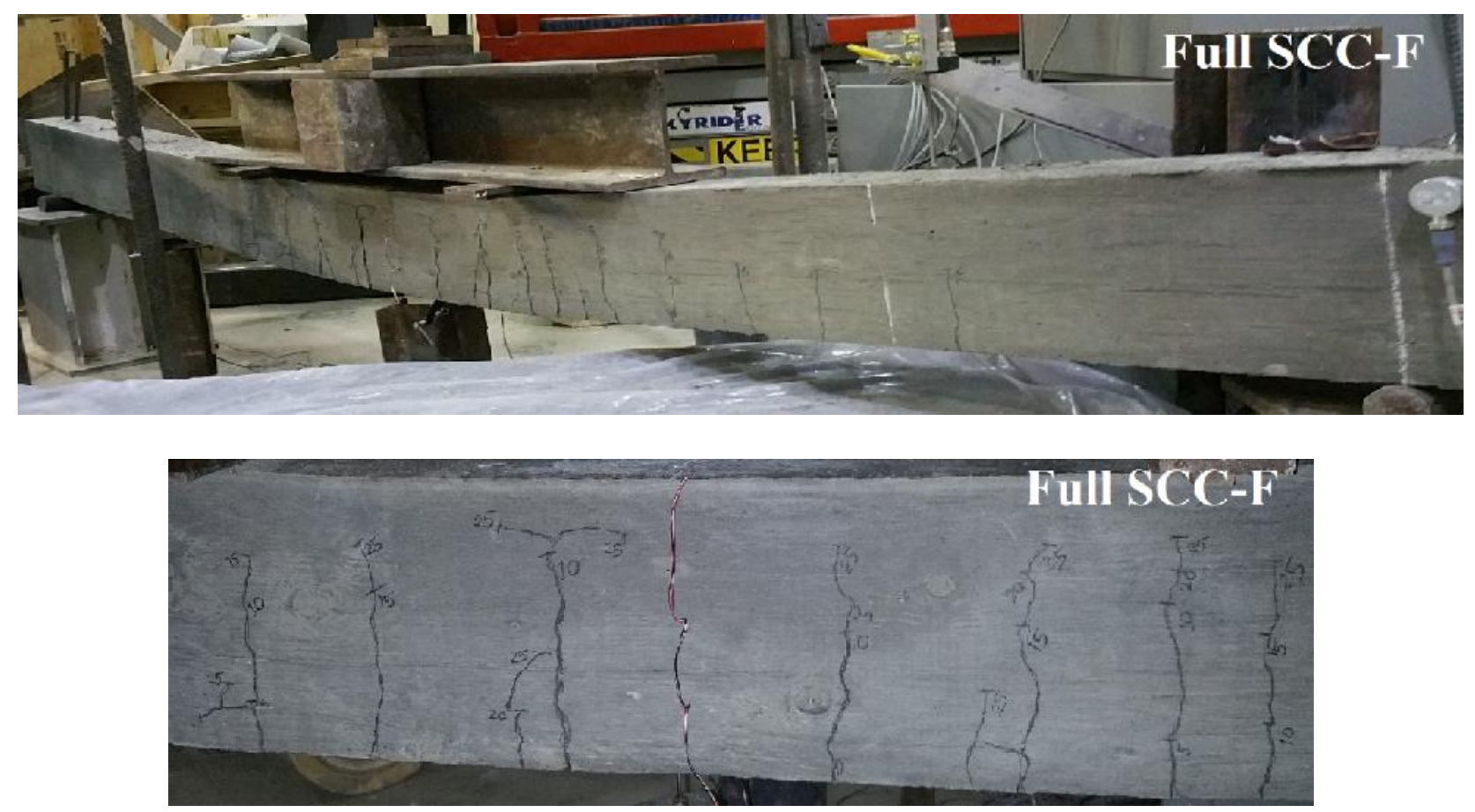

Figure 4.10a: Failure mode and cracking pattern for tested "Full SCC-F" flexural beam 

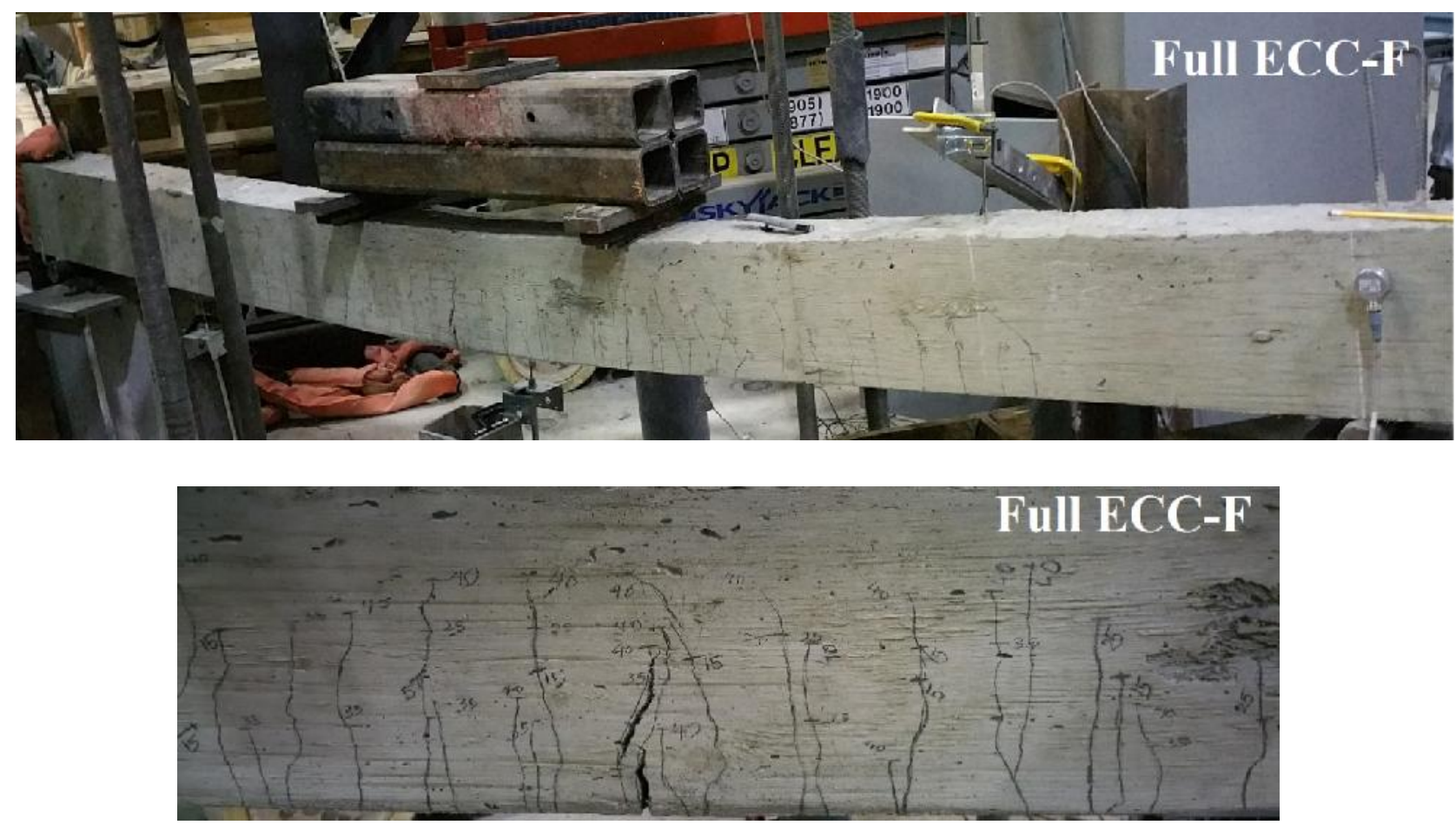

Figure 4.10b: Failure mode and cracking pattern for tested "Full ECC-F" flexural beam
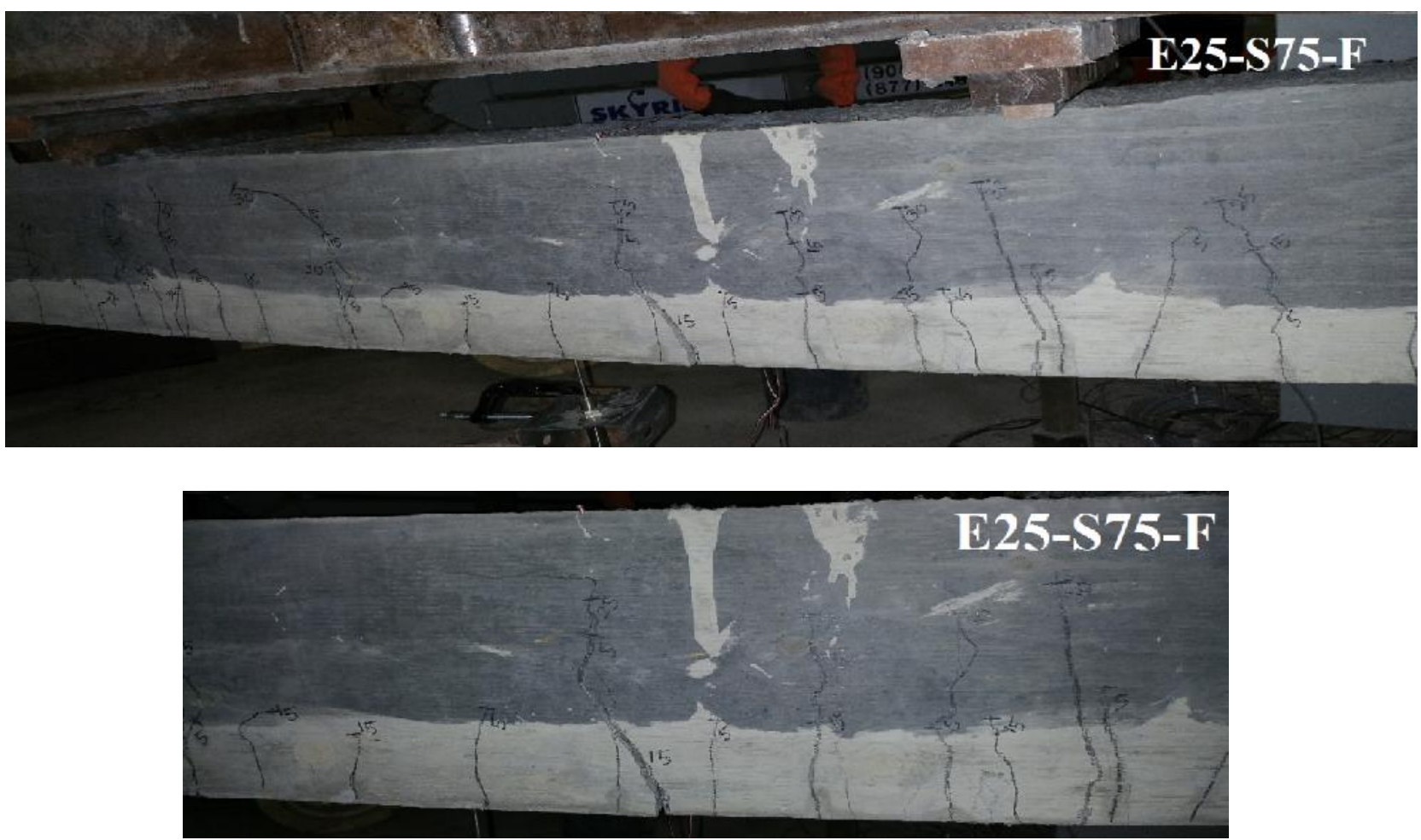

Figure 4.10c: Failure mode and cracking pattern for tested "E25-S75-F" composite flexural beam 


\subsubsection{Strain development in flexural and shear reinforcements}

Figure 4.11 (a-c) shows the strain development in flexural and shear reinforcements throughout the loading history for all three flexural beams. Tensile strain in bottom flexural reinforcement for all flexural beams gradually increased with the increase in load up to the yielding (Figures 4.11a-c) and yielding of the flexural reinforcement occurred at failure, as expected. No shear cracks observed in any of the flexural beams until failure and strain in the shear reinforcement was very small during the test.

Table 4.6 summarizes the first steel yielding load, failure load, strain values at the onset of large strain development and failure strain for "Full SCC-F", "Full ECC-F" and E25-S75-F flexural beams. It can be observed from the table that the development of the strain for tension rebar at ultimate load was much higher for E25-S75-F composite beam than other flexural beam counterparts. As expected, "Full ECC-F" showed higher ultimate load capacity including load at first steel yielding compared to "Full SCC-F" and E25-S75-F flexural beams. The shear reinforcements were not yielded in all of the flexural beams. Strain development in these beams confirmed that flexure failure due to yielding of bottom flexural reinforcement.

Table 4.6: Yield load, ultimate load/moment and strain at different stages for flexural beams

\begin{tabular}{|c|c|c|c|c|c|c|}
\hline \multirow{2}{*}{$\begin{array}{l}\text { Beam } \\
\text { code }\end{array}$} & \multirow{2}{*}{$\begin{array}{l}\text { Load at } \\
\text { first steel } \\
\text { yielding } \\
(\mathrm{kN})\end{array}$} & \multicolumn{2}{|c|}{$\begin{array}{l}\text { Yielding stage (beginning } \\
\text { of large strain } \\
\text { development) } \\
\text { (micro strain) }\end{array}$} & \multicolumn{2}{|c|}{$\begin{array}{c}\text { Ultimate/failure stage } \\
\text { strain } \\
\text { (micro strain) }\end{array}$} & \multirow{2}{*}{$\begin{array}{c}\text { Ultimate } \\
\text { load/moment } \\
\mathrm{kN}(\mathrm{kNm})\end{array}$} \\
\hline & & $\begin{array}{c}\text { Tension } \\
\text { rebar }\end{array}$ & Stirrup & $\begin{array}{c}\text { Tension } \\
\text { rebar }\end{array}$ & Stirrup & \\
\hline Full SCC-F & 24.19 & 2631 & 10 & 3464 & 16 & $35.8(20.58)$ \\
\hline Full ECC-F & 36.06 & 2355 & 12 & 4438 & 15 & $41.65(23.95)$ \\
\hline $\begin{array}{l}\text { E25-S75-F } \\
\text { (quarter depth } \\
\text { ECC) }\end{array}$ & 31.29 & 3129 & 6 & 5588 & 6 & $36.77(21.14)$ \\
\hline
\end{tabular}




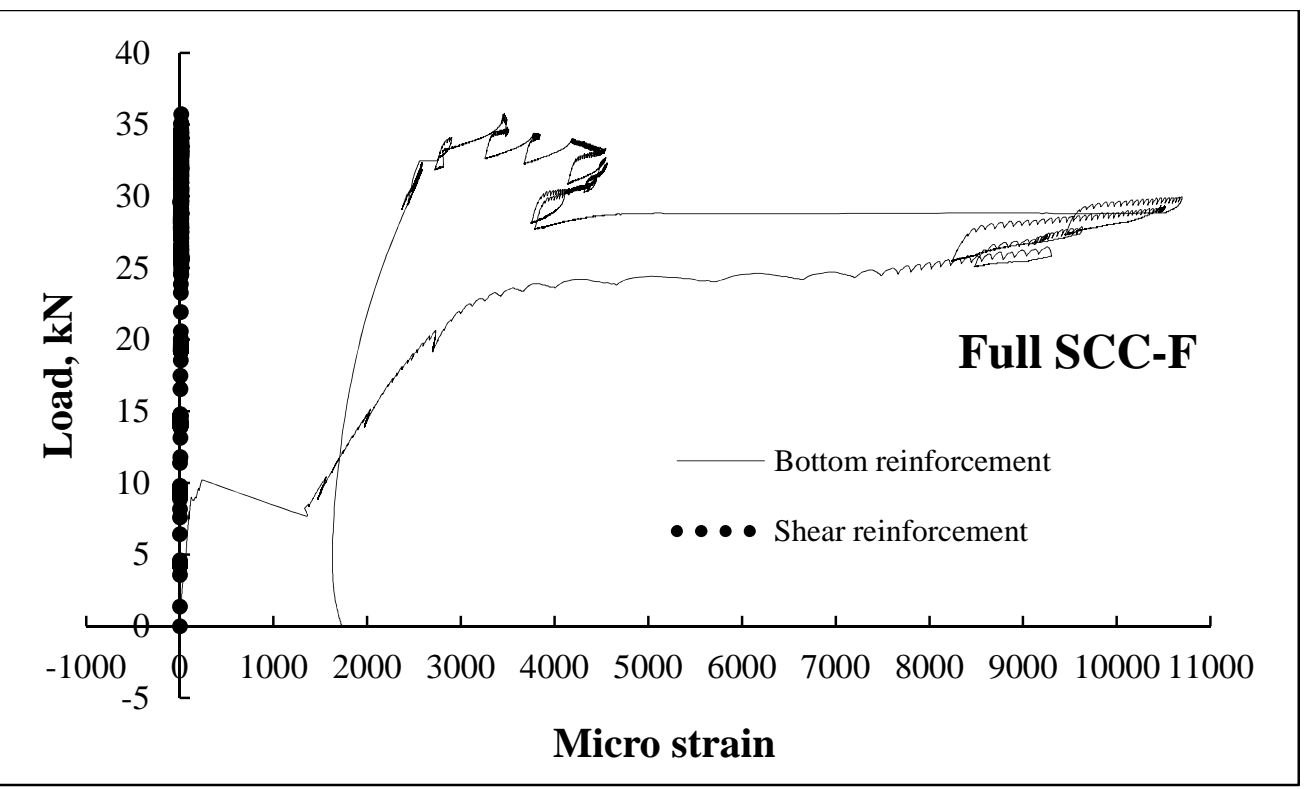

Figure 4.11a: Load vs strain responses for tested "Full SCC-F" flexural beam

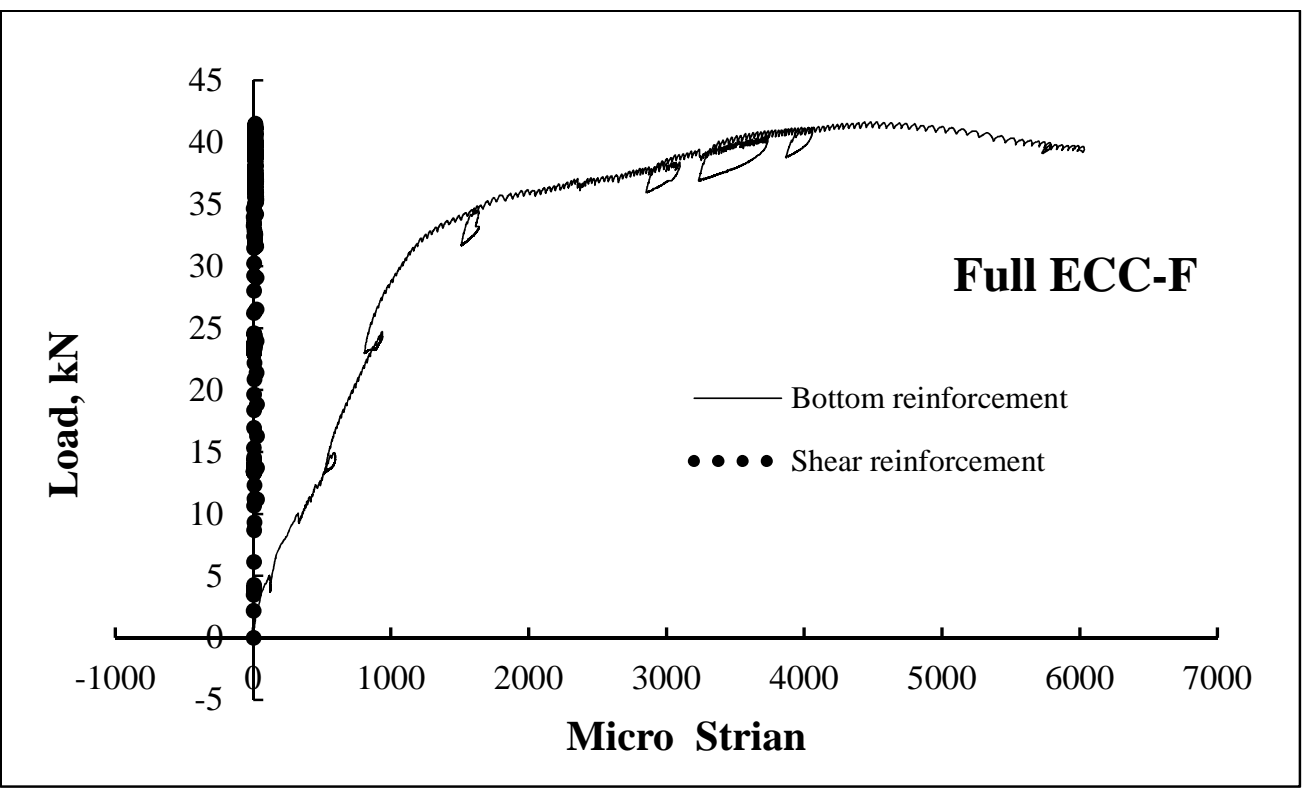

Figure 4.11b: Load vs strain responses for tested "Full ECC-F" flexural beam 


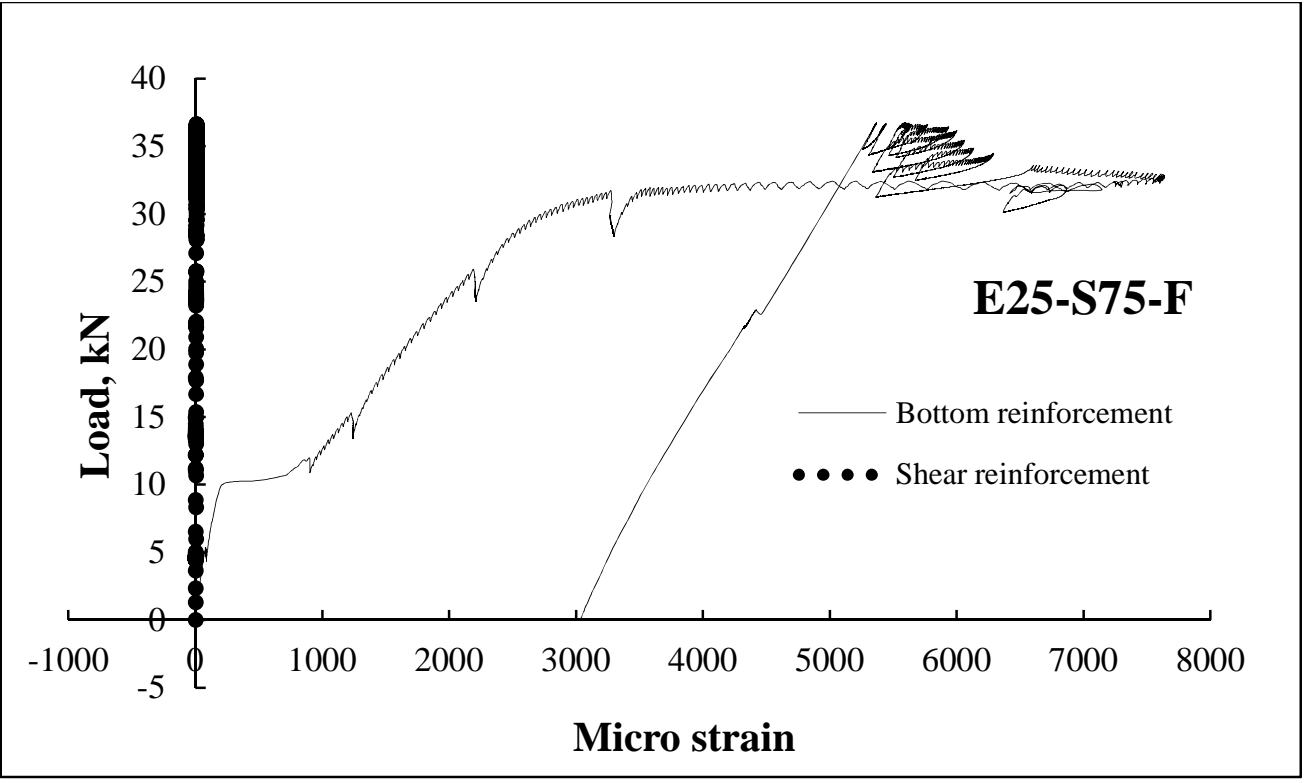

Figure 4.11c: Load vs strain responses for tested E25-S75-F composite flexural beam

\subsubsection{Ductility behavior and energy absorption of flexural beams}

Ductility is the ability of a member to deform without a significant loss of its strength and it is defined by the curvature ductility index (DI). In this study, DI was calculated by the ratio of deflection at failure/ultimate stage $\left(D_{u}\right)$ to that at first yielding of steel $\left(D_{y}\right)$. The energy absorption capacity is calculated by the area under the load-mid span deflection responses presented in Figure 4.9 up to $85 \%$ of the post-peak load. Table 4.7 presents the energy absorption capacity and the ductility index values for flexural beams calculated based on $\mathrm{D}_{\mathrm{y}}$ and $\mathrm{D}_{\mathrm{u}}$ obtained from load deflection curves shown in Figure 4.9. Generally, curvature ductility index is strongly affected by the crushing strain of concrete. All three flexural beams showed good ductility with a DI value of greater than 3.0. All three beams had shear reinforcements in the shear regions only. The DI value for "Full SCC-F" and "Full ECC-F" beam is nearly similar 3.8 and 3.9, respectively but the composite flexural beam E25-S75-F showed ductility index 4.5 which is about $18 \%$ higher than "Full SCC-F" and "Full ECC-F" counterparts. On the other hand, "Full ECC-F" beam absorbed two times higher energy than "Full SCC-F" beam and E25-S75-F composite beam showed 79\% higher energy absorption capacity than "Full SCC-F" counterparts. 
Table 4.7: Energy absorption and ductility index of flexural beams.

\begin{tabular}{|c|c|c|c|c|c|c|}
\hline \multirow[b]{2}{*}{$\begin{array}{l}\text { Beam } \\
\text { code }\end{array}$} & \multirow{2}{*}{$\begin{array}{c}\text { Energy } \\
\text { absorption } \\
\text { capacity at } \\
85 \% \text { ultimate } \\
\text { load (Joules) }\end{array}$} & \multicolumn{2}{|c|}{ First steel yielding } & \multicolumn{2}{|c|}{ Ultimate stage } & \multirow[b]{2}{*}{$\begin{array}{c}\text { Ductility index } \\
\text { (DI) } \\
\mathrm{D}_{\mathrm{u}} / \mathrm{D}_{\mathrm{y}}\end{array}$} \\
\hline & & $\begin{array}{c}\text { Load, } \\
(\mathrm{kN})\end{array}$ & $\begin{array}{c}\text { Deflection, } \\
\mathrm{D}_{\mathrm{y}}(\mathrm{mm})\end{array}$ & $\begin{array}{c}\text { Load, } \\
\text { kN }\end{array}$ & $\begin{array}{c}\text { Deflection, } \\
\mathrm{D}_{\mathrm{u}}(\mathrm{mm})\end{array}$ & \\
\hline Full SCC-F & 1400.25 & 24.19 & 14.52 & 35.8 & 56.47 & 3.8 \\
\hline Full ECC-F & 2841.14 & 36.06 & 16.93 & 41.65 & 65.98 & 3.9 \\
\hline $\begin{array}{c}\text { E25-S75-F } \\
\text { (quarter depth } \\
\text { ECC) }\end{array}$ & 2517.91 & 31.29 & 18.34 & 36.77 & 82.94 & 4.5 \\
\hline $\begin{array}{l}\text { a/d: cons } \\
\text { *load: to }\end{array}$ & $\begin{array}{l}\text { 5.72; b/d: } \\
\text { d; Shear lo }\end{array}$ & $\begin{array}{l}\text { t at } \\
\text { of th }\end{array}$ & $\begin{array}{l}\text { lexural } 1 \\
\text { Corresp }\end{array}$ & $\mathrm{mc}$ & $\begin{array}{l}\text { io: } 0.66 \\
=\text { load*a }\end{array}$ & $\begin{array}{l}\text { all beams; } \\
=1150 \mathrm{~mm})\end{array}$ \\
\hline
\end{tabular}

\subsubsection{Bending moment and development of beam end rotation}

The bending moment vs rotation angle curves of "Full SCC-F", "Full ECC-F" and E25-S75-F flexural beams are shown in Figure 4.12. Similar to the load-deflection response, the curves behave linearly until the yielding of steel reinforcement occurred. After yielding of the flexural steel, rotation of all beams suddenly increased while increment of the bending moment was insignificant. End rotation of the flexural beams was within the range of $4.25-6$ degrees prior to the failure. The rotation angle of "Full ECC-F" and "E25-S75-F" beams was nearly close about 4.32 degree and 5 degree, respectively whereas rotation angle was 6.27 degree for "Full SCC-F" beam at the ultimate load stage. The highest moment capacity $23.95 \mathrm{kNm}$ was carried by "Full ECC-F" beam which was $16 \%$ and 13\% higher than "Full SCC-F" and "E25-S75-F" beams, respectively. 


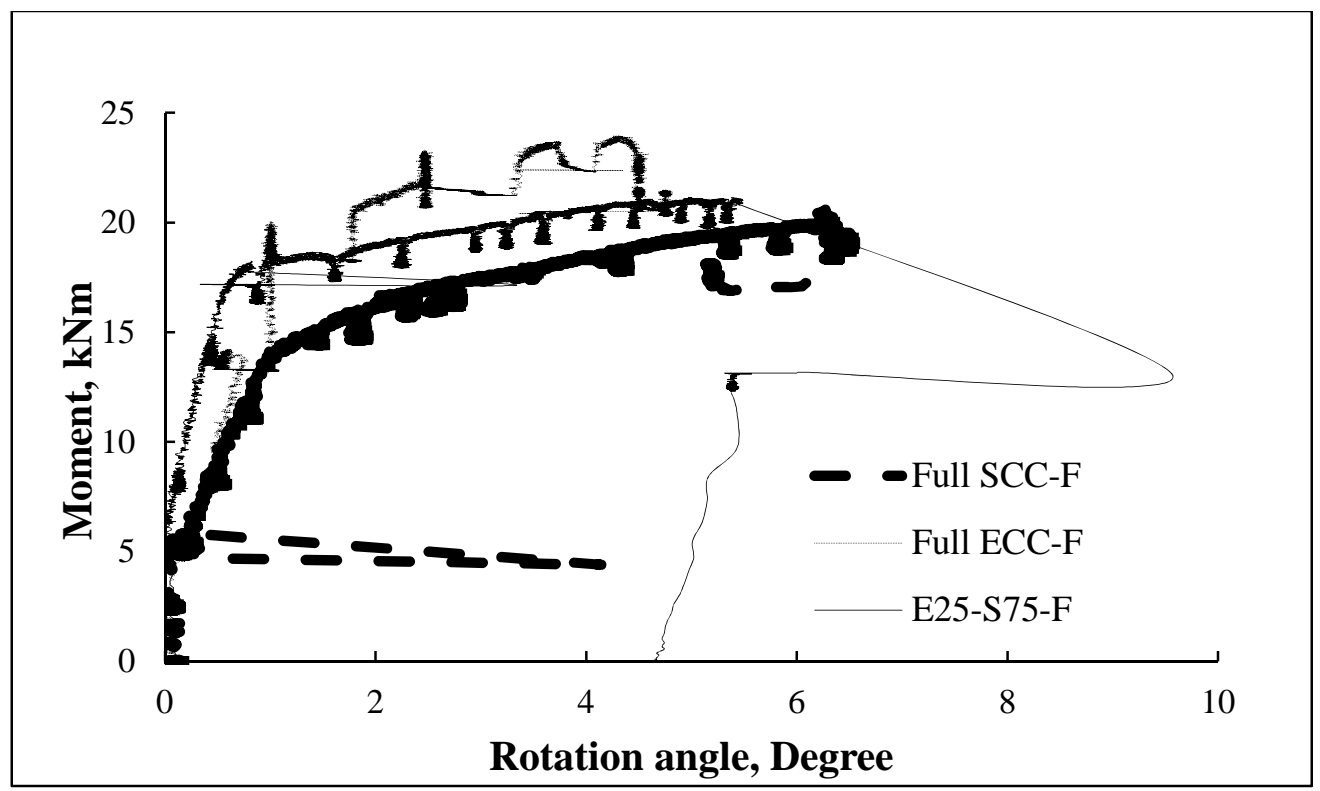

Figure 4.12: Experimental end rotations for tested flexural beams

\subsection{Summary}

In this chapter, the shear and flexure performance of ECC, SCC and composite ECC/SCC beams were described based on the experimental results. Composite ECC/SCC beams without shear reinforcement showed about 24 to $71 \%$ higher shear resistance capacity as well as higher deflection compared to the full depth ECC and SCC shear beams without shear reinforcement. Full depth ECC and SCC shear beams without shear reinforcement showed about 15 to 21 cracks whereas composite ECC/SCC beams showed about 34 to 46 cracks. Shear beams with shear reinforcement showed less crack width than shear beams without shear reinforcement. The diagonal crack angle was close for all beams ranged from 40-45 degree. All beams failed in shear, as expected.

All shear beams with shear reinforcement showed higher shear resistance capacity than shear beams without shear reinforcement, as expected. The diagonal crack angle was less than their shear beams without shear reinforcement counterparts. All beams failed in shear by yielding of the flexural reinforcement except E50-S50-S composite shear beam. Shear reinforcement did not yield for any of the beams. The ECC and SCC depth ratio for composite ECC/SCC beams did not make any significant difference. 
All flexural beams showed typical structural flexure behavior and failed in flexure as designed. Full depth ECC flexural beam showed highest bending moment as expected and also highest number of cracks because of the fiber bridging characteristics. Yielding of the tensile reinforcement happened before failure. E25-S75-F composite flexural beam showed good ductility behavior since all the beams had shown significant amount of deformation before failure. 


\section{CHAPTER FIVE}

\section{THEORETICAL ANALYSIS OF SHEAR AND FLEXURAL CAPACITIES OF EXPERIMENTAL BEAMS}

\subsection{Introduction}

This Chapter compares the experimental shear capacities of full depth SCC, full depth ECC and composite ECC/SCC beams with and without shear reinforcement with those obtained from theoretical formulations and Code based design specifications described in Chapter 2. The experimental cracking and ultimate moment capacities of full depth SCC, full depth ECC and composite ECC/SCC beams are also analyzed and compared with those obtained from theoretical formulations and design specifications. In addition, experimental shear and moment capacities of full depth ECC/FRC beams made with different beams geometry using different types of fiber and volume fraction from previous research studies are also analyzed and compared with those obtained from theoretical formulations and Code based design specifications.

\subsection{Development of shear strength prediction equation of composite ECC/SCC beams}

Based on the design guideline for shear strength of composite members made of normal strength concrete (NSC) and ultra-high performance fiber-reinforced concrete (UHPFRC) without stirrup developed by Hussein et al. (2015), the shear strength ( $\mathrm{V}_{\text {shear }}$ ) of composite ECC/SCC shear beams consisting of polyvinyl alcohol fiber (PVA) with/without shear reinforcement with modified fiber factor has been developed. Figure 5.1 shows the force distributions for the cross-section of a singly reinforced composite ECC/SCC shear beam.

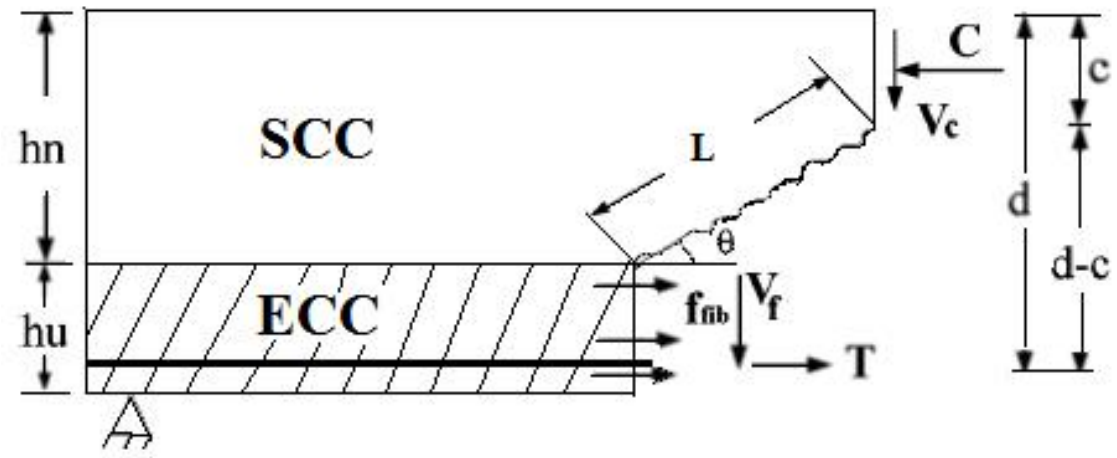

Figure 5.1: Force distribution mechanism of composite ECC/SCC shear beam 
The shear resistance of a composite ECC/SCC shear beam is thus equivalent to the expected shear resistance of a SCC beam without shear reinforcement, $\mathrm{V}_{\mathrm{c}}$, plus the additional shear resistance provided by the fibers, $V_{f}$, due to the improved post-cracking resistance of the ECC layer as shown in Figure 5.1.

The shear strength of composite ECC/SCC shear beams can be calculated from Equation 5.1:

$\mathrm{V}_{\mathrm{u}}=\mathrm{V}_{\mathrm{c}}+\mathrm{V}_{\mathrm{f}}$

The shear resistance provided by the fibers, $\mathrm{V}_{\mathrm{f}}$, can be obtained from Equation 5.2:

$\mathrm{V}_{\mathrm{f}}=\mathrm{F}^{\prime} * \tau * \mathrm{~b} *\left(\mathrm{~d}-\mathrm{h}_{\mathrm{n}}\right)$

In which, $h_{n}$ is the thickness of the SCC layer and $\tau$ is the average bond strength of fibers that can be obtained from tests on single fiber pull out test. For ECC and 2\% volume fraction of PVA fiber, $\tau$ is taken as $2.93 \mathrm{MPa}$ (Yang et al., 2010).

The modified fiber factor for PVA denoted by $\mathrm{F}^{\prime}$ can be calculated using Equation 5.3 (Katz, 1996):

$\mathrm{F}^{\prime}=\frac{\sigma_{c}}{\sigma_{\mathrm{f}} * \mathrm{~V}_{\mathrm{f}}}$

In which, $\sigma_{\mathrm{c}}$ is the flexural strength of ECC testing on $28^{\text {th }}$ day, $\sigma_{\mathrm{f}}$ is the tensile strength of the PVA fiber and $V_{f}$ is the percentage volume fraction of PVA fiber used in ECC.

In this study, NYCON-PVA RECS15 having tensile strength $1600 \mathrm{MPa}$ and 39 micron diameter was used. The $28^{\text {th }}$ day flexural strength of ECC was $5.1 \mathrm{MPa}$ and $2 \%$ volume fraction of PVA fiber was used in ECC. So from Equation 5.3, the fiber factor $\mathrm{F}^{\prime}$ can be found from Equation 5.4:

$\mathrm{F}^{\prime}=\frac{5.1}{1600 * 0.02}=0.159375 \approx 0.16$

The shear contribution by compression zone above the neutral axis can be determined from the Equation 5.5 as per CSA Standard A23.3-04 (2010):

$\mathrm{V}_{\mathrm{c}}=\varphi_{\mathrm{c}} \beta \sqrt{\mathrm{f}_{\mathrm{c}}^{\prime}} \mathrm{bd}$ 
Therefore, the shear capacity of the composite beam without shear reinforcement can be calculated by Equation 5.6:

$\mathrm{V}_{\mathrm{u}}=\varphi_{\mathrm{c}} \lambda \beta \sqrt{\mathrm{f}_{\mathrm{c}}^{\prime}} \mathrm{bd}_{\mathrm{v}}+\mathrm{F}^{\prime} * \tau * \mathrm{~b} *\left(\mathrm{~d}-\mathrm{h}_{\mathrm{n}}\right)$

For the members with transverse/web/shear reinforcement perpendicular to the longitudinal axis, the value of $V_{s}$ can be obtained from Equation 5.7:

$\mathrm{V}_{\mathrm{s}}=\varphi_{\mathrm{s}} \frac{\mathrm{A}_{\mathrm{v}}}{\mathrm{s}} \mathrm{f}_{\mathrm{y}} \mathrm{d}_{\mathrm{v}} \cot \theta$

where, $\theta$ shall be taken $42^{\circ}$ as described in clause CSA 11.3.6.2; $A_{v}$ : area of shear reinforcement; s: spacing between shear reinforcement, $\mathrm{f}_{\mathrm{y}}$ : yield strength of tensile reinforcement bar (MPa),

The value of $A_{v}$ shall be greater than minimum required shear reinforcement based on CSA 11.2.8.2 which can be obtained from Equation 5.8:

$\mathrm{A}_{\mathrm{v}, \min }=0.06 \sqrt{\mathrm{f}_{\mathrm{c}}^{\prime}} \mathrm{bs} / \mathrm{f}_{\mathrm{y}}$

where, $b$ is the width of the beam.

Therefore, the shear strength of composite beams with stirrup can be calculated by using Equation 5.9 derived by combining shear capacity of concrete as per Equation 5.6 and the capacity of shear reinforcement as per Equation 5.7:

$V_{u}=\varphi_{c} \lambda \beta \sqrt{f_{c}^{\prime}} b d_{v}+F^{*} \tau^{*} b^{*}\left(d-h_{n}\right)+\varphi_{s} \frac{A_{v}}{s} f_{y} d_{v} \cot \theta$ 


\subsection{Development of flexural strength prediction equation of composite ECC/SCC flexural beams}

Based on the design guideline for reinforced UHPC beam for flexural resistance as shown in Figure 2.18 (Hossain, 2014) and the principle of force equilibrium, strain- stress distribution of reinforced UHPC flexural beam with half depth fiber dispersion (Figure 2.20), flexural analysis of singly reinforced composite ECC/SCC flexural beams with quarter depth PVA-ECC has been developed based on stress-strain-force distribution as shown in Figure 5.2.

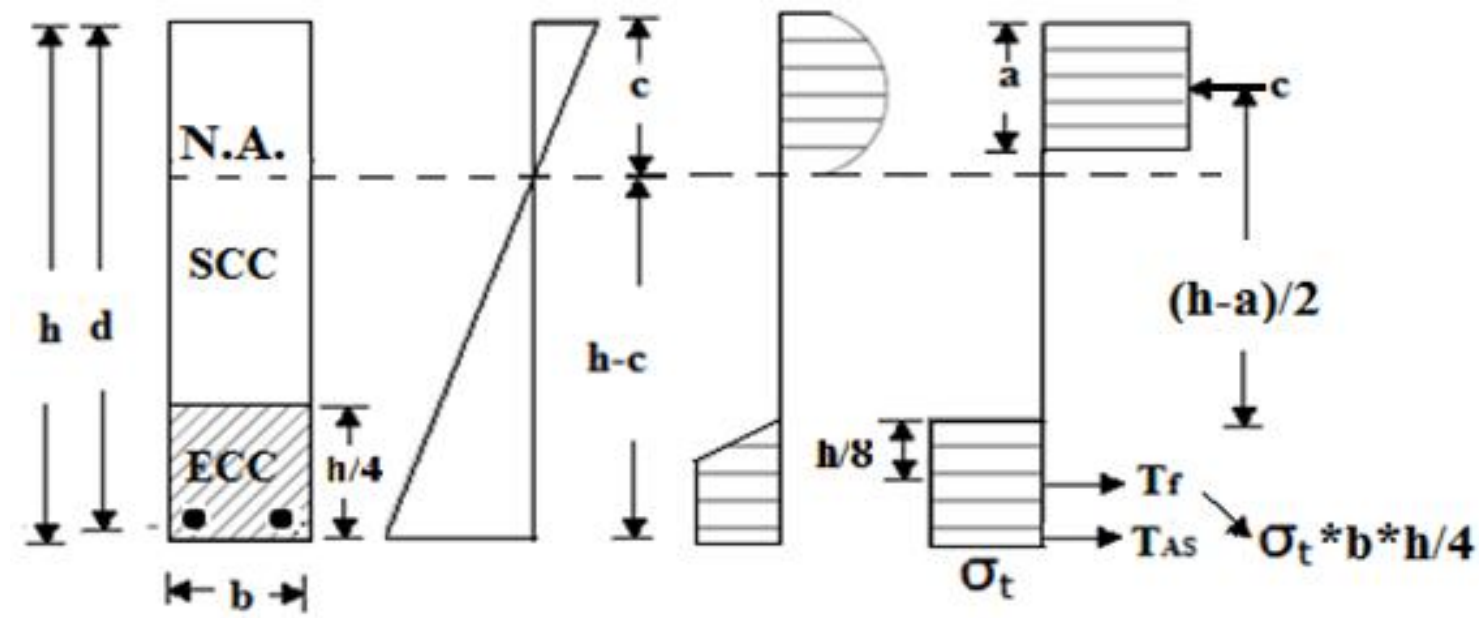

Figure 5.2: Strain- stress-force distribution of reinforced composite ECC/SCC flexural beam with quarter-depth PVA-ECC

The nominal moment capacity $\left(\mathrm{M}_{\mathrm{n}}\right)$ for singly reinforced composite ECC/SCC flexural beams for PVA-ECC (with quarter depth fiber dispersion) can be calculated by Equation 5.10:

$M_{n}=A_{s} f_{y}(d-a / 2)+\sigma_{t} b h / 4 *(h-a) / 2$

where, $\mathrm{f}_{\mathrm{cf}}{ }$ : compressive strength of fibrous concrete $(\mathrm{MPa}), \mathrm{A}_{\mathrm{s}}$ : area of tensile steel bars $\left(\mathrm{mm}^{2}\right), \mathrm{f}_{\mathrm{y}}$ : yield strength of tensile reinforcement bar (MPa), c: neutral axis depth (mm), b: width of the beam cross section $(\mathrm{mm}), \mathrm{h}$ : height of the beam cross section $(\mathrm{mm}), \lambda$ : concrete stress block parameter (equal to 0.86 for $\mathrm{f}_{\mathrm{c}}^{\prime} \geq 55 \mathrm{MPa}$ ), $\mathrm{f}_{\mathrm{c}}^{\prime}$ : compressive strength of plain concrete (MPa), $\beta 1$ : concrete stress block parameter (equal to 0.65 for $\mathrm{f}_{\mathrm{c}} \geq 55(\mathrm{MPa})$, a: depth of the equivalent compressive block $(\mathrm{mm})$.

The value of 'a' can be calculated from Equation 5.11:

$a=\left(A_{s} f_{y}+\sigma_{t} b h / 4\right) / \lambda f_{c f}^{\prime} b$ 
The ultimate tensile strength of fiber reinforced concrete $\left(\sigma_{t}\right.$ in $\left.\mathrm{MPa}\right)$ is given by Equation 5.12 (Ahmed and Pama, 1992; Hossain, 2014):

$\sigma_{\mathrm{t}}=2 \eta_{\mathrm{o}} \eta_{\mathrm{b}} \eta_{\mathrm{l}} \mathrm{V}_{\mathrm{f}} \tau_{\mathrm{f}}\left(\mathrm{l}_{\mathrm{f}} / \mathrm{d}_{\mathrm{f}}\right)$

where, $\eta_{\mathrm{o}}$ : orientation factor $=0.41 ; \eta_{\mathrm{b}}$ : bond efficiency factor $=0.5$ for round steel fibers;

In this study, bond efficiency factor $\left(\eta_{b}\right)$ for PVA fiber can be obtained from using Equation 5.4; $\eta 1$ is the length efficiency factor which can be calculated from Equation 5.13:

$\eta_{\mathrm{t}}=1-\left[\left(\tanh \left(\frac{\beta \mathrm{l}_{\mathrm{f}}}{2}\right)\right) /\left(\beta \mathrm{l}_{\mathrm{f}} / 2\right)\right]$

The value for coefficient $\beta$ can be obtained from Equation 5.14:

$\beta=\sqrt{\frac{2 \pi G_{m}}{E_{f} A_{f} L_{n}\left(\frac{S}{r_{f}}\right)}}$

The value for $\mathrm{S}$, steel fiber characteristic is defined in Equation 5.15:

$\mathrm{S}=25\left(\frac{\mathrm{l}_{\mathrm{f}}}{\mathrm{V}_{\mathrm{f}} \mathrm{d}_{\mathrm{f}}}\right)^{1 / 2}$

where, $V_{\mathrm{f}}$ : volume fraction of steel fiber; $\tau_{\mathrm{f}}$ : bond strength between the fiber and matrix (MPa); $1_{\mathrm{f}}$ : length of fibers $(\mathrm{mm})$; $\mathrm{d}_{\mathrm{f}}$ : diameter of fibers $(\mathrm{mm}) ; \mathrm{G}_{\mathrm{m}}$ : shear modulus of concrete matrix (MPa); $E_{\mathrm{f}}$ : modulus of elasticity of steel fibers $(\mathrm{MPa}) ; \mathrm{A}_{\mathrm{f}}$ : cross-sectional area of steel fibers $\left(\mathrm{mm}^{2}\right)$ and $\mathrm{r}_{\mathrm{f}}$ : radius of steel fibers $(\mathrm{mm})$.

For ECC and 2\% volume fraction of PVA fiber, $\boldsymbol{\tau}_{\mathrm{f}}$ was taken as $2.93 \mathrm{MPa}$ (Yang et al., 2010). 


\subsection{Shear strength prediction of ECC, SCC and composite ECC/SCC beams without shear reinforcement}

Shear resistances of full depth ECC, full depth SCC and composite ECC/SCC beams without shear reinforcement from current experiments and theoretical predictions are analyzed and compared in Table 5.1. As described in Chapter 2, Equation 2.6, Equation 2.1 and Equation 5.6 were used to predict theoretical shear resistance of full depth ECC, full depth SCC and composite ECC/SCC beams without shear reinforcement, respectively. It can be observed that all theoretical formulations were conservative in predicting ultimate shear strength of shear beams without shear reinforcement. Design specifications provided highest safety margin for composite ECC/SCC beams ranged from 2.9 to 3.3 ratio, whereas full depth SCC and full depth ECC beams ranged from 1.1 to 2.5 ratio. It should be noted that, the depth variance of ECC and SCC of composite ECC/SCC beams did not make any significant difference in carrying ultimate shear resisting capacity as well as in the theoretical shear prediction. All beams failed in shear.

Table 5.1: Shear resistance of beams without shear reinforcement from experiment and theoretical predictions

\begin{tabular}{|c|c|c|c|c|}
\hline \multirow{2}{*}{ Beam code } & \multicolumn{2}{|c|}{$\begin{array}{l}\text { Total shear resistance, } \mathrm{V}_{\mathrm{u}}=\mathrm{V}_{\mathrm{c}} \\
\qquad(\mathrm{kN})\end{array}$} & \multirow{2}{*}{$\begin{array}{l}\text { Theoretical shear } \\
\text { predictions; } \\
(\mathrm{kN})\end{array}$} & \multirow{2}{*}{$\begin{array}{c}\text { Ratio of } \\
\text { experimental } \\
\text { to } \\
\text { theoretical } \\
\text { predicted } \\
\text { shear }\end{array}$} \\
\hline & $\begin{array}{l}\text { Experimental } \\
\text { ultimate } \\
\text { load, } \mathrm{P}(\mathrm{kN})\end{array}$ & $\begin{array}{c}\text { Experimental } \\
\text { shear load= } \mathrm{P} / 2 \\
(\mathrm{kN})\end{array}$ & & \\
\hline Full SCC & 84.55 & 42.27 & 16.50 (Equation 2.1) & 2.5 \\
\hline Full ECC & 116.07 & 58.03 & 57.65 (Equation 2.6 and 5.4) & 1.1 \\
\hline $\begin{array}{l}\text { E50-S50 (half } \\
\text { depth ECC) }\end{array}$ & 144.69 & 72.34 & $\begin{array}{c}21.86 \text { (Equation 5.2, } 5.4 \text { and } \\
5.5 \text { ) }\end{array}$ & 3.3 \\
\hline $\begin{array}{c}\text { E25-S75 (quarter } \\
\text { depth ECC) }\end{array}$ & 144.40 & 72.20 & $\begin{array}{c}24.22 \text { (Equation 5.2, } 5.4 \text { and } \\
5.5 \text { ) }\end{array}$ & 2.9 \\
\hline
\end{tabular}




\subsubsection{Detail calculation of shear strength prediction of ECC, SCC and composite ECC/SCC beams without shear reinforcement}

Theoretical shear strength prediction of full depth ECC, full depth SCC and composite ECC/SCC beams without shear reinforcement can be calculated as follows:

\subsubsection{Theoretical calculation of predicted shear strength of 'Full SCC' beam}

Using Equation 2.1, theoretically predicted shear strength of "Full SCC" beam can be calculated based on experimental values obtained from tested specimen.

$\mathrm{V}_{\mathrm{c}}=\varphi_{\mathrm{c}} \lambda \beta \sqrt{f_{\mathrm{c}}^{\prime}} \mathrm{bd}$

where, $\varphi_{\mathrm{c}}$ is 0.65 as per CSA clause 8.4.2 and $\beta$ is taken 0.21 as per CSA 11.3.6.2; $\mathrm{f}_{\mathrm{c}}^{\prime}$ : compressive strength of SCC (59 MPa); b: $100 \mathrm{~mm} ; \mathrm{d}_{\mathrm{v}}: 157.5 \mathrm{~mm}$.

Therefore,

$\mathrm{V}_{\mathrm{c}}=0.65 * 0.21 * \sqrt{59} * 100 * 157.5=16.5 \mathrm{kN}$

\subsubsection{Theoretical calculation of predicted shear strength of "Full ECC" beam}

Using Equations 2.6 and 5.4, theoretically predicted shear strength of "Full ECC" beam can be calculated based on experimental values obtained from tested specimen.

$\mathrm{V}_{\text {shear }}=0.6 \times \frac{1+\sqrt{\frac{5.08}{\mathrm{~d}_{\mathrm{a}}}}}{\sqrt{1+\frac{\mathrm{d}}{25 \mathrm{~d}_{\mathrm{a}}}}} \times \sqrt[3]{\rho_{\mathrm{s}}(1+4 \mathrm{~F})} \times\left[\left(\mathrm{f}_{\mathrm{c}}^{\prime}\right)^{0.44}+275 \sqrt{\frac{\rho_{\mathrm{s}}(1+4 \mathrm{~F})}{\left(\frac{\mathrm{a}_{\mathrm{s}}}{\mathrm{d}}\right)^{5}}}\right]^{*} \mathrm{~b}^{*} \mathrm{~d}$

where, $\mathrm{d}_{\mathrm{a}}$ : max aggregate size $1.05 \mathrm{~mm} ; \rho_{\mathrm{s}}: 0.011 ; \mathrm{f}_{\mathrm{c}}^{\prime}$ : compressive strength of ECC (73 MPa); $\mathrm{a}_{\mathrm{s}}$ : shear span $267 \mathrm{~mm}$; d:175 mm; b: $100 \mathrm{~mm}$ and fiber factor, $F=F^{\prime}=5.1 /\left(1600^{*} 0.02\right)=0.16$ Therefore,

$$
\begin{aligned}
\mathrm{V}_{\text {shear }} & =0.6 \times \frac{1+\sqrt{\frac{5.08}{1.05}}}{\sqrt{1+\frac{175}{25^{*} 1.05}}} \times \sqrt[3]{0.011(1+4 * 0.16)} \times\left[(79)^{0.44}+275\left[\frac{0.011(1+4 * 0.16)}{\left(\frac{267}{175}\right)^{5}}\right] * 100 * 175\right. \\
& =57.65 \mathrm{kN}
\end{aligned}
$$




\subsubsection{Theoretical calculation of predicted shear strength of E50-S50 (half depth ECC) beam}

Using Equations 5.2, 5.4 and 5.5, theoretically predicted shear strength of E50-S50 (half depth ECC) beam can be calculated based on experimental values obtained from tested specimen.

$\mathrm{V}_{\mathrm{f}}=\mathrm{F}^{*} \tau^{*} \mathrm{~b} *\left(\mathrm{~d}-\mathrm{h}_{\mathrm{n}}\right)$

where, $\mathrm{F}^{\prime}: 0.16$; $\tau: 2.93 \mathrm{MPa}$; $\mathrm{b}: 100 \mathrm{~mm}$; $: 175 \mathrm{~mm}$; $\mathrm{h}_{\mathrm{u}}: 100 \mathrm{~mm}$ and $\mathrm{f}_{\mathrm{c}}^{\prime}$ : compressive strength of $\operatorname{ECC}(73 \mathrm{MPa})$

Therefore,

$\mathrm{V}_{\mathrm{f}}=0.16 * 2.93 * 100 *(175-100)=3.5 \mathrm{kN}$

and $\mathrm{V}_{\mathrm{c}}=\varphi_{\mathrm{c}} \beta \sqrt{\mathrm{f}_{\mathrm{c}}^{\prime}} \mathrm{bd} \mathrm{d}_{\mathrm{v}}=0.65 * 0.21 * \sqrt{73} * 100 * 157.5=18.36 \mathrm{kN}$

So, $\mathrm{V}_{\mathrm{u}}=\mathrm{V}_{\mathrm{c}}+\mathrm{V}_{\mathrm{f}}=18.36+3.5=21.86 \mathrm{kN}$

\subsubsection{Theoretical calculation of predicted shear strength of E25-S75 (quarter depth ECC) beam}

Using Equations 5.2, 5.4 and 5.5, theoretically predicted shear strength of E25-S75 beam can be calculated based on experimental values obtained from tested specimen.

$\mathrm{V}_{\mathrm{f}}=\mathrm{F}^{*} \tau^{*} \mathrm{~b}^{*}\left(\mathrm{~d}-\mathrm{h}_{\mathrm{n}}\right)$

where, $\mathrm{F}^{\prime}: 0.16 ; \tau: 2.93 \mathrm{MPa} ; \mathrm{b}: 100 \mathrm{~mm} ; \mathrm{d}: 175 \mathrm{~mm} ; \mathrm{h}_{\mathrm{u}}: 50 \mathrm{~mm}$ and $\mathrm{f}_{\mathrm{c}}^{\prime}$ : compressive strength of ECC (73 MPa)

Therefore,

$\mathrm{V}_{\mathrm{f}}=0.16 * 2.93 * 100 *(175-50)=5.86 \mathrm{kN}$

and $\mathrm{V}_{\mathrm{c}}=\varphi_{\mathrm{c}} \beta \sqrt{\mathrm{f}_{\mathrm{c}}} \mathrm{bd} \mathrm{d}_{\mathrm{v}}=0.65 * 0.21 * \sqrt{73} * 100 * 157.5=18.36 \mathrm{kN}$

So, $\mathrm{V}_{\mathrm{u}}=\mathrm{V}_{\mathrm{c}}+\mathrm{V}_{\mathrm{f}}=18.36+5.86=24.22 \mathrm{kN}$ 


\subsection{Shear strength prediction of ECC, SCC and composite ECC/SCC beams with shear reinforcement}

Shear resistances of full depth ECC, full depth SCC and composite ECC/SCC beams with shear reinforcement from current experiments and theoretical predictions are analyzed and compared in Table 5.2.

Table 5.2: Shear resistance of beams with shear reinforcement from experiment and theoretical predictions

\begin{tabular}{|c|c|c|c|c|}
\hline \multirow[b]{2}{*}{ Beam code } & \multirow{2}{*}{$\begin{array}{c}\text { Exp. } \\
\text { ultimate } \\
\text { load, }(\mathrm{kN})\end{array}$} & \multicolumn{2}{|c|}{ Concrete shear resistance, $\mathrm{V}_{\mathrm{c}}(\mathrm{kN})$} & \multirow{2}{*}{$\begin{array}{l}\text { Exp. / } \\
\text { theo. } \\
\text { predicted } \\
\text { shear }\end{array}$} \\
\hline & & Experimental & Theoretical predictions & \\
\hline Full SCC-S & 50.0 & 25.0 & 16.50 (Equation 2.1) & 1.5 \\
\hline Full ECC-S & 75.0 & 37.5 & 57.65 (Equation 2.6) & 0.7 \\
\hline $\begin{array}{l}\text { E50-S50-S (half depth } \\
\text { ECC) }\end{array}$ & 70.0 & 35.0 & 21.86 (Equation 5.6) & 1.6 \\
\hline $\begin{array}{c}\text { E25-S75-S (quarter depth } \\
\text { ECC) }\end{array}$ & 65.0 & 32.5 & 24.22 (Equation 5.6) & 1.3 \\
\hline \multirow[b]{2}{*}{ Beam code } & \multirow{2}{*}{$\begin{array}{c}\text { Exp. } \\
\text { ultimate } \\
\text { load, }(\mathrm{kN})\end{array}$} & \multicolumn{2}{|c|}{ Stirrups shear resistance, $\mathrm{V}_{\mathrm{s}}(\mathrm{kN})$} & \multirow{2}{*}{$\begin{array}{c}\text { Exp. I } \\
\text { theo. } \\
\text { predicted } \\
\text { shear }\end{array}$} \\
\hline & & Experimental & $\begin{array}{l}\text { Theoretical predictions } \\
\text { (Equation 2.4) }\end{array}$ & \\
\hline Full SCC-S & 47.2 & 23.56 & 32.0 & 0.7 \\
\hline Full ECC-S & 83.6 & 41.80 & 32.0 & 1.3 \\
\hline $\begin{array}{l}\text { E50-S50-S (half depth } \\
\text { ECC) }\end{array}$ & 81.5 & 40.75 & 32.0 & 1.2 \\
\hline $\begin{array}{c}\text { E25-S75-S (quarter depth } \\
\text { ECC) }\end{array}$ & 84.7 & 42.35 & 32.0 & 1.3 \\
\hline \multirow[b]{2}{*}{ Beam code } & \multirow{2}{*}{$\begin{array}{c}\text { Exp. } \\
\text { ultimate } \\
\text { load, }(\mathrm{kN})\end{array}$} & \multicolumn{2}{|c|}{ Beam shear resistance, $V_{u}=\left(V_{c}+V_{s}\right) k N$} & \multirow{2}{*}{$\begin{array}{c}\text { Exp. I } \\
\text { theo. } \\
\text { predicted } \\
\text { shear }\end{array}$} \\
\hline & & Experimental & Theoretical predictions & \\
\hline Full SCC-S & 97.2 & 48.60 & 48.50 (Equation 2.1 and 2.4) & 1.1 \\
\hline Full ECC-S & 158.6 & 79.30 & 89.65 (Equation 2.9) & 0.9 \\
\hline $\begin{array}{l}\text { E50-S50-S (half depth } \\
\text { ECC) }\end{array}$ & 151.5 & 75.75 & 53.86 (Equation 5.9) & 1.4 \\
\hline $\begin{array}{c}\text { E25-S75-S (quarter depth } \\
\text { ECC) }\end{array}$ & 149.7 & 74.85 & 56.22 (Equation 5.9) & 1.3 \\
\hline
\end{tabular}


It can be observed from the Table 5.2 that all theoretical formulations except "Full ECC-S" beam were conservative in predicting shear resistance of concrete $\left(\mathrm{V}_{\mathrm{c}}\right)$ for all beams. The design specification overestimated the shear resistance of concrete $\left(V_{c}\right)$ as well as ultimate shear resistance of experimented "Full ECC-S" beam with ratio of experimental to theoretical values of 0.9 and found not safe. Similar to shear beams without shear reinforcement, design specifications provided highest safety margin for composite ECC/SCC beams with shear reinforcement with ratios ranging from 1.3 to 1.4. The predicted shear resistance of "Full SCC-S" beam was nearly close to the experimental shear strength showing a ratio of 1.1. All beams failed in shear without any yielding of shear reinforcement.

\subsubsection{Detail calculation of shear strength prediction of ECC, SCC and composite ECC/SCC beams with shear reinforcement}

Theoretical shear strength prediction of full depth ECC, full depth SCC and composite ECC/SCC beams with shear reinforcement can be calculated as follows:

\subsubsection{Theoretical calculation of predicted shear strength of "Full SCC-S" beam}

Using Equations 2.1 and 2.4, theoretically predicted shear strength of "Full SCC-S" beam can be calculated based on experimental values obtained from tested specimen.

$$
\mathrm{V}_{\mathrm{c}}=\varphi_{\mathrm{c}} \lambda \beta \sqrt{\mathrm{f}_{\mathrm{c}}^{\prime}} \mathrm{bd}
$$

where, $\varphi_{\mathrm{c}}$ is 0.65 as per CSA clause 8.4.2 and $\beta$ is taken 0.21 as per CSA 11.3.6.2; $\mathrm{f}_{\mathrm{c}}^{\prime}$ : compressive strength of SCC (59 MPa); b: $100 \mathrm{~mm}$; $\mathrm{d}_{\mathrm{v}}: 157.5 \mathrm{~mm}$.

Therefore,

$\mathrm{V}_{\mathrm{c}}=0.65 * 0.21 * \sqrt{59} * 100 * 157.5=16.5 \mathrm{kN}$

Stirrup shear resistance, $\mathrm{V}_{\mathrm{s}}=\varphi_{\mathrm{s}} \frac{\mathrm{A}_{\mathrm{v}}}{\mathrm{s}} \mathrm{f}_{\mathrm{y}} \mathrm{d}_{\mathrm{v}} \operatorname{Cot} \theta=0.85 * \frac{64}{133.5} * 449 * 157.5 * \operatorname{Cot} 42=32 \mathrm{kN}$

So, $\mathrm{V}_{\mathrm{u}}=\mathrm{V}_{\mathrm{c}}+\mathrm{V}_{\mathrm{s}}=16.5+32=48.5 \mathrm{kN}$

\subsubsection{Theoretical calculation of predicted shear strength of "Full ECC-S" beam}

Using Equations 2.4, 2.6 and 5.4, theoretically predicted shear strength of "Full ECC-S" beam can be calculated based on experimental values obtained from tested specimen.

$$
\mathrm{V}_{\text {shear }}=0.6 \times \frac{1+\sqrt{\frac{5.08}{\mathrm{~d}_{\mathrm{a}}}}}{\sqrt{1+\frac{\mathrm{d}}{25 \mathrm{~d}_{\mathrm{a}}}}} \times \sqrt[3]{\rho_{\mathrm{s}}(1+4 \mathrm{~F})} \times\left[\left(\mathrm{f}_{\mathrm{c}}^{\prime}\right)^{0.44}+275 \sqrt{\frac{\rho_{\mathrm{s}}(1+4 \mathrm{~F})}{\left(\frac{\mathrm{a}_{\mathrm{s}}}{\mathrm{d}}\right)^{5}}}\right]^{*} \mathrm{~b}^{*} \mathrm{~d}
$$


where, da: $\max$ aggregate size $1.05 \mathrm{~mm} ; \rho_{\mathrm{s}}: 0.011 ; \mathrm{f}_{\mathrm{c}}^{\prime}$ : compressive strength of ECC (73 MPa); $\mathrm{a}_{\mathrm{s}}$ : shear span $267 \mathrm{~mm}$; d:175 mm; b: $100 \mathrm{~mm}$ and fiber factor, $\mathrm{F}=\mathrm{F}^{\prime}=\frac{5.1}{1600 * .02}=0.16$ Therefore,

$$
\begin{aligned}
\mathrm{V}_{\text {shear }} & =0.6 \times \frac{1+\sqrt{\frac{5.08}{1.05}}}{\sqrt{1+\frac{175}{25^{*} 1.05}}} \times \sqrt[3]{0.011(1+4 * 0.16)} \times\left[(79)^{0.44}+275\left[\frac{0.011(1+4 * 0.16)}{\left(\frac{267}{175}\right)^{5}}\right] * 100 * 175\right. \\
& =57.65 \mathrm{kN}
\end{aligned}
$$

Stirrup shear resistance, $V_{s}=\varphi_{\mathrm{s}} \frac{\mathrm{A}_{\mathrm{v}}}{\mathrm{s}} \mathrm{f}_{\mathrm{y}} \mathrm{d}_{\mathrm{v}} \operatorname{Cot} \theta=0.85 * \frac{64}{133.5} * 449 * 157.5 * \operatorname{Cot} 42=32 \mathrm{kN}$ So, $\mathrm{V}_{\mathrm{u}}=\mathrm{V}_{\mathrm{c}}+\mathrm{V}_{\mathrm{s}}=57.65+32=89.65 \mathrm{kN}$

\subsubsection{Theoretical calculation of predicted shear strength of E50-S50-S (half depth ECC) beam}

Using Equations 2.4, 5.2, 5.4 and 5.5, theoretically predicted shear strength of E50-S50-S (half depth ECC) beam can be calculated based on experimental values obtained from tested specimen. $\mathrm{V}_{\mathrm{f}}=\mathrm{F}^{*} \tau^{*} \mathrm{~b} *\left(\mathrm{~d}-\mathrm{h}_{\mathrm{n}}\right)$

where, $\mathrm{F}^{\prime}: 0.16$; $\tau$ : $2.93 \mathrm{MPa} ; \mathrm{b}: 100 \mathrm{~mm}$; $: 175 \mathrm{~mm}$; $\mathrm{h}_{\mathrm{u}}: 100 \mathrm{~mm}$ and $\mathrm{f}_{\mathrm{c}}^{\prime}$ : compressive strength of ECC (73 MPa)

Therefore,

$\mathrm{V}_{\mathrm{f}}=0.16 * 2.93 * 100 *(175-100)=3.5 \mathrm{kN}$

and $\mathrm{V}_{\mathrm{c}}=\varphi_{\mathrm{c}} \beta \sqrt{\mathrm{f}_{\mathrm{c}}^{\prime}} \mathrm{bd}_{\mathrm{v}}=0.65 * 0.21 * \sqrt{73} * 100 * 157.5=18.36 \mathrm{kN}$

Stirrup shear resistance, $\mathrm{V}_{\mathrm{s}}=\varphi_{\mathrm{s}} \frac{\mathrm{A}_{\mathrm{v}}}{\mathrm{s}} \mathrm{f}_{\mathrm{y}} \mathrm{d}_{\mathrm{v}} \operatorname{Cot} \theta=0.85 * \frac{64}{133.5} * 449 * 157.5 * \operatorname{Cot} 42=32 \mathrm{kN}$

So, $\mathrm{V}_{\mathrm{u}}=3.5+18.36+32=53.86 \mathrm{kN}$

\subsubsection{Theoretical calculation of predicted shear strength of E25-S75-S (quarter depth ECC)}

\section{beam}

Using Equations 2.4, 5.2, 5.4 and 5.5, theoretically predicted shear strength of E25-S75-S beam can be calculated based on experimental values obtained from tested specimen.

$\mathrm{V}_{\mathrm{f}}=\mathrm{F}^{*} \tau^{*} \mathrm{~b} *\left(\mathrm{~d}-\mathrm{h}_{\mathrm{n}}\right)$

where, $\mathrm{F}^{\prime}: 0.16 ; \tau: 2.93 \mathrm{MPa} ; \mathrm{b}: 100 \mathrm{~mm} ; \mathrm{d}: 175 \mathrm{~mm} ; \mathrm{h}_{\mathrm{u}}: 50 \mathrm{~mm}$ and $\mathrm{f}_{\mathrm{c}}^{\prime}$ : compressive strength of $\operatorname{ECC}(73 \mathrm{MPa})$ 
Therefore,

$\mathrm{V}_{\mathrm{f}}=0.16 * 2.93 * 100 *(175-50)=5.86 \mathrm{kN}$

and $V_{c}=\varphi_{c} \beta \sqrt{f_{c}^{\prime}} b d_{v}=0.65 * 0.21 * \sqrt{73} * 100 * 157.5=18.36 \mathrm{kN}$

Stirrup shear resistance, $\mathrm{V}_{\mathrm{s}}=\varphi_{\mathrm{s}} \frac{\mathrm{A}_{\mathrm{v}}}{\mathrm{s}} \mathrm{f}_{\mathrm{y}} \mathrm{d}_{\mathrm{v}} \operatorname{Cot} \theta=0.85 * \frac{64}{133.5} * 449 * 157.5 * \operatorname{Cot} 42=32 \mathrm{kN}$

So, $\mathrm{V}_{\mathrm{u}}=5.86+18.36+32=56.22 \mathrm{kN}$

\subsection{Analysis of shear resistance of ECC and FRC beams from previous research studies and performance of theoretical formulations}

Data from author's research and previous research studies were used to analyze the shear resistance of ECC and FRC beams and to assess the predictive ability of the theoretical formulations and design specifications as described in Chapter 2 and Chapter 5. This comparative study was categorized in terms of using different fiber types/composition, fiber volume fraction, failure mode and presence/absence of shear reinforcement.

\subsubsection{FRC beam without shear reinforcement}

Table 5.3 represents the experimental and theoretical shear resistance capacity and failure mode of experimented full depth ECC beams without shear reinforcement by author and previously experimented FRC beams (with steel fiber) without shear reinforcement by Dinh et al. (2010). About 24 shear beams without shear reinforcement using steel fiber, different fiber volume fraction, varying shear span (a) to depth (d) ratio, longitudinal reinforcement ratio and concrete compressive strength were tested by Dinh et al. (2010). The beam's geometry and reinforcement details were described in Chapter 2. Theoretically predicted shear capacity has been calculated using fiber factor for steel and PVA (Equation 2.7 and 5.4, respectively) for any justification of using modified PVA fiber factor in the case of steel fiber reinforced beam.

From Table 5.3, it can be observed that the theoretical formulations/design specifications (used in this study to predict shear resistance of shear beams without shear reinforcement) were highly conservative for all of the beams tested by Dinh et al. (2010). The beams with less longitudinal reinforcement ratio $\left(\rho_{\mathrm{s}} \%\right)$ and low fiber volume fraction $\left(\mathrm{V}_{\mathrm{f}} \%\right)$ carried highest safety margin with experimental to theoretical predicted shear ratio ranging from 3.0 to 4.0. It can also be noticed that beams having longest steel fiber $(60 \mathrm{~mm})$ carried highest ultimate load compared to their counterparts with shortest steel fiber. 
Theoretical predicted shear strength (calculated by using PVA fiber factor) of all beams tested by Dinh et al. (2010) was highly underestimated compared to those calculated using steel fiber factor. So modified PVA fiber factor cannot be used in theoretical equation to calculate the shear strength of FRC beams with steel fiber. So steel fiber factor cannot be used in the prediction of shear strength of ECC beams with PVA fiber.

Table 5.3: Shear resistance of ECC/FRC beams without shear reinforcement - experimental and theoretical predictions

\begin{tabular}{|c|c|c|c|c|c|c|c|c|}
\hline \multirow[b]{2}{*}{$\begin{array}{l}\text { Beams } \\
\text { code }\end{array}$} & \multirow[b]{2}{*}{$\mathrm{a} / \mathrm{d}$} & \multicolumn{2}{|c|}{$\begin{array}{l}\text { Total shear resistance, } \\
\qquad \mathrm{V}_{\mathrm{u}}=\mathrm{V}_{\mathrm{c}}+\mathrm{V}_{\mathrm{s}} ;(\mathrm{kN})\end{array}$} & \multicolumn{2}{|c|}{$\begin{array}{l}\text { Theo. shear predictions, } \\
(\mathrm{kN})\end{array}$} & \multicolumn{2}{|c|}{ Exp./theo. predicted shear } & \multirow[b]{2}{*}{$\begin{array}{l}\text { Failure } \\
\text { mode }\end{array}$} \\
\hline & & $\begin{array}{c}\text { Exp. } \\
\text { ultimate } \\
\text { load, } \mathrm{V}_{\mathrm{u}} \\
(\mathrm{kN})\end{array}$ & $\begin{array}{l}\text { Exp. shear } \\
\text { load }=V_{\mathrm{u}} / 2 \\
(\mathrm{kN})\end{array}$ & $\begin{array}{l}\text { Using steel } \\
\text { fiber factor, } \\
\text { (Equation } \\
2.6 \text { and 2.7) }\end{array}$ & $\begin{array}{l}\text { Using PVA } \\
\text { fiber factor, } \\
\text { (Equation } \\
2.6 \text { and } 5.3 \text { ) }\end{array}$ & $\begin{array}{l}\text { Using steel } \\
\text { fiber factor, } \\
\text { (Equation } \\
2.6 \text { and } 2.7 \text { ) }\end{array}$ & $\begin{array}{l}\text { Using PVA } \\
\text { fiber factor, } \\
\text { (Equation } \\
2.6 \text { and } 5.3 \text { ) }\end{array}$ & \\
\hline \multicolumn{9}{|c|}{ Author; ECC with PVA fiber } \\
\hline Full ECC & 1.53 & 116.07 & 58.03 & 202.2 & 57.65 & 0.3 & 1.1 & Shear \\
\hline \multicolumn{9}{|c|}{ Dinh et al. (2010); FRC with steel fiber } \\
\hline B18-1a & 3.43 & 441 & 220.5 & 71.89 & 68.37 & 3.0 & 3.2 & $\mathrm{SC}+\mathrm{ST}$ \\
\hline $\mathrm{B} 18-1 \mathrm{~b}$ & 3.43 & 413 & 206.5 & 71.89 & 68.37 & 2.8 & 3.0 & $\mathrm{ST}+\mathrm{DT}$ \\
\hline B18-2a & 3.5 & 437 & 218.5 & 72.21 & 64.07 & 3.0 & 3.4 & $\mathrm{ST}+\mathrm{DT}$ \\
\hline B18-2b & 3.5 & 445 & 222.5 & 72.21 & 64.07 & 3.0 & 3.4 & $\mathrm{ST}+\mathrm{DT}$ \\
\hline B18-2c & 3.5 & 503 & 251.5 & 84.08 & 74.30 & 2.9 & 3.3 & NA \\
\hline B18-2d & 3.5 & 367 & 183.5 & 84.08 & 74.30 & 2.1 & 2.4 & NA \\
\hline B18-3a & 3.43 & 384 & 192 & 91.83 & 71.33 & 2.0 & 2.6 & $\mathrm{ST}+\mathrm{DT}$ \\
\hline B18-3b & 3.43 & 507 & 253.5 & 91.83 & 71.33 & 2.7 & 3.5 & $\mathrm{SC}+\mathrm{ST}$ \\
\hline B18-3c & 3.43 & 494 & 247 & 101.16 & 79.29 & 2.4 & 3.1 & $\mathrm{ST}+\mathrm{DT}$ \\
\hline B18-3d & 3.43 & 490 & 245 & 101.16 & 79.29 & 2.4 & 3.0 & $\mathrm{ST}+\mathrm{DT}$ \\
\hline B18-5a & 3.43 & 445 & 222.5 & 102.96 & 81.47 & 2.1 & 2.7 & DT \\
\hline B 18-5b & 3.43 & 565 & 282.5 & 102.96 & 81.47 & 2.7 & 3.4 & $\mathrm{ST}+\mathrm{DT}$ \\
\hline B18-7a & 3.43 & 498 & 249 & 77.92 & 67.66 & 3.1 & 3.6 & $\mathrm{ST}+\mathrm{DT}$ \\
\hline B18-7b & 3.43 & 490 & 245 & 77.92 & 67.66 & 3.1 & 3.6 & $\mathrm{ST}+\mathrm{DT}$ \\
\hline B27-1a & 3.5 & 908 & 454 & 125.85 & 119.83 & 3.6 & 3.7 & $\mathrm{ST}+\mathrm{DT}$ \\
\hline B27-1b & 3.5 & 837 & 418.5 & 125.85 & 119.83 & 3.3 & 3.4 & DT \\
\hline B27-2a & 3.5 & 872 & 436 & 116.79 & 100.62 & 3.7 & 4.3 & $\mathrm{SC}+\mathrm{ST}$ \\
\hline B27-2b & 3.5 & 854 & 427 & 116.79 & 100.62 & 3.6 & 4.2 & DT \\
\hline B27-3a & 3.5 & 846 & 423 & 106.83 & 101.75 & 3.9 & 4.1 & $\mathrm{~F}$ \\
\hline B27-3b & 3.5 & 863 & 431.5 & 106.83 & 101.75 & 4.0 & 4.2 & $\mathrm{SC}+\mathrm{ST}$ \\
\hline
\end{tabular}




\begin{tabular}{|c|c|c|c|c|c|c|c|c|}
\hline \multicolumn{9}{|c|}{ Table 5.3: Continued } \\
\hline B27-4a & 3.5 & 663 & 331.5 & 105.19 & 90.99 & 3.1 & 3.6 & $\mathrm{ST}+\mathrm{DT}$ \\
\hline B27-4b & 3.5 & 556 & 278 & 105.19 & 90.99 & 2.6 & 3.0 & $\mathrm{ST}+\mathrm{DT}$ \\
\hline B27-5 & 3.5 & 1081 & 540.5 & 148.64 & 117.58 & 3.6 & 4.5 & $\mathrm{SC}+\mathrm{ST}$ \\
\hline B27-6 & 3.5 & 1046 & 523 & 167.72 & 116.2535 & 3.1 & 4.4 & $\mathrm{ST}+\mathrm{DT}$ \\
\hline \multicolumn{9}{|c|}{$\begin{aligned} \text { a/d: Shear span to depth ratio; SC: Shear in compression; } \mathrm{ST} \text { : Shear in tension; DT: Diagonal tension; F: Flexure; NA } \\
\text { Not applicable } \\
\begin{aligned} & \mathrm{V}_{\mathrm{c}}=\text { Concrete shear resistance contribution; } \mathrm{V}_{\mathrm{s}}= \text { Shear reinforcement contribution is zero for beams without shear } \\
& \text { reinforcement; } \\
& \text { Steel fiber factor, } \mathrm{F}=2.05 ; \text { PVA fiber factor } \mathrm{F}^{\prime}=0.16\end{aligned}\end{aligned}$} \\
\hline
\end{tabular}

\subsubsection{PVA-ECC beams without shear reinforcement}

Alyousif et al. (2015) tested six ECC beams without stirrup having three different shear spans to effective depth ratios and two main longitudinal reinforcement amounts, beams geometry and reinforcement details as described in Chapter 2. The type/configuration of PVA fiber was as same as author's study. The ultimate load carrying capacity decreased with decreased shear span to depth ratio $(\mathrm{a} / \mathrm{d})$. The doubly reinforced beam denoted by " $\mathrm{B}$ " having higher longitudinal reinforcement ratio $\left(\rho_{\mathrm{s}} \%\right)$ carried highest ultimate load than those corresponding singly reinforced beams denoted by "A". All beams tested by Alyousif et al. (2015) except Beam 1B failed in flexure whereas the author's beam failed in shear (Table 5.4). The possible reasons that beams failed in flexure rather than shear are - the use of hooked flexural reinforcing bars which were extended over the support to the top causing bars to yield and limit the crack and the presence of shear reinforcement over the support region which prevented the formation of diagonal crack.

Theoretical moment capacity was calculated using Equation 2.30. The theoretically predicted moment capacities of author's beam as well as all beams tested by Alyousif et al. (2015) were found conservative compared to experimental ones. 
Table 5.4: Moment capacity of ECC beams without shear reinforcement- experimental and theoretical predictions

\begin{tabular}{|c|c|c|c|c|c|c|c|c|}
\hline $\begin{array}{c}\text { Beam } \\
\text { code }\end{array}$ & a/d & $\begin{array}{c}\text { Shear } \\
\text { span, } \\
(\mathrm{mm})\end{array}$ & $\rho_{\mathrm{s}} \%$ & $\begin{array}{c}\text { Exp. } \\
\text { shear } \\
\text { load, } \\
(\mathrm{kN})\end{array}$ & $\begin{array}{c}\text { Exp. } \\
\text { moment } \\
\text { capacity, } \\
\text { based on } \\
\text { shear } \\
\text { load,(kN.m) }\end{array}$ & $\begin{array}{c}\text { Theo. } \\
\text { moment } \\
\text { capacity, } \\
\text { using } \\
\text { (Equation } \\
2.30) \mathrm{kN} . \mathrm{m}\end{array}$ & $\begin{array}{c}\text { Exp. } \\
\text { /theo. } \\
\text { moment } \\
\text { ratio }\end{array}$ & Failure mode \\
\hline \multicolumn{7}{|c|}{ Author; ECC beams with PVA fiber } \\
\hline Full ECC & 1.52 & 267 & 1.10 & 58.03 & 15.5 & 10.7 & 1.4 & Shear \\
\hline \multicolumn{7}{|c|}{ Alyousif et al. (2015); ECC beams with PVA fiber } & Flexure \\
\hline Beam 1A & 1 & 365 & 1.29 & 205.7 & 91.5 & 22.5 & 4.0 & Comp. strut crushing \\
\hline Beam 1B & 1 & 340 & 2.57 & 275.4 & 93.67 & 32.9 & 2.8 & Flexure-shear \\
\hline Beam 2A & 2 & 580 & 1.29 & 110.33 & 63.97 & 22.5 & 2.8 & Flexure \\
\hline Beam 2B & 2 & 530 & 2.57 & 145.41 & 77.06 & 32.9 & 2.3 & Flexure \\
\hline Beam 3A & 3 & 795 & 1.29 & 71.63 & 56.92 & 22.5 & 2.5 & Flexure \\
\hline Beam 3B & 3 & 720 & 2.57 & 95.29 & 68.54 & 32.9 & 2.0 & \\
\hline
\end{tabular}

\subsubsection{FRC/ECC beams with polypropylene (PP) and steel fiber with shear reinforcement}

Table 5.5 represents the moment capacity of FRC/ECC beams with shear reinforcement tested by author as well as from other researchers Amin et al. (2016) using steel fiber and Zhang et al. (2014) using polypropylene (PP) fiber. Shear span to depth ratio (a/d) was kept constant for all beams tested by both researchers; other perimeters and beam's geometry were described in Chapter 2. Modified PVA fiber factor, $\mathrm{F}^{\prime}=0.16$ was used in predicting theoretical moment capacity for all beams. It can be observed that the theoretical equations were conservative in predicting moment capacity for all beams. The theoretical prediction of the beams tested by Zhang et al. (2014) using PP fiber was reasonably close to those obtained from experiments as the ratio of experimental to predicted (theoretical) ranges between 1.02 to 1.13 . The fiber dosage, shear reinforcement ratio and compressive strength affected on the ultimate load carrying capacity of the beams.

Theoretical predicted moment capacity (calculated by using PVA fiber factor) of all beams tested by Amin et al. (2016) was highly underestimated in the case of FRC beam with steel fiber. So modified PVA fiber factor cannot be used in theoretical equation to calculate the moment capacity of FRC beams with steel fiber. On the other hand, moment prediction of ECC beams with PP fiber tested by Zhang et al. (2014) was reasonably good. 
Table 5.5: Moment/shear capacities of FRC/ECC beams with shear reinforcement - experimental and theoretical predictions

\begin{tabular}{|c|c|c|c|c|c|c|c|c|}
\hline Beam code & $\mathrm{a} / \mathrm{d}$ & $\begin{array}{l}\text { Shear } \\
\text { span, } \\
(\mathrm{mm})\end{array}$ & $\rho_{\mathrm{s}} \%$ & $\begin{array}{c}\text { Exp. } \\
\text { ultimate } \\
\text { load, kN }\end{array}$ & $\begin{array}{l}\text { Exp. } \\
\text { moment } \\
\text { capacity, } \\
\text { kN.m }\end{array}$ & $\begin{array}{c}\text { Theo. } \\
\text { moment } \\
\text { capacity, kN.m } \\
\text { (Equation } 2.30 \text { ) }\end{array}$ & $\begin{array}{l}\text { Exp. / } \\
\text { theo. } \\
\text { moment } \\
\text { ratio }\end{array}$ & $\begin{array}{l}\text { Failure } \\
\text { mode }\end{array}$ \\
\hline \multicolumn{9}{|c|}{ Author; ECC beams with PVA fiber } \\
\hline Full ECC-S & 1.53 & 267 & 1.14 & 79.3 & 21.17 & 10.7 & 1.9 & Shear \\
\hline \multicolumn{9}{|c|}{ Amin et al. (2016); FRC beams with steel fiber } \\
\hline B25-550-6-450 & \multirow{6}{*}{2.8} & \multirow{6}{*}{1750} & \multirow{6}{*}{1.98} & 181.5 & 317.625 & 154.8 & 2.0 & Shear \\
\hline B25-450-10-450 & & & & 167 & 292.25 & 185.1 & 1.5 & Shear \\
\hline B25-400-6-300 & & & & 161 & 281.75 & 161.1 & 1.7 & Shear \\
\hline B25-300-10-300 & & & & 178.5 & 312.375 & 178.2 & 1.7 & Shear \\
\hline B50-550-6-450 & & & & 231 & 404.25 & 295.9 & 1.3 & Shear \\
\hline B50-450-10-450 & & & & 267.5 & 468.125 & 324.4 & 1.4 & Shear \\
\hline \multicolumn{9}{|c|}{ Zhang et al. (2014); ECC beams with PP fiber } \\
\hline RE-42 & \multirow{4}{*}{2.8} & \multirow{4}{*}{700} & \multirow{4}{*}{2.7} & 70.55 & 49.3815 & 43.34 & 1.13 & Shear \\
\hline RE-30 & & & & 65.28 & 45.696 & 43.34 & 1.05 & Shear \\
\hline RE-24 & & & & 62.62 & 43.834 & 43.34 & 1.01 & Shear \\
\hline RE-12 & & & & 63.03 & 44.1175 & 43.34 & 1.02 & Shear \\
\hline
\end{tabular}

\subsection{Moment capacity of ECC, SCC and composite ECC/SCC flexural beams}

Experimental and theoretical ultimate moment capacities of full depth ECC, full depth SCC and composite ECC/SCC flexural beams are compared in Table 5.5. Equation 2.30, Equation 2.23 and Equation 5.10 were used to calculate theoretical moment capacity of "Full ECC-F", "Full SCC-F" and E25-S75-F beams, respectively. It can be noted from Table 5.6 that the theoretical equations predicted the ultimate moment capacity for all beams with good accuracy as the ratio of experimental $\left(\mathrm{M}_{\mathrm{u} . \exp }\right)$ to theoretical $\left(\mathrm{M}_{\mathrm{u} . \text { the }}\right)$ predicted values ranged from 1.05 to 1.45. 
Table 5.6: Comparison of experimental and theoretical ultimate moments capacity of flexural beams

\begin{tabular}{|c|c|c|c|}
\hline Beam code & $\begin{array}{c}\text { Experimental } \\
\text { ultimate } \\
\text { moment } \\
\mathrm{M}_{\mathrm{u}(\mathrm{exp})}(\mathrm{kNm})\end{array}$ & $\begin{array}{c}\text { Theoretical ultimate } \\
\text { moment } \\
\mathrm{M}_{\mathrm{u} \text { (the) }}(\mathrm{kNm})\end{array}$ & $\begin{array}{c}\text { Ratio of } \\
\text { experimental } \\
\text { to theoretical } \\
\text { ultimate } \\
\text { moment }\end{array}$ \\
\hline Full SCC-F & 20.58 & 18.31 (Equation 2.23) & 1.12 \\
\hline Full ECC-F & 23.95 & 16.52 (Equation 2.30) & 1.45 \\
\hline $\begin{array}{c}\text { E25-S75-F (quarter depth } \\
\text { ECC) }\end{array}$ & 21.14 & 20.01 (Equation 5.10) & 1.05 \\
\hline
\end{tabular}

\subsubsection{Detail calculation of moment capacity prediction of ECC, SCC and composite ECC/SCC flexural beams}

Theoretical moment capacity prediction of full depth ECC, full depth SCC and composite ECC/SCC flexural beams can be calculated as follows:

\subsubsection{Theoretical calculation of predicted moment capacity of "Full SCC-F" beam}

Using Equations 2.22 and 2.23, theoretically predicted moment capacity of "Full SCC-F" beam can be calculated based on experimental values obtained from tested specimen.

$a=\frac{\varphi_{s} A_{s} f_{y}}{\alpha_{1} \varphi_{c}^{\prime} f_{c}^{\prime} b}=\frac{0.85 * 200 * 567}{0.65 * 0.7615 * 59 * 150}=22 \mathrm{~mm}$

$\alpha_{1}=0.85-0.0015 f_{c}^{\prime}=0.85-(0.0015 * 59)=0.7615$

Therefore, $\mathrm{M}_{\mathrm{f}}=\varphi_{\mathrm{s}} \mathrm{A}_{\mathrm{s}} \mathrm{f}_{\mathrm{y}}\left(\mathrm{d}-\frac{\mathrm{a}}{2}\right)=0.85 * 200 * 567 *\left(201-\frac{22}{2}\right)=18.31 \mathrm{kN} . \mathrm{m}$

\subsubsection{Theoretical calculation of predicted moment capacity of "Full ECC-F" beam}

Using Equation 2.30, theoretically predicted moment capacity of "Full ECC-F" beam can be calculated based on experimental values obtained from tested specimen.

$\mathrm{M}_{\mathrm{r}}=\left\{\mathrm{T}_{\text {Steel }} \mathrm{d}+\mathrm{T}_{\text {ECC-1 }}\left(\frac{\left(1-\mathrm{n}_{\varepsilon}\right) \mathrm{d}+\mathrm{c}}{2}+\mathrm{n}_{\varepsilon} \mathrm{d}\right)+\mathrm{T}_{\text {ECC- } 2}\left(\frac{2}{3}\right) * \mathrm{v} * \mathrm{~d}+\mathrm{C}_{\mathrm{ECC}}\left(\frac{2}{3}\right)\left(\mathrm{t}_{\mathrm{s}}-\mathrm{d}-\mathrm{c}\right)\right\}\left(\frac{1}{1000}\right)$ 
where,

$$
\begin{aligned}
& \mathrm{T}_{\text {Steel }}=0.4 \mathrm{f}_{\mathrm{y}} \mathrm{A}_{\mathrm{s}}=0.4 * 567 * 200=45.36 \mathrm{kN} \\
& \mathrm{n}_{\varepsilon}=\frac{\varepsilon_{\mathrm{y}-\mathrm{ECC}}}{0.4 \varepsilon_{\mathrm{y}-\text { steel }}}=\frac{0.0002}{0.4 * 0.002355}=0.2123 \\
& \mathrm{c}=232-201=31 \mathrm{~mm} \\
& \mathrm{~T}_{\mathrm{ECC}-1}=\mathrm{f}_{\mathrm{t}}\left[\left(1-\mathrm{n}_{\varepsilon}\right) \mathrm{d}+\mathrm{c}\right] \mathrm{b}=3.45[(1-0.2123) \mathrm{d}+31] * 150-407.63 \mathrm{~d}+16042.5 \mathrm{~N} \\
& \mathrm{~T}_{\mathrm{ECC}-2}=0.5 \mathrm{f}_{\mathrm{t}} \mathrm{n}_{\varepsilon} \mathrm{db}=0.5 * 3.45 * 0.2123 * \mathrm{~d} * 150=54.93 \mathrm{~d} \mathrm{~N} \\
& \mathrm{C}_{\mathrm{ECC}}=0.5 \mathrm{f}_{\mathrm{t}}\left(\frac{1}{\mathrm{n}_{\varepsilon} \mathrm{d}}\right)\left(\mathrm{t}_{\mathrm{s}}-\mathrm{d}-\mathrm{c}\right)^{2} \mathrm{~b}=0.5 * 3.45\left(\frac{1}{0.2123 \mathrm{~d}}\right)(232-\mathrm{d}-31)^{2 * 150} \\
& \quad=1218.7(40401 / \mathrm{d}-402+\mathrm{d}) \mathrm{N}
\end{aligned}
$$

Now, $\mathrm{T}_{\text {steel }}+\mathrm{T}_{\mathrm{ECC}-1}+\mathrm{T}_{\mathrm{ECC}-2}=\mathrm{C}_{\mathrm{ECC}}$

$>\mathrm{d}^{2}-729.12 * \mathrm{~d}+65115.9=0$

$>\mathrm{d}=104 \mathrm{~mm}$

Therefore, $\mathrm{T}_{\mathrm{ECC}-1}=58.43 \mathrm{kN} ; \mathrm{T}_{\mathrm{ECC}-2}=5.71 \mathrm{kN}$ and $\mathrm{C}_{\mathrm{ECC}}=110.26 \mathrm{kN}$

So,

$$
\begin{aligned}
\mathrm{M}_{\mathrm{r}} & =\left\{45.36 * 104+58.43\left(\frac{(1-0.2123) * 104+31}{2}+0.2123 * 104\right)+5.71\left(\frac{2}{3}\right) * 0.2123 * 104+110.26\left(\frac{2}{3}\right)(232-104-31)\right\}\left(\frac{1}{1000}\right) \\
& =16.52 \mathrm{kN} . \mathrm{m}
\end{aligned}
$$

\subsubsection{Theoretical calculation of predicted moment capacity of E25-S75-F (quarter depth ECC) beam}

Using Equation 5.10, theoretically predicted moment capacity of "E25-S75-F" beam can be calculated based on experimental values obtained from tested specimen.

$\mathrm{M}_{\mathrm{n}}=\mathrm{A}_{\mathrm{s}} \mathrm{f}_{\mathrm{y}}(\mathrm{d}-\mathrm{a} / 2)+\sigma_{\mathrm{t}} \mathrm{bh} / 4 *(\mathrm{~h}-\mathrm{a}) / 2$

where,

$a=\left(A_{s} f_{y}+\sigma_{t} b h / 4\right) / \lambda f_{c f}^{\prime} b$

$\sigma_{\mathrm{t}}=2 \eta_{\mathrm{o}} \eta_{\mathrm{b}} \eta_{\mathrm{l}} \mathrm{V}_{\mathrm{f}} \tau_{\mathrm{f}}\left(\mathrm{l}_{\mathrm{f}} / \mathrm{d}_{\mathrm{f}}\right)$

$\eta_{\mathrm{o}}$ : orientation factor $=0.41 ; \eta_{\mathrm{b}}$ : bond efficiency factor $=0.16$ for PVA fiber; $\eta_{1}=$ length efficiency factor $=0.86 . V_{\mathrm{f}}=$ fiber volumn fraction $2 \% ; \tau_{\mathrm{f}}=2.93 \mathrm{MPa} ; \mathrm{l}_{\mathrm{f}}=$ fiber length $8 \mathrm{~mm} ; \mathrm{d}_{\mathrm{f}}=$ fiber dia $0.039 \mathrm{~mm}$

$\sigma_{\mathrm{t}}=2 * 0.41 * 0.16 * 0.86 * .02 * 2.93 *\left(\frac{8}{0.039}\right)=1.35 \mathrm{MPa}$ 
So, $\mathrm{a}=(200 * 567+1.35 * 150 * 232 / 4) /(0.86 * 73 * 150)=13.28 \mathrm{~mm}$

Therefore, $\mathrm{M}_{\mathrm{n}}=200 * 567(201-13.28 / 2)+1.35 * 150 * 232 / 4 *(232-13.28) / 2=20.01 \mathrm{kN} . \mathrm{m}$

\subsection{Summary}

This chapter compares the experimental shear and flexure capacities of the tested beams with those obtained from theoretical equations and design specifications. Higher margin of safety was identified in predicting the concrete shear resistance of composite ECC/SCC beams with and without shear reinforcement using theoretical equations.

From the analysis of forty experimental beams from other researchers with different types of fibers, different shear span to depth ratio and different reinforcement ratio showed conservativeness of theoretical equations in predicting shear and moment capacities of ECC and FRC beams.

Theoretical equations also accurately predicted the ultimate moment capacities of composite ECC/SCC flexural beams. 


\section{CHAPTER SIX CONCLUSIONS}

\subsection{General}

This research studied the shear and flexural behavior of composite beams made of engineered cementitious composite (ECC) and self-consolidating concrete (SCC) compared to full depth ECC and full depth SCC beams. The variables of this study were: two different ECC to SCC depth ratio (half depth "E50-S50" and quarter depth "E25-S75") and presence or absence of shear reinforcement. Shear span to depth ratio (a/d), longitudinal (flexural) reinforcement ratio and types of fiber in ECC were kept constant. All flexural beams were singly reinforced.

\subsection{Conclusions}

The test results of eight shear beams with and without shear reinforcement and three flexural beams tested under four point monotonic static loading to failure were described. In addition, data of fiber reinforced concrete (FRC) and ECC beams (with and without shear reinforcement) from previous experimental research studies were collected and investigated from the perspective of the effect of fiber types on shear capacity/shear transfer mechanism and the performance of existing design specifications. Within the scope of the investigation, the following conclusions were drawn:

$\checkmark$ The ultimate load/shear capacity for both composite beams "E50-S50" and "E25-S75" without shear reinforcement was about $71 \%$ and $24 \%$ higher than full depth SCC and full depth ECC beams, respectively. The mid span deflection was also higher for composite beams. The ECC to SCC depth ratio of composite ECC/SCC beams without shear reinforcement did not make any significant difference.

$\checkmark$ Diagonal shear crack loads varied from 41.5 to $45 \%$ of ultimate loads for composite ECC/SCC beams without shear reinforcement whereas $47.3 \%$ to $51.7 \%$ of ultimate loads for full depth SCC and full depth ECC beam.

$\checkmark$ As expected, composite ECC/SCC beams exhibited significantly higher number of cracks but less crack width than their full depth ECC and full depth SCC counterparts because of the fiber bridging and micro - cracking characteristics. 
$\checkmark$ Shear beams (both composite ECC/SCC beams and full depth SCC/full depth ECC beams) with shear reinforcement showed less crack width than shear beams without shear reinforcement.

$\checkmark$ Full depth SCC and E25-S75 (quarter depth) composite beams without shear reinforcement exhibited higher post-cracking shear resistance (as defined by shear resistance factor 'SRF' -ratio of failure to first diagonal crack load) because of the presence of higher percentage of coarse aggregates (due to better aggregate interlock mechanism) than their full depth ECC and E50-S50 (half depth) composite beam counterparts.

$\checkmark$ Shear ductility (defined by Ductility Factor 'DF' - ratio of deflection at peak/failure load to first diagonal crack load) of full depth SCC and E25-S75 (quarter depth) composite beams without shear reinforcement was also found about $9 \%$ to $15 \%$ higher than corresponding full depth ECC and E50-S50 (half depth) composite beams.

$\checkmark$ The energy absorption capacity of E50-S50 (half depth) and E25-S75 (quarter depth) composite ECC/SCC beams without shear reinforcement was 4.0 and 4.4 times higher than full depth SCC beam, respectively as well as 1.96 and 2.14 times higher than full depth ECC beam, respectively. Composite ECC/SCC beams were more efficient in terms of energy absorption capacity than their full depth ECC or full depth SCC counterparts - this indicates their suitability to be used as earthquake resisting elements.

$\checkmark$ Both composite beams (half or quarter depth) with shear reinforcement exhibited 3.5 to 4.5\% higher shear resisting capacity compared to full depth ECC and full depth SCC shear beams without shear reinforcement.

$\checkmark$ The angle of dominant diagonal crack of shear beams with shear reinforcement was approximately within the range of 25-45 degree whereas crack angle ranged from 40-45 degree for beams without shear reinforcement (for composite beams and full depth SCC or full depth ECC beams).

$\checkmark$ As expected, all shear beams with reinforcement showed higher ultimate load carrying capacity and higher stiffness than their corresponding beams without shear reinforcement.

$\checkmark$ All shear beams with and without shear reinforcement failed in shear. 
$\checkmark$ All flexural beams showed typical structural behavior in flexure, since the beams were under-reinforced. Yielding of the tensile reinforcement happened before crushing of the compression concrete in the pure bending region.

$\checkmark$ E25-S75-F (quarter depth) composite flexure beam showed $18 \%$ and $15 \%$ higher ductility than full depth SCC and full depth ECC flexure beams, respectively. The energy absorption capacity of E25-S75-F (quarter depth) composite flexure beam was approximately 80\% higher than full depth SCC flexure beam whereas $11 \%$ less than full depth ECC flexure beam.

$\checkmark$ The design equations slightly overestimated the shear capacity of experimented full depth ECC beam with shear reinforcements with experimental to theoretical predicted shear load ratio 0.9. However, the design equations/specifications were found to be conservatively predicted the shear capacities of other shear beams with and without shear reinforcement.

$\checkmark$ For all design equations, experimental to predicted shear strength ratios of composite ECC/SCC beams were high and these ratios ranged from 2.9 to 3.3 for beams without shear reinforcement and 1.3 to 1.4 for beams with shear reinforcement.

$\checkmark$ From the analysis of previous experimental data, theoretical formulations/design equations were found to conservatively predict shear and moment capacities of full depth FRC or ECC beams made of different fiber types and compositions.

$\checkmark$ All theoretical formulations/design specifications accurately predicted the ultimate moment capacities of flexural beams.

\subsection{Recommendations for future research studies}

The following recommendations are made for future research studies:

$\checkmark$ Investigate experimentally and theoretically shear and flexure capacities of composite ECC/SCC beams with different types of fiber such as steel, polymeric, glass, carbon and asbestos.

$\checkmark$ Investigate experimentally and theoretically shear and flexure capacities of composite ECC/SCC beam (using various code based analysis) with variable shear span to depth ratio, longitudinal and shear reinforcement ratio. 
$\checkmark$ Do investigation on ECC/SCC joint as a composite beam under monotonic and cyclic loading.

$\checkmark$ Perform durability studies of composite ECC/SCC beams under aggressive environments quantifying reinforcement corrosion and over strength degradation.

$\checkmark$ Carry out extensive finite element (FE) modeling of composite ECC/SCC beams based on experimental investigations to develop models. After verification of the FE models with experimental results, extensive numerical modelling with varying structural parameters is to be conducted for evaluating their influence on structural performance. 


\section{REFERENCES}

ACI 318M-11 (2011). Building code requirements for structural concrete (ACI 318M-08) and commentary. ACI Committee 318. American concrete institute, Detroit, USA

ACI Committee 318. Building code requirements for reinforced concrete, ACI-2011 and commentary ACI 318R-2011, pp. 509. American concrete institute, Detroit, USA

ACI Committee 318. Building code requirements for structural concrete (ACI 318-05) and commentary (318R-05). American concrete institute, Farmington Hills, MI, 2005, 430 p

ACI Committee 544. (1988). Design considerations for steel fiber reinforced concrete. ACI Structural Journal, 85(5), pp. 563-580.

ACI Committee 544.4.R-88 (1994), Design considerations for steel fiber reinforced concrete. ACI manual of concrete practice, Part 1, material and general properties of concrete. pp. 1-18.

ASTM C39/C39M (2003). Standard test method for compressive strength of cylindrical concrete specimens, American Society for Testing and Materials, West Conshohocken, Pennsylvania, USA, pp.1-7.

ASTM C78/C78M (2010). Standard test method for flexural strength of concrete (using simple beams with third-point loading), Cement Standards and Concrete Standards, pp.1-7.

Alyousif, A., Anil, O., Sahmaran, M., Lachemi, M., Yildirim, G. and Ashour, A. (2015). Tests of high-performance fiber-reinforced concrete beams with different shear span-to-depth ratios and main longitudinal reinforcement, Journal of Reinforced Plastics and Composites, Vol. 34, No. 18, pp. 1491-1505

Amin, A. and Foster, S. (2016). Shear strength of steel fibre reinforced concrete beams with stirrups, Engineering Structures, Vol.111, pp. 323-332

Bairagi, N. K. and Modhera, C. D. (2001). Shear strength of fiber reinforced concrete, ICI Journal, Vol. 1, No. 4, pp. 47-52.

Bisaillon, A. Rivest, M. and Malhotra, V. (1994). Performance of high volume fly ash concrete in large experimental monoliths. ACI Materials Journal, Vol. 91, No. 2, pp. 178-187.

Campion, M.J. and Jost, P. (2000). Self-compacting concrete, Concrete International: Design and Construction, Vol. 22, No. 4, pp. 31-34.

Chaallal, O. and Lachemi, M. (2010). Reinforced concrete structures, Design according to CSA A23.3-04, Presses de I' University du Quebec, Canada, 465p. 
CSA Standard A23.3-04. (2004). Canadian standard association (CSA), Design of Concrete Structures, CSA Standard A23.3-04. Rexdale, Ontario.

Dinh, H., Parra-Montesinos, G. and Wight, J. (2010). Shear behavior of steel fiber-reinforced concrete beams without stirrup reinforcement, ACI Structural Journal, V. 107, No. 5,

Fang, Y., Jinlong, P. and Yufei, W. (2014). Numerical study on flexural behaviors of steel reinforced engineered cementitious composite (ECC) and ECC/concrete composite beams. Sci China Tech Sci, 57: 637:645, doi: 10.1007/s11431-014-5478-4

Fang, Y., Jinlong, P. and Leung, C. K. Y. (2013). Flexural behaviors of ECC and concrete/ECC composite beams reinforced with basalt fiber-reinforced polymer. Journal of Composites for Construction, Vol. 17, No. 5, pp. 591-602

Fischer, G. and Li, V. C. (2003). Deformation behavior of fiber-reinforced polymer reinforced engineered cementitious composite (ECC) flexural members under reversed cyclic loading conditions, ACI Structural Journal, Vol. 100, No. 1, pp. 25-35.

Gao, S. and Zijl, V. (2005). Tailoring ECC for commercial application. In: M. di Prisco, R. Felicetti and G.A. Plizzari, Editors, Fiber Reinforced Concretes (BEFIB'2004), RILEM Pro039, 1391-1400.

Hassan, A. A. A., Hossain, K.M.A. and Lachemi, M. (2010a). Strength, cracking and deflection performance of large-scale self-consolidating concrete beams subjected to shear failure, Engineering Structures, Vol. 32, No.5, pp.1262-1271.

Hassan, A. A. A., Hossain, K. M. A. and Lachemi, M. (2010b). Structural assessment of corroded self-consolidating concrete beams, Engineering Structures, Vol. 32, No.3, pp.874-885.

Hassan, A.A.A, Hossain, K.M.A. and Lachemi, M. (2008). Behavior of full scale self consolidating concrete beams in shear, Cement and Concrete Composites, Vol. 30, No.7, pp.588-596.

Hossain, K.M.A., and Lachemi, M. (2010). Fresh, mechanical, and durability characteristics of selfconsolidating concrete incorporating volcanic ash, ASCE Journal of Materials in Civil Engineering, Vol. 22, No. 7, pp. 651-657.

Hossain, K.M. A., Samani, S.G., and Ehsani, Y.A. (2015). Prediction of strength properties of engineered cementitious composites using artificial neural network, CSCE conference, Building on Our Growth Opportunities, Regina, SK, Canada. 
Hossain, K.M.A. (2014). Structural performance of ultra-high performance concrete beams, Research Report, Department of Civil Engineering, Ryerson University, 89p.

Hossain, K.M.A. and Anwar, M.S. (2014). Properties of green engineered cementitious composites incorporating volcanic materials, structural faults + repair, Imperial College, London, UK.

Hossain, K.M.A., Ametrano, D., Mak, C., and Lachemi, M. (2011). Bond strength and development length of GFRP bars in ultra-high performance concrete, Ministry of Transport Ontario (MTO) Technical Report (HIIFP Research Project), May, 89p.

Hossain, K.M.A., Ametrano, D., and Lachemi, M. (2014). Bond strength of GFRP bars in high strength concrete, ASCE Journal of Materials in Civil Engineering, Vol. 26, No.3, pp. 449456.

Hossain, K.M.A., Ametrano, D., Mak, C., and Lachemi, M. (2011). Bond strength and development length of GFRP bars in ultra-high performance concrete", Ministry of Transport Ontario (MTO) Technical Report (HIIFP Research Project), May, 89p.

Hossain, K.M.A., and Anwar, M.S. (2014). Strength and deformation characteristic of ECC link slab in joint-free bridge decks, Istanbul Bridge Conference, August, Istanbul, Turkey.

Hossain, K.M.A. and Ghatrehsamani, S. (2015). Flexural fatigue performance of ECC link slabs for bridge deck applications, 8th New York City Bridge Conference.

Hossain, K.M.A., and Taormina, A. (2012). Axial load behaviour of profiled composite walling system under elevated temperatures, CSCE 3rd Int. Structural Specialty Conference, June 69, Edmonton, Canada.

Hossain, K.M.A., Kayes, M.A., Mavani, M.B. and Lachemi, M. (2013). Influence of ECC mixture on the structural performance of link slabs in bridge decks, 3rd CSCE Specialty Conference on Material Engineering \& Applied Mechanics, Montréal, Québec, May 29-June 1.

Hossain, K.M.A., Mak, C., and Ametrano, D. (2012). GFRP reinforced UHPC composites for sustainable bridge construction, Canadian Civil Engineer, spring Vol. 29, No. 1, pp. 12-15.

Hussian, S. E. and Rasheeduzzafar, M. (1994). Corrosion resistance performance of fly ash blended cement concrete. ACI Materials Journal, Vol. 91, No. 3, pp. 264-272.

Hussein, L. and Amleh, L. (2015). Structural behavior of ultra-high performance fiber reinforced concrete-normal strength concrete or high strength concrete composite members, Construction and Building Materials, Vol. 93, pp. 1105-1116. 
Imam, M., Vandewalle, L., Mortelmans, F., and Van- Gemert, D. (1997). Shear domain of fibrereinforced high-strength concrete beams. Engineering structures, Vol. 19, No. 9, pp. 738747.

Japanese Society of Civil Engineering (JSCE), (1998). Guide to construction of high flowing concrete, Gihoudou publication, Tokyo, Japan.

JCI-DFRCC Committee. (2003). DFRCC terminology and application concepts, Journal of Advanced Concrete Technology, Vol. 1, No. 3, pp. 335-340.

Katz, A. (1996). Effect of fiber modulus of elasticity on the long term properties of micro-fiber reinforced cementitious composites, Cement and concrete composites Vol. 18, pp. 389-399

Kanda, T. and Li, V. C. (1998). Multiple cracking sequence and saturation in fiber reinforced cementitious composites. Concrete Research and Technology, JCI, Vol. 9, No. 2, pp. 19-33.

Karahan, O., Hossain, K.M.A., Ozbay, E., Lachemi, M. and Sancak, E. (2012). Effect of metakaolin content on the properties self-consolidating lightweight concrete, Construction and Building Materials, Vol. 31, No. 6, pp. 320-325.

Kima,_J.J., Limb, Y.M., Wonc, J., Parkd, H. and Leea, K. (2007). Shear capacity and failure behavior of DFRCC repaired RC beams at tensile region, Engineering Structures, Vol. 29, pp. $121-131$

Kosmatka, S. and Panarese, W. (1988). Design and control of concrete mixtures, 13th Edition. Skokie, IL: Portland Cement Association, 205.

Khayat, K.H., and A'itcin, P.C. (1999). Use of self-consolidating concrete in Canada - present situation and perspectives, Universite de Sherbrooke, Quebec, Canada.

Khayat, K.H., Bickley, J., and Lessard, M. (2000). Performance of self-consolidating concrete for casting basement and foundation aalls, ACI Materials Journal, Vol. 97, Issue 3, pp. 374-380

Kuroda, M. Watanabe, T. and Terashi, N. (2000). Increase of bond strength at interfacial transition zone by the use of fly Ash, Cement and Concrete Research, Vol. 30, No. 2, pp. 253-258.

Kunieda, M. and Rokugo, K. (2006). Recent progress on HPFRCC in Japan. Journal of Advanced Concrete Technology, Vol. 40, No. 1, pp. 19-33.

Lacombe, P., Beaupre, D. and Pouliot, N. (1999). Rheology and bonding characteristics of selflevelling concrete as a repair material, Materials and Structures, Vol. 32, No. 222, pp. 593600. 
Lachemi, M., Hossain, K.M.A., Lambros, V.B., and Bouzoubaâ, N. (2003). Development of costeffective self-consolidating concrete incorporating fly Ash, slag Cement or viscositymodifying admixtures, ACI Materials Journal, Vol. 100, No. 5, pp. 419-425.

Lepech, M. and Li, V.C. (2005b). Durability and long term performance of engineered cementitious composites, Honolulu, Hawaii, In proceedings of international RILEM Workshop on HPFRCC in Structural Applications, pp. 165-174.

Li, V. C. (2011). High-ductility concrete for resilient infrastructures. Journal of Advanced and High-Performance Materials, pp. 16-21.

Li, V.C. and Lepech, M. (2004). Crack resistant concrete material for transportation construction. Washington, DC, In TRB 83rd Annual Meeting, Compendium of Papers CD ROM

Li, V.C., Wang, S. and Wu, C. (2001). Tensile strain-hardening behavior of polyvinyl alcohol engineered cementitious composite (PVA-ECC). ACI materials journal, Vol. 98, No. 6, pp. 483-492.

Li, V.C., Lepech, M.D. and Li, M. (2005). Field demonstration of durable link slabs for jointless bridge decks based on the strain-hardening cementitious composites, Michigan Department of Transportation Report No. RC-1471, pp. 1-147.

Li, V.C., Fischer, G., Kim, Y.Y., Lepech, M., Qian, S., Weimann, M. and Wang, S. (2003). Durable link slabs for jointless bridge decks based on strain-hardening cementitious composites, Report for Michigan Department of Transportation RC- 1438.

Li, V.C. (1993). From micromechanics to structural engineering-the design of cementitious composites for civil engineering applications, JSCE J of Structural Mechanics and Earthquake Engineering, Vol. 10, No. 2, pp.37-48.

Li, V.C., Mishra, D. and Wu, H. (1995). Matrix design for pseudo strain-hardening fiber reinforced cementitious composites. RILEM Journal of Materials and Structures, Vol. 28, No. 183, pp. 586-595.

Li, V. C., Wang, S., Ogawa, A. and Saito, T. (2002). Interface tailoring for strain-hardening PVAECC. ACI Materials Journal; Vol. 99, No. 5, pp. 463-472.

Li V. C. and Wang, S. (2002). Flexural behaviour of glass fiber reinforced polymer (GFRP) reinforced engineered cementitious composite beams, ACI Materials Journal, Vol. 99, No. 1. 
Li, V.C. (1998). ECC tailored composites through micromechanical modeling, Fiber Reinforced Concrete: Present and the Future Edited by Banthia et al., CSCE. Montreal, pp. 64-97.

Li, V.C. and Kanda, T. (1998). Engineered cementitious composites for structural applications. Journal of Materials in Civil Engineering. Vol. 10, No. 2, pp. 66-69.

Li, V.C. (2003). Engineered cementitious composites (ECC) - a review of the material and its applications. Journal of Advanced Concrete Technology, Vol. 1, No. 3, pp. 215-230.

Li, V.C. (1995). New construction materials proliferate in Japan. Civil Engineering, Vol. 65, No. 8, pp. 38-41.

Li, V. C. and Mishra, D. K. (1994). On the shear behavior of engineered cementitious composites, Advanced Cement Based Materials, Vol. 1, No. 3, pp. 142-149

Lin, Z., Kanda, T. and Li, V. C. (1999). On interface property characterization and performance of fiber reinforced cementitious composites. Concrete Science and Engineering, RILEM, Vol. 1, pp. 173-184.

Maalej, M. and Li, V.C. (1994). Flexural/tensile strength ratio in engineered cementitious composites, ASCE Journal of Materials in Civil Engineering, Vol. 6, No. 4, pp. 513-528

Maalej, M., Quek, S.T., Ahmed, S.F.U., Zhang, J., Lin, V.W.J., Leong, K.S. (2012). Review of potential structural applications of hybrid fiber engineered cementitious composites, Construction and Building Materials, Vol. 36, pp. 216-227

Maulin, B.M. (2012). Fresh/mechanical/durability properties and structural performance of engineered cementitious composite (ECC), Published master's thesis, Ryerson University, Toronto, Canada.

Maruta, M., Kanda, T., Nagai, S. and Yamamoto, Y. (2005). New high-rise RC structure using precast ECC coupling beam, Concrete Journal, Vol. 43, No. 11, pp. 18-26.

Nawy, E. (2008). Concrete construction and engineering handbook, Second Edition, New York, CRC Press

Neville, A.M. (2002). Properties of Concrete. Fourth and Final Edition, John Wiley \& Sons, New York, pp. 884.

Okamura, H. (1996). Self-compacting high-performance concrete, Concrete International, Vol. 19, No. 7 , pp. 50-54. 
Özbay, E., Karahan, O., Lachemi, M., Hossain, K. M. A. and Atis, C. D. (2013). Dual effectiveness of freezing-thawing and sulfate attack on high-volume slag-incorporated ECC. Composites Part B: Engineering, Vol. 45, No. 1, pp. 1384-1390.

Özbay, E., Karahan, O., Lachemi, M., Hossain, K.M.A. and Atis, C.D. (2012). Investigation of properties of engineered cementitious composites incorporating high volumes of fly ash and metakaolin. ACI materials journal, Vol. 109, No. 5, pp. 565-571.

Ozawa, K., Maekawa, K., Kunishima, H. and Okamura, H. (1989). Performance of concrete based on the durabiity design of concrete structures, Proce. The second East-Asia-Pacific Conference on Structural Engineeing and Construction, Vol. 1, pp. 445-456

Qian, S., Lepech, M. D., Kim, Y. Y. and Li, V. C. (2009). Introduction of transition zone design for bridge deck link slabs using ductile concrete, ACI Structural Journal, Vol. 106, No. 1, pp. 96-105.

Peled, A. and Shah, P. S. (2003). Processing effect in cementitious composites: extrusion and casting, Journal of Materials in Civil Engineering, Vol. 15, No. 2, pp.192-199.

Ramualdi, J. P. and Batson, G. B. (1963). Mechanics of crack arrest in concrete, Journal of ASCE, EM3, pp. 147-168,

Ranade, R., Zhang, J., Lynch, J. P. and Li, V. C. (2014). Influence of micro-cracking on the composite resistivity of engineered cementitious composites. Cement and Concrete Research, Vol. 58, No. 1, pp. 1-12.

Rokugo, K., Kunieda, M. and Lim, S. (2005). Patching repair with ECC on cracked concrete surface, CONMAT 5.

Şahmaran, M. and Li, V.C. (2009). Engineered cementitious composites: an innovative concrete for durable structure. Proceedings of the 2009 Structures Congress - Don't Mess with Structural Engineers: Expanding Our Role, pp. 2219-2231.

Sakata, K., Kanda, T. and Hiraishi, M. (2004). Application of direct sprayed ECC for retrofitting dam structure surface-application for Mitaka-Dam. Japan Concrete Institute Concrete Journal, Vol. 42, No. 5, pp. 135-139.

Sathiyamoorthy, K. (2016). Shear and flexure behavior of lightweight self-consolidating concrete beams, Published master's thesis, Ryerson University, Toronto, Canada.

Sivaraja, M. and Kandasamy, S. (2007). Reinforced concrete beams with rural composites under cyclic loading, Journal of Engineering and Applied Sciences, Vol. 11, No. 2, pp. 1620-1626. 
Sherir, M.A.A., Hossain, K.M.A., and Lachemi, M. (2015). Structural performance of polymer fiber reinforced engineered cementitious composites subjected to static and fatigue flexural loading, Polymers 2015, Vol. 7, pp. 1299-1330.

Sherir, M.A.A. (2012). Fracture, fatigue and creep performance of ECC mixtures with reference bridge deck applications, MASc Thesis, Dept. of Civil Engineering, Ryerson University

Spadea, G. and Bencardino, F. (1997). Behavior of fiber reinforced concrete beams under cyclic loading, Journal of Structural Engineering, Vol. 123, No. 5, pp. 660-667.

Taylor, H. P. J. (1970). Investigation of the forces carried across cracks in reinforced concrete beams in shear by interlock of aggregate (No. TR 42.447 Tech. Rpt.).

Taylor, R. and Brewer, R. S. (1963). The effect of the type of aggregate on the diagonal cracking of reinforced concrete beams, Magazine of Concrete Research, Vol. 15, No. 44, pp. 87-92.

Wang, S. and Li, V. C. (2007). Engineered cementitious composites with high-volume fly ash. ACI materials journal, Vol. 104, No. 3, pp. 233-241.

Weimann, M.B. and Li, V. C. (2003). Hygral behavior of engineered cementitious composites (ECC). International Journal for Restoration of Buildings and Monuments, Vol. 9, No. 5, pp. 513-534.

www.tornadoseo.wordpress.com, Accessed on May, 23 ${ }^{\text {rd }}, 2016$

$\mathrm{Xu}$, S.L., Wang, N. and Zhang, X. F. (2012). Flexural behavior of plain concrete beams strengthened with ultra high toughness cementitious composites layer, Materials and Structures, Vol. 45, pp. 851-859.

Yang, E., Yang, Y. and Li, V.C. (2007). Use of high volumes of fly ash to improve ECC mechanical properties and material greenness. ACI Materials Journal, (104-M68), pp.303-311.

Yahia, A., Tanimura, M., Shimabukuro, A. and Shimoyama, Y. (1999). Effect of rheological parameters on self-compatibility of concrete containing various mineral admixtures, Proceedings of the First RILEM International Symposium on Self- Compacting Concrete, Stockholm, Sweden, September, pp. 523-535. 
Zhang, J. and Stang, H. (1998). Fatigue performance in flexural of fiber reinforced concrete, ACI Materials Journal, Vol. 95, No. 1, pp. 58-67.

Zhang, J., Leung, C.K.Y. and Cheung, Y.N. (2006) .Flexural performance of layered ECC-concrete composite beam, Composites Science and Technology, Vol. 66, pp. 1501-1512

Zhang, R., Matsumoto, K., Hirata, T., Ishizeki, Y. and Niwa, J. (2014). Shear behavior of polypropylene fiber reinforced ECC beams with varying shear reinforcement ratios, Journal of JSCE, Vol. 2, pp. 39-53. 